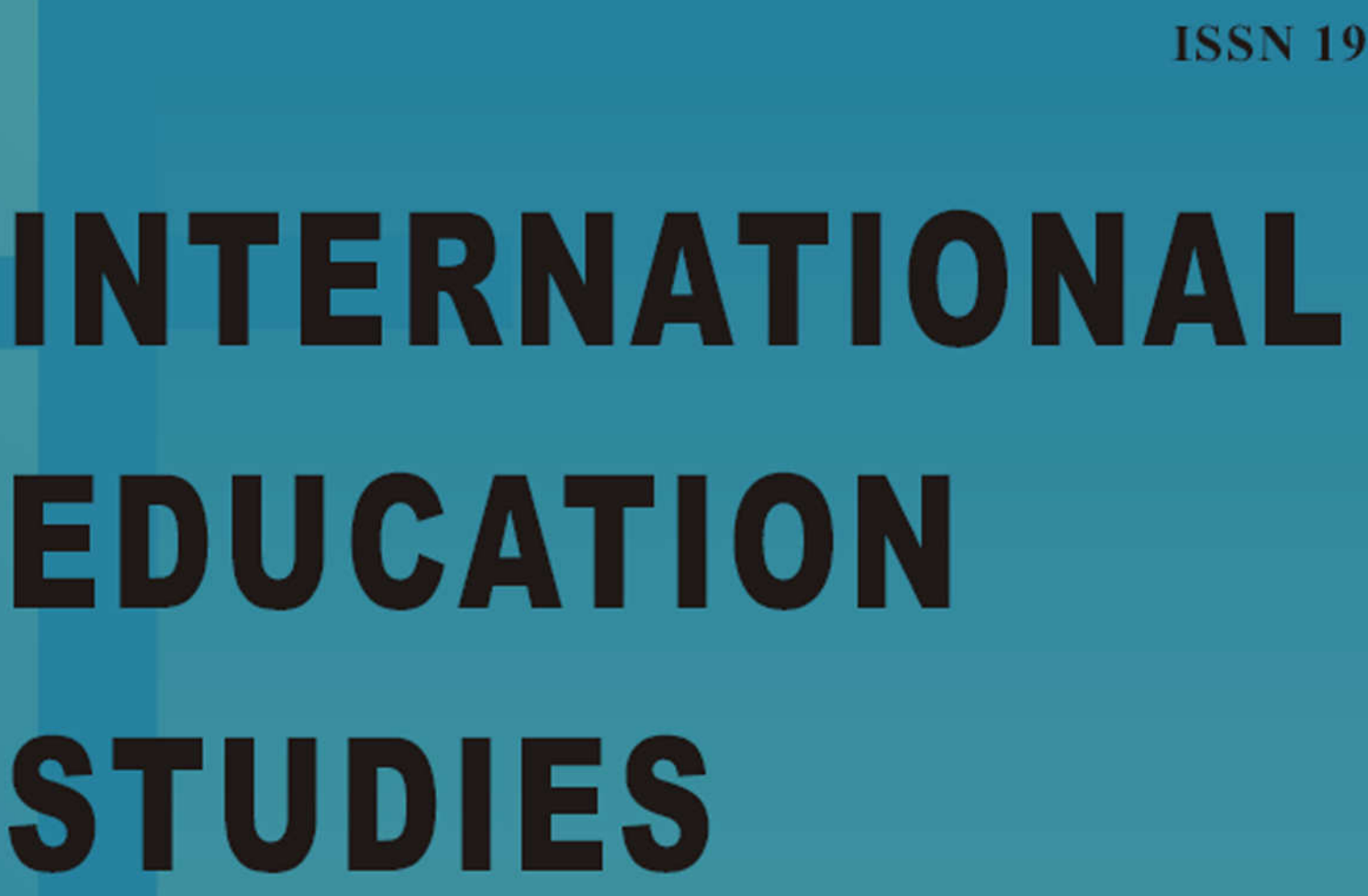

Vol. 1, No. 1

February 2008

CCSE

Canadian Center of Science and Education 


\section{Contents}

Information and Communications Technology in Teaching Marketing: Benefits and Problems

Ernest M Kadembo

The Design of Health Care Management Program for Chinese Health Care Professionals

Xiao Ling Qiu

Secondary School Admissions: The Choice for Black Parents in the London Borough of Hackney, United

Kingdom

Lionel McCalman

Effective Classroom-based Evaluation on English for Specific Purposes Teaching in China

Youqin Yuan

Employability of Graduates - A Search through the Educational Processes of Indian Engineering

Institutions

K G Viswanadhan

Reflection on Personal ELL Experience and ELT Practice

Zhicheng $\mathrm{Ma}$

An Alternative Model of Continuing Professional Development for Teachers: Giving Teachers Time

Terry Haydn, Roy Barton, Ann Oliver

How to Cultivate the Ability of Innovative Thinking in Computer Programming Teaching

Fuqian Shi \& Jincai Wei

Empowering School of Accounting Websites through Quality Assurance: Development and

Implementation of a User-perceived Instrument

Hadrian G. Djajadikerta, Terri Trireksani, Hamfri Djajadikerta

A Teaching Attitude Adjusting Model for College Teachers Based on Attitude Theories

Linying Zhang \& Zhijun Han

Studies on the Internationalized Higher Education

Li-juan Ren \& Zheng Tang

The Research on Several Critical Issues in the Development of Higher Vocational Education

Yufei Long \& Tingqin Zhang

Trying to Meet the Demands of English in a Global Market: A Critical Discussion of the National Bilingual

Programme in Colombia

John Wells

Globalization and Its Impact on the Medium of Instruction in Higher Education in Malaysia

Mohini Mohamed

The Importance of the Teacher for Developing Interest in Learning English by Chinese Students

Yunbao Yang

Simulation of Forming Process as an Educational Tool Using Physical Modeling

A. B. Abdullah, M. R. Muda, Z. Samad

Problems in Library Construction of Newly-upgraded Local Undergraduate Institutions

Chunlan Qiu \& Rongsheng Wen 


\title{
Information and Communications Technology
}

\section{In Teaching Marketing: Benefits and Problems}

\author{
Ernest M Kadembo \\ Department of Marketing, The Business School, University of Huddersfield \\ University Centre Oldham, Cromwell Street, Oldham, England, UK, OL1 1BB \\ Tel: 01612135049 E-mail: e.m.kadembo@hud.ac.uk
}

\begin{abstract}
The advent of a continuous innovation and improvement, particularly in respect of information and communications technology has had a huge impact on the quality of life and in education delivery is an open secret. The benefits from exploiting ICT in education are ernomous but there are abuses that have tarnished its use in education. The excellence ICT is attributed with has been put to the sword and will stretch this innovation to develop tools for redressing these predicaments. ICT is with us from the cradle to the grave. This research reviewed published information and confirmed the overwhelming importance of information technology in marketing education. ICT has revolutionalised learning by enabling easy access to information through online materials and learning has become more convenient as students can combine work and online learning to good effect. However, academics and students have found it easier to access materials and often fail to acknowledge the source thus distorting the originality of the source. Where the systems for guarding against plagiarism are not thorough there is widespread abuse of the learning process. The paper recommends stringent systems for checking against plagiarism and that work submitted should be current if not live so as to avoid students duplicating work from elsewhere and appropriate punishment meted. At the same time there is software for detecting cheating in education which has gone some way in detecting the culprits and that had had a significant effect in reducing the proliferation of education malpractices.
\end{abstract}

Keywords: Marketing, Education, Internet, Information Technological

\section{Introduction}

Facets of modern day life continue to transform, largely because of the advancements in the area of Information Communications and Technology (ICT). Mankind has managed to replace the bulk of operations in daily life and in the corporate world with programmed automated ICT based self directed systems. This paradigm shift has put ICT at the heart of human functionalities in virtually every sphere of operation as in manufacturing, medicine, media production and broadcasting, transport, warfare, research, communication, education, etc. Close et al (2005: p81) emphatically state:

Just as the business world is in a constant state of flux and evolution, so is the technologically advancing in which academics operate. The "4Ps" (and C's) of marketing cannot be conceptualized without consideration of technological implications. ... The internet rounds out a marketing education, as it is both a class-based exercise tool and an analytical problem solving tool.

Kaynama and Keesling (2000) point out that the use of the internet in marketing practice and education is increasing exponentially and would affect the mode of delivery and role of marketing educators. Writing for the Guardian newspaper in the United Kingdom Geraldine Kenney-Wallace the director of e-strategy and learning at City \& Guilds states that over $65 \%$ of e-learners in employment or out of employment are motivated by prospects for career progression, or getting into employment and that each e-learner would prefer learning systems that are user-friendly, mutual interaction with other e-learners, and support from online materials (http://www.guardian.co.uk/Archive/Article/

0,4273,4394262,00.html, accessed 16.07.07). The Sloan consortium estimated that in 2005 there were over 2.3 million online learners taking at least one course with $40 \%$ of schools with master's courses offering them online. The Sloan consortium further states that:

"Thus, a very rough estimate of the total reachable population for online education is about 100-120 million. For a current online U.S. learning population of nearly 2.5 million to reach 100 million at a component annual growth rate (CAGR) of $20 \%$, would require over 20 years. Assuming a CAGR of $40 \%$, this level could be achieved in under 12 years." http://www.sloan-c.org/publications/JALN/v10n3/v10n3_1bourne.asp, accessed 20.07.07 
Naude and Holland (2004; p165) suggest that ICT “...effects on marketing are not only potentially dramatic and/or catastrophic to managers, they are indeed reliant on understanding and knowing about new concepts and skills". They further argue that the idea of a changing world is not a new phenomenon but the challenge is to understand the direction of change and determine the nature and importance of the variables in influencing and how they are influenced by the change. Roffe (1997) argues that the search for new student groups and new products has meant that innovation has become a familiar mission for the educational entrepreneur. Burd and Buchnanan (2004) point out that online learning opportunities are abundant within the framework of post-secondary education and as part of continuing education offered through professional associations. Ueltschy (2001) maintains that the use of technology in the classroom is now an expectation for the student given that children of today face an interactive, communications intensive and knowledge based environment and that has led to increasing changes in education. The ICT revolution is so powerful to the extend that its transforming the way businesses use marketing, the way marketing students learn marketing and such students often understand technologies better than their professor, hence the need for professors to adapt such technologies (McCorke et al, 2001).

The paper acknowledges the enormous contributions made by ICT to the field of education and learning on one hand and the challenges that it poses when used abused by the learners or academics. The growth in online learning bears testimony to its efficacy in providing access to education.

\subsection{Objectives}

This paper seeks to critically argue the phenomenon of ICT applications in teaching. The issues put forward are meant to take into account the effects of the revolution on the modern day teacher and the modern day student. It seeks to question their efficacy in the quest for a better quality of life and the degree to which they make education the most valued human investment for a better world. In the main the specific objectives to be achieved in this paper are:

a) To provide a comprehensive ICT literature review so as to develop a framework for analysis

b) To capture the benefits of ICT applications in the teaching of marketing for both staff and students.

c) To determine the adverse impact of ICT in the teaching of marketing.

d) To recommend approaches that could enhance the usage of ICT in the teaching of marketing

\section{Concepts of ICT and Applications in Education}

A comprehensive definition for ICT provided by on the website: http://searchwebservices.techtarget. com/gDefinition/0, 294236,sid26_gci928405, 00, accessed 27 April 2005:

ICT (information and communications technology - or technologies) is an umbrella term that includes any communication device or application, encompassing: radio, television, cellular phones, computer and network hardware and software, satellite systems and so on, as well as the various services and applications associated with them, such as videoconferencing and distance learning

The above definition shows that ICT is diverse in nature as it includes multitudes of tools and processes needed to execute the information management function. In business and in education it is extremely important to consider the objective and the efficacy of the tools employed.

Dixon et al (2005) demonstrate the key forces at play that drive competition and put information and communications technology at the heart of it. To the extent that their model acknowledges the critical impact of information and communications technology, there is no doubt that education should take this phenomenon on board. The Internet in particular has become a way of life and it is expected that education institutions and businesses integrate it into their systems for effective management of information.

Ayres (1999) argues that the internet will give people access to vast amounts of information and that economic success in future will depend on the information workers and this belief has led to vast investments in education, governments, industry and commerce. He questions the authenticity of the internet as there is no cross-checking of the accuracy of information posted on the internet. Kospoulos (1998) points out that education and culture are the intellectual treasure of any individual and the cyber-campus has created a resource beyond reasonable comprehension. This phenomenon follows technological advancement as the human being makes an effort to remain contemporary in the face of the changing world.

The website http://www.tutor2u.net/business/ict/intro_what_is_ict.htm,accessed 12.05.05 defines ICT as:

ICT covers any product that will store, retrieve, manipulate, transmit or receive information electronically in a digital form. For example, personal computers, digital television, email, robots.

From the above it is clear that ICT is focused on information gathering, processing and storage with the aid of technology. The computer, more specifically the computer chip is the heart of the computing phenomena. The ability to reduce information to the binary system, keep it in a compact form and still be able to access, disseminate, analyze it 
electronically is phenomenal. This has meant that the processing of information is very fast. The fact that multitudes of activities are now ICT driven suggests that society in general and business in particular find ICT useful in operationalising activities, no surprise education has joined the bandwagon.

Bates (1997) puts forward four reasons for using ICT in education as:

(1) Improving the quality of learning

(2) Improving access to education and training

(3) Reducing the costs of education

(4) Improving the cost effectiveness of education

Bates seems not to acknowledge the obvious; that ICT is fashionable across the plethora of human engagements and it has spilled into the education arena. His arguments are consistent with what can be observed in education. Material production and dissemination has meant that learners gain more value from the delivery by teachers because of the capturing capacity and accuracy- virtual illustrations that can be printed in hard copy and simulations can be employed to resemble real operations. Distance education like in the case of the Open University in the UK tends to make use of broadcasting and the internet. Previously such provisions would necessitate the transportation of mountains of information at a substantial cost whereas for now its simply the stroke of a key that would enable all students to access the material. It is clear that with the various cost reductions in delivery the overall cost of accessing education has been reduced. Overall, one would argue that learners are getting value for money in education largely because of the advent of ICT. Benbunan-Fich et al (2001) points out that technologies are radically changing the four elements of the marketing mix and the advanced software and internet technologies have created for one-to-one marketing which help customise messages; to that end they further assert that, in a study by faculty at Seton Hall University there are five competencies that students require which are communication, critical thinking, technology, teamwork and change management.

The challenge for digitalising various spheres of life has brought pressure to the education arena. Osborne and Oberski (2004) state

As society demands that universities provide mass education systems for their citizens while at the same time reducing the amount of funding to these institutions, it is not surprising that technology is being seen as providing the solution.

Alexander (2001) argues that investment in ICT is a solution to a crisis in education. It is important to reflect on the common cliché that necessity is the mother of invention and no surprise everyone is in transition, the education facilitator, the learner and the investor in learning and development. Such is the pull of ICT that literacy in computing is now the rule and not the exception in the developed world. The developing world is grappling with its usual problems trying to somewhat move in the right direction.

Appleton (2005) in a paper on the ICT transformation of Edge Hill College argues that "The development of hybrid libraries has had an impact on electronic publishing and has generated new types of electronic resource, including e-books". This demonstrates the range of challenges and options that come with ICT. Abouchedid and Eid (2004) point out that e-learning is a building bloc for initiating modernisation in the Arab region. The ICT revolution is a global phenomenon that knows no boundaries and enjoys a lot of interest across national boundaries. The expectations in teaching and other applications have meant that the presence of a computer in an office or a classroom are basic expectations in every part of the world even where computers are scarce.

Farmer (2003) suggests that information in the digital world doubles up every two years, hence the need for students to be on the alert, and further states that online learning is cost effective and efficient. With the increasing information as a result of links and easy of dissemination the biggest challenge for educators and learners at large is the ability to focus on the relevant information and being able to avoid drifting in paralysis by analysis.

According to Tenneth et al (2004) some internal students use the online lectures to reinforce the face-to-face delivery and in their study students felt all their subjects be delivered via online. The obvious argument about the benefits of ICT in education tend to be addressed to distance education as it has made a big difference there by revolutionalising the whole process. However, the current explosion in the virtual environment in universities bears testimony to the fact that even students who attend classes on a regular basis will benefit from ICT. When in the past students had to submit their work for assessment in long hand that is now history. Where students had to be in class all the time to get lecture notes is no longer the norm as the same material tends to be posted on the virtual environment for access at the convenient time. Learners will be able top access assessment material at a convenient time and can submit work for assessment electronically.

The framework in figure 2 illustrates the education experience in distance learning as put forward by Tenneth (2004). The framework links all aspects of distance learning that come into perspective when ICT drives distance learning. 
The illustration in figure 2 demonstrates that whatever teachers do in a classroom can be done via online provisioning. The obvious advantages with online delivery are speed and convenience.

\subsection{The Myths and Misconceptions of Information and Communications Technology}

While the notion of Information and Communications Technology is often associated with what is good it is important that academics appreciate some of the myths associated with the phenomena of ICT.

Dublin (2004) points at nine myths about information and communications technology which are summarised in Figure 3.

A lot of the issues where most people have misconceptions are centred around the notion of information technology being a panacea for success and that it will take charge.

\subsection{The Benefits of ICT in Marketing Education}

The Department of Trade and Industry in UK notes the benefits to industry of adopting information and communications technology by providing a model of e-adoption. To the extent that industry has benefits realised from IT, it is therefore imperative to marketing educators that they embrace this new phenomenon.

The gigantic paradigm shift in modern day practice in the last twenty years has significantly changed the way of life in business, education, science, health, entertainment etc. The ICT advancements cut across a plethora of human engagements. The world is now digital in most spheres. Much success has been attained with the aid of efficient and effective utilisation of ICT. More specifically the teaching pedagogy has changed for good. The modern day teacher has to be ICT literate. Teaching in general is no exception to the norm and moreso the opportunity availed by the virtual experience makes it more compelling to use ICT in teaching. It can be argued that teaching excellence can be enhanced by effective use of ICT.

Essentially ICT is the icing on the cake in teaching excellence. According to Kostopoulos (1998) the internet technology as an educator's resource outperforms the sun in that it covers the whole world all the time while the sun shines on half the world at any time. To that end Malhotra et al (2002) while acknowledging the potential of the internet to fundamentally transform educational delivery provides the benefits of computer networks in education as team facilitation, better meeting employer expectations, better meeting student expectations and facilitating information access.

On a broader context the OECD states on their website, www.oecd.org, Accessed 20 May 2005, that:

The growth and development of information and communication technologies (ICTs) has led to their wide diffusion and application, thus increasing their economic and social impact. The OECD undertakes a wide range of activities aimed at improving our understanding of how ICTs contribute to sustainable economic growth and social well-being and their role in the shift toward knowledge-based societies.

The OECD while acknowledging the importance of ICT seems to be adding another dimension that it is a vehicle for development and can lead to sustainable economic growth and well-being of society. There are multitudes of benefits that ICT brings to society.

ICT benefits in the teaching of marketing can be summarised as follows:

(1) Quality presentation- graphs, powerpoint

(2) Easy Access to teaching information for courses on blackboard/virtual environment

(3) Convenient research on the net - virtual experience

(4) Student academic exchange via remote interaction on the discussion board

(5) Large quantities of data sent via email

(6) Easy transfer and reference of information

(7) Enormous storage facilities of mountains of information

(8) Experiencing the virtual organisational marketing environment through the internet and the reality as captured and presented through multimedia

Morrison and Stein (1999) point out that information technology has transformed the search for knowledge into a multi-dimensional activity which brings with it challenges on how to prepare students. This is the case because there are multitudes of formats information can be stored in for different purposes and by different parties which are constantly changing. In the same vein Benbunan-Fich et al (2001) conclude that information technology offers great value for business education and marketing courses offer even more potential for application to motivate students to learn, increase students' proficiency in both general business and discipline specific skills upon graduation. In a related argument Berry (2002) highlights the importance of participating in international virtual teams as a way of enriching 
student learning.

\section{The ICT based crisis in the Teaching of Marketing}

Rawwas et al (2004) makes references to multitudes of research in acknowledging that academic dishonesty, which includes everything from wrongfully getting information by looking at a neighbour's test to plagiarising from a term paper and a big and still growing problem in higher education.

The thesis in this discussion is ICT drives excellence in teaching with its antithesis being the disaster or crisis in teaching emanating from the advent of ICT complexity. Morrison and Stein (1999: p 317 -318) suggest that what is at stake is academic integrity and he goes on to argue:

Although technology can annihilate distance in terms of finding sources of information, it can also annihilate authenticity and worthiness if quality measures are not an integral part of the synthesizing of data into a meaningful account.

To the same end (Phillips and Horton 2000; Owens Swift et al (1998) point out that a new tool has entered the marketplace enhancing the ease of finding term papers, reducing the risk of being caught, and making it unnecessary to track former students, and furthermore, there are internet sites that aid cheating providing for examinations, banks of previous assessments and customised paper ordering hence cheating or academic dishonest, at the university level is a nationwide concern. Effectively this observation amounts to opportunities for buying education as those who have the inclination to pay to cheat could easily complete their education on the strength of their purse not necessarily their understanding of concepts and their applications or hard work which should be the case. Sharma and Maleyeff (2003) argue that there is a problem in judging the credibility of the internet in that the appearance and immediacy may give the impression of accuracy, aspects which may cloud the student's understanding of business, may also alienate students from society as it appears the internet is addictive and thereby kill social skills of students. Malhotra et al. (2002) concluded that the new technology and the internet are fundamentally enhancing both the classroom and distance marketing research education experience thereby presenting opportunities and challenges.

(1) Excessive plagiarism by students via wantom cutting and pasting

(2) Excessive plagiarism by academics to get academic mileage by submitting works of other people pretending to be theirs.

(3) Increased abuse of academic materials by other institutions through unsanctioned use of copyrighted material

(4) Outright cheating by students by purchasing answers or written work for gaining academic mileage via the internet. A simple search on the net will provide thousands of sources of assignments or dissertations, priced on the basis of the grade such work could earn the student.

(5) Death by powerpoint, a common reference to the notion of simply throwing in a number of graphics at the expense of quality presentation

(6) Reducing education to a very abstract process with very little interaction by virtue of distance and virtual learning which in some instances might not be a true reflection of the learning by the individual in question as some students will opt not to use IT and have their work done on their behalf by someone else.

Ayres (1999) highlights that the easy with which information can be accessed and copied on the internet many people are reluctant to publish online as they would lose royalties as the copyright control is very difficult. Given this scenario most people tend to use the internet because it is easy to access and ignore other sources this limiting access to information.

\section{Recommendation in dealing with the ICT Crisis in the Teaching of Marketing}

Taylor (2002) suggests that developing online systems necessitates that trainers and teachers should ensure that the environment enables learning to take place. In the same vein Teare (2000: p111) poses the question "If staying abreast of change means sustaining a perpetual forward motion, then how do you do this without creating chaos?" It is important that the utilisation of the key resources created by ICT is complemented by a change management strategy with a strong focus on the adverse effects of the whole process. Teare (2000) further states that the rise of the "corporate university", especially in the USA is linked to rapid pace of change and the need to align such learning with the needs of organisations. Ueltschy (2001) concludes that faculty, university administration, government officials must cooperate in securing emerging technologies and integrate them into the learning environment.

(1) The utilisation of plagiarism detecting software will go a long way in warning the student and thereby discouraging such acts and identifying it where it takes place

(2) Educational institutions should put in place strict rules and regulations of dealing with the acts of plagiarism which will demonstrate the non-tolerance of such acts. 
(3) Students should be tasked with assessments that require them to work in groups and make presentations to ensure that they are analytical rather than cut and paste warriors with no analytical capacity.

(4) In cases where students share an assignment write-up it is important to make it clear that if this was a deliberate exchange then both are liable to a heavy punishment and only in the case of theft of such work should it be heavy on one student.

(5) Student monitoring of assignment execution and submission should be tracked so that they do not buy it off traders in academic assessments, moreso, it is important to do random checks with such organisations on selected assessments which might help detect some of the perpetrators.

Phillips and Horton (2000) recommend four strategies for dealing with academic cheating; 1. Use current developments for assignments which would mean no previous works can be used for cheating; 2 . Use group work which will not give scope to rushed work and abuse; 3 . Police the internet for potential abuse and thereby minimize cut and paste by making the students aware; 4 . Develop a strict policy that is incorporated in the assignment.

While cheating is a natural human phenomenon it goes without saying that it has never been tacitly legalised in academia and will never be. The recommendations suggested in all honesty are meant to minimize the proliferation of cheating as it is virtually impossible to completely eradicate it.

\section{Conclusion}

The advent of ICT remains the greatest human invention as it cuts across all human engagements. There is no doubt that excellence has been realised through ICT driven teaching. In acknowledging the crisis created by this phenomenon it is important that every effort is made that abuses are minimised. Where cheating has been detected people involved must be shamed and punished. At the same time the use of detecting instruments is of the essence. It is important that the long arm of the law must stretch to reach out for the criminals bent on profiteering from the sale of educational qualifications or educational materials in view of the fact that these are accomplices in the crime against academia. Jones and Kelly (2003) make a very objective argument in advising that while the internet has proved to be a very powerful tool in teaching it is important that marketing educators adapt the internet to their teaching style instead of falling prey to the trendy feeling of using the internet. The information and communications technologic wave will continue to transform business, education and society in general as Close et al. (2005) point out that from the "chalkboard to cyber-course" the internet greatly impacts modern marketing education and the internet will in future dominate both research/education and topic of study. The ICT wave currently sweeping across nations and professions has a global reach, a sophisticated information technology, mass customisation of products and services, and technological revolution hence today's students need to be globally literate

While the abuses may be difficult to detect given the complexity of the mechanics of cheating employed the real test comes in the work environment. There is a limit to how much one can pretend to be informed where they have simply got the better of technology and got a qualification.

The solutions for the way forward must incorporate the whole process of ICT related instruments of delivery in education and their adverse effects. The focus of any solution is to try and minimize cheating via the use of ICT tools.

The gigantic impact of technology for today and in future is without question as McCorke et al (2001) put it that they have become a constant in the business education and will continue to increase in importance in future, it is therefore without question that it will forever remain a key facet of all aspects of human functionalities but its pitfalls must be managed.

\section{References}

Abouchedid, K. \& Eid, G. M. (2004). E-learning challenges in the Arab world. Quality Assurance in Education, Vol 12 , No 1, pp $15-27$.

Alexander, S. (2001). E-learning developments and experiences, Education + Training, Vol 43, No 4/5, pp 240 - 248.

Appleton, L. (2005). Using electronic textbooks: promoting, placing and embedding. The Electric Library, Vol 23 , No. 1 , pp $54-63$.

Ayres, R. (1999). The Essence of Professional Issues in Computing, Pearson Education, Limited, Essex, England.

Bates A. W. (1997). Restructuring the university for technological change, paper presented at What kind of University? 18 - 20 June, The Carnegie for the Advancement of Teaching, London, available at http://bates.cstudies.ubc.ca/carnegie.html, accessed 12.05.05.

Benbunan-Fich, R, Lozada, H. R, Pirog, S., Priluck, R. and Wisenblit, J. (2001). Integrating information Technology into the Marketing Curriculum. Journal of Marketing Education, Vol 23 No 1, pp 5 -15.

Berry, R .W. (2002). The Efficacy of Electronic Communication in the Business School: Marketing Students' 
perspective of virtual teams. Marketing Education Review, Volume 12, Number 2, pp 73 - 78.

Burd BA and Buchanan LE. (2004). Teaching the teachers: teaching and learning online; Reference Services Review; Vol 32 No 4, pp 404-412.

Close, A.G., Dixit, A. and Malhotra K.N. (2005). Chalkboards to Cyber-courses: The Internet and Marketing Education, Marketing Education Review, Volume 15, Number 2, pp 81-80.

Dixon, T., Thompson, B., McAllister, P., Snow, J. and Marston, A. (2005). Technology and Real Estate in The New Economy, Real Estate Issues Series, Blackwell, Oxford.

Dublin, L. (2004). The nine myths of e-learning implementation: ensuring the real return on your e-learning investment; Industrial and Commercial Training.

Volume 36, No 7, pp 291-294.

DTI (2001). Business in the Information Age, International Benchmarking Report, DTI, London.

Farmer, S.J.L. (2003). Facilitating faculty of information literacy skills into the curriculum through the use of online instruction, Reference Services Review, Vol 31, No 4, pp 307 - 312.

Jones, K. O. and Kelley, K. A. (2003). Teaching Marketing via the internet: Lessons learned and challenges to be met, Marketing Education Review, Volume 13, Number 1, pp 81-89.

Kaynama, S. A. and Keesling, G. (2000). Development of a Web-Based Internet Marketing course, Journal of Marketing Education, Volume 22, No 2, pp 84-89.

Kostopoulos, G. K. (1998). Global delivery of education via the internet, Internet Research, Electronic Networking Applications and Policy, Volume 8, Number 3, pp257 - 265.

Malhotra K. N., Dixit, A. and Uslay, C. (2002). Integrating Internet Technology in Marketing Research Education, Marketing Education Review, Volume 12, Number 3, pp 25-34.

McCorke, D.E., Alexander, J. E. and Reardon, J. (2001). Integrating Business Technology and Marketing Education: Enhancing the Diffusion Process through Technology Champions, Journal of Marketing Education, Vol 23, Number 1, pp $16-24$.

Morrison, J.L. and Stein L. S. (1999). Assuring integrity of information utility in cyber-learning formats, Reference Services Review, Volume 27. Number 4, pp 317 - 326.

Naude, P. and Holland, C.P. (2004). The role of information and communications technology in transforming marketing theory and practice, Journal of Business and Industrial Marketing, Volume 19, No. 3, pp165- 166.

Osborne, M. and Oberski, I (2004). University continuing education: The role of communications and information technology, Journal of European Industrial Training, Vol 28, No 5, pp $414-428$.

Owens Swift, C., Denton, L. and Nonis, S. A. (1998). Cheating, Internet Style: Guarding Against On-Line Term Paper Mills, Marketing Education Review, Volume 8, No 2, pp 19 - 27.

Phillips, M. L. and Horton, V. (2000). Has morality evaporated in business education?,

The International Journal of Educational Management, Volume 15, No. 4, pp 150-155.

Rawwas M. Y.A., Al-Khatib, J.A. and Vitell S. J (2004). Academic Dishonesty: A Cross- Cultural Comparison of U.S.and Chinese Marketing Students, Journal of Marketing Education, Vol 26, No 1, pp 89 - 100.

Roffe I (1997). Developing a dynamic in a learning innovation; Quality Assurance in Education, Volume 5, No 2, pp 90 $-96$.

Sharma, P. and Maleyeff, J. (2003). Internet education: potential problems and solutions, The International Journal of Educational Management, Volume 17, No.1, pp 19-25.

Teare, R. (2000). Modelling the virtual university. Journal of Workplace Learning: Employee Counselling Today, Volume 12, Number 3, pp 111- 123.

Tenneth, B. et al. (2004). Teaching with Technology: value-added innovation or necessity? Campus Wide Information Systems, Volume 2, Number 4. pp $144-150$.

Ueltschy, L. C. (2001). An Exploratory Study of Integrating Interactive Technology into the Marketing Curriculum. Journal of Marketing Education, Volume 23, No 1, pp 63-72.

\section{Electronic Sources}

http://www.guardian.co.uk/Archive/Article/0,4273,4394262,00.html, accessed 16.07.07.

http://www.oecd.org/topic/0,2686,en_2649_37409_1_1_1_1_37409,00.html, Accessed 20.05.05. 
http://www.tutor2u.net/business/ict/intro_what_is_ict.htm, accessed 12.05.05.

http://searchwebservices.techtarget.com/gDefinition/0,294236,sid26_gci928405,00.accessed 27.04.05.

http://www.sloan-c.org/publications/JALN/v10n3/v10n3_1bourne.asp, accessed 20.07.07.

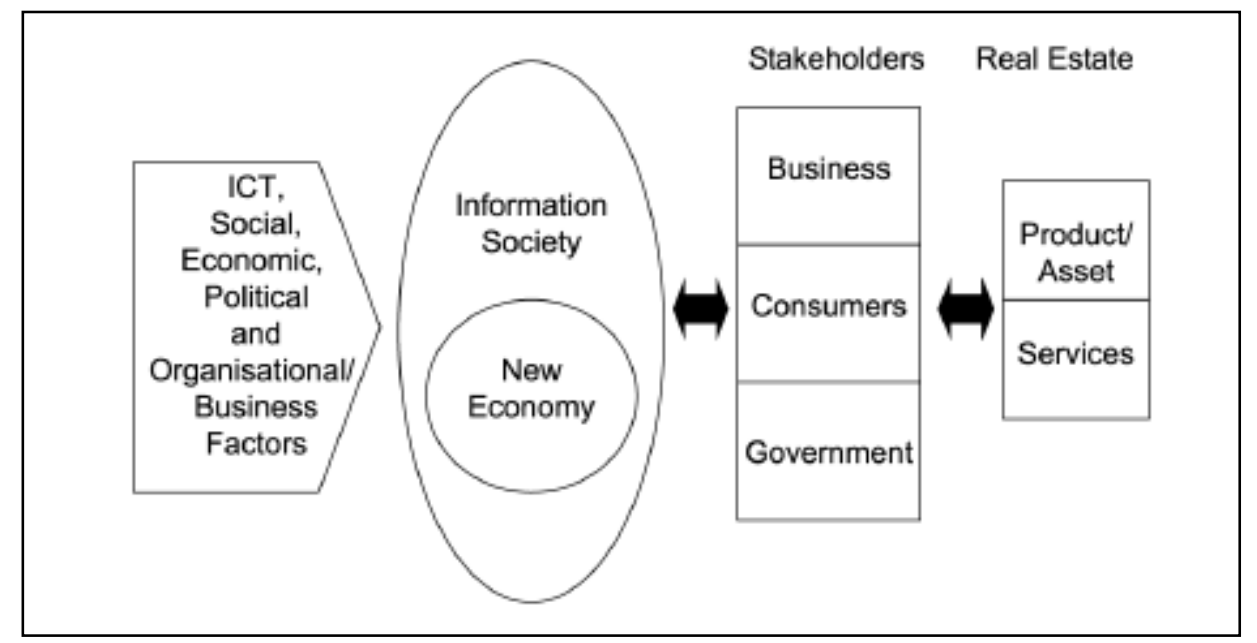

Figure 1. Key new economy drivers in property/real estate (societal technical model)

(Source: Dixon et al 2005)

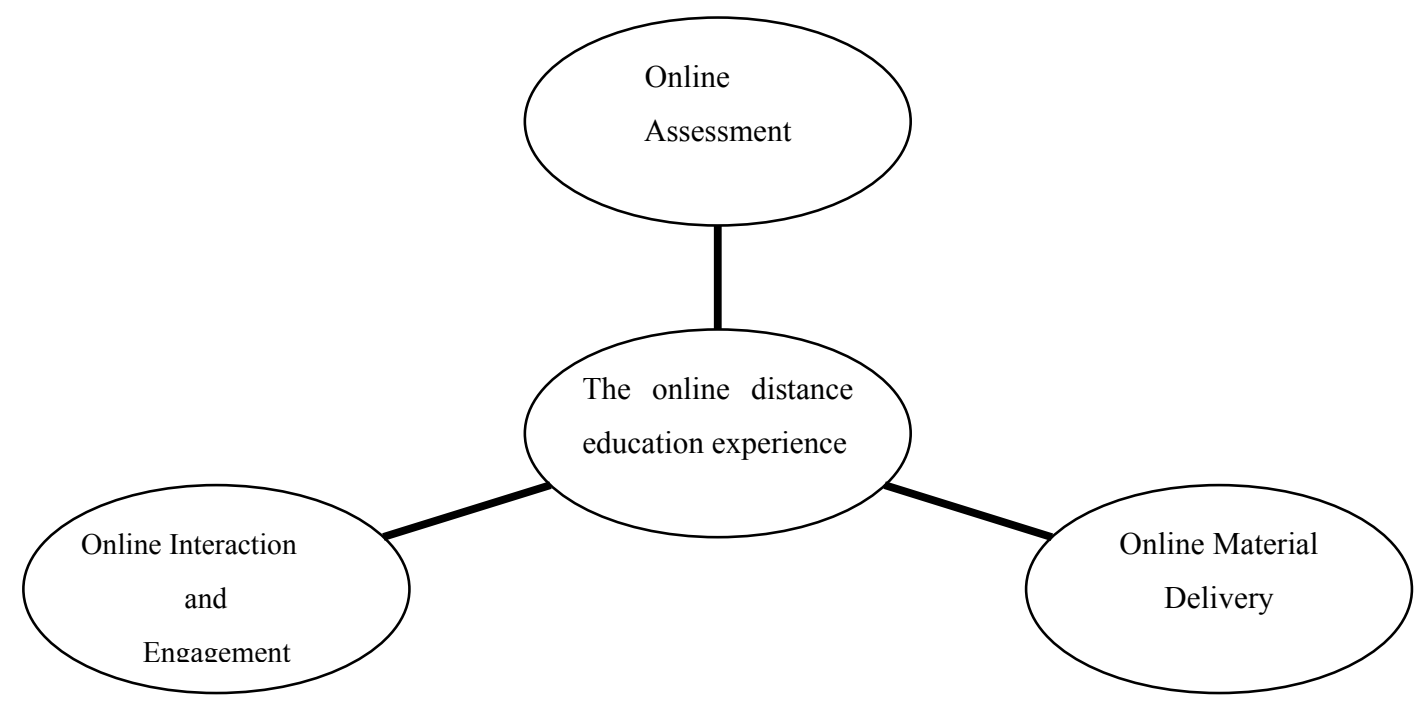

Figure 2. Components of the online distance education experience 
Myth 1: everyone knows what you mean when you talk about e-learning

Myth 2: e-learning is really no big deal

Myth 3: the "hard-stuff" - the technology - is what's really difficult

Myth 4: the learners are who really count

Myth 5: learners know what to expect

Myth 6: communication is about telling

Myth 7: success is getting it to work

Myth 8: once is enough

Myth 9: it's magic

Figure 3. Nine myths about information and communications technology

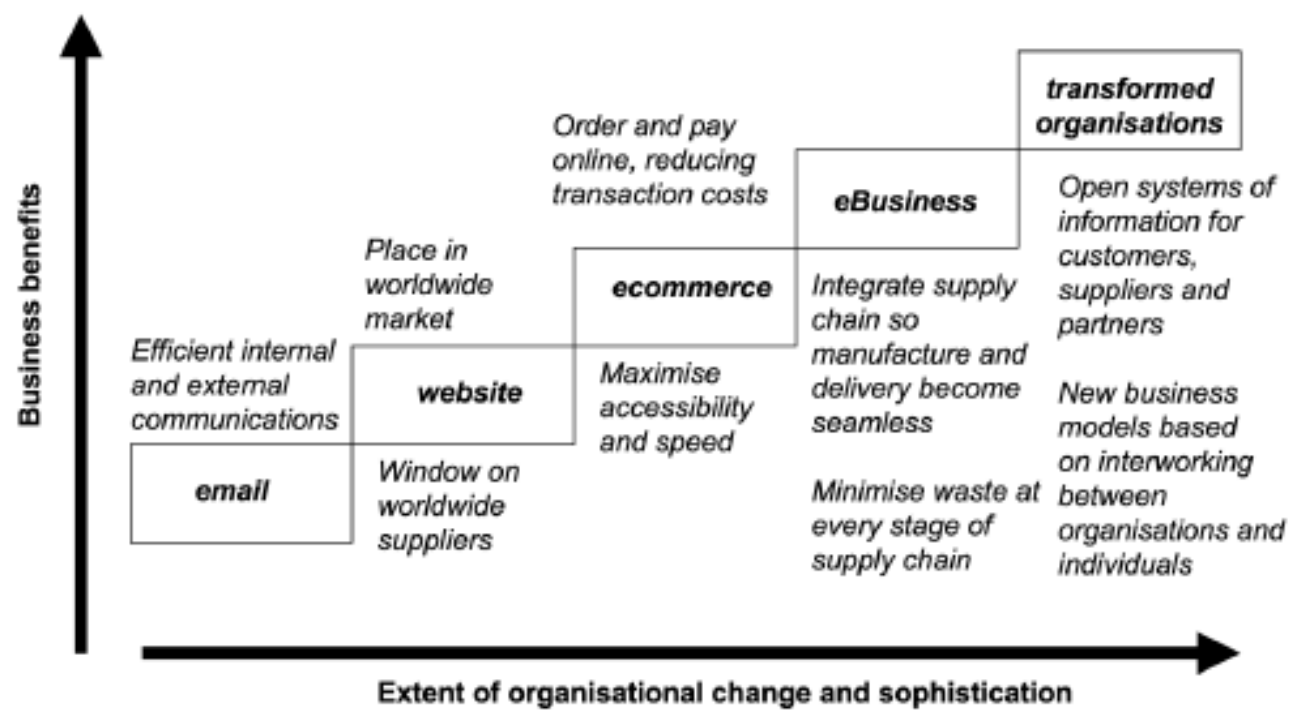

Figure 4. Model of e-adoption ladder

(Source: After DTI 2001) 


\title{
The Design of Health Care Management Program
}

\section{For Chinese Health Care Professionals}

\author{
Xiao Ling Qiu \\ Keller Graduate School of Management of Devry University \\ 30 Clara Street Brooklyn NY 11218, USA \\ Tel: 001-917-434-3418Ｅ-mail: qiuus168@yahoo.com
}

\begin{abstract}
Business education has been booming in China due to the increasing demand of business graduates since China's economic reform. Chinese health care professionals are eager for business education to improve their competencies. The purpose of the study was to investigate the determinants of a successful health care management program for Chinese health care professionals.

In-depth personal interview was applied in the study. There were 40 Chinese health care professionals that participated in the study in Guangzhou City China. They came from five local hospitals. The findings indicated that the Chinese health care professionals considered some health care management program attributes to be more important than other health care management program attributes.

The study indicated that the flexible and practice-oriented health care management programs which are accredited by Chinese education authorities and provided by reputable schools were welcomed by the Chinese health care professionals.
\end{abstract}

Keywords: Health, Education, Program, Professional, Chinese

\section{Introduction}

Business education was initiated in the United States of America (Robinson, 1995). The world's first college-level business school, now know as the Wharton School, was established at the University of Pennsylvania in 1881. The purpose of the University of Pennsylvania's business school at that time was to deliver business education to respond to the industrialization in the country and to meet the needs of managers

Typical MBA program curriculums focus on various functional business areas such as marketing, management, administration, accounting, and finance early in their program development (Haight \& Kwong, 1999). The major emphasis of these programs is on skill development and tools of business practice. The teaching method provides students limited opportunities to integrate the various disciplines within the MBA program. Today, business schools expand their emphases on leadership, teamwork, communication skills, and globalization knowledge along with the traditional functional areas. Welch (2002) argued that the trend towards using information systems were used as management tools in the practice of conducting business in a global environmental setting had become much more common. Most importantly, students are taught how to act in an entrepreneurial practice both within large and small organizations.

China is a newly industrialized country in the $21^{\text {st }}$ century and its economy has been booming during the past two decades (Lanchovichina \& Walmsley, 2005). China has gradually moved from the traditional planned economy system towards a free market economy system after it adopted the "open-door" policy in late1978. After more than thirteen years of negotiation, China was admitted as the World Trade Organization's (WTO) $143^{\text {rd }}$ member in December, 2001. All of these new economic environments have accelerated China's need for Western-trained managers with knowledge in business fields such as accounting, finance, management, marketing, international business, and international business law (Lavelle \& Rutledge, 2006). Currently, there are about 20,000,000 total enterprises in China; however, it is estimated that by the year 2006, the total number of MBA graduates in China will only be 130,000. There is a huge gap between the demand for MBA graduates and the supply of MBA graduates in China. It is estimated that by 2010, China will need 75,000 trained managers with international experience; however, there are currently only about 5,000 managers with international experience in China. 
In order to meet the increased demand of Western-trained managers, the Chinese government tried to launch more Master of Business Administration (MBA) and Executive Master of Business Administration (EMBA) programs in the nation (Hulme, 2004). In 1991, the Chinese government first recognized MBA programs. The Chinese Minister of Education had approved such programs in only nine of the top universities in the nation. The quota of students in these programs was assigned by the Chinese government, and only 86 students were enrolled at that time. The supply of MBA program graduates was still far below the demand. In 2001, the Chinese Minister of Education had approved 62 universities to establish MBA programs and by 2003, there were 10,000 students enrolled in China's MBA programs nationwide. The EMBA program was officially introduced in China in the year of 2002, and there are currently only 32 EMBA programs that have been approved by the Chinese Minister of Education. The amount of MBA programs in China and the numbers of enrolled MBA students continued to increase under the pressure of the increasing demand for MBA graduates. By 2004, there were more than 18,000 Chinese students enrolled in 96 MBA programs in the nation (Lavelle \& Rutledge, 2006).

In 2007, other 31 MBA programs are approved by Chinese Minister of Education; currently, there are 127 officially approved MBA programs nationwide. However, most of these programs focus on general management topics such as Marketing, Finance, Human Resource Management, and Accounting; other management topics such as Health Care Management and Real Estate Management don't attract the business schools' attention (MBAhome.com, 2007).

Both Johnstone (1997) and Kamis (1996) stated that China's education market was booming and that it could become the world's largest new market for business education in the next few decades. Full-time working professionals have become the fastest growing segment in the higher education market in recent years (Smith, 2001). In China, the body of working professionals is huge; many of them are looking for business education to improve their business skills and knowledge in order to compete more effectively in today's global environments (Curtis \& Lu, 2004). In China, the body of health care professionals is huge, the professionals include medical doctors, pharmacists, nurses, nutritionist, and lab technicians. Most of the Chinese health care professionals didn't receive business education in medical schools. They are eager for business education to improve their management skills and competition. It is critical for business schools to design proper health care management programs to meet the Chinese health care professionals' needs.

\section{Literature review}

Different nations are featured with different cultural values. The Eastern countries have quite different cultural characteristics compared to the Western countries (Hofstede, 1980). Hofstede identified four dimensions of culture in terms of Power Distance, Uncertainty Avoidance, Individualism, and Masculinity. In another study, Hofstede (1991) identified the traditional Chinese culture - Confucianism as the fifth dimension of cultural measurement. Culture is the most complicated and the most profound factor that can influences various aspects of the society in the long run. The education system as well as other social systems in China have been forged and led by Confucianism for more than two thousand years (Kang, 2006).

From the establishing of the People's Republic of China in 1949 to 1978, China government adopted the central planned economy policy (Cai, 2004). Within this period, the event of the Cultural Revolution, which lasted for 10 years from 1966 to 1976, had seriously destroyed the higher education system in China. Admissions to the university which was dependent on University Entrance Examination and academic records during the pre-Cultural Revolution, then depended on the political backgrounds of the individuals and the recommendations of their working unions during the Cultural Revolution. The Chinese educational system, instead of having its own purpose and focus of education and training, was designed to serve the political movement during that period. During this period, business education was almost ignored (Alon \& Lu, 2004).

In 1977, which was the second year after the termination of the Cultural Revolution in China, the higher education national entrance examination system was restored. This was the turning point of the China higher education system (Hu, 1988). The Chinese higher education system started to adopt the modern Western higher education model under the forces of the "open-door" policy and economic reform started in 1978.

The reason why China's higher education system focused on science and technology education instead of business education was due to the government's policy (Hu, 1988). In the late 1980s, the Chinese economy developed at an increasing pace. China successfully attracted many direct foreign investments in the southeastern coastal open cities and regions, especially the Four Special Economic Zones in terms of Shenzhen City, Zhuhai City, Xiamen City, and Shantou City (Linn, 1998). The Four Special Economic Zones, which were approved by China's central government in the early 1980s and supported by local governments, were opened to foreign investors on a trial basis by providing favorable policies such as tax-free and duty-free customs. The successful attracting of foreign direct investment led to the booming of foreign joint ventures and foreign direct-owned subsidiaries in China. The Chinese domestic enterprises had to start their structural reformations in response to the economic reform. The success of China's economic reform led to competition, which transferred China from a sellers' market structure towards a buyers' market structure. From that time, the demand of trained managers, especially the Western-trained managers with international business 
experiences, increased rapidly. Business education and MBA education in China started to boom based on the market forces (Ralph, 2001).

The People's Republic of China was established in 1949. Before 1949, business and management were taught in universities throughout China (Zhou, 1991). At that time, the business education focused on the introduction of Western business and management theories and principles. After 1949, the Chinese central government controlled all the market activities because of the scarcity of resources in China. All the enterprises belonged to the State; all the enterprises received a quota from the governments and then focused on production. They were not consumer-oriented and therefore, they did not need to care about the distribution, pricing, promotion, and branding of the products because the governments would distribute all the products based on the State's needs. A seller's market was created at that time.

In 1978, China adopted an "open-door" policy, and started its economic reform. From that point, China worked hard to transfer its economic system from the centrally planned economy toward a market-oriented economy, which the Chinese government called a socialist market economy (Williams, Liu, \& Shi, 1997). The success of China's economic reform created an unprecedented economy development. Today China is called the "world factory" because it functions as one of the world's largest merchandise producers and exporters. China is also one of the top countries which attract direct foreign investment. China's economic reform, which is coupled with the globalization, pushes China to a buyer's market (Lavelle \& Rutledge, 2006).

China actually began to enroll students into formal business programs and business schools in 1978 - the second year of the restoration of the university entrance examination, which was eliminated during the ten years of "Cultural Revolution" (Gang, 2000). One of the business schools that admitted students in 1978 was the Shanghai University of Economics and Finance. In the late 1970s, China restarted its business education programs with a poor quality of students and faculty members, as well as a lower-quality business education system.

In response to the increasing demand for business professionals beginning during the Chinese economic reform in 1978, more Chinese universities set up business departments or even business schools to offer business education programs (Alon \& Lu, 2004). Not only did the body of business students expand, but the available business majors also expanded to include accounting, finance, marketing, management, international business, entrepreneurship, and management of information systems. The market force attracted a huge amount of top students who enrolled in business programs. The Chinese government's financial support also attracted many excellent faculty members to teach in business programs nationwide.

In order to improve China's business education rapidly and effectively, the Chinese government started to introduce modern business education models from North American and European countries in 1980s (Hulme, 2004). China has been eager for the business education partnership programs created by Chinese business schools with Western business schools, because this is the most effective way to introduce modern Western business education models directly to China.

While the business education in China grew quickly from the late 1980s, there are many challenges facing Chinese business education (Zhou, 1991). The lack of suitable business textbooks, qualified business faculty members, and teaching resources were the major issues in late 1980s and in the early 1990s. Although China can import many business textbooks today, most of these textbooks focus on Western business environments rather than Chinese business environments. Similarly, the direct import of Western faculty members can not solve the problem in the long-run because most of the Western faculty members do not understand the Chinese business environment very well. These problems existed both during that time period and during the present day and may well exist into the future as well.

Alan and Lu (2004) stated that there were three challenges facing China business education today. The first challenge emerges when the Chinese educational system transfers from the traditional Confucian culture to the modern Western thoughts. The second challenge is that China lacks business education resources and qualified business teachers. The third challenge emerges when most of the Chinese business programs depend on the importing of foreign business education materials, foreign business faculty members, and foreign business education pedagogies.

$\mathrm{Hu}$ and Grove (1999) pointed out that the transmission of Western business knowledge in today's China business schools was theory-oriented instead of practice-oriented. Chinese students are taught to remember the business theories, principles, and concepts. Chinese students are not trained to improve their analytical skill, problem-solving skill, and other job-related skills and knowledge.

Curriculum design is a challenge for Chinese business schools (Haight \& Kwong, 1999). While most of Chinese business schools still focus on the teaching of traditional functional areas of business such as accounting, finance, marketing, management, and international business, many Western business schools have begun to emphasize leadership skills, teamwork skills, communication skills, entrepreneurship, critical thinking and global thinking in their 
traditional curriculums. The curriculum design in China business schools must borrow from the successful Western design concepts and meanwhile reflect the unique business practices of China.

Students look for high quality business education and therefore, business education providers must understand what the determinants of quality are in business programs from the students' points of view. Different students may have their own preferences of business programs; therefore, business education providers must segment the business students based on their specific needs and expectations of business education, and then tailor business programs to meet their unique needs and expectations (Farquharson, 2005).

LeBlanc and Nguyen (1997) examined the concept of quality in business education settings. They identified seven factors which would influence students' evaluation of service quality in business education institutions. These seven factors were the school's reputation, the attitude of administrative personnel, the ability and attitude of faculty members, the curriculum design, the responsiveness of administrative personnel and faculty members, the school's physical environment and the access of facilities in the school. Other previous studies (Bitner, 1992; Hampton, 1993; Herbig, Milewicz, \& Golden, 1994; Winters, 1991) also support LeBlanc and Nguyen's (1997) findings regarding quality factors in business education.

Stefan, Roxana, and Markus (2004) conducted a survey at European universities and found that the following dimensions of quality were considered important by students in business school settings: corporate collaboration, information and responsiveness, courses offered, campus facilities, teaching practices, internal evaluations, external evaluations, computer facilities, collaboration and comparison, post-study factors, and library resources. Rapert, Smith, Velliquette, and Garretson (2004) conducted a survey to investigate the students' expectations of quality in business education, and found that the students' expectations of business education fell in two categories in terms of in-class environment and outside-class environment. In each category, there were numerous determinants which explained quality in business education. The in-class environment category included numerous determinants such as "encourages intellectual growth," "overall professionalism," "specialized training and instruction," "generalized/integrated training and instruction," "teamwork and group dynamics," "devoted and knowledgeable faculty members," and "classmate and faculty intimacy." The outside-class environment category included numerous determinants such as "integration with business community," "career preparation service," "availability of financial assistance," and "program clarity." Each determinant explained one aspect of expectations for quality business education; some determinants were composed of numerous specific attributes which students expected from quality business education.

Telford and Masson (2005) suggested a framework of quality values in higher education. In this framework, the following aspects of education processes contributed to the quality of higher education: course design, course marketing, student recruitment, induction, course delivery, course content, assessment monitoring, miscellaneous, and tangibles.

Mustafa and Chiang (2006) identified four key factors that reflect quality in business education, namely, teacher abilities, teacher attitude, course materials, and course load. Currently, most of the research topics on quality business education are conducted in Western developed countries in North America and in Europe and there are few studies that focus on China and other Asian countries. Sohail and Shaikh (2004) conducted a study in Saudi Arabia to explore the local students' expectations of quality in business education, and found that the local students identified six factors which contributed to their expectations towards quality business education. The six factors were "contact with personnel," "physical environment," "reputation," "responsiveness," "access of facilities," and "curriculum."

Kwan and Ng (1999) applied the SERVQUAL to examine the quality indicators in higher education from the points of view of students from Hong Kong and Mainland China, and found that students from both Hong Kong and Mainland China shared similar expectations towards higher education. Although both Hong Kong and Mainland China students considered factors such as course content, concern for students, facilities, assessment, medium of instrument, social activities, and people all contributed to the perceptions of quality of higher education, most of their expectations focused on study-related matters such as course content, and facilities rather than social life on campus.

Thompson (2002) stated that faculty members' ability, faculty members' attitude, and teaching style were important indicators of quality in business education. Since Chinese students have their own cultures and learning styles, they may have their own preferences regarding business teachers compared to those that Western students might have. Thompson (2002) investigated what factors contributed to a good business teacher from the point of view of Chinese students and found that the quality of a business teacher fell into five categories in terms of "teaching abilities," "personal qualities," "individual business credential," "individual academic credentials," and "course and class practice."

Huang (2005) argued that working professionals had their own expectations towards MBA education. A big challenge to these working professionals was that they had ongoing job responsibilities and family obligations and could not study the way as full-time students did. They needed flexibly designed MBA programs to fit their life styles. Huang (2005) conducted a survey in Taiwan to investigate the determinants of a successful MBA program from the points of view of working professionals. The survey found that there were eight attributes that must be integrated into an MBA program 
in order to attract and satisfy Taiwan's working professionals when they were seeking MBA education. The eight attributes were "capacity of faculty," "tuition fees," "delivery method and time availability," "on- or off-campus," "time required to complete," "country of origin," "reputation of school," and "degree accredited by Taiwan's ministry of Education." Among these eight attributes, the attribute of "degree accredited by Taiwan's Ministry of Education" and the attribute of "reputation of school" were ranked as the most important attributes by Taiwanese working professionals in seeking an MBA education.

In recent years, full-time working professionals have become the fastest growing segment in the higher education market (Smith, 2001). Johnstone (1997) and Kamis (1996) stated that China's education market was booming and it could become the world's largest new market for business education in the next few decades. Wang (2006) estimated that there only $5 \%$ of students were enrolled in full-time MBA programs. One reason was that the job market in China was competitive and working professionals were afraid of losing their jobs if they enrolled in full-time programs. The other reason was that most of the Chinese working professionals tried to keep their current jobs and their family lives while enrolled in MBA programs. That is why working professionals have their own needs and expectations of business programs (Southworth, 1999).

What are the determinants of a successful health care management program for health care professionals in China? This is the general research question in the study.

Since the school reputation and the program accreditation are important determinants when students consider a business program (Huang, 2005; Nguyen \& LeBlanc, 2001), the Chinese health care professionals' opinions towards school reputation and program accreditation must be investigated in the study. Therefore, the research question 1 is asked:

How important do the Chinese health care professionals consider the school reputation and the program accreditation when they choose a health care management program?

Since the business program formats, such as the combination of on-campus learning and distance learning, the guest lecturer teaching, the case method pedagogy, and the company internship program opportunity, are all considered important determinants when students choose an business program (Chen, Lin, \& Lee, 2004; Jennings, 1997; Mackay \& Stockpot, 2006; Patel \& Patel, 2006; Ulrich, 2005), the Chinese health care professionals' preferences towards health care management program format must be investigated in the study. Therefore, the research question 2 :

What kinds of program formats do the Chinese health care professionals prefer when they choose a health care management program?

Since school administrative services such as friendly and courteous administrative staff, easy access to library resources, easy access to computer facilities, and alumni networking are considered important determinants when students choose a business program (Sahney, Banwet, \& Karunes, 2004; Stefan, Roxana, \& Markus, 2004; Telford \& Masson, 2005), the Chinese health care professionals' expectations of school administrative services must be investigated in the study. Therefore, the research question 3:

What kinds of administrative services do the Chinese health care professionals expect from the business school when they choose a health care management program?

Since faculty member's capabilities such as the teaching experience, the business background, the ability to stimulate class discussion, the research ability, and the academic qualification are considered important determinants when students choose a business program (Rapert, Smith, Velliquette, \& Garreston, 2004; Thompson, 2002), the Chinese health care professionals' expectations towards faculty capability must be investigated in the study. Therefore, the research question 4 :

What kinds of capabilities do the Chinese health care professionals expect from the program faculty members when they choose a health care management program?

A business program's outcome is to improve students' business skills and knowledge including skills such as analytical skills, managerial knowledge, communication skills, teamwork skills, and creative ability (Mustafa \& Chiang 2006; Pariseau \& McDaniel, 1997; Rapert, Smith, Velliquette, \& Garretson, 2004). Since the understanding of what kinds of business skills and knowledge the students expect to improve can help faculty members design updated curricula and apply effective pedagogies to meet the students' expectations, the Chinese health care professionals' expectations towards business skills and knowledge improvement must be investigated in the study. Therefore, the research question 5:

What kinds of business skills and knowledge do the Chinese health care professionals expect to improve when they choose a health care management program?

In order to explore more Chinese health care professionals' expectations of health care management program, the research question 6 asks: 
Beyond the above five questions, can you recommend more expectations that you have of a desirable health care management program?

\section{Methodology}

In order to investigate what the determinants of a successful health care management program are from Chinese health care professionals' point of views, an in-depth personal interview was conducted with Chinese health care professionals. The purpose of the interview was to discover some qualitative information regarding the Chinese health care professionals' opinions towards the determinants of a successful health care management program.

There were 40 health care professionals participated in the in-depth personal interview in 2007. These 40 health care professionals were recruited from 5 hospitals in Guangzhou City, China by referrals. They were all full-time working professionals. 10 interviewees were medical doctors, 10 interviewees were nurses, 10 interviewees were pharmacists, 5 interviewees were nutritionists, and 5 interviewees were lab technicians. Among these 40 interviewees, 18 were female professionals, 32 were male professionals. The interview was a face-to-face, in-depth personal interview held by the researcher. Each interview lasted for about half an hour.

For the purpose of ease, expression, relaxation, and effectiveness, the interview was conducted in Chinese, the local language. The six interview questions were asked by the researcher in order during the interviews, and the interviewees were encouraged to express their own opinions freely. At the beginning of the interview, the researcher confirmed if the interviewee was a full-time health care professional, however, the interviewee's other personal information was not asked. The interviewees' answers and opinions were recorded on notes written by the researcher instead of by audio taping or video taping.

\section{Findings}

Regarding the interview question 1: How important do you consider the school reputation and the program accreditation when you choose a health care management program? All 40 interviewees said that they considered school reputation and program accreditation were very important when they chose a health care management program.

Regarding the interview question 2: What kinds of program formats do you prefer when you choose a health care management program? There were 35 interviewees who said that they considered the following three program attributes to be important when they chose a health care management program: foreign joint venture programs, on-campus and distance learning blended programs, and some classes taught by guest lecturers from the industry. There were 28 interviewees who said that they considered the following three programs attributes to be important when they chose a health care management program: the course created in cooperation with businesses, the program provides corporate internship opportunity, and some classes taught by overseas faculty. There were 20 interviewees who said that they considered the following four program attributes to be important when they chose a health care management program: some classes taught in English, small class format, group project study format, and the program provides overseas study opportunities. There were five interviewees who said that they considered short programs run by professionals to be important when they chose a health care management program.

Regarding the third interview question 3: What kinds of administrative services do you expect from the business school when you choose a health care management program? There were 38 interviewees who said that they considered the following three program attributes to be important when they chose a health care management program: convenient campus location, alumni networking, and career preparation services. There were 29 interviewees who said that they considered the following three program attributes to be important when they chose a health care management program: networking with the business community, reasonable faculty/student ratio, and faculty members can be contacted by students outside of class times. There were eight interviewees who said that they considered the following three program attributes to be important when they chose a health program: reasonable tuition rate, availability of financial assistance, and program clarity.

Regarding the fourth interview question 4: What kinds of capabilities do you expect from the program faculty members when you choose a health care management program? There were 35 interviewees who said that they considered the five following program attributes to be important when they chose a health care management program: courteous and devoted faculty, faculty holds doctorate degrees, faculty has overseas education backgrounds, faculty has local Chinese business experiences, and faculty can stimulate class discussion. There were 25 interviewees who said that they considered the following four program attributes to be important when they chose a health care management program: the faculty has international business experiences, the faculty has college teaching experiences, the faculty has excellent Chinese language skills, and the faculty has excellent English language skills. There were six interviewees who said that they considered the following three program attributes to be important when they chose a health care management program: faculty member graduates from top university, open-minded faculty members, and faculty members' welcoming of criticism. 
Regarding the interview question 5: What kinds of business skills and knowledge do you expect to improve when you choose a health care management program? There were 40 interviewees that considered that the ability of the curriculum of the programs in improving analytical and managerial skills and knowledge of the students was important when they chose a health care management program. There were 36 interviewees that considered that the curriculums could improve the communication and teamwork skills. There were 32 interviewees that considered that the ability of the curriculum of the program to help improve interpersonal skills and negotiation skills was an important factor in choosing a health care management program. There were 20 interviewees that considered that the ability of the curriculum design of the program to help improve the students' entrepreneurial ability as well as global business skills and knowledge was important in choosing a health care management program. There were two interviewees that considered the ability of the program to improve the students' research skills was important to consider when they chose a health care management program.

Regarding the interview question 6: Beyond the above five questions, can you recommend more expectations towards a desirable health care management program? There were eight interviewees that considered that the evaluation of courses and faculty members were important factors to consider when choosing a health care management program. There were five interviewees that said that they considered the following three program attributes to be important in choosing a health care management program: frequent feedback on students' performance, keeping work outside of the classroom to a minimum and proper course loads.

The 40 interviewees expressed a total of 48 program attributes that they considered to be important elements for a successful health care management program. The researcher categorized the 48 program attributes into three groups: the most frequently mentioned program attribute group (program attributes were mentioned by 31 to 40 interviewees), the frequently mentioned program attribute group (program attributes were mentioned by 11 to 30 interviewees), and the less mentioned program attribute group (the program attributes were mentioned by one to 10 interviewees).

There were 19 attributes included in the most frequently mentioned program attribute group: the school has a high reputation, the program is accredited by the Chinese Minister of Education, foreign joint venture programs, on-campus and distance learning blended program, some classes taught by guest lecturers from industry, convenient campus location, alumni networking, career preparation services, courteous and devoted faculties, faculty holds doctorate degrees, faculty has overseas education backgrounds, faculty has local Chinese business experiences, faculty can stimulate class discussion, the curriculums can improve my analytical skills, the curriculums can improve my managerial skills and knowledge, the curriculums can improve my communication skills, the curriculums can improve my teamwork skills, the curriculum can improve my interpersonal skills, and the curriculums can improve my negotiation skills,

There were 16 attributes included in the frequently mentioned program attribute group: course created in cooperation with business, the program provides corporate internship opportunity, some classes taught by overseas faculty, some classes taught in English, small class format, group project study format, the program provides overseas study opportunities, networking with business community, reasonable faculty/student ratio, faculty members can be contacted by students outside of class times, the faculty has international business experiences, the faculty has college teaching experiences, the faculty has excellent Chinese language skills, the faculty has excellent English language skills, the curriculums can improve my entrepreneurial ability, and the curriculums can improve my global business skills and knowledge.

There were 13 attributes included in the less mentioned program attribute group: short program run by professionals, reasonable tuition rates, availability of financial assistance, program clarity, faculty members graduated from top universities, open-minded faculty members, faculty members' welcoming of criticism, the curriculums can improve my research skills, evaluation of course, evaluation of faculty member, frequent feedback on student's performance, keeping out-of-class work to a minimum, and adequate course loads.

\section{Summary and conclusions}

In the interview, the participants consider that both the program accreditation and the school reputation are important program attributes. In the survey conducted by Huang (2005) in Taiwan, the programs accredited by the Taiwanese Ministry of Education and the programs offered by a reputable school were considered the two single most important program attributes by Taiwanese working professionals. This study indicated similar results. The reason is that an accredited business program offered by a reputable school ensures the quality of the program, and consequently, the future job opportunities of the graduates.

Most of the prestigious joint venture business programs in China are accredited by the Chinese Ministry of Education and offered by reputable schools (Scallberg 2001). Based on current Chinese education law, joint venture business programs are the only format which can obtain accreditation from the Chinese Ministry of Education if foreign education investors want to set up business programs in China to recruit local Chinese students. In order to establish a 
successful business program for the Chinese working professionals, foreign education institution should partner with a reputable Chinese business school and apply for program accreditation from Chinese education authorities.

The study reveals that the relative important program formats include foreign joint venture program, on-campus and distance learning blended program, some classes taught by guest lecturers from industry, and programs that provide corporate internship opportunities.

Since business education in China lags behind its Western counterparts (Chao \& Dubas, 1995), Chinese working professionals prefer foreign joint venture programs, which could offer a better quality education. On-campus format is the basic study format because pure distance learning program is not currently accredited by the Chinese Ministry of Education. Blended programs with distance learning components are welcomed by working professionals, because the professionals have ongoing job responsibilities and family obligations. Because they can not study like full-time students do, the distance learning format is a valuable supplement to the on-campus format. Working professionals come from industries and prefer practice-oriented program formats (Huang, 2005) and that is why they consider guest teaching and corporate internships as important program attributes.

The study reveals that the relative important administrative services include the alumni networking, career preparation services, networking within the business community, convenient campus locations, and reasonable Faculty/student ratio.

Business education provides good business opportunities and career opportunities to students (Thompson \& Gui, 2000). Networking is important in China because it provides various opportunities between people who become connected in networking opportunities (Kang, 2006). That is why participants consider alumni networking, business community networking, and career preparation service to be important school administrative services. Traveling consumes time, money, and energy, Chinese health care professionals prefer a campus with a convenient location. A reasonable faculty/student ratio is a signal of quality education and was considered to be an important program attribute by Chinese health care professionals. Financial issues were not a major concern in the study; it is understandable that health care professionals can afford the tuition because they have income from working.

The study reveals that the relative important faculty member capacities include the capability of case method teaching, holding a doctorate degree, an overseas education background, local Chinese business experience, international business experience, excellent Chinese language skills, and the ability to stimulate class discussion.

Compared to theory teaching, case method teaching is practice-oriented. Case method teaching was initiated in Harvard Business School and adopted by many worldwide business schools today (Contardo \& Wensley, 2004). Chinese health care professionals prefer faculty members that can teach by the case method and by stimulating class discussion. Chinese health care professionals also prefer that faculty members have both Chinese business experience as well as international business experience. The faculty members' capability to bring real world business experience and case study into the classroom is welcomed and valued. The Chinese health care professionals also considered that an overseas education background and doctorate degree can ensure the qualification of the faculty members, and hence they are important attributes of a successful health care management program. On the contrary, academic qualifications such as graduated from top universities and research ability are not considered important by Chinese health care professionals.

The study reveals that the relative important business skills and knowledge improvement considered by Chinese health care professionals include analytical skills, managerial skills and knowledge, communication skills, teamwork skills, interpersonal skills, leadership skills, negotiation skills, entrepreneurial ability, and global business skills and knowledge.

A business program's outcome is to improve students' business skills and knowledge (Mustafa \& Chiang 2006; Pariseau \& McDaniel, 1997). It is understandable that most of the participants considered different business skills and knowledge improvement to be important. Most of the skills and knowledge improvements considered important by the participants are practice-oriented. Faculty members must develop practical program courses and teaching materials to meet the Chinese health care professionals' needs. Case method teaching, in-class discussion, group project study, and corporate internship program are valuable for the improvement of many business skills and knowledge.

In conclusion, School reputation and program accreditation are crucial for recruiting, retaining, and satisfying business students. Foreign education institutions should choose to partner with a reputable Chinese business school as part of the market entry strategy in China. The joint venture program is the exclusive program format which can guarantee accreditation from Chinese education authorities if foreign education institutions want to establish business programs to recruit students in China.

Compared to full-time students, Chinese health care professionals do have their own expectations and preferences toward business education. Chinese health care professionals are characterized as having time constraints and a practice-orientation, which is why they prefer flexible and practical health care management program. The on-campus 
and distance learning blended programs are suitable for working professionals because they can overcome the barriers of time constraints and travel problems. Programs held in convenient locations such as in cities can attract more students. Guests from industries could bring real world business experiences into classroom, and are welcomed by students. Working professionals come from industries and prefer those faculty members who have business experiences, can apply case method teaching, and can stimulate class discussion. School administrators and faculty members should design flexible business programs, and apply practice-oriented pedagogies to meet the Chinese health care professionals' needs.

Career development is a major concern of business students. Business schools should provide career preparation services to students. Alumni networking and business community networking are crucial for Chinese health care professionals' career development; business schools should build a network to connect the current students, alumni, and the greater business community. Networking is a part of social life and it is very important for career development and in doing business in China (Szeto, Wright, \& Cheng, 2006).

Some business skills and knowledge which the Chinese health care professionals eager to improve include communication skills, teamwork skills, analytical skills, managerial skills and knowledge, leadership skills, interpersonal skills, global business skills and knowledge, and negotiation skills. Faculty members should develop appropriate courses and teaching materials and apply appropriate pedagogies to improve the corresponding business skills and knowledge. Courses developed in cooperation with business, case method teaching, group project study, class discussion, guest teaching, overseas faculty teaching, overseas study, and corporate internship are some of the effective ways to improve students' business skills and knowledge.

\section{Limitations and recommendations}

Two limitations should be noted in this study. First, the major limitation of the study is that the samples were not randomly selected. The using of a convenience sampling technique may lead to the selection bias, which could influence the generalization of the findings. Since the samples were drawn in Guangzhou City solely, they can not represent the Chinese health care professionals in other areas very well. Second, employers are major stakeholders of business education, their opinions are critical for the evaluation of the success of a health care management program. The samples did not include employers, constituting a drawback of the study. The validity of the study was compromised due to the unrepresentative samples in the study.

There are several opportunities for future research that are suggested from this study. Since most of the business graduates will enter the job market, employers' opinions are crucial to def business program. Therefore, employers' expectations of business program should be explored in future research. Online learning is an important component of flexible business programs for working professionals; today, online learning is becoming popular worldwide (Moskal, Dziuban, Upchurch, Hartman, \& Truman, 2006). Online learning is new for Chinese working professionals; the design of online learning courses and integration of online learning components into business program should also be addressed in future research.

\section{References}

Alon, I., \& Lu, L. (2004). The state of marketing and business education in China. Marketing Education Review, 14, $1-10$.

Bitner, M. J. (1992). Servicescapes: the impact of physical surroundings on customers and employees. Journal of Marketing, 56, 57-71.

Cai, Y. (2004). Confronting the global and the local—a case study of Chinese higher Education. Tertiary Education and Management, 10(2), 157-169.

Chao, C. N., \& Dubas, K. M. (1995). A short-term business training program for Chinese managers at a U.S. university. Journal of Education for business, 70, 300-308.

Chen, S. H., Lin, H. T., \& Lee, H. T. (2004). Enterprise partner selection for vocational education: Analytical network process approach. International Journal of Manpower, 25(7/8), 643-655.

Contardo, I., \& Wensley, R. (2004). The Harvard Business School story: avoiding Knowledge by being Relevant. Organization, 11(2), 211-231.

Curtis, S., \& Lu, W. (2004). The impact of Western education on future Chinese Asian managers. Management Research Review, 27(10), 58-68.

Farquharson, M. (2005, April). Tailor-made MBAs. Human Resources, 38-40.

Gang, D. (2000). Innovation: Mission of Education. Beijing, China: Education and Science Publishing House.

Haight, T., \& Kwong, K. K. (1999). Future of the MBA in China. Business Forum, 24, 33-36. 
Hampton, G. M. (1993). Gap analysis of college student satisfaction as a measure of professional service Quality. Journal of Professional Services Marketing, 9(1), 115 - 127.

Herbig, P., Milewicz, J., \& Golden, J. (1994). A model of reputation building and destruction. Journal of Business Research, 31, 23-31.

Hofstede, G. (1980). Culture’s Consequences. Beverly Hills, CA: Sage.

Hofstede, G. (1991). Culture and Organizations: Software of the mind. London: McGraw-Hill.

$\mathrm{Hu}$, T. (1988). Teaching about the American economy in the People's Republic of China. Journal of Economic Education, 19(1), 87-96.

Hu, W., \& Grove, C. (1999). Encountering the Chinese. Yarmouth, Maine: Intercultural Press.

Huang, C. H. (2005). Exploring employed-learners' choice profile for VMBA Programs. Journal of American Academy of Business, 7(2), 203-211.

Hulme, V. A. (2004). The MBA boom. The China Business Review, 31(1), 24-28.

Jennings, D. (1997). Researching and writing strategic management cases: a systems view. Management Decision, 35(2), 100-107.

Johnstone, H. (1997). Lesson is supply and demand. Asian Business, 33(6), 58-59.

Kamis, T. L. (1996). Education for the PRC executive. China business Review, 23(4), 36-39.

Kang, X. (2006). Confucianization: a future in the tradition. Social Research, 73(1), 77-121.

Kwan, Y. K., \& Ng, W. K. (1999). Quality indicators in higher education Comparing Hong Kong and China's students. Managerial Auditing Journal, 14(1), 20-26.ine the success of a

Lanchovichina, E., \& Walmsley, T. (2005). Impact of China's WTO accession on East Asia. Contemporary Economic Policy, 23(2), 261-277.

Lavelle, L., \& Rutledge, S. (2006). China’s B-school boom. Business week, 3966, 40-45.

LeBlanc, G., \& Nguyen, N. (1997). Searching for excellence in business education: an exploratory study of Customer impressions of service quality. The International Journal of Educational Management, 11(2), 72-80.

Linn, G. (1998, October 21). China bids for foreign capital by expanding trade zones Inland. Journal of Commerce, p. A7.

Mackay, S. \& Stockport, G. J. (2006). Blended learning, classroom and e-learning. The Business Review, 5(1), 82-88.

Moskal, P., Dziuban, C., Upchurch, R., Hartman, J., \& Truman, B. (2006). Assessing online learning: What One university learned about student success, Persistence, and satisfaction. Peer Review, 8(4), 26-29.

Mustafa, S. T., \& Chiang, D. (2006). Dimensions of quality in higher education: How academic Performance affects university students' teacher evaluations. Journal of American Academy of Business, 8(1), 294-303.

Nguyen, N., \& LeBlanc, G. (2001). Image and reputation of higher education institutions In students' Retention decisions. The International Journal of Educational Management, 15(6/7), 303-311.

Ralph, J. (2001). China embraces the MBA. Far Eastern Economic Review, 164(28), 61- 62.

Pariseau, S. E., \& McDaniel, J. R. (1997). Assessing service quality in schools of business. The International Journal of Quality \& Reliability Management, 14(3), 204- 215.

Patel, C. \& Patel, T. (2006). Exploring a joint model of conventional and online learning systems. E- Service Journal, 4(2), 27-46.

Rapert, M. I., Smith, S., Velliquette, A., \& Garretson, J. A. (2004). The meaning of quality: Expectations of Students in pursuit of an MBA. Journal of Education for Business, 80(1), 17-24.

Robinson, P. (1995). Snapshots from hell. New York: Warner Books.

Sahney, S., Banwet, D. K., \& Karnes, S. (2004). A SERVQUAL and QFD approach to total quality education: A student perspective. International Journal of Productivity and Performance Management, 53(1/2), 143-166.

Scallberg, E. J. (2001). Lessons from China. Selections, 1(1), 6-13.

Smith, L. J. (2001). Content and delivery: A comparison and contrast of electronic and Traditional MBA Marketing planning courses. Journal of Marketing Education, 23 (1), 35-44.

Sohail, M. S., \& Shaikh, N. M. (2004). Quest for excellence in business education: A study of student Impressions of service quality. The International Journal of Education Management, 18(1), 58-65. 
Southworth, D. B. (1999). Building a business school in China: The case of the China Europe International Business School (CEIBS). Education \& Training, 41, 325-330.

Stefan, L., Roxana, S., \& Markus, L. (2004). Examination of the dimensions of quality in higher education. Quality Assurance in Education, 12(2), 61-69.

Szeto, R., Wright, P. C., \& Cheng, E. (2006). Business networking in the Chinese context: Its role in the Formation of guanxi, social capital and ethical foundations. Management Research News, 29(7), 425- 438.

Telford, R., \& Masson, R. (2005). The congruence of quality values in higher education. Quality Assurance In Education, 13(2), 107-119.

The expansion of MBA education in China. (2007, August 31). Retrieved September 20, 2007, from http://www.mbahome.com/newss/Article/UploadFiles/200709/20070917190219524.doc

Thompson, E. R. (2002). Chinese perspectives on the important aspects of an MBA teacher. Journal of Management Education, 26(3), 229-258.

Thompson, E.R., \& Gui, Q. (2000). Hong Kong executive business students' motivations for pursuing an MBA. Journal of Education for Business, 75(4), 236-240.

Ulrich, T. A. (2005). The relationship of business major to pedagogical strategies. Journal of Education for Business, 80(5), 269-274.

Wang, J. (2006). China's thirst for middle managers. Far Eastern Economic Review, 169(6), 44-48.

Welch, A. (2002). Going global? Internationalizing Australian universities in a time of global crisis. Comparative Education Review, 46, 433-454.

Williams, G., Liu, S. S., \& Shi, Q. (1997). Marketization of higher education in The People's Republic of China. Higher Education Policy, 10(2), 151-157.

Winters, R. S. (1991). Total quality in higher education. San Francisco, CA: The Jossey-Bass Publishing.

Zhou, N. (1991). The revival and growth of marketing education in China. Journal of Marketing Education, Summer, 18-24. 


\title{
Secondary School Admissions: The Choice for Black Parents
}

\section{In the London Borough of Hackney, United Kingdom}

\author{
Lionel McCalman \\ School of Education, University of East London \\ Stratford Campus; London, United Kingdom, E15 4LZ \\ Tel: 0044(0)2082232592Ｅ-mail: L.McCalman@uel.ac.uk
}

\begin{abstract}
In the UK, the law places a lot of emphasis on parental rights and choice - the right to choose the school that suits the needs of your child. Parents can list in order of preference and this ranked order is lodged with the education authority (through one common application form), and hope that within the complexities of the admissions process, the system mitigates in their favour. For some black parents, the oversubscription criterion is often perceived as the hurdle within the allocation procedure. Their children will loose out. This paper provides an insight into the views of some black parents in the London Borough of Hackney and through a personal and critical engagement; analysis is brought to bear on a terrain of current educational debate. An attempt is made here to address the role of education in a capitalist society.
\end{abstract}

Keywords: School admissions, African Caribbean, Hackney, Educational underachievement, Black children, Black parents, Transition

\section{Introduction}

Wearied by the lack of mobility for the urban poor, including the majority of minority ethnic residents in London, and the evidence of social exclusion of African Caribbean children (Wright et al 2005), the black community has begun a search to provide an alternative conceptual framework to redress the educational isolation of their children. In an engaging and highly explosive national debate on secondary education and school admissions, Hackney's lack of a clear vision for secondary school provision has embodies a new level of political engagement for the wider community. At stake is the flagship policy of New Labour to further erode the role of Local Education Authorities and give to schools greater control over their admissions policy. Without downplaying the importance of communities in having a say in their local schools, New Labour has re-introduced 'parents power' in the form of parent councils in the newly constituted 'Trust-Status Schools', though it is not clear whether their role would be consultative rather than decision-making (Hatcher 2005). The White Paper 2005 sets out to encourage all schools to become 'Trust Schools' with greater independence and freedom to run their own affairs - including statutory powers to appoint the majority of the governing body, control their assets, and set admission policies.

\subsection{The Skills Agenda and school selection practices}

The logic of capitalism is the commodification of all essential services that affect our daily lives. Within the realm of the state education system the liberalisation of trade in services seems to many to have heralded a new era of 'business takeover of schools'. Rikowski and Rikowski (2006) contended that the Education White Paper 2005 is the manifestation of the General Agreement of Trade in Services (GATS), along with its elements of commercialisation, privatisation and profit-making, which gives the green light to multinational companies to gradually make inroads into the state education system - the state funded services, schools and libraries. This new approach and the injection of private investment are seen as the solution to the crisis in education within the inner city areas. The authors further explained how the government's political agenda has been the development of a 'skills agenda, namely lifelong learning, to focus and accelerate the capabilities of individuals to become efficient workers' (Rikowski and Rikowski 2006: 25).

Current policies in British schools do not address satisfactorily the problem 'school selection practices' that openly discriminate against some groups of parents and pupils. It is most parents' wish to enrol their child in an education institution where students as a rule do well academically. However a number of other factors influence black parents' choice of a secondary school for their child. One overriding factor has been whether secondary schools actively discriminate against black children in their admissions criteria. The two major concerns of this paper are: What does 
'choice' mean for black parents and (b) How systematic are black parents in their choice of secondary schools for their children.

Although in most areas, transfer from primary to secondary schools is automatic, (with the exception being where the 11plus exam exists), it is widely accepted that some schools are increasingly placing a significant emphasis on the potential academic performance of their secondary intake. Within the paradigm of formal and informal evaluation, school effectiveness characteristics are embedded in parents' minds in the form of academic grounding in particular knowledge, linguistic and social behaviour, styles, personal dispositions and modes of thought and expression, and - the crowning virtue - good examination results. Students are judged 'qualified and able' or 'academic failures' according to how completely and convincingly these characteristics are displayed. 'Cultural Capital not only produces distinctions among individuals, it also produces its own value' (Olneck 2000: 321).In the UK, an assumption is made on the likelihood of the candidate achieving five higher grade/ passes at GCSE (General Certificate of Secondary Education), which is then seen as the performance indicator of the school's education provision. The DfEE document, 'Excellence in Schools' (1997) stressed the fact that educational attainment demands in schools were now becoming a key factor in the isolation, non-participation and social exclusion of young people within our society - thus exacerbating social inequality.

As secondary schools are essentially the avenues through which individuals move through the education system - from childhood to adolescence, the establishment's point of view is that a balanced national curriculum is provided which enables the individual to acquire knowledge and conceptual understanding through a range of subject areas. Success at the knowledge prescribed virtually guarantees the recipient enhanced occupation status - tied to education through the notion of meritocracy. This view sees competitiveness through value added measurements as the levelling out of opportunities by which skills and abilities of individuals are assessed. Are black parents aware of the competitiveness of the education system and is there a realisation of these political and economic goals that permeate the state education system? In this article I will argue that the black community in London is aware of the value of educational qualifications and that, most black parents are aware that secondary school selection is a vital process in the ladder of opportunity, and in consolidating the aspirations and aptitudes of their offspring.

\section{Methodology}

For the purpose of this study, 'black' represents people of African and African Caribbean background. A group of 25 black parents from the London Borough of Hackney, were canvassed for their views on secondary school selection. No claim would be made here that this group is representative of Hackney's black community, but their views raise a number of concerns about the local education provision.

\section{Background to the article}

Hackney is considered a deprived and socially disadvantaged area. All the government benchmarks attest to this fact. The recent report by OFSTED spelt out the problem:

"The London Borough of Hackney is one of the most deprived parts of London. Many residents experience economic disadvantage and crime rates are high. It is also a borough with great diversity amongst its population: about $80 \%$ of school pupils are from minority ethnic groups. The largest ethnic group in Hackney schools are those of African and Caribbean heritage." OFSTED (2003) pp. 7.

The extraordinary proportion of over $80 \%$ ethnic minority pupils in Hackney schools invite the question; 'Where do the indigenous population educate their children?' The report admits that a high proportion of children attend schools outside the borough, but omits to state their ethnic origin. Key to all this has been the issue of educational standards, and has led to the borough's education service being taken over by an independent body, a private public partnership, The Learning Trust (2002). Unfortunately, The Learning Trust has not been an unalloyed success. Attempts to boost academic achievement still seem a distant dream and Hackney continues to be placed in the lowest category in the Comprehensive Performance Assessment (2005).

No evidence exists to confirm that the white middle-classes are abandoning Hackney schools to avoid their children attending the same schools as black and ethnic minority children, but the stereotyping of the black child in the education literature as un-teachable, underachieving, uncooperative - (ungrateful even).... is well documented (Gillborn and Mirza 2000; Mirza and Reay 2000; Blair 2001; Gillborn 2002). Moreover, critics have recently pointed out that of the 2,200 pupils of primary school leaving age in Hackney, secondary places are only available for 1,500 pupils (Saum 2004). Some secondary school places are increasingly at a premium as the crisis in primary-secondary transfer grows. However, there is also a general assumption among the middle classes that schools outside the borough provide the best chance for a good education. Also in an increasing competitive environment, the middle classes are more able to 'manipulate' the admissions system, master the appeals process and to identify the schools where multiple applications can be sent. The same schools are in a position to 'cream' the pupils who would maximize their examination results. In 
a recent study on secondary schools admissions, West and Hind (2003) concluded that some schools adopt unfair admissions criteria to exclude some groups and include others.

"A significant minority of schools, notable those that are their own admission authorities - voluntary-aided and foundation schools - a variety of criteria are used which appear to be designed to select certain groups of pupils and so exclude others. These include children of employees; children of former pupils; partial selection by ability/ aptitude in a subject area or by general ability; and children with a family connection to the school". (West and Hind 2003, pp. 3)

The Code of Practice on school admissions clearly suggests that some of these practices may contravene the Race Relations Act 1976, and the fact that some schools continue to ignore this advice is noteworthy. What is even more astonishing is that in a follow-up study by the said researchers on the admission criteria of secondary schools in London, not once did they raise the issue of black children in London schools (West, Hind \& Pennell 2003). Writing in general terms, the researchers identified a number of other 'idiosyncratic' criteria and practices that were 'potentially unfair', such as interviews, imprecise and unclear criteria, reference to pupil's academic record, or the record of siblings. One conclusion that could be drawn here is that some secondary schools in London, (particularly foundation and voluntary-aided schools), actively discriminate against some groups - on the basis of race and ethnicity - and in so doing create enclaves of educational desirability and underachievement ghettos. If black children are to meet their academic potential, then they need schools with good records to prepare them for university. However the serial wastage of black boys and young black men in particular, attest to the fact that they continue to loose out and that in the largely unregulated market, and may not be engaging in further endeavours (as adults) to further their own education. Some groups continue to benefit at the expense of others.

\subsection{Can Black parents exercise 'Choice' on a similar basis as other parents?}

The question of choice is a highly contentious issue in the literature. The New Labour government sees 'choice' as a mechanism to drive up standards in the state educational institutions; the benefits derived would be for all sectors of society. However, Gewirtz et al (1995) pointed out that choice in education varies across social class and ethnicity, and is inequitable. The issue of social class permeates the mechanisms of the system and restricts the range of options for some groups. As they pointed out:

"First, choice is very directly and powerfully related to social class differences. Second, choice emerges as a major new factor in maintaining and indeed reinforcing social-class divisions and inequalities" Gewirtz et al (1995), pg. 55.

For some theorists, the problem is amplified through the outmoded and outdated structures that prop up the education system, which do not have a tendency to enhance equality. It is the system itself that needs an overhaul.

"While society moves into a post-industrial, post-modern age, our schools and teachers continue to cling to crumbling edifices of bureaucracy and modernity: to rigid hierarchies, isolated classrooms, segregated department and outdated career structures......" (Hargreaves 1994, p. x)

Should parents be asked to place the development and education of their children on hold while awaiting the long revolution in provision? Choice in education appeals to a growing sector of middleclass Londoners, and this 'flight' further erodes attempts to achieve prosperity and well being for all children in our schools. In this explanation, 'choice' is a clever ploy designed to appeal to the middle classes - particularly those who believe that self interest is the only motivator.

One parent, himself a teacher, said the following:

Conrad: "We have lived in Hackney for the greater part of our lives. My three children were all born here. We wanted to stay loyal to The Borough of Hackney, despite the issue of quality of secondary school education. Of the four secondary schools we selected for our son, our first three choices were in Hackney and the fourth - in Tower Hamlets. We got none of the schools we chose. Instead we were offered two all-boys schools in Tower Hamlets, which - we are told, are almost 90\% Bangladeshis. We wanted to stay loyal to Hackney, but Hackney is not loyal to us".

By far the most incisive comment came from Gladys, a mother of three with a history of fighting the Borough of Hackney for appropriate schools for her children.

Gladys: "Black parents in Hackney do not have choice. They have preference. They are given a chance to select their preference of secondary schools by the Learning Trust, then they cross their fingers and hope that their preference is translated in the choice of school for their child"

\subsection{Black children and educational achievement}

Black children have not had a similar measure of success within the British education system as other indigenous groups have had, even though surveys have shown that black families tend to be more positive about the values and need for education than their white counterparts (DfEE 2001, Parekh 2000). Indeed, recent statistics show that black boys were more likely to be excluded ( $83 \%$ of the permanent exclusions in 1995-6); six times higher than their white 
counterparts. Poor academic outcomes of black children, particularly black boys have been well documented (DfES 2006; DfES 2004); Majors (2001), and it is suggested that the differences in attainment levels, (particularly in GCSEs between black children and their white counterparts), may represent a long process of decline in relative attainment of black pupils in the compulsory education system. The most recent published national statistics clearly stated that:

"All minority groups within the Black category, and pupils of Mixed White and Black Caribbean heritage are consistently below the national average across all Key Stages, at GCSE and equivalent and Post -16.

For example, at GCSE and equivalent, $41.7 \%$ of Black Caribbean pupils, $44.1 \%$ of pupils of Mixed White and Black Caribbean heritage, $48.3 \%$ of black African pupils and $41.7 \%$ of other Black pupils achieve $5+\mathrm{A} * \mathrm{C}$ compared to $54.9 \%$ nationally". (DfES 2006, 2)

In a recent review of educational attainment in Hackney, underachievement was particularly noted among black children.

"Evidence shows a clear dip in performance among Afro-Caribbean boys between Key Stage 2 and Key Stage 3" (The Learning Trust 2003, p. 4). This is further reinforced by the government's own analysis that ... "despite general improvement..... there is evidence that the attainment gap for this group is widening..." (DfES 2006, p.2).

Supported by statistics from sources such as the Ethnic Minority Monitoring Programme, African Caribbean children seem to perform as well as other groups at the Baseline Assessment Tasks. By Key Stage One, they are falling behind other groups. This trend continues to Key Stage Two, but the dramatic drop in performance of African Caribbean Children (especially African Caribbean boys) seems to be between Key Stage Two and Key Stage Three. Here we see significant attitudinal changes and pressures that shape the relationship between teachers and African Caribbean boys many at this stage are bordering on inevitable exclusion or alternative learning strategies. In 2001/2002, The London Borough of Hackney recorded only $8 \%$ of African Caribbean boys achieving the standard of 5+ A-C passes in the national attainment tests - GCSE exams.

Many mistaken assumptions have been made regarding the awareness of educational expectations held by black parents of the academic abilities of their children. Gillborn (2002) pointed out that teachers' assumptions about 'ability' based on 'standardised' tests, have been for most the corner-stone of their predictive power of pupils' eventual performance at national attainment tests (i.e. GCSE exams).

"Teachers make judgements about ability in a wide range of different contexts and using a variety of criteria, including test scores, judgements of written work, oral presentations and in relation to students' behaviour. These judgements and the labels they produce are of differing degrees of importance" (Gillborn 2002, p. 4).

(Gillborn and Mirza 2000) have suggested that the term 'underachievement' has become loaded in stereotype and has somehow slipped into the pervasive 'discourse of despair' among and about some ethnic minority groups. They contended that some groups, say African Caribbeans may be ranked low in the national measure of achievement, yet the said group may well be achieving highly is some schools and some LEAs. Replying to the question, "Why do some schools do better than others?" Blair (2001) stated that:

"Black students need to know that they are not only welcome and wanted in the school, but that they are treated fairly, their cultures will be respected, the political issues that beset them as black people will be understood, and form part of the schools' sensitive responsibilities towards them. They need to know that their particular needs will be recognised as complex and comprising their ethic and 'racial' identities as well as their needs as 'children' or young people, but also that their differences will be appreciated.” (Blair 2001, p. 42).

\subsection{Transition to Secondary Schools}

The careful selection of a pupil's secondary school has increasingly been promoted as vital to the academic sustainability of individuals as the link between educational attainment and occupational attainment in industrial countries is made. The educational reforms of the New Right in the UK were instrumental in expanding social inequality, imposed around the economic imperatives of a polarised workforce. Through the state agencies 'to promote competition' (OFSTED), the successful schools which guarantee higher yields in scholastic outcomes are seen as the engines producing status advantage, leading to a workforce increasingly polarised between the highly paid skilled elite and the low paid, unskilled.

One of the respondents, a black parent in Hackney revealed:

Jonathan: "We selected four secondary schools from the given list, and graded them on a scale of 1 to 4, the choices we thought would be good educational institutions for our son. Though we would have been overjoyed if our 'First Choice' had been given to our son, we would have accepted any of our four choices. In the end, we were given none. All the schools we placed on our list were Hackney schools and we now feel very let down by the Hackney Learning Trust. We do intend to appeal the decision, but we are not confident that it would get us anywhere." 
Another black parent - also disappointed by the unavailability of good secondary schools in Hackney commented:

Angelia: "My child has not been allocated a school, despite our selection of four. One third of the Year 6 group in our (Hackney) school (transferring to secondary schools) have not been allocated a place. This is very bad indeed. And as it happens, most of them happen to be boys. I was sent a list of schools that have available secondary school places. Two are in the neighbouring borough of Tower Hamlets (both all-boys schools); two are in The Borough of Haringey, two are in the borough of Islington and one in the Borough of Waltham Forest. We went on the internet to read the OFSTED report of the seven schools on the list and they were all low achieving schools. We will be going through the appeals process”.

Primary and secondary schools are characteristically of different cultures, associated with the pupil's age and stage of development. It is usually the case that one secondary school has several primary schools as 'feeders'. As argued by Hargreaves (1980), the transition process represents the notion of a particular phase of development between childhood and adolescence highlighting the supposedly existing homogeneity in physical, moral, emotional and intellectual growth. Within this paradigm, whole cohorts of pupils are transferred to another school, many to face new teachers and new pupils in a totally new environment. At the end of key stage 2 (national SAT tests) primary schools (5-11age group) deliver their pupils up to the secondary schools (11-18 age group), where the compulsory education requirement ends. Most will encounter for the first time specialist subject teachers with widely differing practice and subjective perceptions that have significant implications for some ethnic minority groups. Pupils are then transferred to Sixth Form colleges, colleges of Further Education or are deemed ready for transition to university education. The transition from primary to secondary schools is seen as a critical period in the education system. Pupils are seen as agents moving through changing social contexts of the social structures which entails targets, quotas and ethnic monitoring.

For many the designated secondary school is greatly influenced by the Local Education Authority's (LEAs) provision, the size of the catchment area and the projected population growth (Galton et al 2000), sometimes based on the assumption that able children in the top half of the ability range of primary schools need specialist schools that recognise their aptitude and abilities. Though setting and streaming are widespread throughout secondary education, the cognitive and affective learning outcomes were sometimes at odds with that of children's assessment of the characteristics of their classroom environment. From a secondary schools' point of view, the most frequently used admissions criteria are: siblings, distance, medical/social need, catchment area, 'first preference', pupils with special educational needs and feeder schools.

While there is a recognition that some pupils are adversely affected by the change from primary school to secondary, many studies that propose to throw light on the issue seem to offer limited advice on how best to address the problems. Galton \& Willcocks (1983) reported a marked decline in achievement, motivation and enjoyment and attributed this to the discrepancy between the child centeredness of primary school and the subject centeredness of secondary school. This key explanatory factor, they suggested, accounted for the slow-down rate of task engagement of some pupils in their new secondary school environment.

In Delamont \& Galton (1996) ORACLE study (Observation Research and Classroom Learning Evaluation), teachers and pupils were observed and pupils were tested in the final term before leaving primary school, and at the end of the first school year of secondary school. They reported that in regards to curriculum delivery, curriculum content and teaching method, very little attempt was made to maintain continuity between the two phases of school experience. Earlier studies, e.g. Dutch and McCall (1974) had concluded that the children most at risk from the transition process were the less confident pupils, those from poor economic and social backgrounds and the younger and less mature pupils. They seemed to experience problems with the physical and academic organisation of the new school, as well as the standards of work. Other recognisable problems were also the breakdown in pupil/ teacher relationships particularly with pupils of a non-academic disposition. Most endured a climate of low expectation.

There is evidence that some of the lessons of the past have been learnt. Further analysis from Rudduck, Chaplain and Wallace (1996) suggests that transition to secondary school is not quite as painful as it used to be. They however pointed out that for most pupils, full engagement with the learning process (i.e. good study habits, good attendance and homework) did not take on significance until year 10, when the realisation that this was an opportunity to gain meaningful qualifications for employment, was grounded. However, for many the gaps in knowledge were too large to bridge to enable them to catch up fully.

It is important to note that each school responds to the needs of pupils at an individual level, - termed 'functional individuality' - implementing school improvement strategies to suit their own cohort groups. It is the pupils as individuals who decide on the degree of their commitment, although it is the teachers' skilled intervention that reinforces that commitment to the academic aspirations of the school. Most people in an inner-city area know someone who lived in the city when their children attended primary school, but fled to suburban areas to avoid urban state secondary schools. Research into underachievement has highlighted boys' restlessness when confined for long periods in one space. As pointed out by Gordon \& Lahelma (1996), cited in Pointon (2000) 
"Boys in secondary schools ....try to, so it seems, decrease their immobility and increase their limited space by rocking their chairs, tapping their pencils, shifting and tapping the floor......... Girls, however, tend to sit more quietly" (Pointon 2000, p. 378).

Is this the general picture in most schools and what about the perceived notion that many teachers do not seem to be engaging the pupils?

\section{Should we blame the schools .... or parents?}

Why are inner city secondary schools so repellent to parents? Is the performance of a secondary school the sole consequence of what is taught, how it is taught and who teaches it? The conventional view is that inner city schools have their share of problems and, as a result, have a predominance of 'bad schools' while suburban schools provide children with a 'better' education, (i.e. schools with shared vision, strong leadership, well organised structure and visionary well trained staff). They are effective because they have high expectations for their pupils. The opposing view put forward by progressive educators is that inner city schools - when they are not effective - are so because of the appalling poverty that prevails in the neighbourhoods, the under-funded state of affairs which exacerbates social inequality (Davies 2000), and the emphasis on low skills (vocationalism of the curriculum) which polarises the workforce. There is a general feeling among some black parents that, if inner city schools were funded as generously as their Middle England /suburban neighbours, the attainment gap would disappear.

If we subscribe to the 'bad school' theory of school improvement, we are rejecting the dominant paradigm of 'technical rationality' that though inner city teachers are trained in the same way, and should have the same subject knowledge as their suburban counterparts, teachers in inner city schools nevertheless perform badly, unable to meet the current urban complexities facing teachers and learners. By coincidence, suburban schools, it may be argued, just happen to have the best teachers with higher level of professional expertise than their less affluent counterparts. Issues such as poor resources and working environment, pay stagnation, increased workload, and declining status and morale are alien to this workforce. It is the collaborative professional action that brings about the successful school environment, as measured by national exam and SATs performance.

Observers will testify however, that when inner city schools can restrict their intake, (eliminating the most distasteful aspects of social behaviour), to children from more affluent backgrounds, they perform just as well as their suburban counterparts. It is a known fact that most parents - black and white alike - do not warm to the idea of sending their children to secondary schools which, in their eyes, are underachieving. Can we therefore assume that the school location is the only locus for school performance? To some observers, it is a combination of a bright, affluent intake and adequate resources that is the real foundation of a school's success (Davies 2000). Christopher Jencks cited in Lewyn (2000, p.5), stated that qualitative differences between high schools seem to explain about two percent of the variation in the students' educational achievement ......... (and that) equalizing the quality of elementary schools would reduce [test score] inequality by 3 percent or less.

Commenting on similar concerns in the USA, Lewyn then concluded;

"It appears that there is little educational difference between 'good' suburban schools and 'bad' urban schools: rather the difference is in the schools' student bodies. In other words, if the Buffalo and Clarence school districts retain their current school boards, teachers and administrators, but switched students, parents would be fleeing Clarence for Buffalo, and would be complaining about the alleged idiocy of the Clarence school board" (Lewyn 2000, p.5).

In another view, the problem of the education system lies with irresponsible parents who are too lazy to take seriously their responsibility of their child's education and as such, 'free ride' on the responsibility of others (Tooley 1999). This view criticises not only the 'irresponsible parents' who place no effort into their child's education, but also the parents who are 'disconnected' when it comes to choosing the education institutions for their children. It sees the characteristic of 'choice' as essential if 'sink schools' - failing schools are to be rooted out of the system. The fact that these institutions are allowed to 'limp along .... perpetuating disadvantage for those who have to patronise them', is simply the result of poor judgement of the consumers (parents).

"If I do not want to be bothered to choose, then as long as there are a significant number who are discriminating choosers, suppliers and producers cannot take the risk that I am not one of them.... In exactly the same way, 'educationally irresponsible' parents would be able to 'free ride' on the responsibility of others. Provided that there are some educationally concerned parents using the education service, all will be able to benefit from their responsibility" Tooley (1999), p. 8.

The problem with this model is that it sees 'choice' as inevitable within the diversity of provision, and assumes parents would choose within an ethically prescribed framework. It ignores the fact that parents usually exercise their prejudices - within choice - on the basis of social class, race and ethnicity, religion and a host of other factors. What parents want is not 'choice', but a greater realisation that their nearest comprehensive would be of sufficiently good quality to deliver the services that are needed. 


\subsection{Education and Capitalism}

One explanation of the problem is to see the system as a product of inevitable inequality in the capitalist system - and the failure of its educational policies to expand its 'circle of opportunity'. We do not believe that it is coincidental that a small group of individuals have access to the 'better' educational institutions and that the majority have to 'put up' with their lot. Marxist theorists agree that the main purpose of education in capitalist societies is to produce the kinds and types of labour that are needed for effective competition with other capitalists. (Saltman \& Gabbard 2003) see the function of schools in capitalist societies as moulding children to fit the goals of the government, and as such, the market. It is therefore an education system geared towards selecting people for the job market. But the way this process is set in place has the distinct effect of polarisation within the education system. The presence of an ever increasing private fee-paying sector in the U.K. education system has the effect of dividing pupils into two main groups. One group benefits from the increasing hierarchies of education provision, resulting in social class inequalities, and the other has to contend with an education system which teaches compliance and subordination to the state agents and an acceptance of their role, embedded in their social relationship within the economy.

For those with money and influence, under-funded schools are not an option. Their children are selected for those parts of the education system where privatisation redirects public funds for private accumulation. This is effectively done by setting aside educational institutions for the sons and daughters of the capitalist ruling class and their chief servants and agents. Teachers and trainers have huge strategic importance in capitalist society. They are saddled with responsibility for generating 'work ready graduates' for the ruling class. Sparks (1994) puts it like this:

"Much of what is involved in that process is precisely learning obedience and deference to authority figures. But a part of education is concerned with transmission of the social and technical skills needed to administer capitalist society. Part of what is taught to working class children is, potentially at least, valuable material that can be used to change the world. Above all, what actually goes on in education is not the direct result of what the ruling class want. They, or at least their servants and agents, try to achieve that end, but they are challenged, more or less successfully, from below, by teachers, parents and by young people themselves" (Sparks 1994, p14).

However, even within the state education system, little replicas of the private education system exist, i.e. selective state schools and highly sought after - specialist schools - generally reserved for the middle classes. This leads to huge pressures from parents to ascertain for themselves the 'juicy bits' on offer, and the system to fit people into a niche within the class structure. The vicious hierarchical system is designed to preserve the rights of the ruling class; (providing a few entrants to the upper reaches of the class system); a middle tier for the sons and daughters of the middle classes, (providing the technical specialists needed lower down the order), and a state system for the rest of the population (providing a regulated process of state testing, league tables and a National Curriculum, instructing teachers what they should teach). Competition for funding in these schools is also crucial to the capitalists' ideology.

"Under-funded schools struggling to provide mandated requirements can only provide an emaciated education which in turn funnels any graduates into meaningless work or jail. The minimum standards for an education are those that would only qualify a person for a low paying job. Schools in trouble are punished, while those that succeed are rewarded" Daims (2004; p. 121)

But capitalism is a dynamic system which is constantly demanding new inputs of labour, new inputs of energy and new inputs of talents and ideas. It requires therefore some degree of flexibility within the system to produce all the new ideas and technological inputs that are needed to ensure the capitalist system stays competitive. Therefore, what capitalists want out of education is deeply contradictory. It would like an education system that maintains the status quo, but at the same time, they would like the education system to adapt to their demands, and change to their economic needs (Sparks 1994). The replicas (of the private education system) within the state education system, goes some way towards achieving this, and for this reason, selection is necessary. All these factors apply even more strongly in the case of national school exams and the relentless vilification of teachers. The rising rates of school exams passes in the U.K. tell only part of the story. Large numbers of working class children still leave school with little or no qualifications and African Caribbean boys in the school system appear at the 'top the league' in two areas. They are the lowest achievers of all groups when national examinations (GCSEs and 'A' levels) are taken into consideration; and are over-represented on the tables for children being excluded from school.

Of the Hackney parents who were interviewed, most seem to agree that:

1) The state of schools in Hackney is a disgrace:

2) It is a disgrace that hundreds of Hackney children this year (2006), can't even find a place in a secondary school.

3) It is a disgrace that so many schools have to rely on agency teachers

4) It is a disgrace that libraries are closing all over the borough. 
5) Private companies have been sent in to run Hackney's education before (a reference to Nord Anglia). 6) They have long gone. Most parents are not convinced that this private/ independent body (The Learning Trust) will be any different.

That if schools do not reflect the local community, and if there is no balanced intake in secondary schools, there will never be a balanced education system

Black parents interviewed felt that the education system seems to be harping back to the days when black children were seen as "educationally sub-normal" (Coard 1972). (One mother of three applied for a place at the London Nautical School - referred to as the naval college. Hers was one of four families from the same primary school to have applied for places at this Foundation school. Her child was rejected; the other three white children all received places at the school). Black parents in Hackney were under no illusion that their children have the same chance - as the white middle classes - to get into the high achieving London secondary schools.

\section{Conclusion}

Black parents are just as concerned about educational achievement as all other parents. The issue of school admissions has not been adequately dealt with and it is the view of the author that current practice encourages enclaves of privilege and ghettos of underachievement. Two sets of factors are easily isolated, social class / cultural capital, and poverty (Davies 2000). The first is explained through socio-economic status and mobility; the second is inhibiting as the 'disconnected' display less involvement in children's education at home.

Wragg (2003) has accurately summarised the present as a mixture of altruism and self-interest: "Education policies from both Labour and Conservative governments have polarised schools. Give top priority to league tables and test scores and better off, more mobile parents will move in next to, or even lie about living close by, the highest scoring schools. Consequently, schools at the bottom of the heap accrue more of society's downtrodden - free meal and special needs pupils increase. The free market separates rich and poor better than the finest sheepdog" (Wragg 2003, p. 10).

Who will be there to protect black and working class people when head-teachers of newly formed 'Trust' schools weald absolute power through school admissions? Until all sections in our society join with the wider community in supporting the local schools; join with the teachers in their battle for higher educational expectations for children, nothing will change.

If our schools do not have balanced intakes, we could never have a balanced education system.

\section{References}

Blair, M. (2001). Why do some schools do better than others; in Majors, R (Ed) Educating our Black Children, New Directions and Radical Approaches, London, Routeledge/ Falmer.

Bourdieu, P. (1984). Distinction: A Social Critique of the Judgement of Taste: Cambridge MA, Harvard University Press.

Coard, B. (1972). How the West Indian Child is being made Educationally Sub-normal in the British Education System. London, New Beacon Books.

Davies, N. (2000). The School Report: Why Britain’s Schools are Failing: London, Vintage Books.

Delamont, S \& Galton, M. (1996). Inside the Secondary Classroom, London; Routledge \& Kegan Paul.

DfEE. (1997). Excellence in Schools; Department of Education and Employment, HMSO, www.dfes.gov.uk

DfEE. (2001). The Department for Education and Employment; Youth Cohort Study: The activities and experiences of 16 year olds, England and Wales 2000, London, DfEE.

DfES. (2004). National Curriculum Assessment and GCSE/GNVQ Attainment by Pupil Characteristics in England: Department for Education and Skills; National Statistics.

DfES. (2006). National Curriculum Assessment, GCSE and Equivalent Attainment and Post 16 Attainment by Pupil Characteristics in England 2005: National Statistics; DfES.

Dutch, R \& McCall, J. (1974). Transition to Secondary - An experiment in a Scottish comprehensive school: British Journal of Educational Psychology, 44(3), p.282-289.

Galton, M \& Willcock. (1983). Moving from Primary School: London; Routledge and Kegan Paul.

Galton, M, Morrison, I \& Pell, T. (2000). Transfer and Transition in English Schools: Reviewing the Evidence. International Journal of Educational Research, vol. 33, (2000), p. 341-363.

Gewirtz, S, Ball, S and Bowe, R. (1995). Markets, Choice and Equity in Education; Buckingham and Philadelphia, Open University Press. 
Gillborn, D. (2002). Education and Institutional Racism; The Inaugural lecture; Institute of Education, University of London.

Gillborn, D \& Mirza, H.S. (2000). Educational Inequality; Mapping Race, Class \& Gender, London, OFSTED.

Hargreaves, A. (1980). The Ideology of Middle Schools; in A. Hargreaves \& L. Tickle (eds.) Middle Schools: Origins, Ideology and Practice; London, Harper \& Row.

Hall, S. (2003). I'd rather beg than send children to a state school, Letwin says; The Guardian, Friday $10^{\text {th }}$ October 2003.

Hargreaves, A. (1994). Changing Teachers, Changing Times, London, Cassell.

Hatcher, R. (2005). The White Paper: What does it intends; What would it mean; Will it happen. Some initial thoughts on some of the themes in Labour's latest education policy document. London, Socialist Teachers Alliance.

Lewyn, M. (2000). No Bad Schools, Just Bad Students, Buffalo Beat, Rochester, New York, April 27 - May $3^{\text {rd }}$, 2000.

Majors, R. (2001). Educating our Black Children, New directions and radical approaches, London and New York, Routledge/ Falmer.

Mirza, H and Reay, D. (2000). Spaces and Places of Black Educational Desire: Rethinking Black Supplementary Schools as a new Social Movement: Sociology; Vol. 34; No. 3; pp. 521-544.

OFSTED. (2003). Inspection Report: HACKNEY; Local Education Authority; Date of Inspection: September 2003; Office for Standard in Education, in conjunction with the Audit Commission.

Olneck, M. (2000). Can Multicultural Education Change What Counts as Cultural Capital: American Educational Research Journal: Summer 2000, Vol. 37, No. 2; pp. 317-348.

Parekh, B. (2000). The Future of Multi-ethnic Britain, The Parekh Report, London, Profile Books.

Pointon, P. (2000). Students' view of environments for learning from the primary to the secondary school: International Journal of Education Research, 33 (2000), p. 375-382.

Richardson, B (Ed.). (2005). Tell it Like it is. How Our Schools Fail Black Children: London; Bookmarks Publications and Trentham Books.

Rikowski, R and Rikowski, G. (2006). Discussions on the Education White Paper for England and Extensions of the commodification Process in Libraries and Schools; Information for Social Change Issue; 22; London, $4^{\text {th }}$ January 2006.

Rudduck, J, Chaplain, R, \& Wallace, G (eds.). (1996). School Improvement: What can pupils tell us? London, David Fulton.

Saltman, K and Gabbard, D (eds.). (2003). Education as Enforcement: The Militarization and Corporatization of Schools; New York, Routledge Falmer.

Saum, D. (2004). Parents Stage Angry Protest at Ceremony; Hackney Gazette, $1^{\text {st }}$ April 2004, pg. 5.

Sparks, C. (1994). The Tories, Labour and the Education Crisis; International Socialism, Spring 1994, pp. 3-40.

The Learning Trust. (2003). Entitled to Succeed: A Strategy for Success in Secondary Education, London Borough of Hackney, The Learning Trust.

Tooley, J. (1999). Is more choice in Education always better than less? University of Manchester.

West, A and Hind, A. (2003). Secondary School Admission in England: Exploring the extent of overt and covert selection; Centre for Educational Research; Department of Social Policy; London School of Economics and Political Science.

West, A, Hind, A \& Pennell, H. (2003). Secondary Schools in London: Admissions Criteria and Cream Skimming. Centre for Educational Research, Department of Social Policy; London School of Economics and Political Science.

Wragg, T. (2003). Poverty is not Catching; Working class children are stigmatised from their earliest years as 'not nice to go to school with'; The Guardian; Wednesday $5^{\text {th }}$ November 2003.

Wright, C, Standen, P, John, G, German, Patel, T. (2005). Social Exclusion and Transition into Adulthood in African-Caribbean; Joseph Rowntree Foundation and Nottingham Trent University. 


\title{
Effective Classroom-based Evaluation on English
}

\section{For Specific Purposes Teaching in China}

\author{
Youqin Yuan \\ Tianjin Agricultural University, Tianjin 300384, China \\ Tel: 86-22-23789023Ｅ-mail: cfxyy@126.com
}

This paper sponsored by the Institute of Higher Education "The study on multi-mode and English ability effectiveness," and "The study on serving the building of a new socialist countryside farmers education training system project", approval No: 06TG011; 06AIQ0030018.

\begin{abstract}
There is often no simple or single way to interpret assessment results or to make instructional decisions based on results. Thus, This research found that classroom -based evaluation calls for a great deal of judgment, which can be enhanced if the logic of evaluation is understood. This consists of comparisons between observed or actual states of affairs and desired states of affaire. When there is a mismatch, change is call for that will reduce the mismatch. The key is that how to deal with the difference between personal and professional decision-making. The latter one must be systematic, explicit, and well documented.
\end{abstract}

Keywords: Classroom -based evaluation, Planning evaluation, Result

\section{Effective classroom-based evaluation requires correct usage of many mechanisms}

\subsection{Understanding of the role of evaluation in planning and delivering instruction}

Evaluation is a purposive activity that includes the collection of relevant information, interpretation of that information, and making decisions about teaching and learning. In the past, discussions about second language evaluation, particularly when testing involved, have often focused on making decisions about students- their placement, promotion, advancement, and certification. Certainly, these are important reasons for doing second language evaluation, but they are not the only ones. In fact, the majority of decisions teachers make concern instruction-decisions about how and when to teach particular objectives; about the instructional needs of individuals or groups of students; about the appropriateness of instructional objectives and plans; and so on. Even decisions about students often call for choices regarding instruction. For example, decisions to admit particular students to a class or to promote students to the next level affect the composition of the classroom and may alter instruction plans for that class.

\subsection{The collection and interpretation of a wide range of information.}

Much discussion about evaluation has also focused on assessment of student achievement. This makes sense if the primary reason for evaluation is to make choices regarding students. Decisions about instruction, however, require more than data on student achievement. They require information about students' needs, goals, preferences, and attitudes towards school and learning. They often draw on students previous linguistic experiences, educational history, and cultural background. They utilize information about the coherence of instructional objectives and plans, the feasibility of instructional plans given an instructor's qualifications and the resources available in the classroom or school. They require knowledge of current research and thinking about second language teaching and learning.

\subsection{Familiarity with a variety of different methods of assessment and for competence in using these methods creatively.}

The range of information needed to make the many decisions that crop up in second language classroom cannot be obtained from any single assessment procedure. A variety of methods for collecting assessment information are needed. Disillusionment with the shortcomings of tests has led to great deal of discussion about alternative methods of assessment. It is certainly true that test alone is not sufficient. This is not to say that they can't be useful, but rather that additional methods of assessment are also important. In fact, no single method of assessment would be sufficient to provide all the information teachers need to plan effective instruction. Teachers need a repertoire of assessment methods. Different methods of assessment provide many different kinds of information, depending on how they are used, whereas others provide very limited data. Some provide information about student achievement along with learning strategies, but others do not. Some provide information about students' views, attitudes, and motivations, whereas 
others do not. Some engage students actively in the process of self-assessment and thereby encourage student ownership of and responsibility for evaluation and ultimately learning; others do not. The nature of the information you need will determine the method or combination of methods of assessment you select.

1.4 Effective evaluation reflects important features of classroom instructional purposes, plans, and practices and lead to improvements in second language teaching and learning.

The chief shortcoming of standardized tests and, indeed, of many classroom tests, is their failure to mesh with instructional objectives, plans, and practices. If tests and other methods of assessment are to be instructional on improving second language teaching and learning, they must reflect important aspects of teaching and learning in your classroom. As we noted that classroom -based evaluation is like a feedback loop-assessment activities are motivated and shaped by instructional purposes, plans and practices in the classroom, and the decisions that arise from the results of these activities, in turn, lead to reshaping of these instructional purposes, plans, and practices.

\subsection{Careful and systematic record keeping and judgment}

There is often no simple or single way to interpret assessment results or to make instructional decisions based on these results. Thus, classroom-based evaluation calls for a great deal of judgment, which can be enhanced if the logic of evaluation is understood. This consists of comparisons between observed or actual states of affairs and desired states of affairs. There is a mismatch, change is called for that will reduce the mismatch. This is not as complex as it sounds- we do this when we make everyday decisions. The difference between personal and professional decision- making is that the latter must be systematic, explicit, and well documented.

In many cases, teachers need to demonstrate to others- parents, other educators, and students themselves- what information they have collected, how they have collected it, and how they have used this information to make choices. Teachers must also keep records of this process for themselves, so that modifications to instructional purposes, plans, and practices that are indicated by their evaluations are made. Otherwise, important information will be forgotten and needed changes will not be made.

1.6 Teachers to become agents of change in their classrooms actively using the results of assessment to modify and improve the learning environments they create.

All too often, classroom tests are given, the results reported to students, and instruction proceeds unchanged. In such instances, the results of assessment are not used to improve instruction; rather, they are used only as indicators of student achievement. As a result, student learning becomes disconnected from the learning environment in which it occurs. Effective classroom-based evaluation is part of a process of continuously monitoring and modifying instruction to enhance second language learning. This calls for teachers to take charge of and responsibility for their instructional purposes, plans, and practices.

\section{Planning evaluation}

Preliminary to planning for evaluation, it is important to understand the capabilities and uses of alternative methods of assessment. Collectively, the methods we have discussed are useful for a variety of purposes:

(1) To monitor students' language proficiency in and outside class, the methods could be observation; objective-referenced tests; conferences; journals; portfolios and standardized tests.

(2) To understand students' learning styles and strategies, the methods could be observation; conferences; journals; portfolios.

(3) To know students' interests and attitudes about learning, the methods could be observation; conferences; journals; questionnaires; interviews

(4) To know students' background experiences (linguistic, educational, cultural, and medical) that can influence their learning in the classroom. The methods could be questionnaires; interviews; conferences and journal

(5) To ascertain students understanding and perceptions of classroom activities, The methods might be used journals; questionnaires; observation and conferences

(6) Develop students' self-assessment skills, might thorough the methods of portfolios; conferences; journals and questionnaires;

(7) Promote student responsibility and ownership of evaluation, the methods might be used like portfolios; conferences journals

(8) Involve students in identifying instructional goals and planning instructional activities, might be carried on through portfolios, conferences and journals.

Effective second language evaluation must consider variety factors like if the process that improves decision making in the classroom; focusing on improving second language instruction, 
Specific methods of assessment that can aid in accomplishing each of these purposes are shown on the next page. We have placed an asterisk next to the methods we think are generally most useful for accomplishing these purposes. These are general opinions; individual readers must decide which method of information collection would be most helpful for their particular purposes.

The mere use of each of these methods will not necessarily achieve these purposes. Special care must be given during the planning and implementation of them to ensure that they serve these purposes effectively. Moreover, these suggestions do not exhaust all possibilities. With creative adaptation, other possibilities are also possible; for example, tests could be included under (6), develop students' self- assessment skills, if teachers were to include students in the construction, scoring, and interpretation of test results.

It should now be evident that (1) different methods of collecting information lend themselves to different purposes, (2) assessment activities can do more than monitor student achievement, and (3) by planning evaluation you can take maximum advantage of the variety of purpose that different methods of assessment afford.

Having a repertoire of assessment methods and an understanding of their specific uses, you can now elaborate a plan for evaluation. In what follows, we have identified the kinds of decisions that might be made before, during, and after instruction, and then we have indicated the kinds of information that could assist in making those decisions and the methods of assessment that would be appropriate for collecting this information. We have included information and methods of assessment not discussed here, such as checking up school records, examining curriculum documents, and consulting with instructional teachers and other teachers.

The synopsis is that individual readers may be able to think of additional sorts of information or methods of data collection of each kind or type of decision. Nor is this synopsis applicable without modifications to any group of learners or classroom setting. It would need to be adapted to be appropriate for particular classroom settings. It serves only to illustrate very generally how to put together much we have discussed into a plan for evaluation in your classroom. Individual readers need to elaborate their own plan, using this for reference. Once again, we have identified with asterisks the kinds of information we believe to be generally useful for making each type of decision. We have not done this for methods of information collection since deciding on these depends critically on the classroom context and, therefore, cannot be done without more information. Only individual teacher can make those choices.

\section{Conclusion}

Effective second language evaluation may have several themes. We think it may be useful to mention them explicitly here. The first, many scholars call the "no right way" idea. Teaching and evaluating are very complex enterprises. It is misguided to think that we have discovered the best of all possible ways to undertake those enterprises. The second theme is to compare the actual with the ideal. Evaluation calls for action when an actual state of affairs does not correspond with the state you want. Assessment is guided, therefore by what you aim for, what you need, or what you expected. These are the details of a second language course. The third theme is related with the above mentioned, is needed to plan evaluation. Without a plan for evaluation, you will find that all too often opportunities have passed you by. The fourth theme is the need to multiply and vary in your methods of assessment. All assessment procedures give you error together with accurate information. Therefore, you want to multiply your assessment. Sound decisions are much more likely to be made when a variety of assessment methods produce the same set of facts.

\section{References}

Croft,W.\&A.D. Cruse. (2004). Cognitive Linguistics. Cambridge: CUP.

Clark,H.H.\&E.Clark. (1977). Psychology and Language. New York: Harcourt, Brace, Jovanovich, (Chaptert 2).

Calrk,J.M.\&A. Paivio. (1991). Dual coding theory and education. Educational Psychological Review 3(3):149-170.

Fred Genesee, \& Johna A. Upshur. (2001). Classroom- based Evaluation in Second Language Education. (1 ${ }^{\text {st }}$ ed.). Beijing: Foreign Language Teaching and Research Press, (Chapter14).

Massaro,D.W.\&M.M. Cohen. (1987). Evaluation and Integration of Second Language Classroom. Journal if Experimental Psychology 9: 753-771.

Murphy,V. (1997). The effect of modality on a grammaticality judgment task. Second language Research 13: pp.34-65. Sachs, Jacqueline. (1974). Course Design $\left(2^{\text {nd ed. }}\right)$. New York: OUP. 


\title{
Employability of Graduates - A Search through the Educational
}

\section{Processes of Indian Engineering Institutions}

\author{
K G Viswanadhan \\ Department of Mechanical Engineering, NSS College of Engineering, \\ Palakkad, Kerala, India, PIN: 678008 \\ Tel: 919446238935 E-mail:kgv1964@yahoo.co.in
}

\begin{abstract}
There is a big boom in manpower requirements in IT industries in India in recent years. Presently India is aiming at becoming the major source of manpower in IT and other technical fields in the global scenario. To achieve this target, enhancement of employability of graduates coming out of engineering colleges are very important. A study has been conducted, which critically evaluates the educational processes and its influence on the student performance, which can be treated as a measure of employability. The study is primarily based on the accreditation data of National Board of Accreditation (NBA), India. Most of the process factors are found to be correlated with the student performance and major differences were observed between the process levels of various categories of institutes. Integration of effective teaching methodologies and necessary supporting processes in the curriculum may enhance the performance of the graduates from the engineering institutes.
\end{abstract}

Keywords: Employability, Processes, Engineering institutions in India

\section{Introduction}

Software development and IT enabled services are emerging as a niche opportunity for India in the global market. Electronics and information technology is the fastest growing segment of Indian industry both in terms of production and exports. Today, the electronics industry is de-licensed, and along with the liberalization in foreign investment and export-import policies of the entire economy, this sector is attracting considerable interest not only as a vast market but also as potential production base by international companies (Indiacore, nd). Engineering graduates from different disciplines are coming to IT field. 'Employability' rather than mere subject knowledge is important for these graduates. Role of engineering colleges as 'production centers of employable human resources' are becoming dominant in this situation. Employability can be considered as the ability of employees to actively manage their work life to be assured of continued employment in a rapidly changing environment. In order to remain employable, they should update their skills to adapt to changing job requirements, and there by, enhance the odds of getting another job (Lee et al, 2003). Fugate et al. (2003) define employability construct as a multidimensional aggregate of career identity, personal adaptability, and social and human capital. It is asserted that employability captures the conceptual commonalities among these dimensions, as they relate to active adaptability at work. Moreover, employability includes a strong and important cognitive-affective element (career identity) that both directs and energizes one's active and adaptive efforts.

Engineering council/Royal academy of engineering, UK, defines engineering (E C, 1997) as: "a creative process in which facts, experience and skills in science, engineering and technology are applied to seek one or more technical solutions to meet a requirement, solve a problem, and then exercise informed judgment to implement the one that best meets constraints”. The engineering problem-solving process is not a simple systematic procedure involving the mechanical completion of one task after another. An engineering graduate would be expected to have an appropriate level of understanding of all of the steps involved in engineering problem solving, and to have recognized the need to develop and apply iterative procedures efficiently. The Engineering Professors Council (EPC), UK, through discussions with an advisory group consisting of members from the engineering employer's federation, the engineering council, the department for education and employment and the quality assurance agency, formed a profile of attainment for a graduate from an engineering course (EPC, 2002). Engineering graduate output standards could be both defined and expressed using this profile. According to EPC, the ability to exercise key skills is expected of all engineering graduates and these should be encouraged and developed during the degree course. The key skills are 'communication abilities, general IT user abilities, application of number, working with others, problem solving and improving own learning and performance'. In addition to this, the graduates should also demonstrate attributes of drive, motivation and innovation. 
These standards and the demand of industrial sector for enhanced employability in engineering graduates ask for a detailed study to find out the ways and means to achieve this target.

\section{Problem formulation and Objectives}

In India, except for a few autonomous institutes, all engineering colleges are affiliated to different universities. These universities frame curriculum for various programmes and the syllabus for various courses coming under these programmes. Some studies on scientific and technical manpower development (STMDI, 2000) and employability profile of fresh engineers (Ghani, 2002) in India points out the inadequacy of the curriculum followed by these universities. National Board of Accreditation (NBA) is charged with the task of evolving a procedure for quality assessment in the technical education sector in India on the basis of specified guidelines, norms, benchmarks and criteria. NBA aims to recognize and acknowledge the value addition in transforming the admitted raw student into a capable engineer, having sound knowledge of fundamentals and acceptable level of professional and personal competence for ready employability in responsible engineering assignments (NBA, 2000). NBA has formulated the criteria or standards, by which the strengths and weaknesses of the individual programmes in any institution be judged. Though the NBA criteria are not covering all the features that are described earlier and that are expected from a graduate engineer, some representative measures can be developed by combining different variables staggered under various criteria of NBA. Hence it is decided to formulate the study of Indian engineering education programmes based on the NBA assessment process and data.

NBA uses eight criteria (Mission, goals and organization, Financial \& physical resources, HR-faculty \& staff, HR-students, Teaching learning processes, Supplementary processes, Industry institute interaction and Research \& development activities) to assess the capabilities of engineering programmes. Out of these eight criteria, fourth criterion represents student aspects and the next four criteria represent the process aspect of the programme. For a specified programme where almost every resource can be treated as unchanging over the time period of concern, the processes play the major role in achieving the objectives. More over, the focus of present study is to determine the possibilities of enhancing employability skills through the educational processes. Hence the last five criteria scores of NBA assessment data are taken up for the study.

Undergraduate engineering programmes are offered by four major categories of institutes in India. National Institute of Technologies (NIT) and some other high profile colleges are functioning under autonomous status. They enjoy academic, administrative as well as financial autonomy. Central and state governments administer the second category. Third category of colleges is coming under grand-in-aid sector. Education societies or private bodies are managing these institutes. They take up the responsibility of providing capital assets like land, buildings, etc. Government provides salary and other working expenses to these colleges. AICTE, state governments and universities to which these colleges are affiliated fix pay scales and service rules for the staff employed in the second and third categories of institutes. Fourth category of colleges is working fully under self-financing scheme. Education societies or private bodies, which take up the responsibility of running these institutes, are mainly responsible for providing physical facilities, teaching staff, equipments and other supporting staff etc. For the last three categories of colleges, university is mainly responsible for the framing of rules for the academic part. They frame course duration, subjects to be taught, examination pattern, grading system etc. Students are admitted to these institutes by government and management on merit, as well as reservations basis. As the engineering institutions are coming under four different categories, the second part of the study is designed for analyzing the Process factors of these four categories of colleges, namely Autonomous colleges, Government colleges, Aided colleges and Self-financing colleges. Hence, objectives of the study are set as

a) To determine the correlation structure of process factors to the outcome - student performance

b) To assess the level of Process and Outcome factors in various categories of engineering institutes

\section{Methodology}

As the number of variables involved in the assessment of student and process parameters in NBA accreditation process seem to be high (33 variables under the 5 criteria), an attempt has been made to find out the minimum number of variables that can explain the variability of performance and that will allow an objective assessment. NBA assessment scores of 49 undergraduate engineering programmes from different parts of India have been collected for preliminary study. Principal Component Factor method is used for data reduction and summarization. Since the process is categorized into 5 criteria, Factor Analyses (FA) are conducted on the variables pertaining to each of these 5 criteria. By looking at the weights on the underlying variables given by the FA, suitable names are given to these factors (Table 1). Out of the 9 factors, the first one 'Student performance', which is a combination of dimensions 'Academic results, Admission to post-graduate courses, Performance in competitive examinations, Placements, and Employer's feedback' is taken as the outcome factor representing the employability of the students. Second and third factors (Student Intake and Learning Facilities) are resource components and hence neglected from the analysis. The remaining 6 factors - 
Instruction, evaluation \& feedback, Academic calendar, Supplementary processes, Institute initiatives, Industry initiatives, and R\&D activities are process representatives of the NBA accreditation and taken for framing the study. The entire framework is exhibited in Figure 1.

Data of additional 191 engineering programmes that have undergone accreditation process have been collected for further analysis. The degrees of association of various process factors with the outcome factor are analyzed to draw conclusions about the development of 'Student Performance'. The study is extended to determine the level of process factors in various categories of engineering programmes to find out the ways of improving the student performance. Categorization of programmes that are coming under the present study is given in Table 3 . As the variances of four populations are not equal, the non-parametric counterpart of one-way ANOVA, Kruskal Wallis test is selected for comparison. The null hypothesis of equal median for all the four populations is tested using Kruskal Wallis formula (Table 4).

\section{Results and Discussion}

All factors with the exception of 'Academic Calendar' are significantly correlated (Table 2) with Student Performance. 'Institute Initiatives' for industry institute interaction exhibits the maximum association with student performance. Figure 2 demonstrates the average level of process factors of Indian engineering programmes. Academic calendar, which is an indicator of pre-scheduled activities, seems not to be influencing the student performance/employability of the graduates. As most of the colleges in a state are affiliated to a single university, all the activities can be preplanned and hence the academic component acquired high scores irrespective of the category. Theoretical knowledge, which is tested through examinations, is only one of the several features of employability. Low value of correlation coefficient of 'instruction, evaluation and feedback' with student performance is an indication of this fact. Supporting processes (supplementary processes, institute \& industry initiatives for interactions and R \& D activities) exhibit high amount of correlation with the Student performance.

The performance of Process factors is not the same and the level of 'Supplementary processes; Institute-initiatives, Industry-initiatives and R\&D activities' are significantly different in the four categories of colleges (Table 4). Level (\%) of significant Process factors and Outcome factor for the four categories of engineering colleges are displayed in Table 5. Supplementary processes are at high levels in autonomous colleges and aided colleges (68\%) in comparison with the other two categories. Government engineering colleges show the lowest level in supplementary processes. While good amount of institute initiatives for interaction with industries are there in autonomous and aided colleges, this is only at a nominal level $(48 \%)$ in the other two categories of colleges. There is a major difference between the autonomous and self-financing colleges in terms of industry initiatives for interaction with institutes. Research and development activities are very limited in the engineering colleges, among which autonomous colleges are better (54\%) and self-financing colleges are at the worst (39\%) condition.

\section{Conclusions}

Employability is a generic term and can be treated as the capability of a person (engineering graduate) to readily take up a job assigned to him with out much amount of training. It is a holistic term representing all the attributes of an employee/employment. In the present study, a five-facet capability of an engineering graduate, Student Performance, is taken as the representative of employability. Supplementary processes, which promote informal interactions, among the students and with experts from various fields, are inadequate in most categories of engineering colleges. R \& D activities and industry-institute interactions are in pathetic condition in all categories of colleges. These are the major impediments to the enrichment of student performance, and as a consequence, to the inadequate employability of engineering graduates. Embedding all the processes, which enhance employability of the graduates into the curriculum of engineering programmes is the only way to overcome this difficulty. Effective teaching methodologies and necessary supporting processes are to be integrated in the curriculum by which employability can be enhanced in the graduates of engineering institutes.

\section{References}

EC - Engineering Council. (1997). Standards and Routes to Registration. SARTOR 3rd Edition.

EPC - The Engineering Professors Council. (2002). Output Standard - An employer-group interpretation . Report of the Employers’ Working Group, January, 2002.

Fugate, M., Kinicki, A. J. \& Ashforth, B. E. (2004). Employability: A psycho-social construct, its dimensions, and applications, Journal of Vocational Behavior, 65, 14-38.

Ghani, A. (2002). Impact of Technological Change on Employment Requirement of Engineers, The Indian Journal of Technical Education, 25(4), pp-19-28, Oct-Dec.

Indiacore (nd).Available online at www.IndiaCore.com 
Lee, S., Phan, P. H., Tan, Y. W. G. (2003). Impact of the Asian economic crisis on training intentions and outcomes, Human Resource Management Review, 13, 467-486.

NBA - Manual for NBA Accreditation (2000). All India Council for Technical Education, New Delhi, India. STMDI - Scientific and Technical manpower development in India. (2000). World Bank report.

Table 1. Summary of PCA results

\begin{tabular}{|l|l|}
\hline \multicolumn{1}{|c|}{ Criterion -NBA } & \multicolumn{1}{c|}{ Principal Components extracted } \\
\hline \multirow{2}{*}{$\begin{array}{l}\text { Students } \\
\text { Suman Resources }\end{array}$} & 1.Student Performance \\
\cline { 2 - 2 } $\begin{array}{l}\text { 2.Teaching - } \\
\text { Learning Processes }\end{array}$ & 3. Student Intake \\
\cline { 2 - 2 } & 4.Instruction, Evaluation and feedback \\
\cline { 2 - 2 } & 5.Academic calendar \\
\hline 3. Supplementary Processes & 6.Supplementary Processes \\
\hline 4.Industry - Institution Interaction & 7.Institute initiatives \\
\cline { 2 - 2 } & 8.Industry Initiatives \\
\hline 5. Research \& Development & 9.R\&D Activities \\
\hline
\end{tabular}

Table 2. Correlation coefficients of process components with Student Performance

\begin{tabular}{|l|c|c|}
\hline \multicolumn{1}{|c|}{ Process components } & $\begin{array}{c}\text { Correlation coefficient } \\
\text { (Pearson) }\end{array}$ & Sig. \\
\hline Instruction, Evaluation and feedback (IEF) & .179 & .007 \\
\hline Academic calendar (AC) & .078 & .236 \\
\hline Supplementary Processes (SP) & .359 & 0 \\
\hline Institute initiatives (II) & .532 & 0 \\
\hline Industry Initiatives (IyI) & .310 & 0 \\
\hline R\&D Activities (R\&D) & .421 & 0 \\
\hline
\end{tabular}

Table 3. Number of programmes under the four categories

\begin{tabular}{|l|c|}
\hline Category of Engineering Colleges & Number of Programmes \\
\hline 1.REC \& other Autonomous Colleges & 37 \\
\hline 2. Government Colleges & 32 \\
\hline 3. Aided Colleges & 124 \\
\hline 4. Self - financing Colleges & 240 \\
\hline Total & \\
\hline
\end{tabular}

Table 4. Result of Kruskal Wallis test

\begin{tabular}{|l|c|c|c|c|c|}
\hline & IEF & SP & II & IyI & R\&D \\
\hline Chi-Square & 2.170 & 20.498 & 67.287 & 14.187 & 77.937 \\
\hline df & 3 & 3 & 3 & 3 & 3 \\
\hline Significance & .538 & .000 & .000 & .003 & .000 \\
\hline
\end{tabular}


Table 5. Level (\%) of significant process components and outcome component

\begin{tabular}{|l|l|c|c|c|c|c|}
\hline Components & Level & Autonomous & Government & Aided & Self-financing & Overall \\
\hline \multirow{3}{*}{$\begin{array}{l}\text { Supple-mentary } \\
\text { Processes }\end{array}$} & Min & 52 & 34 & 46 & 42 & 34 \\
\cline { 2 - 7 } & Max & 86 & 80 & 86 & 78 & 86 \\
\cline { 2 - 7 } & Mean & 68 & 60 & 68 & 61 & 63 \\
\hline \multirow{3}{*}{$\begin{array}{l}\text { Institute } \\
\text { initiatives }\end{array}$} & Min & 50 & 0 & 55 & 13 & 0 \\
\cline { 2 - 7 } & Max & 85 & 85 & 90 & 95 & 95 \\
\cline { 2 - 7 } Initiatives & Mean & 69 & 49 & 72 & 48 & 55 \\
\cline { 2 - 7 } & Min & 50 & 47 & 53 & 33 & 33 \\
\cline { 2 - 7 } & Max & 83 & 90 & 80 & 83 & 90 \\
\hline \multirow{3}{*}{ R\&D Activities } & Min & 70 & 66 & 67 & 63 & 65 \\
\cline { 2 - 7 } & Max & 83 & 27 & 23 & 0 & 0 \\
\cline { 2 - 7 } & Mean & 54 & 41 & 45 & 31 & 83 \\
\hline \multirow{3}{*}{$\begin{array}{l}\text { Student } \\
\text { Performance }\end{array}$} & Min & 60 & 33 & 46 & 37 & 33 \\
\cline { 2 - 7 } & Max & 89 & 88 & 83 & 85 & 89 \\
\cline { 2 - 7 } & Mean & 76 & 67 & 68 & 61 & 66 \\
\hline
\end{tabular}

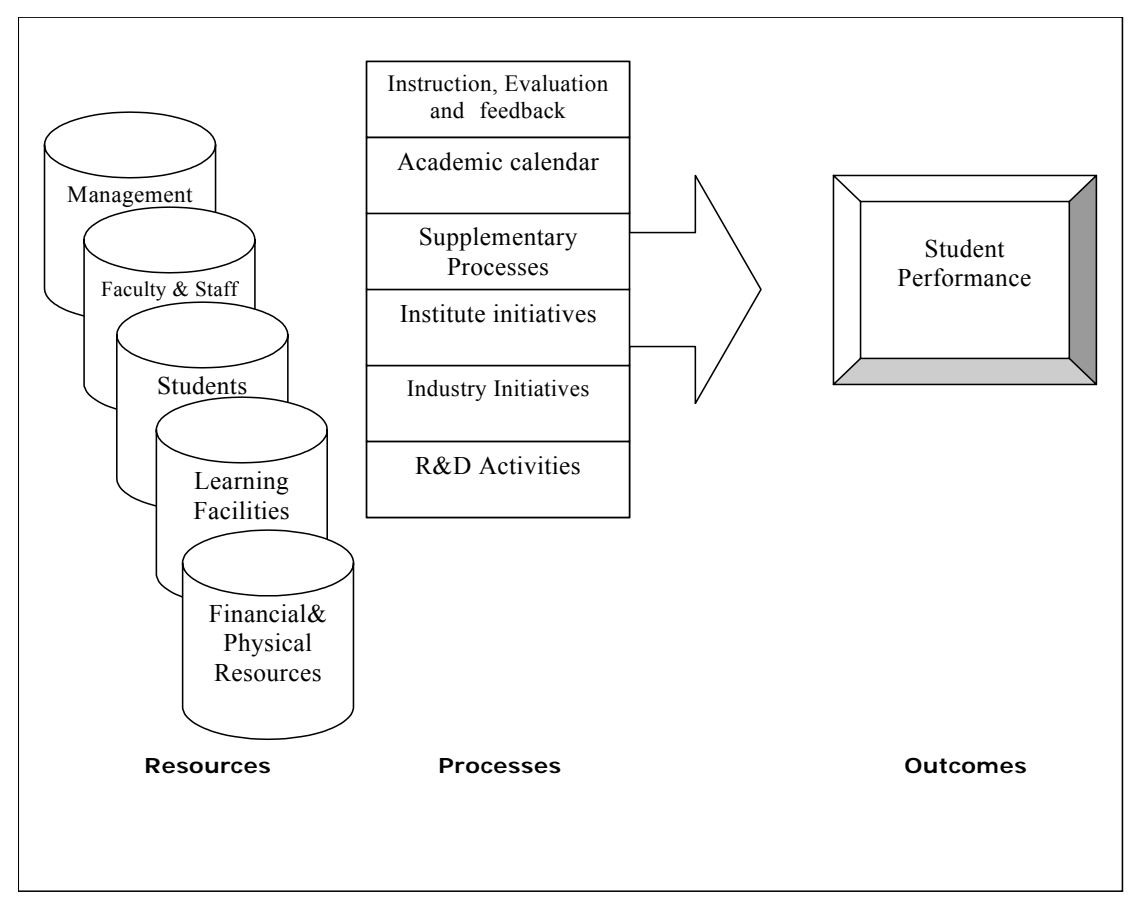

Figure 1. Framework of the study 


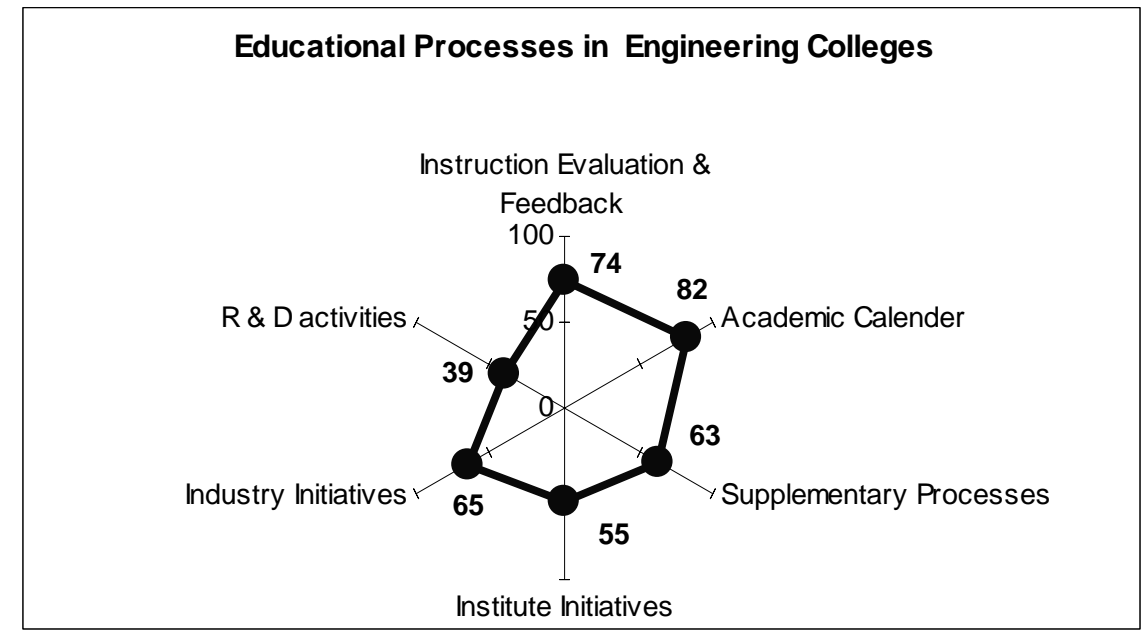

Figure 2. Average levels of process components of Indian engineering programmes 


\title{
Reflection on Personal ELL Experience and ELT Practice
}

\author{
Zhicheng Ma \\ Department of Foreign Languages, Chongqing Education College, Chongqing 400067, China \\ E-mail: dolphin7979@126.com
}

\begin{abstract}
Multitudes of language teaching practice shows that great attention drawn to language learning can help language teachers better their teaching and give appropriate learning support to language learners. A critical analysis of the author's English language learning experience is given in the paper, encompassing the approaches used, the role of the teachers, expectations on the learners at different times and the effectiveness of the learning. In addition, how the language teacher can benefit from this experience for his own TESOL (Teaching English to speakers of other languages) practice is addressed.
\end{abstract}

Keywords: Reflection, ELL experience, ELT practice

\section{Introduction}

It is commonly believed that teaching is for learning and learning is the goal of teaching. The function of teaching can be defined as a guide or catalyst in the process of learning, which reinforces effective learning and promotes learning achievement. On the other hand, the effect of learning reflects whether teaching approaches and methods are appropriate, providing feedback leading to adjustment or improvement of teaching methodology. Therefore, language teaching and learning interact closely with each other. As language teachers, we should attach importance to 'the learners themselves, the act of learning and the particular context in which this learning is to occur' (Nicholls, 2003:1). Great attention drawn to language learning can help language teachers better their teaching and give appropriate learning support to language learners. They can focus on or reflect on language learning in different ways. As Freeman (1992a) notes, 'Teachers' beliefs about learning may be based on their training, their teaching experience, or may go back to their own experience as language learners.'

Having been experiencing the whole process from being an English language learner to being an EFL teacher, I need to carry out some reflection on my ELL (English language learning) so as to be clear about what approaches should be adopted and what good practice should be implemented in my ELT (English language teaching). Based on the English language learning experiences I have undergone in Chinese schools, this paper emphasizes critical analysis of the approaches used, the role of my teachers, expectations on me and my fellow learners at different times and the effectiveness of my learning. It also discusses what I have learnt from this experience for my own TESOL (Teaching English to speakers of other languages) practice.

\section{Analysis of my English language learning experiences}

In China, the English language is regarded as a foreign language compared to the official language or mother tongue Chinese. The Cambridge Encyclopaedia of the English language defines EFL (English as a foreign language) as: English seen in the context of countries where it is not the mother tongue and has no special status (Crystal, 1995: 108). Long and Richards (1987) also mention: a non-native English speaker who studies English in an environment where the dominant population speaks a language other than English is studying EFL (Long \& Richards, 1987:4). Due to the role of English in China, Chinese English speakers mainly acquire the language at school as an academic subject. As Bright and McGregor (1977) have observed, 'If a language other than English is the medium of instruction in their school, then their only exposure to English will be in English lessons.' In the following, I will give an account of as well as analysis of my English language experiences at three different stages of my schooling.

\subsection{Junior high school phase}

I began to learn English at the age of 12, i.e. in 1984, when I studied in the first year of junior high school. It was a subject prescribed by the Chinese National Education Committee (CNEC) for junior high school students to learn with the intention of enriching students' knowledge and meeting students' professional requirement in the future. That is, English was not taught until junior high school in the Chinese educational system at that time. To unify teaching content and process, the CNEC issued the same English textbooks and set the same teaching curriculum and syllabus for all schools throughout the country. 
As junior high school introduces a primary level of English for Chinese students to learn, the textbook starts from very fundamental knowledge of the English language, including English phonetics, common words, simple sentence patterns and grammar. Learners are required to have a general command of English listening and speaking skills. In class, the English teacher asked the students to follow her to read the word or text, explaining the meaning of each word and giving examples of using the word. There were also a lot of sentence pattern drills but all was conducted by repeating mechanically what the teacher said. Though the expectation on training learners' listening and speaking skills should be addressed, few activities concerning such skills in the process of teaching were applied. The role of the teacher in such a class is only as a 'giver' of information in that no effective interaction occurs between the teacher and the learner. The approach that is used in this type of English teaching can be thought of as a teacher-centred or cramming approach for the teacher dominates the process of language teaching and learning from beginning to end.

This period of English language learning brought me a little interest in learning English. It was not because I could just pass the English examination without obtaining a high mark, but because I did not obtain the required skills of learning the language. I could not understand what the native speakers said on the tape. Nor did I use English to communicate with others. Reflecting on this experience, I have found out the teacher-centred approach may not be a good way to suit students' language acquisition, though it helps to build up the basic system of the English language, especially grammar. In the process of such learning, the fact that learners may have very different goals is not valued. For example, acquiring a native-like accent in English might be considered an important goal for me in that I could speak English fluently with native-speakers if I could study in an English-speaking country. Students in such a class, nevertheless, could not get any opportunity to talk or use elementary English to express what they want to say. The approach stresses the role of the teacher in imparting the knowledge to the learner only through himself or herself, paying little attention to the role of the teacher as a helper or guide, and the role of the learner. On the teacher's role in language teaching, Brindley (1984: 9) notes:

It is the role of the teacher to assist learners to become self-directed by providing access to language data through such activities as active listening, role play and interaction with native speakers.

\subsection{Senior high school phase}

My English language learning in senior high school gradually helped me to develop a systematic English grammar. During this stage, English language teaching focused on cultivating students' general reading and writing skills in the language. Another goal of teaching at this level was to integrate and refine what students had been taught in the subject of English so as to prepare them for the CEC (College entrance examination). In classroom teaching and learning, we got a lot of illustrations of grammatical rules and analysis of sentence structures from the English teacher. We also gave responses to the content-oriented questions raised by the teacher, giving examples for a grammatical point or key sentence pattern. To ensure we had a better comprehension of the text, the teacher often translated most sentences into Chinese. Once a week, we submitted an English diary in order to practise writing.

The approach used in this stage can be viewed as the grammar-based teaching and translation method. The former indicates that grammar has a central role in language teaching. In this approach, the teacher plays a dominant role in illustrating English grammar step by step so that students can understand how English sentences are grammatically structured and how they can employ English correctly either in speech or written form. This traditional grammar-based instruction has been widely criticized as being ineffective, yet grammar can influence the four skills of learning a foreign language. For example, if an EFL learner does not have a grasp of fundamental English grammar, he or she may have difficulty in uttering or writing an English sentence which is accepted or understood by native speakers. Similarly, the learner cannot comprehend what English reading material is about and what native speakers are talking about on tape or in real life if he or she has little knowledge of English grammatical rules. Accordingly, it is entirely essential for the foreign learner to grasp English grammar. As Bright and McGregor (1977:236) point out:

Nobody disputes that the foreign student must learn the grammar of English in the sense that the sentences he produces must conform to English patterns in the accepted mode.

With systematic grammar knowledge, students can easily distinguish grammatical phenomena they encounter and do well in their CEE. However, the communicative ability of students like speaking and listening is not developed in this process of language teaching and learning.

The translation method emphasizes studying another language by translating it into L1 (first language). In this approach, the first language is used as a medium of understanding the foreign language and the teacher guides the student from the target language to the mother tongue, which makes the student clear about the differences between the two languages. Nicholls $(2003,78)$ also says that the traditional Translation approach 'has a cognitive orientation, regarding the language as an object to be studied rather than as a tool to be used, and thus encouraging students to study its grammatical and other systems, particularly in their written form, comparing them with those of the mother-tongue' As a result of interference from $\mathrm{L} 1$, the language environment of the target language cannot be fully exposed to the learner, 
and the learner does not actually get enough practice of the target language. Affected by this sort of teaching method, some of my fellow learners rarely used English without thinking of Chinese first.

\subsection{Tertiary education phase}

It was in the University that I acquired basically the four skills of using English: listening, speaking, reading and writing. During college, we followed different courses relating to the training of each skill and were expected to study the English language at greater depth through guidance from the language activity or self-exploration. In class, the teacher gave lectures on a variety of topics associated with the English language, assisting us to obtain academic and professional skills in the field of English language learning and future teaching.

The approach adopted in this stage can be called Active Teaching that focuses on the teacher's ability to involve students productively in learning tasks during lessons (Richards \& Lockhart, 1994:102). In this methodology, the teacher sets a task to engage the students or raises a topic for them to discuss, providing chances for learners to practise the language actively and creatively. In the process of involvement, besides language competence, other abilities like logical thinking and reasoning can also be achieved. Furthermore, language learners can continue to develop their interlanguage, a system of abstract linguistic rules which underlies comprehension and production of the L2 (Ellis, 2002:33).

\section{My TESOL practice}

Reflection on the English language learning experiences I have undergone lets me gain useful insights on what to teach and how to teach in my English language teaching. It is vital to consider what methodologies in TESOL fit our social context and the special teaching targets which I am facing, and how to design my teaching and implement good practices of language teaching with the purpose of helping my students gain effective strategies for learning the language.

The methodology employed in my own TESOL practice, is mainly based on the three terms: approach, design, and procedure, which are 'used to label three interrelated elements of organization upon which language teaching practices are founded' (Long \& Richards, 1987:146). 'Approach' refers to the language teaching method that language teachers adopt in their teaching. All language teaching methods operate as guidance and provide theoretical foundations for what language teachers may do with learners in classroom. The method I have applied in my teaching generally relies on my students' learning level and teaching contents. 'Design' specifies how language teachers plan the instruction with a particular approach. The design for my language teaching relies on specifications of the content, my roles, the students' roles and teaching aids. 'Procedure' focuses on the actual teaching techniques, practices and activities that operate in the process of English language teaching and learning. Usually, at this level, I provide the students with communicative language tasks and activities. According to the three elements of language teaching practice, most of my teaching practice shows that I prefer using the two methodologies or approaches: learner-centred and cooperative learning.

\subsection{Learner-centred approach}

In this approach, the teacher's role changes from a language instructor to a language guide, organizer or facilitator, while the learner has a central and active role in the process of language learning. I often supply students with different sorts of activities which involve their participation in learning by doing and practising English. One of these activities I would like to mention here is brainstorming. I design such questions in accordance with what I am going to teach and what the students are supposed to learn and grasp, usually without a fixed answer, to challenge the students' thinking or create more opportunities in class for them to ask meaningful questions. For instance, in one of my listening and speaking classes for college students, I asked the student a question challenging their brains after we had listened to the material and discussed the listening comprehension questions in the textbook, to which we could get the answers directly from the listening material. The main content of the material is about Mr. Brown was taking the 4 PM train to London. It was 4:25 PM, but the train did not depart. Mr. Brown felt very angry, and he was out of temper with one of the train staff. Finally, he was told that he had got on the wrong train. My question is 'Why did Mr. Brown take the 4 PM train to London?' The students could not find out the answer from the material, yet the question drew their attention to give a possible answer with their imagination and they actively worked out lots of the answers, such as Mr. Brown wanted to visit his friends; He lived in London; He was an artist and went there to see a painting exhibition, etc. By working at the answers, the students can practise the language they have learned and develop their thinking ability.

I also organize pair-work and group discussion in terms of the task or topic, arousing their interest in learning the language. Take one pair-work activity I designed as an example. Two students were required to think out three or four questions concerning job-hunting, took turns to ask their partner and noted down the answers. To let them have a group discussion, I even set a task in which the students in a group of five talked about one effective way of dealing with water pollution in the city. After a 10-minute discussion, a reporter from each group gave a presentation before the class about what they had discussed and how they would carry out the plan. The students' achievements in these activities prove that the learner-centred approach in ELT can be very practicable and also important for language teachers to take 
some practice. As Armstrong (1992:114) quoting Omaggio-Hadley (1986) has pointed out, students frequently become more motivated after being given individual opportunities to share information about themselves and their interests with their teacher.

\subsection{Cooperative learning}

This methodology 'relies less on teacher-directed teaching and more on cooperative group work and pair work activities' (Richards \& Lockhart, 1994:102). Before the students are thrown into the situation of cooperative learning, one thing I have to focus on is to let them know what they are going to do and why they need to do that. Most importantly, I always make sure the tasks planned can engage students in achieving learning goals or solving problems through collaborative reasoning, opinion sharing or values clarification. One cooperative learning activity I carried out with my students is the students worked collaboratively in groups of four, talking in English about the characteristics of a good friend, choosing the two most important they all agreed on and giving the reasons. By working with their group members, the students put what they had learned into topic-oriented and real use, shared opinions with each other and made joint efforts to fulfil the learning task. As proposed by Colville-Hall (1992:55), 'Cooperative learning is vital because it can provide the opportunity for students to develop skills in cooperation and in communicative competence.'

\section{Conclusion}

In sum, language teachers would profit from reflecting on their own experience as language learners, from the role of their former language teachers, which provides them with a good reference point and guidance in their ELT and makes teaching become an aid to the learners in the process of language learning, not a hindrance to the fulfilment of the students' individual interests and the realization of their potentials.

\section{References}

Armstrong, Gregory K. (1992). 'Learner-Initiated and Learner-Friendly: Questions to Get Them Talking' in Creative Approaches in Foreign Language Teaching, National Textbook Company, Lincolnwood (Chicago).

Bright, J. A. \& McGregor, G. P. (1977). Teaching English as a Second Language, Longman, London.

Brindley, G. P. (1984). Needs Analysis and Objective Setting in the Adult Migrant Education Program. AMES, Sydney.

Colville-Hall, Susan. (1992). 'A Case for Cooperative Learning in the Foreign Language Classroom' in Creative Approaches in Foreign Language Teaching, National Textbook Company, Lincolnwood (Chicago).

Crystal, David. (1995). The Cambridge Encyclopaedia of the English Language, Cambridge University Press, Cambridge.

Ellis, Rod. (2002). Second Language Acquisition, Oxford University Press, Oxford.

Freeman, D. (1992). Language teacher education, emerging discourse, and change in classroom practice. In J. Flowerdew, M. Brock, and S. Hsia (eds.), Perspectives on Second Language Teacher Development, City Polytechnic of Hong Kong, Hong Kong Pp.1-21.

Long, Michael H. \& Richards, Jack C. (1987). Methodology in TESOL, A Book of Readings, Newbury House Publishers, New York.

Nicholls, R. (2003). Lecture Notes, TESOL Methodology Module1, the University of New England, Armidale.

Richards, Jack C., \& Lockhart, Charles. (1994). Reflective Teaching in Second Language Classrooms, Cambridge University Press, Cambridge. 


\title{
An Alternative Model of Continuing Professional Development for \\ Teachers: Giving Teachers Time
}

\author{
Terry Haydn \\ School of Education and Lifelong Learning, University of East Anglia \\ Norwich, NR4 7TJ, England \\ Tel: $00441603593150 \quad$ E-mail: t.haydn@uea.ac.uk \\ Roy Barton \\ School of Education and Lifelong Learning, University of East Anglia \\ Norwich, NR4 7TJ, England \\ Tel: 00441603593155 E-mail: r.barton@uea.ac.uk \\ Ann Oliver \\ School of Education and Lifelong Learning, University of East Anglia \\ Norwich, NR4 7TJ, England \\ Tel: 00441603592627 E-mail: a.e.oliver@uea.ac.uk
}

The research was financed by the Department of Culture, Museums and Sport, UK.

\begin{abstract}
The paper reports on the outcomes of a Department of Culture, Museums and Sport (DCMS) funded project which provided resources for three groups of teachers in different subjects and age phases to have some time where they were freed from their teaching responsibilities, and also given time to meet together with other teachers to share ideas. The idea underpinning the project was to explore a model of continuing professional development for teachers which was different in approach to recent Department for Education and Skills (DfES) 'strategy' and training based approaches.
\end{abstract}

The three groups of teachers (primary science, secondary history and secondary science) met together with curriculum tutors from the local School of Education to explore ideas about how to develop innovative approaches in aspects of their subject teaching. In addition to funding four days of supply cover for the teachers involved to meet, the teachers were also given at least two days of supply cover during the course of the project to develop their ideas. Towards the end of both academic years, the groups met again to share their ideas.

The paper describes the outcomes of the project and the teachers' perceptions of the process issues and problems involved in pedagogical innovation. The paper also considers some of the broader issues arising from the project, in terms of how to make the most effective use of teachers' time, in an era when there are many competing demands on this finite resource.

Keywords: Education, New technology, Teacher education, In-service training, Continuing professional development

\section{Background to the project}

The past few years have seen a resurgence of interest in the idea of 'teacher-centred' professional development in the United Kingdom, with initiatives such as the Networked Learning Communities initiative (NCSL, 2004), the 'Best Practice Research Scholarships' sponsored by the Department for Education and Skills (DfES), and the idea that teachers across schools will work collaboratively to improve teaching and learning outcomes (DfES, 2005a). However, in terms of overall investment in continuing professional development for teachers in England, the emphasis has been on centrally directed programmes and 'strategies' which are 'rolled out' and 'delivered' across the system as a whole (see, for instance, DfES, 2005b, DfES, 2005c).

\subsection{The teachers involved in the project}

Many of the teachers and lecturers in our initial teacher education partnership had expressed concern about the increasing prescription of DfES initiatives in recent years, with the proliferation of strategy documents and the possible 
atrophy of teacher initiative, originality and imagination in approaches to subject pedagogy and the erosion of subject specific Continuing Professional Development (CPD) courses. A generation of teachers has grown up unaware of the previous existence of Teachers' Centres where teachers from local communities of schools used to meet up, both to socialise and to discuss educational issues.

\subsection{Funding for the project}

Funding from the Department of Culture, Museums and Sport (DCMS) as part of its 'Creative Partnerships' initiative enabled us to undertake a two year action research project which aimed to give teachers in particular subject areas time to develop their own ideas for enhancing teaching and learning and time to meet up to share their ideas and initiatives. The underpinning hypothesis behind the project was that recent government initiatives in education in England have added to teachers' overall workload (see, for example Smithers and Robinson, 2000, NFER, 2000, Cockburn and Haydn, 2004) and resulted in a lack of time and opportunity for teachers to develop their own ideas and talk about teaching and learning issues with fellow professionals.

\subsection{The aims of the project}

The overarching aims of the project were to use the funding to provide time for teachers to develop their ideas for innovative pedagogy in subject teaching, to be able to 'try things out' in areas of their subject which were of interest to them, and to provide time for them to meet together to discuss and share their ideas with other teachers.

\subsection{Teacher response to the project}

The first year of the project involved over 40 teachers and almost all the teachers who were involved in the first year of the project wanted to be involved in the subsequent work when Phase Two funding was secured. Overall, numbers had to be limited because of funding constraints. The response led us to feel that we were to at least some extent 'knocking on an open door' in terms of teachers' desire to have time to pursue their own learning agendas and talk about these with colleagues from other schools.

\section{The three stands of the project}

We were aware from our work with teachers in our initial teacher education partnership that many regretted the paucity of subject specific CPD courses in the wake of the recent priority given to government directed national strategy programmes, which have an emphasis on generic teaching skills rather than subject specific dimensions of pedagogy. The three stands of the project reflected the subject areas of the university tutors involved; primary and secondary science, and secondary history. The pattern of activity was the same for all three strands; a one day research workshop to explain the project, share ideas and identify areas of interest, the funding of a day of supply cover so that teachers got some time to follow up and develop their interests, and an end of year follow up workshop, to share ideas and reflect on the experience of this form of CPD.

\subsection{Project ethos}

In all three cases, it was deemed important that teachers should be free to pursue whatever aspects of subject pedagogy interested them. There was no attempt to 'sub-contract' areas of work in order to achieve 'coverage' of the subject domain, and there was a deliberate attempt to avoid any audit or target setting procedures. In many respects, this goes 'against the grain', in terms of current emphasis in the UK education system (and elsewhere) on teacher accountability, audit and target setting (Ball, 2004, Elliott, 2001). Teachers were encouraged to come to the second workshop whether or not they had come up with a substantial 'outcome' from their involvement in the project. The final part of the day in the end of year workshops was devoted to evaluation of the experience of involvement in 'teacher-centred' CPD.

\subsection{Project activities}

The three stands spawned a range of activities. In secondary science, these included work on pupil misconceptions at Key Stage 3, 'Bringing applied science to life', running Science clubs outside taught time, the development of online testing for Triple Science GCSE and developing skills in scientific investigation. Many of the participants were at the 'cutting edge' in their particular field of interest and one participant described the final workshop as ' $a$ series of masterclasses in science teaching'. In addition to presenting their work, in several cases, the teachers involved had made their work available on the internet so that others could access it.

The secondary history strand of the project focused primarily on developing the use of ICT in subject teaching, a major concern for many heads of department in the partnership. Teachers worked on a range of projects, sometimes within their own department, sometimes pairing up with colleagues with similar interests. Areas of work included 'How to make PowerPoint less boring', the use of digitized 'impact' moving image resources, the development of departmental and revision websites, and building up 'collections' of visual resources on particular historical topics.

At the end of year meeting, 13 teachers attended the session, with two others sending their apologies for absence. Twelve of those attending the session had some form of 'product' which had stemmed from their involvement in the 
project, and some form of story to tell about how the product had been developed and how the department had progressed in ICT over the course of the year.

In the second year of the project, activities included work on using digital video editing with internet archive resources, advanced elements of Macromedia Flash, exploring the potential of interactive whiteboards and using Microsoft Photostory for storyboarding in history.

Participants ranged widely in their degree of prior expertise in ICT, with some at the 'cutting edge' of developments in ICT and others acknowledging that they were less assured in their technical expertise. This did not seem problematic, and there seemed to be some advantages to having a 'mixed ability' group, given the overall collegial 'climate' of the workshop. Those who had developed resources and activities in the course of the project were happy to share these on CD-roms.

The primary science strand of the project involved 18 teachers. Numbers were limited because of funding constraints, and several other schools expressed an interest should places become available. Research interests and activities included pupil participation in a science club, questioning, replacing activities to teach the QCA scheme of work, using models to enhance understanding, using thinking skills to develop science knowledge, linking DT and science, 'not setting targets', 'giving pupils ownership', teaching science through challenge and science through play.

\subsection{End of project teacher responses}

As with the secondary history and secondary science strands of the project, the end of year workshops evinced positive comments and feelings from those involved. Teachers talked about their individual projects with enthusiasm. It was generally felt that the projects had inspired a freer and more creative approach to teaching science. Many commented on a positive attitude and higher level of engagement from pupils. One teacher especially felt that her teaching had changed considerably and so had her feeling about science. She felt less constrained by plans and more driven by the children's questions. Through the project she realised that her teaching style had become more creative and she was more enthusiastic about science. As a result she ran a session for teachers in her school:

'I can't believe the difference it has made to my teaching. Now I let the children take the lead, follow the questions they ask and it all happens, it really does. They are just so keen, they ask me when are we doing science. They just love it and there are always bits of experiments going on, not just in the lesson.'

None of teachers felt that the action research which they had undertaken had had a detrimental effect or that it was a waste of time. They were all keen to talk about their projects with the group. It was noticeable that they were impressed by each others' explanations and several thought that they would try out some of the ideas presented. In the end of year workshop, feedback on involvement in the project was very positive; one teacher remarked that 'it is just amazing that we have all tried such different things, there is so much here. It's so diverse but so much we could take from every project' and there was a general murmur of assent to this.

\section{Teachers' reflections on the project}

Evaluation of the project was conducted partly through discussion groups in the concluding sessions of the research workshops, and partly through e mails and subsequent phone or face to face conversations with participants.

In all, over 60 teachers were involved in the three projects, spread across over 30 different schools. There is ample evidence from the project outcomes that many of the teachers involved invested many hours of work in the project, above and beyond the days of supply cover which was funded by the project.

\subsection{Outcomes and process issues}

The project was not uniformly successful; not all the teachers involved made progress with their declared area of interest, and good intentions had not always translated into action. At the end of year research workshops, there were a few teachers who acknowledged that they had not completed the work that they had intended to. One of them reported 'I'm afraid I don't have a great deal to offer. We were supposed to work on updating the revision website but as with many great intentions it didn't end up happening.' However, over $85 \%$ of the participants felt that they had accomplished something worthwhile from involvement in the project, and in some cases, reported that the work had a transformational effect on their practice. Sometimes this was in the form of a particular resource, such as a departmental website, in other cases it was a radical change in the use of new technology, the ways in which planning for learning was organised, or the degree of autonomy and responsibility accorded to pupils.

Initially it was envisaged that participants would stay in close touch by e mail and phone over the course of the year to keep up to date, share ideas and map developments, but beyond a handful of phone calls and e mails this didn't happen. The business of school life interceded and 'chats' to talk about how things were progressing clearly fell into the category of 'luxury items'. 
Also, although funding was available to provide supply cover which would give teachers time to develop their ideas, in some cases, the exigencies of examination classes or the overall cover situation within schools prevented teachers from making use of the funding which was available.

But in spite of these caveats, it was clear that the participants involved had enjoyed being involved in the project and considered it worthwhile, in spite of the many other demands on their time. In the words some teachers 'confessed' to not getting as far as they had hoped with their research but still felt that there had been some positive aspects to having been involved in the project:

'The day gave you time to think and it was very enjoyable... there was a nice atmosphere.. I like the combination of having some time with other teachers to just share ideas - and frustrations.'

The end of term was taken up with the organization of the Battlefields trip. We were hoping to spend time on it towards the end of term but I'm not sure. I would love to have the opportunity to try and do something like this at my new school so if anything ever comes up let me know.'

'We've not followed up things as much as we hoped but I am meeting up with J. (from another school involved in the project), using one of the supply days.... I It was helpful and I'm glad I got involved.'

Apart from gains in terms of 'outcomes' and products there were important 'process' issues involved in participation. Teachers welcomed the opportunity to talk about pedagogy with their peers, they enjoyed having time to reflect and explore ideas and recent developments which have the potential to influence the ways in which they teach their subject, and they enjoyed the chance to be creative in their approaches to subject pedagogy. This was apparent from the end of session discussions (teachers valued both the chance to meet up together and to have time to develop their ideas further within their own departments), and from the fact that nearly all of the teachers involved in phase 1 of the project had wanted to be involved in phase 2 .

The end of workshop discussions included (unsolicited) comments about other recent experiences of CPD, and in particular, unfavourable comparisons were made with participants' experiences of New Opportunities Fund (NOF) training in the use of ICT. (This was a compulsory and highly directive training programme for practising teachers to address a perceived deficit in qualified teachers' ICT proficiency: see Leask, 2002 and Ofsted, 2002 for external evaluations of the programme). Almost without exception, experiences of this training programme were described in very negative terms. A selection of comments which is not unrepresentative is given below:

'A waste of money.. and created a lot of resentment.'

'It was like a driving lesson that consisted only of learning the highway code but which had not actual driving tuition.'

'The training provided was patronising, unrealistic and painful in its delivery... The effect on staff morale was devastating. Nothing in recent years has done more to put teachers off using ICT.'

'I was tasked to deliver the training and implemented one course with 15 members of staff.... attendance dwindled within weeks to four or five and the course was never fully completed. I was unable to coax any other staff onto the course as they had heard of the experiences of others.'

'It was "done to us" in a way that left us deflated and angry. We needed time to debate and trial ideas - we did not have this. The sessions were geared around certain information which was going to be delivered come what may and usually this was not really linked to what we wanted to do. We persevered despite the training, not because of it.'

Although not all the teachers involved in the project had made drastic or transformational progress in their declared area of interest, none of them suggested that involvement had been 'harmful' or a waste of time. Feedback suggested that a key element of the positive views expressed was the degree of autonomy accorded to participants, and the absence of 'target setting' and 'audit' activities and climate. This relates to Woods' (1990) principles of 'relevance, ownership and control'; at least they had been free to explore aspects of teaching and learning that they were interested in and had chosen to pursue. In many cases, the teachers involved felt that they had achieved their objectives and had managed to improve aspects of teaching or learning in their schools. Some had clearly invested much more time in their research than that provided for by the funding of the project. The idea of simply giving teachers free time, with a fairly general brief to explore an area of interest goes 'against the grain' in these audit-heavy and target driven times, but it seemed to us that teachers were so thrilled to get even these modest amounts of time that they regarded it as a wonderful luxury that should not be abused.

\section{Implications for investment in post qualification development for teachers}

In the end of year workshops, teachers in all three groups felt that the combination of being given some time to work within their own departments in school, and some time to 'bounce ideas off each other', and demonstrate their work in progress and receive feedback on it from others, had been more helpful than having one or the other option. Fullan (1982, p. 259) has argued that 'teaching suffers from the lack of opportunity that teachers have as individuals, and 
particularly in interaction with other teachers, to reflect, to observe, to discuss, to plan.' This was borne out by the feedback from the end of project comments of the teachers involved. As one teacher remarked:

'We did feel inspired and energised after talking with everyone during the first meeting, it was the stimulus of this contact and interaction that started us going, and got us beyond the 'good intentions' stage. Sharing the outcomes and meeting up again was also really enjoyable and interesting, and has set us off on new tracks.'

There were several comments of this nature, and even the teachers who admitted that they had not brought their good intentions to fruition reported that they were still glad that they had got involved and felt that they had still 'got something out of it'. Teachers who had successfully developed some facet of their teaching showed no apparent rancour or unwillingness to share their work with those who had not 'brought something to the table'.

In all three strands of the project, teachers felt that 'lack of time' was a key deterrent to developing subject pedagogy. Many of those involved felt that without the day of cover and two days to meet and talk, their personal project would not have got off the ground. In 1975, Stenhouse argued that 'the most serious impediment to the development of teachers as researchers - and indeed as artists in teaching - is quite simply shortage of time.' (Stenhouse, 1975: 111). From the comments emanating from the end of workshop discussions, it was clear that teachers felt that the balance of 'time to do what you yourself would like to do professionally', and 'time during which you are directed what to do professionally' had shifted in a way which created resentment and which was not seen as helpful or effective.

This is not to argue against any form of centralised national strategy type forms of CPD for teachers, but to suggest that teacher-led, 'bottom-up' forms of CPD may well constitute a useful complement to standardised 'rolled out' forms of $\mathrm{CPD}$, and that the balance between the two forms of CPD may not be optimal at the present moment in the UK. Desforges (2004: p. 2) has argued that in terms of 'significant return', decentralised teacher led research may well be a more powerful driver of educational improvement than government programmes.

Many teacher training programmes, both for pre-service and qualified teachers have tended to go for a 'coverage' model. In 1998, Anthea Millett, Chief Executive of the Teacher Training Agency argued that by spelling out more comprehensively than ever before the competences which trainee teachers would be obliged to possess before being licensed to teach, these new 'improved' Standards for the award of Qualified Teacher Status would ensure that the breadth of newly qualified teachers' competence would be higher than ever before (Millett, 1998). The New Opportunities Fund Programme for developing teachers' ability to use ICT in subject teaching was another example of 'coverage' mentality - teachers were to be 'trained' to use a wide variety of ICT applications so as to become 'completely equipped' in ICT.

The experience of this project suggests that there may be some advantages in letting teachers have at least some say in determining their own learning agendas for their CPD, and that allowing them to pursue particular areas of interest and enthusiasm may be more beneficial than attempting 'across the board' training, which may be broader but more shallow in effect. Although this may result in some 'black holes' in their areas of expertise, there would appear to be significant advantages in terms of their motivation, engagement and sense of professionalism. The cost of the project was not inconsequential (approximately $£ 7,000$ per year for each strand), but the costs of other forms of investment, such as the NOF training programme, and DfES directed 'strategies' are substantial. It is possible that simply providing teachers with time to think, and to talk to each other, is a comparatively cost-effective form of continuing professional development.

\section{References}

Cockburn, A. and Haydn, T. (2004). Recruiting and retaining teachers: understanding why teachers teach. London: RoutledgeFalmer.

Department for Education and Skills. (2005a). White Paper: Higher standards, better schools for all. London: DfES.

Department for Education and Skills. (2005b). Secondary National Strategy for school improvement: pedagogy and practice, teaching and learning in secondary schools. London: DfES.

Department for Education and Skills (2005c). Secondary National Strategy for school improvement: leading and coordinating CPD in secondary schools. London: DfES.

Desforges, C. (2004). On learning and teaching. Cranfield: NCSL.

Elliott, J. (2001). Characteristics of performative cultures: their central paradoxes and limitations as resources for educational reform. In D. Gleeson and C. Husbands (Eds.) The Performing School, (pp. 192-209). RoutledgeFarmer: London and New York.

Fullan, M. (1982). The meaning of educational change. Ontario: OISE Press.

Leask, M. (2002). Training for teachers and librarians in the use of ICT, London, TTA.

Millett, A. (1998). Times Educational Supplement, 22 May. 
National Foundation for Educational Research (NFER). (2000). Who would be a teacher? A review of the factors motivating and demotivating prospective and practising teachers. Slough: NFER.

National College of School Leadership. (2004). Networked Learning Communities: learning about learning networks. Cranfield, NCSL.

Ofsted (Office for Standards in Education) (2002). ICT in schools: the effect of government initiatives, progress report, April 2002, London, Ofsted.

S.J. Ball. (2004). Constructing accountability: networking governance and management agency. Public Policy and Administration, 19, 17-33.

Smithers, A. and Robinson, P. (2000). Attracting teachers: past patterns, present policies, future prospects. Liverpool: Carmichael.

Stenhouse, L. (1975). An introduction to curriculum research and development. London: Heinemann.

Woods, P. (1990) Teacher skills and strategies. London: Falmer. 


\title{
How to Cultivate the Ability of Innovative Thinking In Computer Programming Teaching
}

\author{
Fuqian Shi \\ Institute of Hospital Management, Wenzhou Medical College \\ PO box 325035, Wenzhou 325000, China \\ Tel: 086-577-86689913 E-mail:sfq@wzmc.net \\ Jincai Wei \\ Institute of Hospital Management, Wenzhou Medical College \\ PO box 325035, Wenzhou 325000, China \\ Tel: 86-577-86699348_E-mail:prcctv@hotmail.com
}

The research is financed by High Education Reform Project of Wenzhou Medical College, 2007.

\begin{abstract}
In the current teaching activities on curriculum, teachers taught all kinds of computer language at the most of the time. Students also focus on a variety of examinations, but the real time to train students' independent software developing skill is very limited. This has resulted in the students only to copy other people's systems design ideas, materials or other software reproduction procedures and take a simple so-called "Program Design." Based on this, this paper introduced a variety of computer teaching activities in classroom and formed role for training students' imagination, the ability to find and explore, knowledge transfer capability and the quality of innovative thinking of students.
\end{abstract}

Keywords: Independent thinking, Innovative education, Computer programming teaching

How to cope with popular education needs of the situation and train high-quality creative talents is a tough problem currently in the higher education reform process. High-quality creative talent's cultivation is the main object of education. The popularization of education is the current status and the direction of Chinese higher education. Classroom teaching was regard as the main form of higher education personnel training; how to deal with this contradiction? Combining with many years of experience in teaching computer programming, we summed up the following aspects:

In the computer-programming process, it often needs to choice and judge numerous and various complex events, then to classify and rank, and to achieve its work in a variety of applications demand by using the computer language in practice; therefore, in training teaching students, critical thinking ability is the core. But in the cultivation of thinking ability, the ability to cultivate innovative thinking has a unique value. Here, we must be clear, students' cultivate innovative thinking is the ability to develop their sense of innovation and ability to innovate, innovative spirit and habits, not to require students as scientists, inventors, like the number of inventions and creations. Thus, the teaching of computer software programming should not be built on the thinking of teachers or teaching materials on the basis of the authors, and students should be established to start thinking of the classroom structure model. "Study to thinking, study to innovating" as the purpose of thinking innovative classroom structure would focus on the training of thinking ability.

In order to enable students in time and energy on possible in accordance with their own characteristics to develop ourselves, in teaching management, first of all, teaching the basic requirements should be adjusted in order to meet the needs of innovative personnel training, and not a single test scores. Basic requirements of many courses were enacted in the early 1990s. On the one hand, the examination results are everything; on the other hand, this stage is still in the elite stages of education, and would be higher requirement. In the stage of popular education, certain requirements are difficult to achieve for some students. In such a request, some students exhausted their energy and time and still could not meet the requirement; students not only do not have the time and energy to play, develop their own skills, but their interest and confidence in learning are destroyed. So instead, why not reduce the number of requirements in computer programming teaching activities? 


\section{Creating a learning environment which is more relaxed, harmonious and self-sufficient in student performance}

In the process of teaching, teachers love to endless land to educate students on off-the-shelf materials in various languages orders and grammatical rules, and further point out that what is the focus of the examination. Students have little autonomy and the opportunity to participate in teaching activities in accordance with their own choice of study and interest in the content. Soon, their enthusiasm disappeared, and self-confidence lacked. Learning has become a focus for the examination of the contents and mechanical memory. Thinking ability is de-gradated, and creative potentials are mercilessly stifled. Teachers teach hard, students learn fidgety, and even the scope of the examination will not be good results.

Renowned psychologist E. P. Torrance said that if we are to create creativity, we need to provide a friendly and encouraging environment in which to make the prosperity and development. Clearly, a relaxed and harmonious, creative context is to train students to create an important condition for thinking. Therefore, in the process of teaching programming, teachers dare let go, to give the independent learning opportunities for students and to enhance students' self-confidence, encouraging them to use computer language to realize their ideas, their creative thinking to provide a relaxed environment. In classroom teaching, I deal with this: First, change the serious classroom atmosphere, create a relaxed, natural atmosphere, and encourage students to give question to teacher. The more novel issues unique knowledge, the more the better. If teachers didn't resolve it, this is the greatest honor of students. Gradually, students interested in a challenge and confidence stronger. Then, encourage students to question each other, and each completion of a module, conduct a program design contest. Program design of a content-based modular, but not limited to units, not confined to the after-school textbook exercises. Let us see who will design the most creative, original or whether teachers have the final say, but to enable students to democratic evaluation, selection of the winners and record results, when appropriate conditions to encourage. These measures aroused the students learning initiative. In order to design a good program, they will not only seriously reading materials content, but also access to a large number of extra-curricular literature, increasingly keen interest in learning. The potential for better students, the ability to enable him to be further improved, I used student-teaching method, teachers lead students to mobilize awareness of the main roles, and guide students in how to learn, how to teach, after prep, voluntary enrollment of students and teachers under the guidance of lesson preparation. Part of the trial, after a period of training, the analysis found that students learning ability and enthusiasm really improve a lot. Sometimes, the students I was teaching design on unexpected.

\section{Encourage students to a variety of perspectives, levels, areas to explore and train the students' practical ability}

In the culture of innovative thinking, we should minimize a variety of restrictions, and sometimes it needs "contempt" so-called answers. To foster their innovative thinking, the answer is absolutely not the most important; the most important thing is whether students' thinking space is expanded and opened up; whether to find out the answer from a variety of perspectives and a variety of levels; whether a variety of areas of interest is excited up; Whether multi-dimensional thinking capacity -- extremely important innovative education is trained. The design of opening problems such as "One question more answer" is the basis of this mode of training. A result with a variety of programming languages to achieve; a system structure and expand a number of application areas; such training is the key. This is very conducive to culture the students' creative thinking and innovative capability. It need to encourage and cultivate students at unconventional thinking, the answer is not limited to materials and also not restricted to teachers thinking. Unconventional thinking is very important for training students' creative ability, no "Unconventional thinking" has not "innovation." But in the classroom teaching, many teachers often overlooked unconventional thinking training; and even a subtle blow to the students the desire to unconventional thinking. This should not be happened. In order to encourage students' unconventional thinking, we need to take fully affirmed to students even it is a not very good design

At present, many computer curriculums were designed a large number of exercises and materials after school, the teacher also operate many homework under circumstances. But these exercises and operations are basically the so-called "standard answer"; the students will imitate materials, and generally get a high score; so students will only lead to rote. Teaching management department ask teachers to provide a uniform standard answer, and not to allow students for innovative attempt, they do not tolerate mistakes or failures; this stifles students' innovative capacity seriously and cure their brain. Therefore, students should not be satisfied to mention a unified learning methods and standard answer. For homework arrangement, it should be arranged none standard answer; this will enable students to give full play to creative capacity, and make our own operations in a variety of capacity and train the students' independent thinking ability and operation by hands.

\section{Foster students to discovery problem and suspect them}

Learning comes from thinking, thinking comes from question". In classroom teaching, there is no thinking without question; also there is no learning without thinking. Therefore, the classroom should first become a venue for students to question various things. On the basis of learning various ready-made conditions, we need to point out its design flaws, 
suspect its design ideas and concepts and think to improve and refine the program. This should become the direction of computer programming teaching. And as teachers, we should create a wide range of issues situations for students and train the students' innovative thinking ability. Therefore, teachers should have a strong awareness of the problem; cleverly seize the key steps of computer language or procedures. In the core modules, the creation of the problem would be situated to the students, inspire students to think and encourage students to question, even if the problem naïve. It is all right. Perhaps this is the start of independent thinking innovation for students. Such teaching activities in the process, we will discover that different students have different problems. We can show these issues on discussing. Most cases would be discussed very keen because there has not psychological fear between students not like students and teachers. Teachers need to encourage the parties to take such thinking. This opened the students thinking and inspired the students' innovative thinking.

"Doubts-problem-innovation" is a necessary way of creative thinking. Discovering issues and raising questions are the main hallmark of a person with creative potentials.

\section{The key of the innovative thinking is to develop students' imagination ability}

Innovative thinking is a thinking quality built on the innovative spirit. The key of software "innovation" is to create the procedures of currently no exist structural design and ideas, which requires imagination. The thinking of software designer is inseparable from imagination. The imaginative thinking in programming is incomparable. It is no exaggeration to say that no such imagination, there is no current computer software industry. Imagination is the driving force of the computer software, which is the soul of computer to constantly enter behind the area of daily life. Aristotle once said: "Imagination is the discovery, invention activities of the source of all creation." No imagine, no create. No the rich imagination, the variety of computer software programming language has become the most boring. Faced with such a heap of symbols, not imagined, students will not only difficult to understand its contents, but hard to develop thinking ability; While students are the main characteristics of the image of the thinking. Efforts to cultivate and inspire their imagination, is a magic weapon to foster their ability to innovate. Faced with the rapid development of computers, it has been said: the computer, not impossible, only unexpected. From a point of this view, the cultivation of innovative thinking of computer software talents is the key to the cultivation of imagination.

In the process of teaching, we must be bold to train students' imagination; pay attention to capture those students which think fast and have strong curiosity; to protect their curiosity, imagination, and guide them to positive thinking; to take much multi-direction, communicating exploring and pondering between the students and teachers; protect the seeds of their sense of innovation; inspire students through analysis, judgment, summarized and integrated so that they are fully divergent thinking of expression to have constant discoveries and innovations. At the same time, it should be paid to guide these "can think" students "can do", to improve their practical ability; and thereby facilitate the continuous development of creative thinking. Training through divergent thinking will improve students' fluent, flexible and innovative thinking.

In today's world, fierce competition calls for diversification thinking and creative talent. Innovative thinking of independent thinking, challenging and to pursuit the truth are the mainstream in IT industry. Nathan Marsh Puse, Harvard University president y, believes that "whether a person with innovative thinking is the watershed between first-class professionals and third-rate talent." Innovation is the focus of quality education; education need for innovation. In the process on teaching computer programming courses, we need to cultivate and foster the computer software talent be much more innovative, train students to create awareness of the importance of thinking and possibilities and create a environment which suit their own interests, hobbies, talent and personality development, so that they can have the enough competition in the information age, victory by thinking, victory by innovation.

\section{References}

Clifton F. Conrad, Jason Johnson and Divya Malik Gupta. (2007). Teaching-for-Learning (TFL): A Model for Faculty to Advance Student Learning. Innovative Higher Education. Volume 32, Number 3, 153-165.

David F. Treagust. (2007). Research-based Innovative Units for Enhancing Student Cognitive Outcomes and Interest in Science. Roser Pintó, Digna Couso (Eds), Contributions from Science Education Research. Springer Netherlands, pp.11-26.

Gary D. Koppenhaver, Virginia L. Blackburn, Kay M. Palan, Sue Ravenscroft and Charles B. Shrader. (2007). Student/Faculty Connections in the Development of Teaching, Decision Sciences Journal of Innovative Education Vol. 5 Issue 2, 375.

Guijuan Gao. (2002). The Self-Taught Higher Education Examination in China: As Manifested in the Educational Service and National Examination. Educational Research for Policy and Practice Volume 1, Numbers 1, 99-112. 
Nandasara S.T., Samaranayake V. K. and Yoshiki Mikami. (2006). Revolutionary Development of Computer Education - A Success Story. IFIP International Federation for Information Processing- History of Computing and Education 2 (HCE2). Volume 215, 167-180.

Noel watts. (2007). Innovative Second and Foreign Language Education in the South Pacific. In Nancy H. Hornberger (Eds). Encyclopedia of Language and Education, Springer US, pp.1350-1361.

Thomas F., Patterson Jr. (2007). The Rise and Fall of Innovative Education: An Australian University Case Study. Innovative Higher Education. Volume 32, Number 2, 71-84. 


\title{
Empowering School of Accounting Websites through Quality
}

\section{Assurance: Development and Implementation of}

\section{a User-perceived Instrument}

\author{
Hadrian G. Djajadikerta \\ School of Accounting, Finance and Economics, Edith Cowan University, Australia \\ 100 Joondalup Drive, Joondalup, Perth WA 6027, Australia \\ Tel: 61-8-6304-5353_E-mail: h.djajadikerta@ecu.edu.au \\ Terri Trireksani \\ P.O. Box 2210, Kardinya WA 6963, Australia \\ Hamfri Djajadikerta \\ Parahyangan Catholic University, Jln. Ciumbuleuit 94, Bandung 40141, Indonesia
}

\begin{abstract}
Today's institutions of higher education are facing an increased number of significant challenges taking place in the political, economic, social and technological environment. Accordingly, the issues of performance, accountability, and marketing strategies have become ever more important. It has been suggested that universities that are more market or customer orientated can perform better. In dealing with customers, most universities have utilised Web technologies for both informational and promotional purposes. The question is whether they have designed their Web sites well enough in order to gain the benefits from Web utilisation. Previous studies on quality of Web sites are not lacking, but most of them have focussed mainly on business Web sites. Empirical research that focuses on the Web site quality of institutions of higher education has been scarce. This study focuses on the websites of Schools of Accounting, and selects the websites of Schools of Accounting in New Zealand's universities as the research objects. The main objectives of this study are to develop and validate an instrument for measuring School of Accounting website quality from the perspectives of the users, and to implement the proposed instrument to measure and rank the quality of websites of Schools of Accounting in New Zealand. The results from this initial application substantiated the validity and reliability of the instrument.
\end{abstract}

Keywords: Web site quality, Instrument development, School of Accounting, Web site ranking

\section{Introduction}

In recent years, universities globally have experienced a number of significant challenges and changes taking place in the political, economic, social and technological environment. One of the major challenges is the limited amounts of government funding that push universities to act more like business ventures. As a result, universities have to behave as rival firms and compete intensely for market share and revenue (Caruana, Ramaseshan, \& Ewing, 1998; Scott, 2003; Soutar \& Turner, 2002). With this in mind, it is obvious that the issues of performance, accountability, and service quality have become ever more important. It has been suggested that universities that are more market or customer orientated can perform better (Caruana et al., 1998).

The Web has been broadly considered as an effective tool for commercial and communicational purposes (Huizingh, 2000; Lin \& Lu, 2000; Liu \& Arnett, 2000; Ranganathan \& Ganapathy, 2002). Web technologies enable organisations to reach out for broader customers and create more networking opportunities. Most today's universities have taken advantage of the commercialisations of the Internet, Web technologies and their applications, as parts of their customer or internal business process strategies. The purposes of a university website are both informational and promotional - it tells students, academic and administrative staffs about courses, timetables, and other relevant information, and it tells prospective students and prospective employees about the university and its programs. However, simply using websites does not guarantee a success. The benefits of website utilisation are rather hard to pin down. Almost always there are many alternating websites that users or customers can go to. University websites rely on their quality and ability to attract and keep both existing and potential customers, and hence an understanding of the online users' mindset is critical to designing a usable website. The chances of gaining the benefits from the implementation of Web technologies 
are higher if a cautious emphasis is put in place on the user-perceived quality of the websites (Aladwani \& Palvia, 2001; Cao, Zhang, \& Seydel, 2005; Liu \& Arnett, 2000; McMurdo, 1998; Wan, 2000).

A website should be designed to suit relevant target users. Previous studies on quality of websites are not lacking, but most of them have focussed mainly on business websites (Cao et al., 2005; González \& Palacios, 2004; Liu \& Arnett, 2000; Ranganathan \& Ganapathy, 2002). Empirical research that focuses on the website quality of universities has been scarce. This leads to a need for evaluating this issue and developing a relevant instrument to critically measure the quality of university websites. This study focuses on the websites of Schools of Accounting, and selects the websites of Schools of Accounting in New Zealand's universities as the research objects. The main objectives of this study are to develop and validate an instrument for measuring School of Accounting website quality from the perspectives of the users, and to implement the proposed instrument to measure and rank the quality of websites of Schools of Accounting in New Zealand. The results of the study are expected to provide some valuable input that can assist School of Accounting policy makers in designing and developing suitable and effective key performance indicators within their school's customer or internal business process strategies.

The remainder of the paper is structured as follows. First, the conceptual background of website quality is reviewed. Second, the process in developing and validating the instrument is explained. This includes various steps involved in the measurement and scale development. Third, the proposed instrument is used to measure. From this initial implementation, the quality scores and the ranking of websites of Schools of Accounting in New Zealand are described. Finally, concluding remarks are provided.

\section{Website quality}

Website quality can be approached from many different viewpoints. No particular body of literature specifically addresses the concept of website quality (Cao et al., 2005). Computer and information specialists may focus on the technical aspects of the Web, such as how to develop tools to retrieve information from the Web or how to make a website works properly (Arasu, Cho, Garcia-Molina, Paepcke, \& Raghavan, 2001; Kleinberg, 1999; Nel, van Niekerk, Berthon, \& Davies, 1999). Behavioural scholars may be more interested in the issue of why and what users use the Web for or how Web technologies affect the behaviour of users (Burnett \& Marshall, 2003; Rogers \& Marres, 2000; Wellman, Quan-Haase, Witte, \& Hampton, 2001). From a management point of view, it is interesting to see how organisations make the most of the emerging Web technologies and their applications (Huang, 2005; Liu \& Arnett, 2000; Norton \& McGovern, 2001; Wakefield, 2002; Wan, 2000).

The basic goal of a website is to provide information (Angehrn, 1997; Bhatti, Bough, \& Kuchinsky, 2000). Information refers to processed data that is organised, meaningful, and useful to the users (Cushing \& Romney, 1994). There are different dimensions of information quality according to the context it is being referred to (Fox, Levitin, \& Redman, 1994). However, as a basis of any information quality initiative, the quality of information is commonly assessed via evaluation of its generic characteristics (Xu \& Koronios, 2005). These characteristics have been consistently found to be similar across various previous studies, although some studies may make out more attributes than the others. For example, Ballou and Pazer (1982) defined four fundamental dimensions of information quality: accuracy, timeliness, completeness, and consistency. Burk and Horton (1988) identified three attributes of information quality: accuracy, comprehensiveness, and currency. Rai, Lang, and Welker (2002) described three attributes that can be used to measure information quality: accuracy, content and format.

Web operates in a cyber environment, and hence there is no direct human contact offered through a website. This makes website quality contextually different than information quality. Information quality in the virtual environment captures the issue of content, which was traditionally considered as the most important factor of a website. 'Content is king' used to be a well-known slogan (McCarthy, 1995; Huizingh, 2000). Consequently, many previous studies have used mainly information quality criteria in evaluating and designing a website (McMurdo, 1988; Tate \& Alexander, 1996; Huizingh, 2000). However, more recent studies have emphasised that website quality has to go beyond information quality and should focus on the users or customers as the major foundation in designing and evaluating website quality (van Iwaarden, van der Wiele, Ball, \& Millen, 2004; Xu \& Koronois, 2004). Norton and McGovern (2001) said that content is not king on the website, the reader is king. Saying 'content is king' is like saying the product is king, rather than the customer (McGovern, 2000). Katerattanakul (2002) proposed a definition of website quality as the website's fitness for use by users. All these indicate the importance of user-perceived quality.

There have been a few studies that try to accommodate both the 'content' and 'user' perspectives in the process of exploring the dimensions of website quality. These studies collected responses from participants that were selected to match a profile of a certain target Web user. Ranganathan and Ganapathy (2002) examined the dimensions of business-to-customer websites based on a survey of 214 online shoppers. They found four key website dimensions: information content, design, security, and privacy. Aladwani and Palvia (2002) developed a 25-item instrument for measuring user-perceived business website quality. Firstly, they collected responses from 101 Web users during their design process, and came up with four variables of website quality: content quality, specific content, technical adequacy, 
and Web appearance. In the normalisation process, the Web users were split into four different groups and asked to evaluate the websites of a bank ( 25 users), a bookshop (31 users), a car manufacturer (34 users), and an electronics retailer (37 users). Cao et al. (2005) also did a similar but smaller study as Aladwani and Palvia (2002). They asked 71 first and second year university students to express their perceptions of three online bookshops: amazon.com, biggerbooks.com, and half.com. They found four constructs that relate to website quality: information quality, service quality, playfulness, and system quality. These three studies, among others, confirm that in the perception of users, content or information quality is only one dimension of website quality. Therefore, the design and evaluation of a website should be assessed using a multi-item instrument that combines all of the users' or customers' values rather than mainly its informational content.

\section{The design of an instrument for measuring user-perceived School of Accounting website quality}

As a starting point, we used Aladwani and Palvia's (2002) 25-item instrument for measuring website quality. There were two main reasons for this. Firstly, this instrument has encompassed both the perspectives of users and the importance of 'content'. Secondly, this instrument has been developed and validated thoroughly in their study. They started with a conceptualisation process in delimiting the domain of the constructs and identifying indicators of each construct based on academic literature. It was then followed by a scale design step that analysed the validity and reliability of the constructs and their respective indicators. Finally a normalisation process was performed to verify and validate the constructs.

Nonetheless, while the development and validation processes applied to this instrument have been extensive and solid, the main focus of the instrument was measuring website quality of businesses. Therefore, in this study we made a few adjustments to suit the instrument for evaluating School of Accounting websites. Subsequently, we followed Churchill's (1979) recommendations by applying a reliability analysis and a normalisation process to ensure the validity and reliability of the adjusted instrument.

The first adjustment to Aladwani and Palvia's (2001) 25-item instrument was an exclusion of the security indicator. While one of the purposes of university websites is promotional (Brody, 1999), the university websites practically do not involve much the carrying out of transactions (e.g. used of secure sockets layer, digital certificates, etc.) The second adjustment to the instrument was fine-tuning the specific content of a few indicators to suit the academic environment (e.g. owners were changed to academic and administrative staffs, products and/or services were changed to courses and/or subjects, etc.) The result of the adjustment was a 24-item instrument consisting of four constructs: technical adequacy, information quality, service ability, and Web appearance (see Table 1).

\subsection{Reliability analysis}

To evaluate the unidimensionality of the indicators and distinguish the appropriate indicators for each construct, a reliability analysis was conducted. The list of the 24 items was administered to third year accounting students who had experiences in using the Web. Students were selected since they represent one of the major users of School of Accounting websites. They fitted the profile of the target users for both service and marketing purposes. The students were asked to rate the importance of each item for measuring School of Accounting website quality. Each item was measured using a seven-point scale from 1 being 'extremely not important' to 7 being 'extremely important'. There were 126 participants, and 118 responses were usable. $56 \%$ of the respondents were female and $44 \%$ were male. $68 \%$ of the respondents accessed Web more frequently (more than three times a week), and $32 \%$ less frequently (less than three times a week).

From data that were collected, a reliability test was conducted using Cronbach's alpha. The alpha values for technical adequacy, information quality, service ability, and Web appearance were $0.68,0.93,0.72$, and 0.87 , respectively. Since the alpha value for technical adequacy did not achieve the common acceptable value of 0.7 , an analysis of individual indicators was conducted. It was found that interactivity indicator had a low corrected item-total correlation of -0.28 . Hence, the indicator was removed. This screening made up an alpha value of 0.89 for technical adequacy - hence, showed an improved level of reliability. At the end of this process, 23 indicators were kept.

The next step involved a factor analysis to discover whether the four constructs could be explained largely or entirely in terms of their respective indicators. We applied a factor analysis procedure with varimax rotation and used a cut-off point of 0.5, which was considered as a significant loading (Hair, Anderson, Tatham, \& Black, 1995). The results of the factor analysis, which are shown in Table 2, were consistent with Aladwani and Palvia's (2002) findings. There were four website quality constructs explaining $65.22 \%$ of the variance in user-perceived website quality. Each of these four constructs matched all of its respective indicators, and therefore, all 23 indicators were retained.

\subsection{Normalisation of constructs and indicators}

Normalisation process was conducted to verify and validate all four constructs in the instrument. This process was similar to conducting a pilot test to ensure the validity of a questionnaire. Oppenheim $(1966$, p.29) said that "respondents in pilot studies should be as similar as possible to those in the main inquiry" A similar point was also 
mentioned by Sudman and Bradburn (1983, p.282), "pilot-test on small sample of respondents similar to the universe from which you are sampling". Therefore, a different group, consisted of 48 third year accounting students (27 females and 21 males), was asked to participate. Each of the participants was asked to evaluate a website of a School of Accounting in Australia using the 23-item instrument as shown in Table 3. Each item was measured on a seven-point scale with 1 being 'strongly disagree' and 7 being 'strongly agree'. To evaluate the validity of the instrument indicators and constructs, exploratory analyses were conducted. Two tests were conducted in these analyses: individual item reliability and composite reliability. The results of these analyses are presented in Table 4.

In general, for each indicator, a standardised loading of more than 0.7 is considered to be reliable, because it ensures that at least $50 \%$ of the variance of the indicator is explained by the construct that the indicator intends to measure (Bagozzi, 1994). In other words, a standardised loading of more than 0.7 ensures that each indicator distributes more variance with the construct score than with error variance. In studies where the indicators are not well developed, a loading of 0.5 or 0.6 is acceptable (Chin, 1998). The exploratory analyses showed that all 23 indicators had loadings above 0.6 on their particular constructs (as shown in Table 4). Additionally, it showed that in each block of indicators, each loading in the block related to its respective construct was higher than its loadings related to other constructs or other block of indicators. Therefore, all indicators were considered as reliable and were retained as indicators of their respective constructs.

To ensure the estimation of the composite reliabilities of the blocks of indicators, Cronbach's alpha was used to assess the internal consistency for each block of indicators. It was found that alpha values for technical adequacy, information quality, service ability, and Web appearance were $0.84,0.81,0.86$, and 0.93 , respectively. These values were above the acceptable value of 0.7 , and hence, indicated that the composite reliabilities estimated by these measures were satisfactory. Having undergone thorough development and validation processes, we believe that the instrument is sound for measuring School of Accounting website quality.

\section{Measuring and ranking the quality of websites of Schools of Accounting in New Zealand}

There were eight universities in New Zealand. All of them had a "School of Accounting", either as a standalone department or as a part of a collective department. These Schools of Accounting were as follows: (1) Department of Accounting and Finance, Business School, University of Auckland; (2) Accounting Discipline, Faculty of Business, Auckland University of Technology; (3) Accountancy, Finance and Information Systems Department, College of Business and Economics, University of Canterbury; (4) Centre of Accounting Education and Research, Commerce Division, Lincoln University; (5) School of Accountancy, College of Business, Massey University; (6) Accountancy and Business Law Department, School of Business, University of Otago; (7) School of Accounting and Commercial Law, Faculty of Commerce and Administration, Victoria University of Wellington; and (8) Department of Accounting, Waikato Management School, University of Waikato. All eight websites of these Schools of Accounting were evaluated.

To increase confidence that values of website quality found from this study were due to website quality constructs rather than user effects, two groups of students were used as respondents. The first group consisted of 33 third year accounting students (19 females and 14 males), and the second group consisted of 41 first year accounting students (21 females and 20 males). Each respondent was asked to evaluate websites of all eight Schools of Accounting using the 23-item instrument. Each item was measured on a seven-point scale with 1 being 'strongly disagree' and 7 being 'strongly agree'.

The results based on the responses from all respondents are reported in Tables 5 and 6 . It can be seen in Table 5 that the websites of Schools of Accounting in the University of Auckland, the University of Otago, and Victoria University of Wellington are the top-three websites overall. From Table 6, it can be seen that in terms of all constructs (the technical adequacy, information quality, service ability, and Web appearance), the website of School of Accounting in the University of Auckland is consistently in the first position, and the website of School of Accounting in the University of Waikato is consistently in the last position. There are slight variations of ranks in the remaining six websites, but in general the websites of Schools of Accounting in the University of Otago, Victoria University of Wellington, and Massey University are consistently in the second to fourth positions, except for the Web appearance construct where the website of School of Accounting in Massey University is in the fifth position. Concurrently, the websites of Schools of Accounting in the University of Canterbury, Lincoln University, and Auckland University of Technology are consistently in the fifth to seventh positions, except for the Web appearance construct where the website of School of Accounting in Lincoln University is in the fourth position.

We also provide the ranking and descriptive statistics based upon each group of respondents in Table 7. There are four groups of respondents, which include (1) third year students; (2) first year students; (3) female students; and (4) male students. It can be seen that the ranking in each group is generally consistent with the overall ranking based upon responses from all respondents. The website of School of Accounting in the University of Auckland is consistently in the first position. Concurrently, the websites of Schools of Accounting in the University of Otago, Victoria University 
of Wellington, and Massey University are in the second to fourth positions. The websites of Schools of Accounting in the University of Canterbury, Lincoln University, and Auckland University of Technology are in the fifth to seventh positions. Finally, the website of School of Accounting in the University of Waikato is consistently in the last position.

The results of this implementation show that the 23-item instrument is able to differentiate the qualitative value of each School of Accounting website. Hence, it is a valid instrument. Simultaneously, the instrument is also been able to provide consistencies of the results across a diverse range of respondents. Hence, the instrument is also reliable. Nonetheless, chances for further improvement to the instrument are always open and any future change for the better is certainly enviable.

\section{Conclusion}

Websites have been widely used commercially throughout industry, government, education, and practically in any other types of institutions (Liu \& Arnett, 2000). It has been acknowledged that in order to gain the benefits from utilisation of Web technologies, a high-quality website is needed. Previous studies on quality of websites are not lacking. However, most of the previous studies have been focussed mainly on business websites. In this study, an instrument for measuring School of Accounting website quality was developed and validated thoroughly by taking into account both the perspectives of the users and the importance of its informational content. The generated instrument has four main constructs with a total of 23 indicators. It has been subsequently put to the test by implementing it for measuring and ranking the quality of websites of Schools of Accounting in New Zealand. The results from this application have corroborated the validity and reliability of the instrument.

The results of the study provide some important guidelines for the design and evaluation of School of Accounting websites, and university website in general. Hence, not only they contribute to the existing empirical literature, but may also assist the policy makers in universities. The 23 School of Accounting website quality indicators can be used as a foundation for the design and development of a more effective School of Accounting websites. The quality scores and the ranking of websites of Schools of Accounting in New Zealand provide an illustration about the value and attractiveness of each website in the eyes of the users. The quality scores from the respondents give an indication of which website dimensions should be maintained and which dimensions should be improved. The best-performing website can also be used as a benchmarking model. It should be noted though that changes constantly take place in the economic, social and technological environment. Therefore, it is important to continuously monitor these changes and keep updating the instrument as necessary.

\section{References}

Aladwani, A.M., \& Palvia, P.C. (2002). Developing and validating an instrument for measuring user-perceived Web quality. Information and Management, 39, pp. 467-476.

Alexander, J.E., \& Tate, M.A. (1999). Web wisdom: How to evaluate and create information quality on the Web. Marwah, NJ: Lawrence Erlbaum Associates.

Arasu, A., Cho, J., Garcia-Molina, H., Paepcke, A., \& Raghavan, S. (2001). Searching the Web. ACM Transactions on Internet Technology, 1, pp. 2-43.

Ballou, D.P., \& Pazer, H.L. (1982). The impact of inspector fallibility on the inspection policy serial production system. Management Science, 28, pp. 387-399.

Bhatti, N., Bough, A., \& Kuchinsky, A. (2000). Integrating user-perceived quality into web server design. Computer Networks, 33, pp. 1-16.

Burnett, R., \& Marshall, P.D. (2003). Web theory. London: Routledge.

Bagozzi, R.P. (1994). Measurement in marketing research: Basic principles of questionnaire design. In R.P. Bagozzi (Ed.), Principles of Marketing Research. Cambridge, MA: Blackwell.

Brody, R. (1999). Doing business with .edu: Business information at college and university Web sites. EContent, 22, pp. 52-56.

Burk, C.F., \& Horton, F.W. (1988). Infomap. A complete guide to discovering corporate information resources. Englewood Cliffs, NJ: Prentice Hall.

Cao, M., Zhang, Q., \& Seydel, J. (2005). B2C e-commerce web site quality: an empirical examination. Industrial Management and Data Systems, 105, pp. 645-661.

Caruana, A., Ramaseshan, B., \& Ewing, M.T. (1998). Do universities that are more market orientated perform better? The International Journal of Public Sector Management, 11, pp. 55-70.

Chin, W.W. (1998). The Partial Least Squares Approach to Structural Equation Modeling. In G.E. Marcoulides (Ed.), Modern Methods for Business Research. Mahwah, NJ: Lawrence Erlbaum Associates. 
Churchill, G.A. (1979). A paradigm for developing better measures of marketing constructs. Journal of Marketing Research, 16, pp. 64-73.

Cushing, B.E., \& Romney, M.B. (1994). Accounting Information Systems. Reading, Massachusetts: Addison-Wesley.

Fox, C., Levitin, A., \& Redman, T.C. (1994). The notion of information and its quality dimensions. Information Processing and Management, 30, pp. 9-19.

González, F.J.M., \& Palacios, T.M.B. (2004). Quantitative evaluation of commercial web sites: An empirical +study of Spanish firms. International Journal of Information Management, 24, pp. 313-328.

Hair, J.F., Anderson, R.E., Tatham, R.L., \& Black, W. (1995). Multivariate Data Analysis with Readings. Englewood Cliffs, NJ: Prentice-Hall.

Huang, E.Y. (2005). Is revamping your web site worthwhile? Industrial Management and Data Systems, 105, pp. 737-751.

Katerattanakul, P. (2002). Framework of effective web site design for business-to-customer internet commerce. INFOR, 40, pp. 57-70.

Kleinberg, J. (1999). Authoritative sources in a hyperlinked environment. Journal of the ACM, 46, pp. 604-632.

Lin, J.C., \& Lu, H. (2000). Towards an understanding of the behavioural intention to use a web site. International Journal of Information Management, 20, pp. 197-208.

Liu, C., \& Arnett, P.K. (2000). Exploring the factors associated with the Web site success in the context of electronic commerce. Information and Management, 38, pp. 23-33.

McGovern, G. (2000). Managing information in the digital age: How the reader is king. Irish Marketing Review, 13, pp. 55-60.

McMurdo, G. (1998). Evaluating Web information and design. Journal of Information Science, 24, pp. 192-204.

Nel, D., van Niekerk, R., Berthon, J., \& Davies, T. (1999). Going with the flow: Web sites and customer involvement. Internet Research, 9, pp. 109-116.

Norton, R., \& McGovern, G. (2001). Content Critical: Gaining Competitive Advantage Through High-Quality Web Content. London: Financial Times Prentice Hall.

Oppenheim, A.N. (1966). Questionnaire Design and Attitude Measurement. London: Heinemann.

Rai, A., Lang, S.S., \& Welker, R.B. (2002). Assessing the validity of IS success models: An empirical test and theoretical analysis. Information Systems Research, 13, pp. 50-69.

Ranganathan, C., \& Ganapathy, S. (2002). Key dimensions of business-to-customer Web sites. Information and Management, 39, pp. 457-465.

Robbins, S., \& Stylianou, A. (2003). Global corporate web sites: An empirical investigation of content and design. Information and Management, 40, pp. 205-212.

Rogers, R., \& Marres, N. (2000). Landscaping climate change: A mapping technique for understanding science and technology debates on the World Wide Web. Public Understanding of Science, 9, pp. 141-163.

Scott, W.G. (2003). Income Squeeze on New Zealand Universities. Journal of American Academy of Business, 3 , pp. 224-229.

Soutar, G.N., \& Turner, J.P. (2002). Students' preferences for university: A conjoint analysis. The International Journal of Educational Management, 16, pp. 40-45.

Sudman, S., \& Bradburn, N. (1982). Asking Questions: A Practical Guide to Questionnaire Design, San Francisco: Jossey-Bass.

Tate, M.A., \& Alexander, J. (1996). Critical evaluation skills for World Wide Web resources. Computers in Libraries, 16, pp. 49-55.

van Iwaarden, J., van der Wiele, T., Ball, L., \& Millen, R. (2004). Perceptions about the quality of web sites: A survey amongst students at Northeastern University and Erasmus University. Information and Management, 41, pp. 947-959.

Wakefield, R.L. (2002). Using the Internet to enhance CPA service quality. The Ohio CPA Journal, 61, pp. 56-57.

Wan, H. (2000). Opportunities to enhance a commercial website. Information and Management, 38, pp. 15-21.

Wellman, B., Quan-Haase, A., Witte, J., \& Hampton, K. (2001). Does the internet increase, decrease, or supplement social capital?: Social networks, participation, and community commitment. American Behavioral Scientist, 45, pp. 436-455. 
Xu, H., \& Koronios, A. (2005). Understanding information quality in E-Business. The Journal of Computer Information Systems, 45, pp. 73-82.

Table 1. School of Accounting website quality constructs and indicators

\begin{tabular}{|l|l|}
\hline \multicolumn{1}{|c|}{ Construct } & \multicolumn{1}{c|}{ Indicators } \\
\hline Technical adequacy & $\begin{array}{l}\text { Ease of navigation, search facilities, availability, valid links, personalisation or } \\
\text { customisation, speed of page loading, interactivity, ease of accessing the site }\end{array}$ \\
\hline Information quality & Usefulness, completeness, clarity, currency, conciseness, accuracy \\
\hline Service ability & $\begin{array}{l}\text { Finding contact information, finding general information, finding courses/subjects } \\
\text { details, finding academic policies, finding research information }\end{array}$ \\
\hline Web appearance & $\begin{array}{l}\text { Attractiveness, organisation, proper use of fonts, proper use of colours, proper use } \\
\text { of multimedia }\end{array}$ \\
\hline
\end{tabular}

Table 2. Principal component analysis with varimax rotation

\begin{tabular}{|c|c|c|c|c|c|}
\hline \multirow[b]{2}{*}{ Indicator } & \multicolumn{5}{|c|}{ Component } \\
\hline & Factor 1 & Factor 2 & Factor 3 & Factor 4 & Factor 5 \\
\hline Ease of navigation & 0.25 & 0.51 & 0.02 & 0.09 & 0.49 \\
\hline Search facilities & 0.13 & 0.87 & 0.05 & 0.02 & -0.11 \\
\hline Availability & 0.02 & 0.63 & -0.04 & -0.02 & 0.29 \\
\hline Valid links & -0.06 & 0.87 & -0.12 & -0.01 & 0.13 \\
\hline Personalisation or customisation & 0.02 & 0.73 & -0.09 & 0.04 & 0.23 \\
\hline Speed of page loading & 0.18 & 0.82 & 0.15 & -0.05 & -0.24 \\
\hline Ease of accessing the site & 0.09 & 0.87 & 0.25 & -0.01 & -0.22 \\
\hline Usefulness & 0.62 & -0.04 & 0.29 & 0.11 & 0.41 \\
\hline Completeness & 0.85 & 0.05 & 0.22 & 0.03 & 0.09 \\
\hline Clarity & 0.91 & 0.08 & 0.19 & 0.05 & -0.12 \\
\hline Currency & 0.67 & 0.13 & 0.10 & 0.16 & 0.27 \\
\hline Conciseness & 0.91 & 0.11 & 0.20 & 0.09 & -0.12 \\
\hline Accuracy & 0.91 & 0.11 & 0.19 & 0.08 & -0.13 \\
\hline Finding contact information & 0.08 & -0.13 & 0.38 & 0.54 & 0.36 \\
\hline Finding general information & 0.07 & 0.27 & -0.02 & 0.77 & 0.21 \\
\hline Finding courses/subjects details & 0.08 & 0.00 & 0.07 & 0.82 & -0.03 \\
\hline Finding academic policies & 0.11 & -0.22 & 0.20 & 0.69 & -0.29 \\
\hline Finding research information & 0.38 & 0.00 & 0.00 & 0.51 & -0.55 \\
\hline Attractiveness & 0.08 & 0.03 & 0.77 & 0.03 & 0.07 \\
\hline Organisation & 0.42 & 0.08 & 0.78 & 0.06 & -0.08 \\
\hline Proper use of fonts & 0.48 & -0.03 & 0.71 & 0.15 & -0.12 \\
\hline Proper use of colours & 0.44 & -0.05 & 0.78 & 0.09 & -0.21 \\
\hline Proper use of multimedia & 0.07 & 0.11 & 0.67 & 0.16 & 0.34 \\
\hline Eigen value & 4.96 & 4.33 & 3.31 & 2.40 & 1.56 \\
\hline Variance explained & 0.215 & 0.188 & 0.144 & 0.105 & 0.068 \\
\hline
\end{tabular}


Table 3. The user-perceived School of Accounting website quality instrument

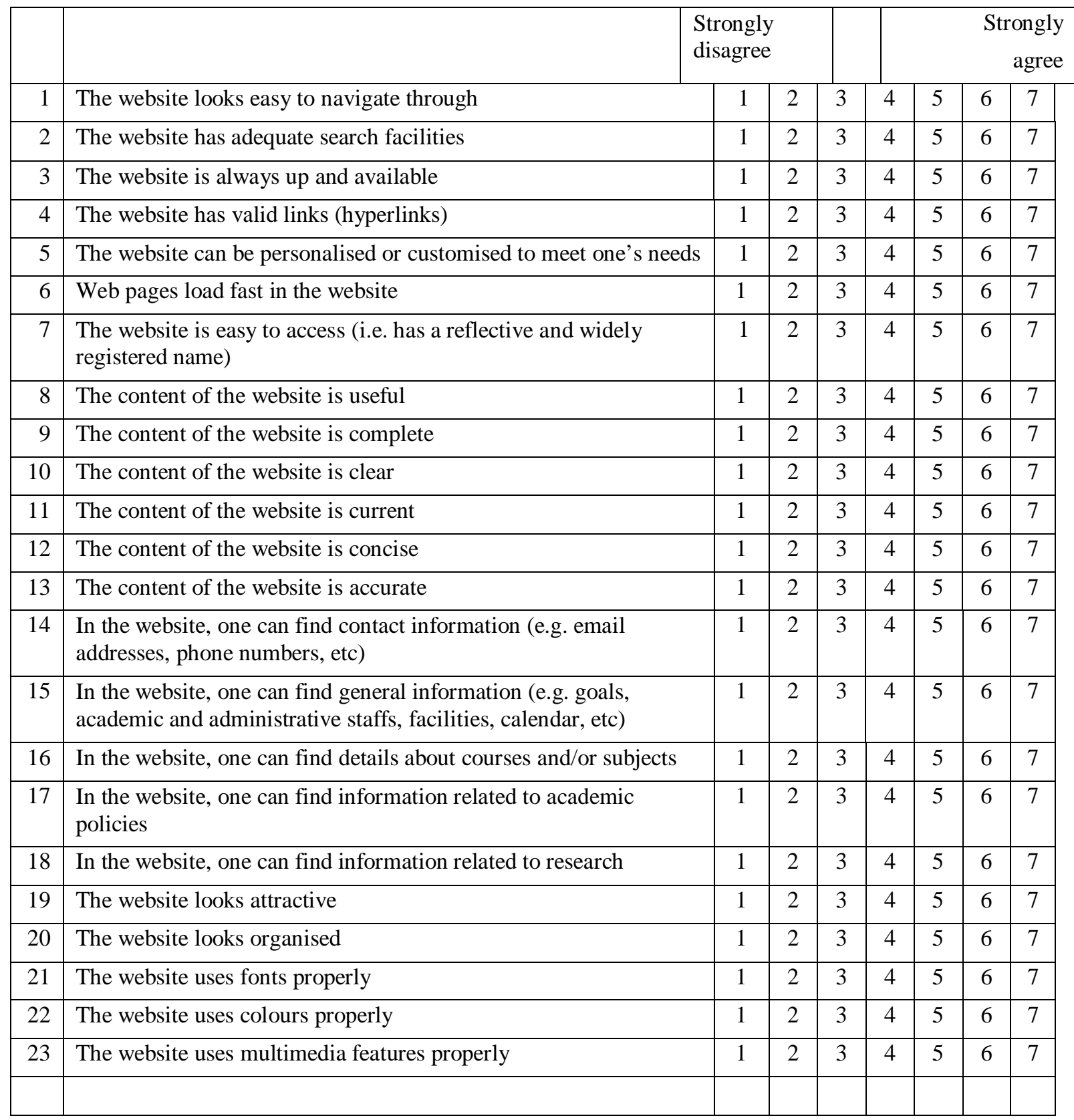


Table 4. Correlations between constructs and indicators

\begin{tabular}{|c|c|c|c|c|}
\hline \multirow[b]{2}{*}{ Indicator } & \multicolumn{4}{|c|}{ Construct } \\
\hline & $\begin{array}{l}\text { Technical } \\
\text { adequacy } \\
\alpha=0.84\end{array}$ & $\begin{array}{c}\text { Information } \\
\text { quality } \\
\alpha=0.81\end{array}$ & $\begin{array}{c}\text { Service } \\
\text { ability } \\
\alpha=0.86\end{array}$ & $\begin{array}{c}\text { Web appearance } \\
\alpha=0.93\end{array}$ \\
\hline Ease of navigation & 0.624 & 0.416 & 0.062 & -0.107 \\
\hline Search facilities & 0.686 & 0.538 & 0.210 & 0.335 \\
\hline Availability & 0.890 & 0.274 & 0.292 & 0.082 \\
\hline Valid links & 0.908 & 0.144 & 0.374 & 0.255 \\
\hline Personalisation or customisation & 0.671 & 0.298 & 0.316 & 0.467 \\
\hline Speed of page loading & 0.713 & 0.146 & 0.435 & 0.205 \\
\hline Ease of accessing the site & 0.638 & 0.106 & 0.528 & 0.394 \\
\hline Usefulness & 0.442 & 0.671 & 0.146 & 0.138 \\
\hline Completeness & 0.367 & 0.751 & 0.160 & 0.245 \\
\hline Clarity & 0.266 & 0.741 & 0.269 & 0.437 \\
\hline Currency & 0.314 & 0.727 & 0.324 & 0.378 \\
\hline Conciseness & 0.201 & 0.785 & 0.140 & 0.384 \\
\hline Accuracy & 0.053 & 0.715 & 0.212 & 0.269 \\
\hline Finding contact information & 0.418 & 0.226 & 0.798 & 0.609 \\
\hline Finding general information & 0.318 & 0.056 & 0.870 & 0.698 \\
\hline Finding courses/subjects details & 0.277 & 0.414 & 0.662 & 0.297 \\
\hline Finding academic policies & 0.412 & 0.142 & 0.834 & 0.564 \\
\hline Finding research information & 0.370 & 0.199 & 0.768 & 0.526 \\
\hline Attractiveness & 0.232 & 0.464 & 0.598 & 0.909 \\
\hline Organisation & 0.316 & 0.394 & 0.510 & 0.609 \\
\hline Proper use of fonts & 0.261 & 0.323 & 0.639 & 0.951 \\
\hline Proper use of colours & 0.296 & 0.273 & 0.665 & 0.952 \\
\hline Proper use of multimedia & 0.296 & 0.273 & 0.665 & 0.952 \\
\hline
\end{tabular}

Table 5. Ranking of the websites of Schools of Accounting in New Zealand

\begin{tabular}{|c|l|c|c|}
\hline Rank & \multicolumn{1}{|c|}{ Website of School of Accounting } & Overall mean & Std. dev \\
\hline 1 & University of Auckland & 5.78 & .33 \\
\hline 2 & University of Otago & 5.57 & .37 \\
\hline 3 & Victoria University of Wellington & 5.46 & .30 \\
\hline 4 & Massey University & 5.35 & .29 \\
\hline 5 & University of Canterbury & 4.95 & .26 \\
\hline 6 & Lincoln University & 4.89 & .28 \\
\hline 7 & Auckland University of Technology & 4.74 & .25 \\
\hline 8 & University of Waikato & 4.14 & .27 \\
\hline
\end{tabular}


Table 6. Ranking and descriptive statistics of the websites of Schools of Accounting in New Zealand based on each website quality construct

\begin{tabular}{|c|c|c|c|c|c|c|c|c|c|c|c|c|}
\hline \multirow{2}{*}{$\begin{array}{l}\text { Website of } \\
\text { School of } \\
\text { Accounting }\end{array}$} & \multicolumn{3}{|c|}{ Technical adequacy } & \multicolumn{3}{|c|}{ Information quality } & \multicolumn{3}{|c|}{ Service ability } & \multicolumn{3}{|c|}{ Web appearance } \\
\hline & Mean & Rank & $\begin{array}{l}\text { Std. } \\
\text { dev }\end{array}$ & Mean & Rank & $\begin{array}{l}\text { Std. } \\
\text { dev }\end{array}$ & Mean & Rank & $\begin{array}{l}\text { Std. } \\
\text { dev }\end{array}$ & Mean & Rank & $\begin{array}{l}\text { Std. } \\
\text { dev }\end{array}$ \\
\hline $\begin{array}{l}\text { University of } \\
\text { Auckland }\end{array}$ & 5.71 & 1 & .46 & 5.83 & 1 & .50 & 5.69 & 1 & .58 & 5.87 & 1 & .51 \\
\hline $\begin{array}{l}\text { University of } \\
\text { Otago }\end{array}$ & 5.66 & 2 & .44 & 5.60 & 3 & .62 & 5.45 & 4 & .54 & 5.57 & 2 & .68 \\
\hline $\begin{array}{l}\text { Victoria } \\
\text { University of } \\
\text { Wellington }\end{array}$ & 5.39 & 4 & .47 & 5.62 & 2 & .66 & 5.52 & 3 & .53 & 5.30 & 3 & .56 \\
\hline $\begin{array}{l}\text { Massey } \\
\text { University }\end{array}$ & 5.64 & 3 & .45 & 5.36 & 4 & .51 & 5.53 & 2 & .51 & 4.87 & 5 & .54 \\
\hline $\begin{array}{l}\text { University of } \\
\text { Canterbury }\end{array}$ & 5.20 & 5 & .45 & 5.09 & 5 & .50 & 4.98 & 6 & .48 & 4.54 & 6 & .50 \\
\hline $\begin{array}{l}\text { Lincoln } \\
\text { University }\end{array}$ & 4.98 & 7 & .44 & 4.59 & 6 & .55 & 5.02 & 5 & .52 & 4.96 & 4 & .63 \\
\hline $\begin{array}{l}\text { Auckland } \\
\text { University of } \\
\text { Technology }\end{array}$ & 5.09 & 6 & .40 & 4.35 & 7 & .59 & 4.98 & 7 & .55 & 4.53 & 7 & .52 \\
\hline $\begin{array}{l}\text { University of } \\
\text { Waikato }\end{array}$ & 4.09 & 8 & .48 & 4.11 & 8 & .63 & 4.15 & 8 & .53 & 4.21 & 8 & .57 \\
\hline
\end{tabular}

Table 7. Ranking and descriptive statistics of the websites of Schools of Accounting in New Zealand based on each group of respondents

\begin{tabular}{|c|c|c|c|c|c|c|c|c|c|c|c|c|}
\hline \multirow{2}{*}{$\begin{array}{l}\text { Website of } \\
\text { School of } \\
\text { Accounting }\end{array}$} & \multicolumn{3}{|c|}{ Third year student } & \multicolumn{3}{|c|}{ First year student } & \multicolumn{3}{|c|}{ Female student } & \multicolumn{3}{|c|}{ Male student } \\
\hline & Mean & Rank & $\begin{array}{l}\text { Std. } \\
\text { dev }\end{array}$ & Mean & Rank & $\begin{array}{l}\text { Std. } \\
\text { dev }\end{array}$ & Mean & Rank & $\begin{array}{l}\text { Std. } \\
\text { dev }\end{array}$ & Mean & Rank & $\begin{array}{l}\text { Std. } \\
\text { dev }\end{array}$ \\
\hline $\begin{array}{l}\text { University of } \\
\text { Auckland }\end{array}$ & 6.03 & 1 & .24 & 5.57 & 1 & .23 & 5.79 & 1 & .33 & 5.76 & 1 & .32 \\
\hline $\begin{array}{l}\text { University of } \\
\text { Otago }\end{array}$ & 5.88 & 2 & .23 & 5.32 & 3 & .27 & 5.57 & 2 & .41 & 5.57 & 2 & .33 \\
\hline $\begin{array}{l}\text { Victoria } \\
\text { University of } \\
\text { Wellington }\end{array}$ & 5.62 & 3 & .25 & 5.33 & 2 & .28 & 5.50 & 3 & .32 & 5.41 & 3 & .28 \\
\hline $\begin{array}{l}\text { Massey } \\
\text { University }\end{array}$ & 5.50 & 4 & .29 & 5.23 & 4 & .24 & 5.36 & 4 & .29 & 5.34 & 4 & .30 \\
\hline $\begin{array}{l}\text { University of } \\
\text { Canterbury }\end{array}$ & 5.06 & 5 & .24 & 4.86 & 6 & .24 & 4.99 & 5 & .29 & 4.91 & 6 & .22 \\
\hline $\begin{array}{l}\text { Lincoln } \\
\text { University }\end{array}$ & 4.72 & 7 & .22 & 5.02 & 5 & .25 & 4.86 & 6 & .32 & 4.92 & 5 & .22 \\
\hline $\begin{array}{l}\text { Auckland } \\
\text { University of } \\
\text { Technology }\end{array}$ & 4.81 & 6 & .24 & 4.68 & 7 & .25 & 4.77 & 7 & .24 & 4.71 & 7 & .27 \\
\hline $\begin{array}{l}\text { University of } \\
\text { Waikato }\end{array}$ & 4.04 & 8 & .24 & 4.22 & 8 & .27 & 4.11 & 8 & .31 & 4.17 & 8 & .21 \\
\hline
\end{tabular}




\title{
A Teaching Attitude Adjusting Model for College Teachers Based on
}

\section{Attitude Theories}

\author{
Linying Zhang \\ School of Economics and Management, Nanjing University of Science and Technology \\ Nanjing 210094, China \\ E-mail: z.ly@163.com \\ Zhijun Han \\ School of Economics and Management, Nanjing University of Science and Technology \\ Nanjing 210094, China
}

\begin{abstract}
Teaching attitude of teachers influences the accomplishment of teaching objectives, the quality of teaching and students' learning outcomes and is the main variable in the process of higher education teaching. By referring to attitude theories and group characteristics of college teachers, this paper analyzes the elements that influence teaching attitude of teachers, establishes a teaching attitude adjusting model for college teachers, aiming at providing new administrative framework and critical control point for the management of teaching attitude of college teachers.
\end{abstract}

Keywords: Higher education, Teaching attitude, Teaching quality

Teaching attitude influences the exterior appearance of teachers' knowledge to a great extent and restricts the development of teaching capacity. Besides specialty knowledge and teaching techniques, teaching attitude is also a key determinant element in teaching performance of higher schools. Yao Liming (2003), Chinese scholar, did research on effective teaching characters and believed, "Teaching has always been carried out by teachers and students under certain mood background. The mood status of teachers and students determines the outcome and efficiency of the teaching." Of course, teaching activities are restricted and influenced by objective elements, such as teaching outlines, teaching materials and students; however, teaching attitude determines the implementation effects of teaching activities. The setting down of teaching plans, the choosing of teaching materials, the selecting of teaching strategies and the designing of mutual activities in teaching are all done or directed by teachers. The teaching effects brought by a positive teaching attitude will certainly and remarkably be different from that by a negative teaching attitude. Kerry D (2001) pointed out that if an effective teacher had demonstrated enthusiasm in discipline contents and in specialty practices of teaching, he or she would be able to activate students' enthusiasm by various means. In addition, attitude of teachers also exerts influences on the formation of students' personalities. Personality-oriented education and humanistic learning theory hold that teaching not only includes knowledge imparting and the cultivation of cognitive capacities but also includes developing sensibility volition, and is an overall personality education. Positive and enthusiastic teaching and living attitude of teachers in teaching activities will exert subtle influence on the formation and the development of students' various psychological characters. Teaching practices have proved that students' psychological characters usually will develop following the track of teaching attitude of teachers.

Researches on teaching quality home and abroad have always been focusing on knowledge levels and personality characters of teachers and few researchers are about teaching attitude of teachers. This paper first analyzes group characters of college teachers and elements that influence teaching attitude of college teachers, then puts forward teaching attitude adjusting model for college teachers, and explores the application of attitude theories in the teaching of higher schools, aiming at providing theoretical supports and administrative framework for the management of teaching attitude of college teachers.

\section{A review of theories related to attitude}

The definition of attitude given by social psychology is that attitude, consisting of cognition, sensibility and will, is a comparatively stable reaction trend towards certain special object. Attitude itself is not an action, but attitude restricts action. Attitude exerts direction and drive towards a person's reaction.

The formation and the change of attitude is not an instant action, but is a gradual and socialized process. Kelmen, social 
psychologist, opines that the formation of an attitude will undergo three processes, obedience, recognition and internalization. An individual receives new information about attitude object, reevaluates the values of the attitude object, and fixes new action trend s, after which a new action attitude is formed. With regards to the methods to change attitude, in the persuasion and attitude change model (refer to Figure 1) put forward by Hovland C.I together with other psychologists, it is stated that there are at least four elements that influence the change of attitude, namely, persuader, information, situation and personal character of an individual. In the process of attitude change, an individual first studies the contents of the information and then on the basis of the study, the sensibility is transferred, in which process the sensibility on one object is transferred to other objects related to the original object. When the information received is discrepant with the original attitude, the individual will be psychologically nervous, at which stage consistency system will start to take effect. However, the effect of persuasion mainly depends on the amount and the quality of the refution caused by the discrepancy of information. If the process of the refution is interrupted, either the attitude is changed or the information source is debased and the persuasive information is deliberately distorted to refuse the information.

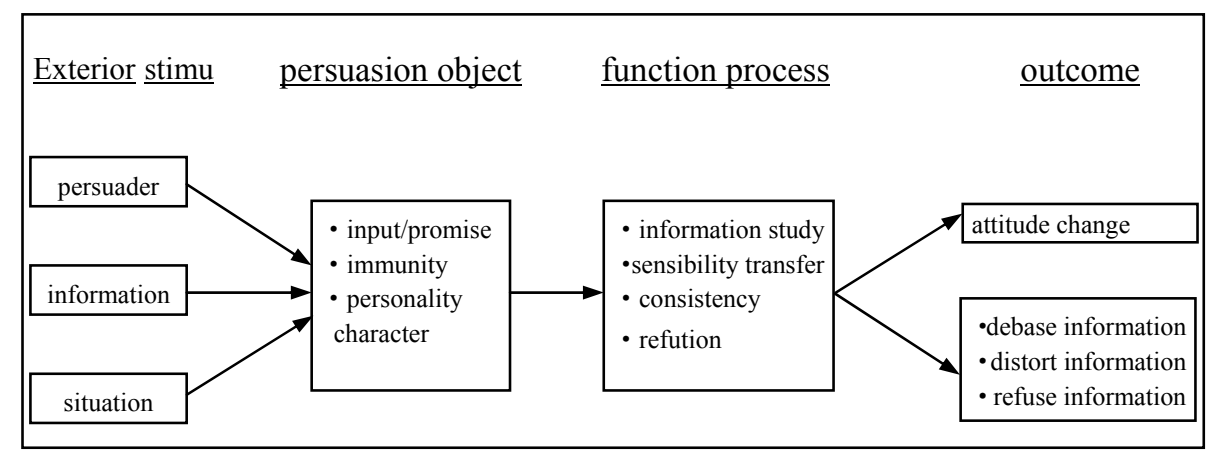

Figure 1. Persuasion and Attitude Change Model

Psychologists had put forward many theories to explain why attitude changes. Cognitive dissonance theory believes that if elements of the cognitive system of an individual are dissonant, the inner feeling of the individual will be unhappy and nervous, resulting in the change of attitude. Participation bringing about change theory advocates that attitude of human beings is changed by way of group standards and values. Human beings are living in groups, so the properties and standards of group activities determine the attitude of human beings. Reference group changing attitude theory is of the opinion that the recognition of each individual towards his or her status and role in a group is an important basis for the individual to form individual attitude and his or her attitude will change with the influence of the reference group.

To understand and study attitude theories and their relevant research outcomes will be of great significance for college teachers in how to keep positive and active teaching attitude and to change negative and listless attitude in the process of teaching in higher schools.

\section{Analysis on elements that influence teaching attitude of college teachers}

Teaching attitude, influencing teaching quality of higher schools, is incarnated by the negativeness and accidie of teachers towards teaching tasks. The negativeness and accidie of teachers is a reaction result of the accumulation of low intensities from their moods when confronted with pressures. Many reasons will lead to the negativeness and accidie of teachers, of which exterior elements include work pressure, intensive colleague relationship, bad performance of students, hardship in promotion and few chances to participate in decision-making and interior elements include personality character, value concept, and the level of self-performance. To combine with the specific situations of Chinese college teachers, there are mainly the following aspects:

\subsection{The influence of talent collective effect and social comparison mode on teaching attitude of teachers}

Personal social comparison modes of teachers also influence the change of teaching attitude. Wood J.V (1989) classified social comparison mode into four types: up recognition, low recognition, up comparison and low comparison. Teachers adopting up recognition focus on the resemblance of themselves with more excellent persons (poles) by which they can recognize their values and deficiencies, which is conducive to the formation of positive teaching attitude. Teachers adopting up comparison will take persons who are better than them in certain aspects as their opponents and negatively evaluate themselves, which can only deepen their feelings of envy and frustration. Teachers adopting low recognition tend to think that they and their futures are similar to those who have gone through frustration or who perform worse, resulting in their negative teaching attitude. Teachers adopting low comparison tend to think that the capacities of other people are rather bad and others are easy to be frustrated. This kind of thinking can also easily trigger positive feeling, but this is a negative way to trigger positive attitude, so it should not be advocated. 
Generally, teachers are specialized in certain field and have profound theoretical knowledge, so college teacher group is a typical talent collective group. The negative effect of conflicts among talents will exert negative influence on personal cognition, mood and other psychological elements of teachers. Teachers who adopt up comparison and low recognition will easily form negative and listless teaching attitude resulting in their lack of impetus in work and their low teaching quality.

\subsection{The influence of work pressure and handling manner on the attitude of teachers}

In modern times, the updating of knowledge is becoming quicker and quicker, which demands teachers to spare more efforts to study so as to keep pace with the updating of knowledge. Meanwhile, the workload of teachers increases with the prevalence of higher education; the assessment and examination by schools for teachers increasingly grows with the implementation of education reform. Consequently, most teachers feel that they are under giant work pressure. If handling manner as against the pressure is not proper, it is easy for those teachers to treat teaching with negative and callous attitude. Handling manner is usually defined as the cognitive and action effort with orientation to manipulate, decrease or abide the pressures arising out of the demands that cannot be met. The research of Gerva K. and Joekes K (2003) indicates that to adopt direct handling manner aiming at problem resolving is good for teachers to secure positive and active teaching attitude and to adopt indirect handling manner with handling sensitivity problem as main task can easily lead teachers to form negative and listless teaching attitude.

\subsection{The influence of system guidance on the attitude of teachers}

The performance assessment and examination system of higher schools is the vane of the work of teachers. The influences of the assessment and examination system on teaching attitude of teachers are mainly shown in the following two aspects. Firstly, it is the influence of teaching evaluation. Variables in the process of teaching are complex. No unified "technical method" or "service procedure" can be followed. Usually, there exist discrepancies among students' evaluation, experts' evaluation and self evaluation of teachers. Improper handling will easily cause disputes and will become important inducement of negative teaching attitude of teachers. Secondly, the assessment and examination and encouragement towards college teachers mainly focus on the accomplishment of scientific research tasks, such as the scientific research projects taken on, the accomplishment awards gained, the academic theses papers published, the works (teaching materials) published and the patents obtained. The direction of the assessment and examination system pulls teachers to spend most of their energy on scientific researchers and to negatively treat teaching jobs.

\subsection{The Influence of organizational support on the attitude of teachers}

Organizational support refers to spiritual and material support for members of an organization, inclusive of to care for members, to listen attentively to members' complaints, to render help when members face problems, and to justly treat members. The care of schools to teachers will be good for teachers to ease their work pressures. The research of Haque and Nargis shows that intensive helps and supports of organizations towards teachers are effective to help them to ease work pressures and occupation accidie.

\section{Teaching attitude adjusting model for college teachers}

Teachers enjoy sublime social status. However, under the influences of the gap of realistic incomes, long term repetitive teaching, and many other elements bad for the formation of positive attitude, it is very easy for college teachers to feel frustrated and to debase their personal values, resulting in negative and listless teaching attitude. Therefore, the management of teaching attitude of teachers becomes a key in the improvement of current teaching performance. In addition, to change others' attitude is a management job and especially, is an important component of the work of leaders.

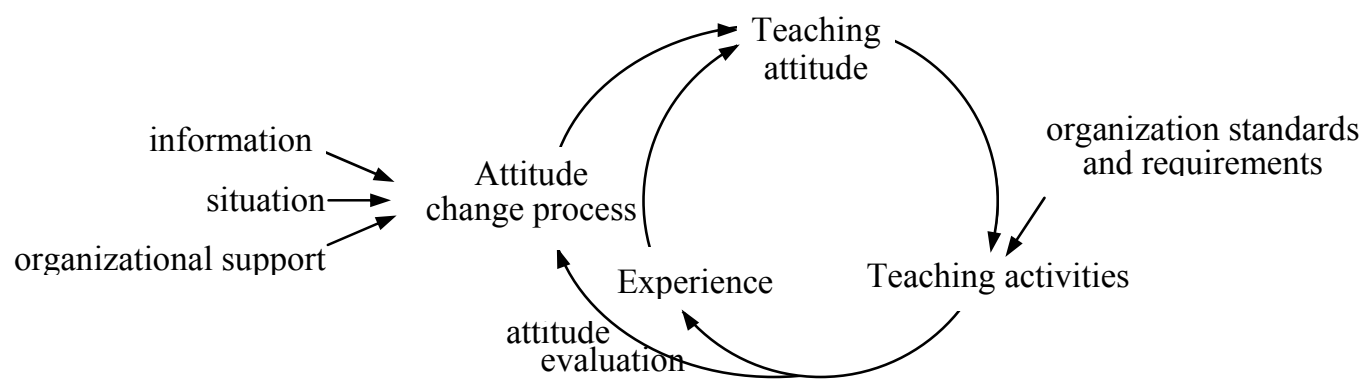

Figure 2. Teaching Attitude Adjusting Model for College Teachers

Modern management theory believes that management objects can be improved if the quality characters of the objects can be measured evaluated and be classified as good and bad. One typical improvement method is "PDCA" circulation proposed by Dai Ming. Attitude theories have proved that the attitude of human being determines his or her actions and 
the exterior action is the token of attitude. Therefore, if can be measured and evaluated, teaching attitude of teachers can also be improved. The teaching attitude model of teachers shown in Figure 1, an inner circulation attitude $\rightarrow$ activities $\rightarrow$ experience $\rightarrow$ attitude, shows the function of reciprocity mode of attitude action in teaching. Under the circumstance without outside interruption, human beings will trap in an intensified circulation, which is "actions determined by attitude", "the obtainment of experience" and "the consolidation of attitude by experience". There are two probable situations in the consolidation of attitude, one is positive consolidation, which refers to the consolidation of positive and active teaching attitude on the basis of active experience; the other is negative consolidation, which means that negative and listless teaching attitude becomes more negative after being beaten by experiences. The ideal state of teaching attitude management of teachers by higher schools is to consolidate positive teaching attitude and to correct negative teaching attitude.

The starting point of the attitude change circulation shown in Figure 2 is teaching evaluation. After being recognized, positive and active attitude is solidified by attitude consolidation. The objects (teachers) with negative and listless attitude to be changed enter into the process of attitude reflection and change. The key influencing elements in the process of teachers' attitude change include information, situation, organizational support and personality character. First of all, the information includes the attitude object information and the pole information of positive and active attitude. Attitude object information stimulates main bodies to change their cognition towards attitude objects, resulting in the unbalance among cognition, sensitivity and will. A re-balance of cognition, sensitivity and will pushes the change of the attitude of main bodies. Secondly, the pole information of colleagues provides reference for the change of attitude and is also a part of situation element. The ways and manners of information spreading influence the change of the attitude of main bodies. For teachers with different opinions, it is more effective to make an overall explanation than to just highlight strong points or weak points. In the process of information spreading, explicit conclusion is more effective than just to provide relevant materials and to let receivers make conclusions. Same information gained from various aspects are better that the information repetitively indicated by a single person. Thirdly, organizational support is the spiritual and material support for members of the organization, including to care for members, to listen attentively to members' complaints, to render help when members face problems, and to justly treat members. The care of organizations for teachers will help teachers to ease their work pressures and to eliminate risky elements which will lead to the occurrence of negative and listless attitude. The research of Haque and Nargis shows that intensive helps and supports of organizations towards teachers are effective to help teachers to ease their work pressures and negativeness and accidie. Administrators of schools, as the persuaders in changing the attitude of teachers, should provide stimulus cognition information to change the main bodies and direct the main bodies' understanding of situation elements. Practices have proved that the higher the prestige of administrators is, the more probably they influence the change of the attitude of main bodies. Fourthly, the personality character of an individual exerts significant influence on the formation and change of attitude. The formation of personality character is the outcome of long term environmental and physical influence, so personality character is hard to change. Nevertheless, under the organizational support and the help of colleagues, it is possible to change attitude by changing some specific characters of personality, such as hobbies and capacities. Besides, to standardize teaching actions and to clarify teaching requirement are also necessary methods to change the attitude of teachers. The researches of attitude theories have proved that to change the exterior actions of an individual can change his or her attitude because when an individual's exterior actions do not comply with his or her interior attitude, he or she will feel unhappy and will think out methods to make the two comply with each other. When one action is a publicly recognized as correct and he or she cannot participate in such an action, he or she will gradually change the inner dissonant attitude.

\section{Conclusion}

Because the elements that influence the change of attitude are in large number and are hard to determine and measure, the management of teaching attitude of teachers has always been a weak point in the management of teaching in higher schools. This paper, in accordance with attitude theories and other relevant theories, does a research on the mutual relationship among teaching attitude, teaching activities and the change process of teaching attitude, and points out the key controlling element in the management of teaching attitude of teachers in higher schools. Therefore, the management of teaching attitude of teachers in higher schools shall proceed from the following aspects. Firstly, a system for the management of teachers' attitude shall be established to evaluate the change of teaching attitude of teachers. Teaching attitude index shall be added into teaching evaluation. With regards to positive and active teaching attitude, schools shall apply encourage methods and ardently render supports; with regards to negative and listless teaching attitude, schools shall render care and directions to help them to change attitude. Secondly, the information channels for teaching shall be extended and the outer information stimuli shall be enlarged in order to change the attitude structures of teachers and to advance the change of negative and listless teaching attitude. Thirdly, teaching management shall be standardized, teaching requirements shall be clarified and teaching actions of teachers shall be regulated in order to accelerate the formation of positive and active teaching attitude by those imperative requirements. Fourthly, supportive and harmonious atmosphere shall be created to help teachers to change certain negative personality 
characters in order to change their attitude.

\section{References}

Gerva K \&Joekes K. (2003). U K teachers under stress: can we predict wellness on the basis of characteristics of the teaching job? Psychology and Health, (18), pp.457-471.

Haque M A \& Nargi A. (2003). Relationship between job stress and burnout:organizational support and creativity as predictor variables. Pakistan Journal of Psychological Research, (18) pp.139-149.

Hovland,C.I., Janis,L.L.\&Kelley,H.H. (1953). Communication and Persuasion. Yalo University Press.

Kerby D. (2002). Project team for teaching and evaluation (final report). Available at http://vpaa.truman.edu/PTFinalReport.pdf.

Meng, Qingmao \& Liu Hongyun. (2003). A research on the evaluation dimension structure and influencing elements in teaching effects of college teachers. Psychological Science, 4(23).

Wood J V. (1989). Theory and research concerning social comparisons of personal attributes. Psychological Bulletin, (22), pp. 520 - 537

Yao, Limin. (2001). The characteristics of effective teaching in colleges. Modern College Education. 


\title{
Studies on the Internationalized Higher Education
}

\author{
Li-juan Ren \\ International College, Bohai University, Liaoning Province 121000, China \\ Tel: 86-416-3400215 E-mail: rlj6661@hotmail.com \\ Zheng Tang \\ Faculty of Engineering, University of Toyama, Toyama 3190, Japan \\ Tel: 81-76-4456752Ｅ-mail: tang@iis.toyama-u.ac.jp
}

\begin{abstract}
As for the heated problem of the Internationalized Higher Education (IHE), the thesis makes a deep research stating the tendency of IHE and focusing on the strategy and the issues that must be paid more attention to in the realization of the Internationalized Higher Education (IHE).

Keywords: The Internationalized Higher Education, The globalized economy, The international exchange

\section{Introduction}

The globalized economy and information cause the reform that the traditional education or methodology has never experienced for thousands of years. It is self evident that education, especially for IHE has become the fact, which is as well the heated topic currently in the field of the higher education. Actually, the process of the acceleration of IHE is not only the only way but the measures that the higher education must take when encountering the irresistible external challenges to improve the competition in the world.
\end{abstract}

\section{The connotation of IHE}

Educators understand IHE in quite different ways because of the broadening respects of it. Different scholars give the different definitions towards IHE; however, they have many things in common. Generally speaking, there are two definitions concerning with IHE: one is that IHE is understood with a result. The so-called IHE should be an advanced, opening and vigorous system, an ideal university education modal which people look forward to in order to keep pace with time. The other one is that it is understood as a tendency or a process as for the traditional or closed education system. It focuses on not only the degree of being internalized but also the process of its realization.

The so-called internationalized higher education refers to in the guidance of the international consciousness and the opening concept the higher education in a country or the certain concrete university is the dynamics and a developing tendency which promote the mutual understanding in the international societies, accelerate the international scholar position, participate the international education affairs, promotes the reform of IHE through international multi-exchange, multi- cooperation and multi-help. In a word, IHE refers to a process or a tendency that the universities in the respective country on the scale of global has to stand in the country inside and face to the outside world. It is a tendency of multi-exchange, multi-corporation and multi-help that is across the countries, across the nations and across cultures.

The aim of it, for the country, is to accelerate the education quality, go to the international stage and cultivate a group of talents who are strong in the global concept and the time sense and, who have the broadened vision and are able to adapt themselves to any situations with the creative spirits to adapt to the country's various needing of development. For the whole world its terminal purpose is to realize the exchange and melting in different cultures to improve the human being's progress and develop through the mutual absorbing of the advanced cultural fruits.

\section{The tendency of IHE}

We can say that the concept of IHE is time-honored, however, up till now a new state and new tendency have appeared towards the world economy. The new development gives the higher education deeper and wider connotation and a new mission will be attached to IHE. The tendency of IHE goes rapid. We can find the cause resulted in IHE by analyzing the historical development.

\subsection{The globalized economy}

The globalized economy refers to the accelerating the mutual existence among the various countries in the sense of 
living and marketing under the condition of the globalized information and the marketing. The globalized economy promotes the across country flowing in human resources, bonds, goods, service, knowledge, technology and information, accelerates the optimizing equipment in productive elements and the resources and promotes IHE. The globalized economy is the materialist foundation. The relationship between economy and education is mutual existing and mutual restraint. When the realization of the globalized economy comes true, it must influence the education deeply and cause the education resource to accelerate the international corporation and exchange more closely and more frequently in the world and force the education resources in different countries to open to the outside world simultaneously.

The globalized economy brings at the same time the brain needing and the globalized standard on talent. Some experts find that in the time of the globlaized economy the two-thirds trade are dealt in the internal transnational corporation or inter-transnational corporation. The enterprise must recruit the brain on the global scale and send them to the different countries in the world. This can bring the international talent flowing, and can as well lead to the international standard on brain. The manager and the employer who are engaged in the trade across the country have to not only gain the proficiency of the rules about the international operation in economy but also know more about local politics, economy and culture. This is the fundamental requirement towards the quality of the talents, which the enterprises operate across the countries in the tendency of the globalized economy. In the wanting of the market objectively the globalized economy accelerates the internationalized education. That's the tendency, which cannot be controlled by people's personal willing.

\subsection{The globalized information}

The globalized economy promotes at present the science and technology rapidly. The modern net of information, which the main body is computers, televisions, and satellites, has combined the world with one entirety forming tendency of the internationalized information. It breaks the division between the countries and regions, the people's traditional concepts and the division in cultures. It provides the internationalized higher education with the necessary conditions. The convenient Internet converses the various universities in the world into a global scholar community, which causes a more and more closed relationship among the universities respectively. It makes easier in the exchange in academy, the mutual utility of curriculum and mutual understanding in concept, especially that the technology of computerizing Internet causes the reform in the higher education, i.e., the higher education is able to work facing with the whole world and eventually it can use for reference from the advantage of the modern net education.

\subsection{Internality of the higher education}

The education is generally regarded as a production in the world. Hence, the market in education is fiercely competitive. In particular, in the Western developed countries, the prestigious universities stand like a forest; the student resources are fiercely competitive. Because of the limited students resources and the declining of the government budget the higher education is eager to widen the education market abroad. Furthermore, the whole national economy and the other advantages makes easier to open the market in the developing countries. This phenomenon accelerates the internationalized higher education. Simulneneously the developed countries take the dominant position and play the leading role in the exchange of the international education. Having the aid of IHE the developed countries can strengthen the cultural permeating to the developing countries. In addition, in the international exchange of education the developed country can not only appeal many batches of the first-rate brain in the developing countries in a low price but also gain the tremendous profit in economy. In particular, the reform taken in the developing and undeveloped countries need guiding in education concepts, the modal in management in education and the education experience from the developed countries to make the native education vigorous. This as well needs international exchanging and cooperating, i.e., not only to improve the local education and gain some advanced technology and experience but also is useful in broaden the local people's vision and promote the opening to the outside world, make social progress and accelerate the process of the moderation of the society.

\subsection{Globalized issues}

Opening our eyes to the whole world we find that human being are facing with the globalized issues such as accelerating the difference between the poor and the rich, the regional wars, the degeneration of the environment, the population expansion and the resources exhaustion. It is difficult for any agency or a certain country to solve these serious problems. It needs the whole world's participation and cooperation. The education is not only the tool to win the victory in the global competition but also the historical responsibility that we human being take to make the earth develop better and more beautiful. Just according to a report pointed out from UNESCO Learning-the Wealth Concealing in It that "education has to take the special responsibility for building a more united world, however, as for the future various challenges that we have encounter, education seemingly is a necessary trump card which causes human being march on the road of peace, justice and freedom."

\section{The measures of realizing IHE}

IHE is a developing tendency including various concrete activities. The purpose of it lies in providing a kind of 
education experience, which can melt in the global sense. It includes three respects: firstly, it concerns with the international content in the curriculum; secondly it is the content concerning with the research and training in international exchange in scholar and students; finally it is the international technological favor and the scheme in the international cooperation.

\subsection{Concept of IHE and goal}

Comrade Deng Xiaoping said early in 1983 that education should be facing to the modernization, facing to the whole world and facing to the future. In fact, this needs to take an internationalized road. The prerequisite of accelerating the process of the internationalized higher education is to break the old thoughts and the traditional ideas. Some educators worry about that the internationalized higher education will pound at the local education and the local culture. This pounding will take the side effect. Although these worries are in some sense rational we couldn't see the negative side only, whereas, we'd better see the positive side. We have to see that IHE is the tendency in the social development, which cannot be centered on the people's willing and cannot be hindered by people. We must welcome it, adapt to it and make the full use of it minimizing the negative affect simultaneously. However the first task of making the education concept internationalized is to establish the training goal of the international brains which conforms to IHE and cultivate the brains who have the global vision, keep pace with time and competitive in the international stage. The quality of being an international person includes first, the international attitude including concerning with the earth, human being; adapting to the changes creating future; fair competition and friendly cooperation; self-respect with self-confidence; taking efforts to improve oneself; second, The international concept including the sense of international understanding, mutual-existence, the peaceful development and the international justice; third, the capability of international communication including the independent ability in thinking, the competence of participation, the ability of dealing with the information, the ability in life long learning, the ability of enduring the frustration and the competence of the international communication; fourth, the international knowledge including knowing the international current affairs, the history and tendency of the world development, the essence of oriental and Western cultures, the nation's central position and the role in the world; shouldering the mission of building the motherland and having the consciousness of serving the whole human being; finally, to gain the proficiency of at least one kind of foreign language.

\subsection{Internationalized curriculum}

In order to build the international education market we must provide the higher education with scientific and rational content of teaching and learning which should follow the international principles, for the cultivation of the brain is realized though the process of education. In other words, the quality of the education should experience the course structure and the teaching and learning. When the Western countries participate the internationalized higher education they take the reform in the course structure and the content of teaching and learning. In the United States in 1970s,in the curriculum of Bachelor education, the new courses of the Western Culture, the International Relations, The International Economy, The International Trade and the Studies on Third Worlds are compulsory. The Australian Curriculum Organization in the seventh plenary of the National Conference points out a new course concept_- the globalized curriculum saying that it is not a concrete course but a new concept towards the education and course focusing on the globalized consciousness in curriculum. In order to adapt to the internationalized higher education in the systematic education and the curriculum the universities have to take the reform. The measures are as follow: first, offer the international courses such as The International Politics, The International Economy, The International Trades, The Foreign History, Geography, The Costumes, etc.. second, add some knowledge in foreign advanced science and culture with their scientific and technological fruits; finally, select the most advanced text books in the world and appeal foreign experts and the scholars to be the visiting scholar.

\subsection{The market of study abroad}

The globalized economy is forming the international tendency in the higher education rapidly. Expanding the international market in study abroad has been the common strategy in the Western countries and America. The total amount of the students of study abroad is over 1 million. Among them half of it is in the United States. The average consumption annually is \$ 20 thousand, for they eat, stay and take the transport in America. This only can provide the United States with 10 billion bonds annually. The United States is a country which appeals to the most amount of students of study abroad and gets rewards most in return. Britain now is advocating building a superpower of students study abroad. Britain has been sponsoring the displays of education in the foreign countries to appeal most foreign students. Japan, the developed country is taking actively the measures to appeal to the foreign students This measure not only bring them with a lot of profit, but also cultivate a batch of first-rate brains who are the cheap "employers" "the part-time workers". These measures contribute more to the acceleration of the economy, science and technology in Japan. The developed countries today, evaluate the universities with the degree of the internationalized higher education of the students and faculties in the universities. They regard building the university across the country, developing the tele-education and promoting the international cooperation in scientific research and teaching and learning as their main tasks. 


\subsection{The international exchange}

IHE refers to making full use of the international education resources and making the native education resources open fully to the outside world to improve the education and the economy. The measures are as follow:

\subsubsection{Strengthening the international exchange with teachers}

It is an important road for the higher education to strengthen and to expand the international exchange with teachers and to export and import the resources actively. Exchanging is the root of the creation in academy. The academic life will be suffocated to death without the exchange, mutual complementing, striking and melting. As for the exchange in visiting scholars and visiting teachers, one way is to send them out, that is to send the skillful and noble scholars and teachers to the first-rate universities or scientific institutes to engage in the research in the advanced science and the fundamental science. In this way they are able to not only get and absorb a lot of latest knowledge, improve their foreign languages and improve their capability of handling but also learn a great deal of latest educative concept and methodology. Another way is to invite, that is to invite the famous scholar and the experts in the world to the local universities to teach and become the visiting scholar and to have the seminar or to cooperate with the academic institutes to have the further researches, to have the academic discussion. This is useful not only to avoid the popularizing of the out of moded and irrational structure in knowledge but also to weed through the old to bring forth the new by way of adopting good advice from all quarters and achieving mastery through a comprehensive study. In this way it can make the new increasing pointing in the academic studies forming the good recycle in the higher education with scientific research and make the advantages mutual-complement.

\subsubsection{Strengthening the multi-cooperation in academic research}

Since science and technology develops rapidly the respective country have its own advantages with its disadvantages so long as the universities strengthen the exchange and carve and polish each other they can learn from each other to make up progress and contribute to the education and scientific development. According to the developing tendency and through observing the situations at the present the multi-cooperation among the universities includes mainly the universities in different countries have to open each other, make interuniversity exchange in academy, issue the thesis in the prestigious academic periodicals abroad, make the financial help to invite the colleagues abroad to participate the local research of the big-sized science and technology item, the designing across the countries and sponsor the relevant scientific research subject to pursue together. Build the information net according to the subject and major making the mutual-complement and mutual-help in the international education resources. Strengthen the cooperation between the researchers research institutes and the corporation cross the countries. Sponsor the international seminars.

\subsubsection{Accelerating the international setting up education in cooperation}

With the development of the international exchange and cooperation in higher education the international cooperative setting up education a new force of international cooperative setting up education in higher education suddenly comes to the fore, and it develops rapidly. In1980s, a great upsurge in setting up education across countries was taken in the Western and American countries. There fore mainly four sorts of international cooperative setting up education: first, the developing countries are actively looking for opportunities of cooperative setting up higher education with developed countries. Second, developed countries want to cooperate with developed countries in higher education. Third, developed countries cooperate with developing countries in setting higher education. Finally, Local universities establish the brotherhood with universities, the academic institutes in foreign countries sending students and teachers to the target cooperative universities to have further study and research.

\section{The problems in accelerating IHE}

IHE is slow in development. It is not advisable for any educators to be prompted by sudden impulse in setting up IHE. However, it is also not advisable for us to wait passively. It will bring the tremendous damage to the career of the higher education. We must promote IHE with an active attitude. So there are four issues that we have to pay attention to:

\subsection{Paying much attention to the humanities education}

To be national is to be international. IHE should embody the utility that the native education absorbs from foreign educations, the locality, and the nationality that the local education forms, becoming the export country in higher education again and finally the cultural exchange become mutual. The Principal of French Normal University Aolu takes the view that the loss in multi-cultures will bring about the affects to the development of human knowledge. If cultures are assimilated, it will fail to develop further.

\subsection{Keeping its own characteristics without imitation in reform of higher education}

We have to avoid losing the original advantages which adopts to our education when accelerating the process of IHE and keep off the draw backs of the traditional education. The locality and nationality of higher education cannot take the place of IHE, or cannot make the excuses of the systems lag behind and denying the advanced culture. Internationality cannot deny the nationality, but should strengthen the characteristics of nationality and promote it to the international 
degree in characteristics forming a tendency of going forward one by one. The two parties should be co-existed and contradictory. So long as higher education takes the road combined the nationality with the internationality higher education is able to occupy a pivotal position in IHE. The authentic IHE is to keep the national characteristics and curry out according to the international rules but not the colonial education.

\section{References}

Liu, Hai-feng. (2001). The Localization and Internalization of Higher Education. P.21.

The Internationalized Higher Education Is a Tendency, Wenhui News Paper.

The UNESCO Organization learns to survive_-Today, Tomorrow of the Educational World, Education and Science Publish House.

The history of Higher education in America, Fujian Education Publishing House.

Tony Spybey. (1996). Globalization and World Society, Polity Press in association with Blackwell Publishers Ltd, P.102.

Yang, Dong-ping. (2000). University Spirit. Liaohai Publishing House. P. 123. 


\title{
The Research on Several Critical Issues in the Development
}

\section{Of Higher Vocational Education}

\author{
Yufei Long \\ Daqing Petroleum Institute, Daqing 163711, China \\ Tingqin Zhang \\ Daqing Petroleum Institute at Qinhuangdao, Qinhuangdao 066004, China
}

\begin{abstract}
Based on the pondering over the establishment of a large educational concept, the implementation of "two-certificate" system, the training of "Double -Professional title teacher staff and some other issues in the development of the vocational and technical education personnel training mode, this paper discusses the issues about their content, significance and the full understanding of them in the new situation in order to promote the healthy development of higher vocational education.
\end{abstract}

Keywords: Higher vocational education, Educational view, Personnel training mode, Double certificate, Double -Professional title teacher staff

To adapt to the demands for application-oriented talents in the socialist modernization Construction, Higher Vocational Education, through hard exploration and practice, has gained preliminary experience, such as: we gradually explore the guiding ideology and the school system with the characteristics of vocational and technical education schools. We have launched the comprehensive construction of a system of "double professional title teachers and "two certificate" students. We have implemented the personnel training mode which centers on the vocational ability to enhance the qualification education. We have opened the entrance channel to enroll students from the Secondary Vocational Technical College. We have established the communication and convergence between the regular higher education and higher vocational education. But it is necessary to further enhance the understanding and the in-depth discussion about the development strategies on the higher vocational education gearing to the new century, and to continually improve the development strategies in order that the higher vocational education can develop on the right track with high quality, high efficiency and distinctive features.

\section{Fostering a large-system education concept to train higher application-oriented professionals}

To meet the challenges of the new century and to comprehensively enhance the students' qualification education, the development of higher vocational education needs the involvement of all society. Therefore, to develop higher vocation education, it is necessary to foster a large-system education concept. The higher education system is the major subsystem of the whole social system and the core of the economy-based social system. The general higher education and the higher vocational education are the two intersecting and complementary subsystems in the core system. In the era of knowledge economy, the core system is necessarily the momentum of the forward development of the overall social system and the entire social system has to operate on the core system consisting of the general higher education and the higher vocational education. Currently, the development of the higher vocational education has obviously lagged behind that of the general higher education, which has seriously affected the transferring speed from science and technology to productive forces. Therefore, in the entire social system, all the resources available for the development of the higher vocational education (talents, funds, equipments, training and practice fields etc.) should become the normal teaching conditions and means of the higher vocational colleges. We must continuously promote the improvement and development of the higher vocational education through the interaction within the entire social system. To guarantee the sustainable and healthy development of the higher vocational education, we must upgrade the sense of quality, change the concept of input, and remodel the criteria of evaluation.

\subsection{Completely updating the awareness of the higher vocational education quality}

Objectively speaking, our county's higher vocational education is sponsored for a short time and lack of the teaching conditions and experience; Subjectively speaking, many people despise the vocational education, and especially in the circumstances of college's expanding enrollment, they are more concerned about the quality of the higher vocational education. Therefore, we must thoroughly update the awareness of the higher vocational education quality and establish 
new evaluation standards.

How to treat the quality of the higher vocational education and especially the quality after the college's expanding enrollment? We should dialectically understand the issue from three aspects:

Firstly, assess the quality of the higher vocational education from the needs of the whole community. Expanding enrollment will inevitably lead to the result that some candidates of lower scores are recruited, but this is only a partial problem. In a perspective view, the candidates of high scores still accounted for over $80 \%$, and we are able to ensure the overall level of quality if we strictly control the education quality of the candidates with lower scores, "slow students" who accounted for about $20 \%$. This is not only able to guarantee the quality level of those normally-enrolled students, but also to cultivate more talents and improve the whole quality of our nation, which is also in line with the international trend. Therefore, we should evaluate the quality of the higher vocational education from the demands of the whole community for continuously improving the quality of the whole nation.

Secondly, treat the quality of the higher vocational education in a dynamic view. The development of the higher vocational education needs expanding enrollment, meanwhile the temporarily insufficient equipments and teacher resources may lead to poor quality. But in the long run, if the scale is developed, coupled with scientific management, it will have huge benefits, which leads to the magnification of teaching inputs, in turn, it will promote the improvements of the teaching quality. Therefore we should treat the quality of the higher vocational education in a view of development, dynamic, and comprehension.

Thirdly, measure the quality of higher educational education from the perspective of practical application. We need an objective standard to evaluate the quality of higher vocational education. Evaluation of different things is bound to have different standards. The different training goals between the higher vocational education and the general higher education should lead to different quality evaluation standards. The evaluation of the students in higher vocational schools depend on their structure of knowledge, theories of subjects, and their abilities of transferring the scientific and technical achievements into productive forces. At present, our county's general higher colleges, especially the famous universities produce very small amounts of students. The undergraduates and postgraduates, elites of the college students, are far from satisfying the community's demands for qualified personnel. Therefore, we should inspect the qualification of higher vocational education from the view of practical application.

\subsection{Fundamentally changing the concepts of higher vocational education inputs}

In order to expand the size of higher vocational schools, we must have the most basic conditions for running schools. When the state and local governments input insufficient funds, we should use all available channels to raise money to expand the size of higher vocational colleges. In particular, the construction of logistical facilities should absorb all social investment funds to complete the structure of education system and to strengthen the functions of education. We should advocate and implement the socialization of logistical services in order that we can completely solve the "bottleneck" problems. Then the funds can be saved for the teaching equipments, the improvements and construction of practice bases, and the purchase of library materials. Only in this way can we ensure the scale, efficiency, and quality of the higher vocational education and form the virtuous circulation.

\subsection{Rebuild the evaluation criteria of vocational education conditions}

Vocational education can not only develop the teaching conditions in the education system, but it also must be placed in the overall social system, adhering to the principles of advantages complement and resources sharing and making full use of the education resources in the entire social system as the an important parameters to evaluate the means of the higher vocational education. This will help our country to do a great education, to break the traditional school patterns, and to cultivate the students' initiative spirits and entrepreneurial skills to serve the economic developments. Therefore, the assessment of teaching conditions of the higher vocational education mainly lies in whether the students have made use of the proper teaching software and hardware, but it doesn't matter whether the hardware belongs to the school or not.

\section{Fully understand and implement the system of "two certificates" or "multiple certificates"}

Practice has improved that implementing the system of "two certificates" or "multiple certificates" helps to upgrade the students' comprehensive qualification, abilities, and the competition for employment. From 1993, our college has launched full implementation of the "two certificate" system. But the grades of the students' certificates are at a relatively low level and far from satisfying the demands of the employers and the knowledge-based era for the qualifications of application-oriented personnel. Here we only take the National Computer Rank Examination as an example, large numbers of students only can achieve the certificates of level one or two but rarely the high-level certificates. This will certainly affect the quality of personnel training in college. More importantly, this will also affect the image of higher vocational schools.

Based on the high school education, our higher vocational education cultivates the high application-oriented personnel 
with the comprehensive vocational abilities and qualifications for the production, management, and service lines. It is equivalent to the LEVEL5B of International Educational Standard Classification presented by the UNESCO. Not only the certificates of the high college graduates should meet this standard, but the "two certificates" or "multi-certificate" should meet with the relevant standards. Currently, students in vocational colleges should receive a vocational qualification certificates which only the students accessing to high school education can achieve. Then it is worthy the name of "two certificates" or "multiple certificates". Therefore, our higher vocational colleges should develop corresponding institution, and meanwhile our state labor department and personnel department should also develop the eligibility criteria in line with the standard of LEVEL5B and clarify the standards in the original standard ratings that reach the LEVEL5B so that the students in higher vocational colleges clearly know how to achieve the "two certificates" or "multiple certificates". This is also in line with the international requirements.

\section{Develop the teacher group of “double teacher" in light of the actual}

Teachers group is the key to the realization of higher vocational education programs and is also the key to the characteristics of higher vocational education. In the process of developing teacher group of "double teacher", some higher vocational college has advertised for a number of personnel as professional teachers to enrich the teacher group, which has played a positive role in developing the teacher group and improving the education quality in higher vocational colleges. In the long run, we should enhance our understanding of this approach in light of the actual situation of our county's higher vocational education.

1) "Double---professional title teachers" is not only the requirement for the teacher group but for the teaching means to reach the personnel training aims, that is, the students of higher vocational college approach the requirements of training aims through accepting the "double teachers" education. This can be completely accomplished by learning, experimenting, and practicing the expertise. This cannot be accomplished by an individual "double teacher" teacher who has mastered both theories and practice, but by the whole group of "double teachers" teachers of a higher vocational college.

2) With the rising of young teachers' professional theory level, the continual emerging of new jobs, and the advancing of technology in these jobs, it is relatively more difficult for these young teachers to reach the "double teachers" requirements in their professions. But students can fully accept the "double teachers" education through learning theories and practicing in the practice field.

3) In the provincial colleges, it is not realistic to require the teachers to be both a "lecturer" and "engineer". (accountant, economist and etc.) These teachers are only reaching the requirements of lecturers in title assessment, and far from the requirements of engineers. But this can be made up by constructing the training base and hiring the teachers who have reached the requirements of engineers. Therefore, we have to construct and perfect the training base, and improve the quality and professions of both the teachers in the courses and the instructors in the training bases so that the students can actually accept the "double teachers" education.

In short, nowadays in the study of the model of vocational personnel training, it is necessary to further reflect on the content, extension of these key issues in light of the new situations and the new requirements so that the higher vocational education can have a healthy development.

\section{References}

Huang, Riqiang \& Zhang, Xia. (2004). On the Mutual Participation of Vocational Education and Enterprise. Vocational and Technical Education, 2004.16.

Leng, Yunxia. Study on Professional Qualification Certificate System Implemented in Vocational Schools.

The constitution of People's Republic of China. (2005). Beijing. China Legal Publishing House: 13.

Yan, Bing. (2005). An Analysis of Educational Model and Features of Talents In Higher Vocational Colleges. Heilongjiang Researches on Higher Education. 2005, 08.

Yu, Jianmei. (2006). Application of Vocational Self-efficiency Theory to Vocational Chinese Teaching. Journal of Sichuan University of Science and Engineering, 2006.04.

Zeng, Yuqing. The Research on the Orientation of the Development of Higher Vocational Education in China. 


\title{
Trying to Meet the Demands of English in a Global Market A Critical Discussion of the National Bilingual Programme in Colombia
}

\author{
John Wells \\ Cra. 8 Bis A no. 148 - 81, Bogota, Colombia. \\ Tel: 5716265812 E-mail: wells.mr@gmail.com
}

The work for this paper was carried out in Bogota, Colombia by the author. It is largely based on the assignment for the module "Educational Policy: Theory and Practice" that he submitted as part of the Doctorate of Education (EdD) offered by the University of Bath, Bath, England.

\begin{abstract}
This paper provides a critical analysis of the National Bilingual Programme in Colombia. It considers how and why it aims to extend the teaching of 'a' foreign language in Primary and Secondary school in 1994, to the teaching of English to an internationally recognized standard in all sectors of education by 2019, while at the same time attempting to promote the bilingual education of the Creole and Amerindian speaking sections of the population. It suggests that although some of the aims of the programme are being met, the contexts in which it is being implemented are too diverse and the aims too broad for the programme to be implemented successfully in its current state.
\end{abstract}

Keywords: Bilingual, Policy, English, Global, Decentralized, Amerindian, Culture

\section{Introduction}

Colombia, like many countries, is promoting the learning of English among its population to meet the opportunities and demands of functioning in a global society. To facilitate this, in 2004 the National Ministry of Education of Colombia embarked on the National Bilingual Programme.

The National Bilingual Programme (NBP) is to be implemented nationally in two phases. The first (2004 - 2010), according to the Minister for Education, seeks to provide students in Primary and Secondary levels of education with a "basic knowledge of English as a Second Language" and students in higher education with a "good knowledge of the language" (Altablero No. 37, 2005 page 2E). In the second phase of the programme (2010 to 2019) "the aim is to develop bilingualism in the country" (ibid. 2E). But, what is meant by a "good knowledge of the language". This will be addressed in section 1.3, but we also need to question what the Minister means when she aims to "develop bilingualism" ... "in the country". The latter phrase, similar to the use of "national" suggests that there is a single programme which is being implemented uniformly, yet more than $50 \%$ of the LEAs have not started to introduce it three years after the programme was initially launched. Furthermore, the very use of the term "programme" presupposes a series of actions which, when put into effect, will lead to a given end. In all this, the National Ministry of Education (NME) has limited itself to specifying the criteria to be used to evaluate the outcome of the "programme" (in reality, the second stage), but it is the LEAs which need to implement it in accordance with local conditions and resources. Finally, the term "bilingual" is not addressed in detail by the National Ministry of Education. On the one hand, it seems to conflate a developed level of English with a certain degree of cultural awareness to signify a bilingual individual, without specifying how schools or LEAs are to move from improving the level of foreign (or English) language teaching to provide bilingual education, nor how the programme and its effects on students should be assessed from a bilingual perspective. And on the other, it considers the provision of bilingual education in communities where Spanish is taught to speakers of a Creole or Amerindian language, thereby applying the term 'bilingual' to two contexts which are not mutually compatible. As a result, rather than talk about "a" or "the" National Bilingual Programme, there are probably as many "bilingual" programmes at the moment as there are LEAs, none of which seem to directly address the provision of bilingual education.

But the purpose of this paper is not to analyse the differences in the roles or functions of the National Ministry of Education and the Local Education authorities, though they cannot entirely be ignored, but rather conduct a critical analysis of the provision of the National Bilingual Programme and consider the appropriacy of the discourse in the programme and the extent to which its implementation is viable in the context of current conditions in state schools. To do so, I will begin by providing a brief synopsis of information about Colombia, its economy and its people so that the complex variables which have influenced the formulation and provision of the policy to date are better understood. 


\subsection{Colombia - the economy}

Colombia is often associated with steps being taken to combat the drug trade or the violence which is instigated by left wing guerilla factions or right wing paramilitary groups. These factors have had implications throughout the country, with concern about travel out of major cities because of the danger of attacks or kidnapping and reluctance to invest in industry from foreign investors resulting in a lack of economic growth up until a few years ago (UNCTAD, 5:2006). However, since 2002 there has been a reduction in terrorist attacks and this, in addition to other factors, has contributed to increased economic development. In 2004 the economy expanded by $4.8 \%$ and in 2005 by $5.2 \%$ of the GDP (Energy Information Administration). But in 2006 it rose to $6.8 \%$, the greatest increase that the country has see in thirty years (El Tiempo, 24 ${ }^{\text {th }}$ March, 2007, page 1). It would seem that increased national security, coupled with confidence in the government of Alvaro Uribe Velez, the first independent president in Colombia's history, have made it possible to make the most of Colombia's location and natural resources. Colombia is the only country in South America which has coastlines on the Pacific Ocean and Caribbean Sea (as well as with five other countries in the region). It has natural reserves of oil, coal, emeralds, gold and silver as well as agricultural products for export such as bananas, coffee and flowers. It has mountain ranges with the capital, Bogota, at 2,600 metres above sea level with temperate weather and vegetation associated with Europe, and as one gets closer to sea level, so one encounters tropical flora and fauna and industry associated with a country bordering the equator.

Colombia has been involved in opening up trade with countries in the region and its president has just signed a free trade agreement with his counterpart of the United States of America, which needs to be ratified by the Congresses of both countries. This has occurred in the wake of foreign investment in Colombia growing substantially over the last couple of years with significant company takeovers and the buying of state industries by companies from the United States and Europe. The largest of these was the buying of the Colombian beer company, Bavaria, by SAB Miller in 2005 for $\$ 3.5$ billion. This is coupled with greater attention being given in Colombia to promoting tourism by drawing attention to colourful yearly carnivals in many of the major cities as well as a variety of conferences and events which take place in one of Colombia's tourist sites, Cartagena. However, despite economic growth and increased foreign investment, unemployment in Colombia is still in double figures, and at the end of 2006 rose from $11.5 \%$ to $12.7 \%$ (National Colombian Statistics, p.5). Here, it is worthwhile to refer to Brown et al (2003:111), who make the point that employability is a two way process, in the sense that opportunities need to exist for people who are appropriately qualified. At the moment, it is not possible to say if there are problems with appropriate vacancies for the population, or if workers are not sufficiently well qualified.

\subsection{Colombia - The people}

The official language of Colombia is Spanish and the vast majority of its 42 million inhabitants speak this as their first language. However, almost one and a half million claim to be of indigenous descent (Government census, 2005 p.2) and speak one or more of the 79 American Indian languages that are spoken by different ethnic tribes in Colombia (in Altablero, no.37, it is stated that there are 65 Amerindian languages spoken by 400,000 people). In addition, there are just over four million people who are of African descent, of whom approximately 60,000 live on the archipelago of San Andres, Providencia and Santa Catalina, and speak a form of creole based on English, and Spanish (Velez-Rendon, 2003:186). Accordingly, Colombia has a rich ethnolinguistic and cultural capital which is reflected in bilingual programmes in some areas of the country which seek to maintain their cultural heritage.

The insecurity that Colombians have been subjected to over the last fifty years or so has left its mark on the mobility of the population. It is estimated that between two, and three and a half million people have been displaced by the violence (UNICEF) and $49.2 \%$ of the population lives below the poverty level. (This is reflected by the way in which zones in cities are stratified for paying the services of electricity, water and gas; there are six "status" levels, with "one" being the lowest and "six" the highest.) These, and other factors, have had ramifications for the school population so that in 2004 only $55 \%$ of the school population were staying to finish secondary school (UNESCO).

\subsection{Colombia - current levels of English in education}

The upper classes, those that belong to "status" levels of 4, 5 and 6, generally send their children to private schools which, increasingly, offer bilingual education in English or have intensive English classes (however, there are also private bilingual schools which function in German, French and Italian, and are part funded by the respective governments of the countries where these languages are spoken). A growing number of these schools enter students for EFL exams provided by UCLES (often requiring that they pass the First Certificate Exam) or the American suite of EFL exams such as TOEFL. The passing of these exams demonstrates a level of competence in a second language equivalent to B2 (advanced independent user) as set out in the Common European Framework for Language, which is described thus:

Can understand the main ideas of complex text on both concrete and abstract topics, including technical discussions in his/her field of specialisation. Can interact with a degree of fluency and spontaneity that makes regular interaction with 
native speakers quite possible without strain for either party. Can produce clear, detailed text on a wide range of subjects and explain a viewpoint on a topical issue giving the advantages and Independent disadvantages of various options. (2005:24)

At present, experience suggests that many students at these schools not only achieve this level, but actually exceed it. On the other hand, students that come from the other "status" levels not only fail to reach this level of English, but are not even close to achieving the previous level of English (B1), described below, which the NBP has set as the aim for students leaving state schools in 2019: Can understand the main points of clear standard input on familiar matters regularly encountered in work, school, leisure, etc. Can deal with most situations likely to arise whilst travelling in an area where the language is spoken. Can produce simple connected text on topics which are familiar or of personal interest. Can describe experiences and events, dreams, hopes and ambitions and briefly give reasons and explanations for opinions and plans. (2006:24)

In 2005, to provide a benchmark by which to plot progress of the provision of the NBP, a sample of 3,759 students in $8^{\text {th }}$ and $10^{\text {th }}$ grade at state schools in 11 departments in Colombia, and 3,422 teachers were given a diagnostic test in English. This was administered by the National Ministry of Education in conjunction with the British Council and its findings were worrying; results showed that only $6.4 \%$ of the students in the year prior to leaving school had the B1 level of English, while only $10.5 \%$ of the teachers had the necessary level of English to teach to this standard (http://www.minieducacion.gov.co/1621/article-97594.html). This led Jan Van de Putte, ELT manager at the British Council, Bogota, to comment that the level of English in Colombia was "appalling" (Moloney in theGuardian Weekly, $17^{\text {th }}$ November, 2006) . But why is this so? Students tend to receive two or three hours a week of English instruction from $6^{\text {th }}$ grade which means that they receive approximately 720 hours of language instruction at secondary school. The Minister of Education claims that this is sufficient for students to reach the intended B1 level of competence so obviously, it is suggested, something is going wrong in the class (Altablero op.cit p.2E). The survey which was conducted of the teachers seems to provide a basis on which the Minister made this observation. First, there is their insufficient command of English but, more to the point, it was found that while many of them have a significant amount of teaching experience (between 15 and 20 years), they may only have two or three years experience of teaching English. However, in addition to the information put forward in Altablero, there are also several other factors that should be taken into consideration. First, there are the conditions in which lessons are held; there tend to be between 40 and 45 students in a classroom which may not have a tape-recorder and the teacher has access to limited resources. This condition is not entirely amenable to developing communicative skills in a foreign language and the point made here is echoed by Valencia Giraldo, who writes specifically about the state school context in Colombia:

Considering that public school students spend only a few weekly hours dedicated to 'learning' the language in conditions that are, in most cases, not conducive to language learning, the proficiency that they achieve in English is unlikely to provide them with access to job opportunities. (2006:8)

In addition, it has been suggested that "two factors responsible for the low levels of participation in secondary education in Latin American countries are loss of interest on part of parents and students because of high repetition levels and perception that the quality and relevance of secondary education is slow" (World Bank, 2005:48). These points are synthesized by Velez-Rendon, who points out that as well as these, there are other social factors which limit the success of EFL teaching in state schools, such as "gang violence, lack of support and resources, overcrowded classrooms, lack of adequate space and quality materials, and low morale" (Velez-Rendon, 2003:192).

It is against this backdrop of teachers that do not have a high level of English, who are not always qualified to teach English, students who are not interested in learning English and classrooms which are over populated and often under equipped, along with social issues such as homelessness and poverty, and cultural issues such as indigenous minorities that speak Amerindian languages or sectors of the population that speak a creole form of language that the National Ministry of Education is asking LEAs to implement the National Bilingual Programme. In order to consider how this is being done it is now necessary to appreciate the educational structure of Colombia, after which I will set out my rationale for providing a critical account of the regulation and provision of the NBP.

\subsection{Colombia - Education}

The Colombian education system is formally decentralised in the new constitution of 1991 and greater specification of the role of the government in Education is provided in the decrees and laws which, together, are known as the General Education Law. This law sets out how education is to be conducted by providing specific guidelines on curriculum issues and the governance of schools. Amongst other issues, it states that education is stratified according to age with one year in Pre-school nine years in "Basic" education (five in Primary and four in lower Secondary), and then two years of "Medium" Education (being the last two years of school) before going onto "Superior" Education, which includes Colleges of Technology and Universities. It also states that the minimum school leaving age is 15 , which should provide students with the opportunity to complete "Basic" Education (Article 19 Law 115 and Article 67 of the Colombian Constitution of 1991). 
Concerning the decentralization of education, the LEAs need to apply for certification based on criteria which were initially set out in Decree 2886 of 1994, but were amended by Law 715 of 2001 . A summary of this update can be found in the World Bank document of 2005. With regard to this, and comparing Colombia to other countries in the region, Carnoy (2002:299) writes "reforms in other countries, such as Colombia, shifted gears quickly, but for a different reason. Without waiting to learn the lessons of the finance-driven educational reforms, municipalities and teachers changed the decentralization reform to make it more competitive and equality driven". Here, it seems that Carnoy is echoing a National Ministry of Education article in Altablero no.8, namely that ".... resources should take into account the population that has been seen to and that which needs to be seen to, the distribution between the urban and rural population, that is, equality and efficiency" (my translation)

(http://www.mineducacion.gov.co/1621/article-87441.html). In addition to the budgetary implications here, the Ministry adds that there are three other purposes in amending the Law 60 of 1993 (which Decree 2882 is based on). These are to take the process of decentralization one step further, clarify the responsibilities between different levels of government, and provide educational institutions with better tools to serve the needs of the community. These factors point to, once again, inherent difficulties in instigating the National Bilingual Programme.

\section{Approach to analyzing the National Bilingual Programme}

To foreshadow some of the complexities of analyzing the NBP, particularly its implementation, it is tempting to refer to Foucault in Ball when he writes "I wouldn't want what I may have said or written to be seen as laying any claims to totality..... I am still working and don't yet know whether I am going to get anywhere” (Ball, 1995:255). It has already been suggested that there is a myriad of factors which needs to be taken into account here, and the ongoing nature of the Ministry of Education having to convince LEAs to implement the programme does little to facilitate the analysis of this policy (see section 2.5).

In setting out where the policy stands with regard to educational theories, I am more than aware of the observation that Parelius and Parelius (1987:14) make when discussing Consensus Theory and Conflict Theory that "no set of concepts is sufficient in itself to illuminate and organize all the complexities of social life". Instead, I am employing a more pragmatic approach to critical policy analysis and will attempt to incorporate as many variables as possible. Ball suggests that:

Abstract accounts tend towards tidy generalities and often fail to capture the messy realities of influence, pressure, dogma, expediency, conflict, compromise, intransigence, resistance, error, opposition and pragmatism in the policy process. It is easy to be simple, neat and superficial to gloss over these awkward realities. (1990:9)

Experience of education in Colombia suggests that even when LEAs and schools are willing to put policy (vis. The National Bilingual Programme) into practice, there may be factors which delay or hinder this. Large LEAs have various Local Education Academic Centres, known by their acronym CADEL in Spanish to liaise with schools and provide guidance on the provision of policy. There are about 10 of these in Bogota, and the one responsible for implementing the NBP in the suburb of Usaquen has selected a new school to serve as a pilot project. However, while this has not received sufficient textbooks, the teachers are undergoing training in applying the grading criteria, there is no written curriculum for English and parts of the school are still being constructed, there is an incredibly positive approach to implementing the National Bilingual Programme within the school and the community (Note 1).

It is obvious, then, that a comprehensive framework needs to be employed when analyzing policy; the more factors which are included, the more complete the analysis will be. Taylor et al go some way towards establishing a framework of factors to be considered when analyzing policy by putting forward six vignettes, namely that;

1) Policy is more than text,

2) Policy is value laden,

3) Policies exist in context,

4) Policy is a state activity,

5) Education policies interact with policies in other fields, and,

6) Policy implementation is never straightforward.

(Taylor et al, 1997:15-17)

However, they do so without taking into consideration the effects of globalization or the myriad of factors present in a developing country, such as Colombia. As a viable alternative, I would suggest that both Dale and Vidovich put forward conceptual frameworks which allow for the best analysis of the NBP. Dale, in his "Governance of Education" diagram (1997), provides a general framework which includes the "three forms of what is usually referred to as 'state intervention"” (ibid: 275). These are regulation, funding and provision. By analyzing the National Bilingual Programme under these headings, the complexity of it will become a little clearer. This is to be complemented by the conceptual 
framework set out by Vidovich (2001) who, under the headings of "Context of Influence", "Context of Policy Text Production" and "Context of Practice/effects" sets out questions (see appendix) for the policy analyst that are wide ranging and refer to many variables which influence the procedures of regulating and implementing policy. She does this by "borrowing" from modernist and postmodernist approaches to education and then adapting elements of the policy cycle of Bowe, Ball and Gold (1992) to put forward "a conceptual framework ..... with a focus on contexts of influence, policy text production and practices/effects" (Vidovich, 2001:12). In doing so, she provides some "specialized 'tools' for policy analysis" which seem to go someway towards filling the "large conceptual tool kit" which Parelius and Parelius call for (1987:14).

\subsection{Funding of the National Bilingual Programme}

Little reference is made to sources of funding for the NBP in the literature, but some is available from the National Ministry of Education for the training of some teachers through institutions such as the British Council. In addition, the National Ministry of Education provides funds for provision of teaching materials such as computer software and audio visual learning aids. The budget for this more than doubled between 2005 and 2006, increasing from 650 million pesos to 1,750 million pesos (Note 2.). But most of the funding comes directly from the LEAs and is currently being used to increase the teachers' level of English at language courses at university or language institutes and enter them for the Cambridge First Certificate exam as well as send them on training courses at local universities. However, there are not sufficient funds to continue entering teachers for the First Certificate language exam and the NME is currently developing in-house exams, which are to be internationally validated, to assess whether or not candidates meet the required B1 level upon leaving school or the B2 level for leaving university. In addition, concern has been raised that the budget for the NBP in the Ministry and the LEAs is not sufficient and this could have negative repercussions for the full provision of the policy.

\subsection{Context of Influence}

The National Bilingual Programme largely addresses the need to improve the level of English at school and, by extension, in the work place. It seems that this is largely due to the belief that in order to succeed in a globally competitive world, it is a command of English which is essential. This point was made by Hernando Jose Gomez, one of the Colombian negotiators with USA when designing the terms of the Free Trade Agreement which was signed in 2006, who suggests that bilingualism should be high on the agenda of Colombia in the forthcoming years in order to improve its competitiveness in the global arena, and points to the success of India in attracting business as a result of having qualified, bilingual workers (Altablero no. 37 p. 15). He is accompanied by five other leaders of industry who, on the same page, underline the importance of workers having a basic knowledge of English in the face of the pressures of globalization. Some LEAs, notably those of Cartagena and Huila, already seem to be acting on this and have developed programmes specifically with a view to preparing students to work in tourism when they leave school (Altablero no. $37 \mathrm{p} 12 / 13$ and p16/17). These points are a reflection of the observation that "the quality of a nation's education and training system is seen to hold the key to future economic prosperity" (Brown and Lauder, 1997:172) and "....another consequence of globalization (is) the tendency to treat languages as economic commodities... individuals who command two languages are attractive to businesses competing in multiple, or multilingual markets" (Block, D and Cameron 2002:7).

The promotion of foreign investment in the economy and development of trade with other nations is also what motivated Chile to develop a similar programme named "English Opens Doors", where the Chilean government expects all "elementary and high school students to be able to pass a standardized listening and reading test a decade from now" (Rohter in New York Times, $9^{\text {th }}$ December, 2004). Like Colombia, this has just been started and has a ten year time frame. However, it differs from the National Bilingual Programme in several respects. First, Chile does not have decentralised education, so the English Opens Doors programme is being introduced uniformly by the Ministry of Education. Secondly, it is able to attract volunteers from the United States to help teach, thereby providing native speakers of English to act as role models (this strategy does not seem to have been considered by the National Ministry of Education in Colombia, but it could be that the violent reputation that Colombia unfortunately has would deter many potential volunteers). Thirdly, Chile does not seem to have the same number of ethnic tribes speaking Amerindian languages as are found in Colombia (Note 3). As a result, and by only addressing improving English, it avoids some of the confusion in implementing its language policy that Colombia has to deal with.

\subsection{Context of Policy Text Production}

Regulation of the National Bilingual Programme can be traced to a combination of the NME putting into effect some of the requirements of the National Constitution of 1991, the General Law of Education of 1994 and also a perceived need for Colombians to have a good command of English because of the effects of globalization. But this does not account for why the programme was launched in 2004 and not before. One reason that may account for the timing of its launch is that the National Bilingual Programme seems to have its antecedents in the programme entitled "Bilingual Bogota" (Bogota Bilingue in Spanish) which was introduced in 2001 by the current Minister for Education,who was then 
working for the Bogota Local Education Authority. Bogota Bilingue was officially launched in 2003 (note 4), but was not fully taken up until 2006, when it was launched again with the backing of Jose Abel Valoyes (note 5) a councilor on the city council. It would therefore seem that the naming, if not the content and provision of the National Bilingual Programme is based on an earlier, smaller scale bilingual programme which was devised with the needs of the capital in mind. Needless to say, in a country with diverse regional, class and cultural differences it would be necessary to make changes to the provision of the programme in order to satisfy local conditions, and this is what the regulation of the National Bilingual Programme contemplates. However, in doing so its "national" nature starts to become fragmented as LEAs which take it up interpret policy so it is best suited to local conditions.

The NBP places a great deal of emphasis on the development of English as the second language in Colombia and barely mentions other languages. But for some stakeholders foreign languages should be valued and included in the bilingual programme and it has been suggested that, as German, French and Mandarin are also of importance for the workforce these should not be neglected at school (Note 6). But of greater concern is the situation of the speakers of Amerindian languages. In issue no. 37 of AlTablero, under the heading 'Advances in indigenous bilingualism' we find the comment "in addition to strengthening quality, breadth and efficiency, bilingualism is being implemented in educational processes developed for indigenous people through the teaching of their own language and the introduction of Castillian as a second language" (2005:18 my translation). Two issues are raised here. One is that, unlike instances of juxtaposing the term 'bilingual' with 'English', there is clear, if limited reference to how bilingual education will be provided for speakers of Amerindian languages. The other point is that no reference is made to the learning of English by these speakers. In other words, it appears that bilingual education for the Amerindian speaking section of the population is different to the rest of the population of Colombia. This is yet another observation that serves to query the validity of the 'bilingual programme' being prefaced with the adjective 'national'

\subsection{Regulation of the National Bilingual Programme}

Although the genesis of the NBP can be found in the National constitution of 1991 and the General Law of Education of 1994, its aims have developed in two or three important ways beyond what is stated in these documents. It has moved beyond the General Education Law (Law 115) of 1994, where students in Primary and Secondary school must acquire reading and conversation skills in a foreign language (Note 7) (my emphasis) to now be in English. Furthermore, there are now language attainment levels that need to be reached, which were not specified before, and the final goal that Colombians should be bilingual by 2019. And yet, as has been mentioned, Colombia already has sections of its population that are receiving bilingual education. This point is clearly recognized in the General Law of Education, where we find "the teaching of the ethnic groups with their own linguistic tradition will be bilingual, being based on the mother tongue of the respective group." (my translation) (Note 8). There is therefore uncertainty among educators in schools, CADEL and LEAs as to what the NME intends with its call for bilingual education. Is the rest of the population to be educated in the same way as the indigenous groups? If it is to be different, how will it be different? Will the indigenous groups need to learn a third language in order to comply with the other injunction of the NBP to learn English? It is this, the aim to provide bilingual education without a clear indication of what is meant nor how this is to take place which is the most contentious aspect of the NBP and will be commented on in more detail in section 2.6.2.

These changes, and the justification for them, are not presented in a single document "due to the continuous changes and additions that the program faces through time" (Note 9). Instead, details of the National Bilingual Programme are found in three documents: in two Ministry of Education circulars entitled "Information about the National Bilingual Programme" and "Education: Vision 2019 - National Bilingual Programme" as well as the Ministry of Education publication "Altablero no. 37", which can be accessed on Internet. The last of these is, in many respects, the most complete document concerning the NBP as it contains a letter from the Minister of Education (in English and Spanish) and articles (some of which are in English and Spanish and others are just in Spanish) which:

a) Postulate the need to be bilingual,

b) Set out the current situation concerning the level of English among students and teachers,

c) Explain the targets which the National Ministry of Education has set,

d) Provide a transcript of a discussion of the issues involved in the bilingual programme between a language consultant and a member of the Centre for Research and Development in Education at the University of Los Andes,

e) Give some examples of how the programme is being implemented in some LEAs and

f) Relate advances in bilingual education for the indigenous population of Colombia.

But all these documents share a common purpose, namely to highlight the need to learn English to an internationally recognized standard and provide bilingual education both in English for the majority of the population and also among the indigenous peoples. This is encapsulated in Altablero: 
.... The purpose of the programme is to respond to national needs in relation to English, to train teachers and students of primary, secondary and higher education so that they will be able to meet the challenges of a bilingual environment, and to promote and protect the use of other languages in border areas, ethnic minority languages and Afro-Colombian groups. With respect to proficiency in English, the aim is to ensure that the actors of the educational system develop communicative competence at levels which are classified as intermediate and sufficient at international level. (Altablero, no.37, 2005 page 3E)

But what is meant by "national needs in relation to English"? Does the whole workforce need to be bilingual? If it were to be, would this solve the unemployment problem? And what or where is the "bilingual environment"? What are the challenges that need to be faced? And can they really be faced with an intermediate or sufficient level of proficiency in English? To what extent can all the teachers in primary, secondary and higher education be trained to provide an education in English for their respective students? Can a language policy set targets for the teaching and learning of a foreign language (English) as well as set out to "promote and protect" the use of Creole and Amerindian languages? The aims of the programme are many, but so are the questions which they raise.

\subsection{Provision of the National Bilingual Programme}

In accordance with the statutes of the General Law of Education of 1994 the National Ministry of Education is only able to suggest policy to certified LEAs, and it is up to each one of these to decide when and how it is to implement it. This is indicative of the trend discussed by Jessop from government to governance (2000:9). And in the case of Colombia there are several reasons as to why policy needs to be sufficiently flexible to cater for different variables. Many of these have been alluded to, but there are several others. One is that that there are variations in levels of funding, in the sense that the cost of educating a child in the capital is different to that of educating one in the tropical region of Choco (Altablero, no.8). This influences the size of the budget for each LEA. Another variable is that of appropriateness of teachers for the subjects they are teaching. Due to teacher shortages, at times teachers are asked to teach a subject that they have not been trained to teach. Furthermore, there is the ethnic/linguistic composition of the school population which exerts an influence on the way in which policy is interpreted and put into effect. There are some areas where all the students have Spanish as their mother tongue, others where there are students that speak a creole version of English and others that speak an Amerindian language. In other words, as each LEA undertakes to implement the National Bilingual Programme, it will take into account a variety of factors in order to decide how best to apply the policy. This observation is similar to that made by Vidovich, who points out that there is a difference between the formulation of a policy and its implementation, and she refers to Malen (1994) when she mentions that people involved in implementing a policy adapt it for their environment $(2001: 2)$. On the one hand this facilitates policy being adapted to local conditions, but on the other it results in a lack of consistency of policy implementation on a national basis.

At the moment eighteen of the 78 certified LEAs are in the process of implementing the NBP, and it is hoped that a further fifteen will join the scheme next year. On a positive note, the largest LEA in Colombia, that of Bogota, recently adhered to the programme. But it must also be born in mind that when an LEA adopts a policy, the form in which it is done and the enthusiasm with which it is implemented is largely a matter of the personal commitment to the policy from the leader of the LEA (Note 10). In addition, practicalities and common sense dictate that the policy cannot be implemented in its entirety to all the school in the LEA. An example is the implementation of the NBP in Bogota. As mentioned, the LEA has recently decided to implement the policy so it has contacted the CADEL for each of the areas into which Bogota is divided. The CADEL for the area of Usaquen has decided to run a pilot scheme with one school to introduce the NBP, and is currently contacting local private bilingual schools to obtain advice on how to develop a language policy in order to implement the NBP, make the most of its resources and develop the language teaching skills of its teachers. The advice which the school receives in Bogota, will probably not be the same as that received by a state school on the Caribbean coast of Colombia.

\subsection{Context of Practice/effects}

\subsubsection{Stage 1 of the National Bilingual Programme: 2004 to 2010}

Many linguists have written on factors which need to be taken into account when developing a second or foreign language programme. These include factors such as theories of second language acquisition, curriculum design, classroom pedagogy and means of evaluation. A far from exhaustive example of these would be Stern (1983), Richards and Rodgers (1986), Spolsky (1989), Robinson (1998) and Baker (1996). Some of these are more prescriptive than descriptive, but I would suggest that those put forward by Baker (1996) are the most practical. He suggests that there are ten elements that need to be addressed when teaching a second language. These are:

(1) A theory of what constitutes a second language

(2) A theory of how children and adults best learn a language

(3) The definition of second language classroom goals. 
(4) A language syllabus.

(5) The form of classroom activities.

(6) The role taken by the teacher.

(7) The role taken by the learner.

(8) The materials and facilities which exist in and out of the classroom.

(9) The forms of assessment.

(10) The contexts of second language learning.

(Baker, 1996:278-281)

As a result of the survey undertaken by the NME and the British Council in 2005 of the teachers, it was noted that many had a lack of understanding of these issues. Accordingly the LEAs, at times based on the recommendation of the Ministry of Education, work in cooperation with either universities or language institutions, such as the British Council, to send teachers on training courses locally such as the In Service Certificate for English Language Teachers (ICELT), through an immersion programme in San Andres - the Programme of Permanent Teacher Training (PFPD as it is known by its acronym in Spanish) or to England for professional development (Altablero no. $37 \mathrm{pp} 10$ and 3E). It is intended that teachers who take part on these courses provide feedback and training sessions to their peers in a 'snowball' effect.

There now appears to be a set of clear guidelines from the Ministry of Education to the LEAs on how to improve the way in which they teach English as a Second Language (at least in schools, though it seems that little reference is made to University level education). Furthermore, the Ministry of Education has negotiated with 21 different language institutes in various regions of the country to provide language classes for the teachers at a discount (Altablero no. 37 p.20), in addition to which it has provided websites where students and teachers can practice and improve their vocabulary. Additionally, the British Council is playing a leading role in the provision of the programme as it works with the Ministry and other local organizations in the development of standards, evaluating, training of teacher trainers, teacher training and accreditation (Note 11). However, at the end of the day it is the LEA or CADEL that needs to choose which local educational organization it should recur to in order that schools and teachers receive instruction in theories of second language acquisition, curriculum design, second language pedagogy and evaluation processes as well as means to improve the level of English of the teachers. The LEAs, then, provide advice on implementing the NBP at a local level, taking into consideration local needs and resources and, although there are differences in terms of the quality of advice which is given, there do appear to have been significant developments in teachers' level of English and their ability to teach English.

It therefore seems that a serious attempt is being made by the National Ministry of Education, in consultation with Local Education Authorities, local higher educational establishments and the British Council to improve the quality of language teaching at school and university. No doubt it is hoped that as the level of English among teachers and the methodology employed by them improves, so students will be more likely to first, apply themselves in class and secondly, have a better level of English. From a linguistic point of view, this may seem somewhat optimistic. Baker suggests that "where children receive a half an hour second language lesson per day for between five and twelve years, few students become functionally fluent in the second language" (1996:179), and he goes on to say "mainstream education rarely produces fully bilingual children (ibid:180). However, he adds that sometimes a second language is learnt to a high standard when "motivation is high, when economic circumstances encourage the acquisition of a trading language" (ibid: 180). In other words, it is not just improving the level of English among teachers and the methodology that they use which is needed here, but also a tangible need for workers to speak English when employed in many organizations and a positive learning environment in the school as well as a decrease in the harsh living conditions that some members of the school population have.

\subsubsection{Stage 2 of the National Bilingual Programme: 2010 to 2019}

Once students have achieved a "basic level" of English, we are informed by the Minister of Education that they will be

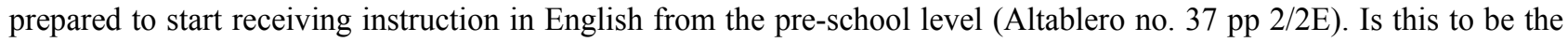
first stage of the ontogeny of bilingualism in Colombia? How will the curriculum be organized? Will teachers be sufficiently trained and how will the students be evaluated in bilingual criteria?

The only reference in the Ministry of Education literature on the NBP to bilingual education is that which draws attention to the need to develop students' appreciation of other cultures in order to communicate and the need to be bilingual (Altablero no. 37 p.3E), thereby establishing a (tenuous) link between cultural awareness and bilingualism. However, in no communication does it specify how bilingual education is to be differentiated from following the curriculum with English as a second language. As with many elements of the National Bilingual Programme, it appears that it is up to each LEA to decide how it is to organize schools to provide bilingual education. As a point of 
reference, they may want to consult Baker, who enumerates 10 types of bilingual education (1996:175). Six of these refer to providing bilingual education for ethnic minorities and the other four for those of the majority language. In the Colombian context (except those areas with ethnic minorities) it would seem that "Bilingual Education in Majority Languages" would be the most appropriate, where bilingual education is provided through "the international language (being) used as a medium of instruction alongside the native language" (ibid:194). But according to Altablero no.37, subject teachers need only have an A2 level of English (Altablero no. 37 p.4), which is below the level of English which is expected of students. As such, it does not seem that the National Ministry is contemplating the teaching of other subjects through the medium of English. It may well be that the second stage of the NBP will only differ from the first stage in the sense that the students will be educated about the culture of English speaking nations. Does this constitute bilingual education? I believe not, if for no other reason than that there is not an evaluative mechanism that can quantify the degree of bilingualism of an individual by assessing their degree of knowledge of other cultures. Bilingual education is notoriously difficult to offer and even more so to assess. Lam refers to studies of bilingual programmes and notes that when evaluation criteria were applied, only between 2 and $22 \%$ of the programmes which had been considered were considered worthy of additional analysis due to serious flaws in the bilingual education that was being offered, or the structure of the programme (Lam, 1992:183/4).

In order to assess whether or not students are attaining an appropriate level of English, the NME has decided that the Common European Framework of Reference for Language be used as the evaluative tool. This provides criteria for evaluating a variety of language skills as well as an overall description of language ability. As a tool for evaluating communicative competence this is all very well, but it does not evaluate the degree of bilingualism of an individual and the two are far from being the same (see Hamers and Blanc, 1989:16/17).

\section{Conclusion}

By making use of a combination of concepts put forward by Dale (1997) and Vidovich (2001), the critical description of the National Bilingual Programme presented in this paper considers and gives some order to factors that influence the regulation and provision of policy in a developing country which is motivated by the global economy. Although this provides an indication of some of the issues that stakeholders are confronting or need to address, it does not develop in sufficient detail the decentralized nature of education in Colombia nor the attitudinal factors mentioned by Ball when discussing the policy process, which can play a significant role in the provision of policy. It also needs to be born in mind that, because of the disperse and ongoing nature of implementing the National Bilingual Programme, conclusions about the efficacy of its provision can only be tentative at best. With this proviso, it can be noted that the Ministry of Education of Colombia has put forward an ambitious National Bilingual Programme so that Colombians, when they leave education, will have an internationally recognized level of competence in English by 2010, and be 'bilingual' by 2019. Although this has led to improved levels of English in some areas, its very name seems to be open to misinterpretation. The aim of improving the level of English among Colombians in order to cope with increased business conducted in English caused by globalization is a valid one. And, just as in the case of Chile, an acceptable time frame, bearing in mind the current level of English of teachers and their knowledge of EFL techniques needs to be set. However, due to the decentralized nature of education in Colombia, the time frame seems a little overambitious, in addition to which the use of the term "bilingual" seems to be insufficiently considered from a linguistic point of view in terms of its concurrent provision in majority language contexts and areas of Amerindian or Creole speakers. Much of this could be avoided by following the example of Chile by giving the policy a more 'neutral' term and having more funding, resources and incentives to improve the level of English at school and university. But it also seems that if students are to achieve high levels of English, other non-educational factors also need to be improved, such as the living conditions of lower status families and the degree of security in schools for these students.

\section{References}

(Some of the documents provided by the National Ministry of Education do not have dates of publication, publisher or place of publication. They all listed under the heading of 'National Ministry of Education of Colombia')

Baker, C. (1996). Foundations of Bilingual Education and Bilingualism (2nd Edition). Clevedon: Multilingual Matters.

Ball, S.J. (1995). Intellectuals of Technicians? The urgent role of theory in educational studies.British Journal of Educational Studies vol. XXXXIII, no. 3 September, 1995.

Ball,S.J. (1990). Politics and Policy Making in Education: Exploration in Policy Sociology. London: Routledge.

BBC - Country Profile - Colombia http://news.bbc.co.uk/2/hi/americas/country_profiles/1212798.stm

Block, D. and Cameron, D. (eds.). (2002). Globalisation and Language Teaching. London:Routledge.

British Council, Colombia

http://www.britishcouncil.org/colombia-events-reports-of-past-events-english-language-teaching-bogota-bilingue-launc h.htm 
Brown, P. and Lauder, H. (1996). Education, Globalization and Economic Development.In Halsey, AH, Lauder, HP and Wells, AS (1997) Education, Culture, Economy and Society (pp.172 -192). Oxford:OUP.

Brown, P., Hesketh, A., and William, S. (2003). Employability in a Knowledge-driven Economy. Journal of Education and Work Vol.16, no. 2.

Carnoy, M. Latin America: The New Dependency and Educational Reform in Daun, H. (ed). (2002). Educational Restructuring in the Context of Globalisation and National Policy. New York:Routledge.

Colombian Government Census, 2005 http://www.dane.gov.co/files/censo2005/perfiles/perfil_nal.pdf

Colombian National Administrative Department of Statistics http://www.dane.gov.co/files/ investigaciones/empleo/ mercado_lab_colombiano/2006-IIItrim06-empleo.pdf

Concejo de Bogota http://www.concejobogota.gov.co/contenido.asp?id_sec=200\&id=2887371\&mode=ver_hoja

Dale, R. The State and the Governance of Education: An Analysis of the Restructuring of the State-Education Relationship. In Halsey, A.H., Lauder, H., Brown, P., and Wells, A.S. (1997). Education, Culture, Economy and Society. Oxford:OUP.

El Tiempo, jueves 21 diciembre, 2006

Energy Information Administration of the US government http://www.eia.doe.gov/emeu/cabs/Colombia/pdf.pdf Hamers, J.F., and Blanc, M. (1989). Bilinguality and Bilingualism. Cambridge:CUP.

Jessop, B. (2000). The State and the contradictions of the Knowledge-Driven Economy, published by the Department of Sociology, Lancaster University, Lancaster LA1 4YN, at http://www.comp.lancs.ac.uk/sociology/papers/Jessop-State-and-Contradictions.pdf

Lam, T.C.M. (1992). Review of Practices and Problems in the Evaluation of Bilingual Education. Review of Educational Research, Vol. 62 No. 2.

Los Mapuche de Chile at http://www.er.uqam.ca/nobel/r27020/id42.htm

Library of Congress country study - Colombia http://lcweb2.loc.gov/frd/cs/cotoc.html

Moloney, A. (2006). Ambitious reforms held back by budget in Guardian Weekly, Friday, November $17^{\text {th }}, 2006$.

National Ministry of Education of Colombia:

i) Ley General de la Educacion. - composed by the Law 107 of 1994, Law 115 of 1994, Decree 1857 of 1994 , Decree 1860 of 1994, Decree 2886 of 1994 and Law 30 of 1992

ii) Altablero, No. 8, 2001 http://www.mineducacion.gov.co/1621/article-87441.html

iii) Altablero, no. 37, 2005 http://www.mineducacion.gov.co/1621/propertyvalue-32266.html

iv) Información del Programa Nacional de Bilingüismo - Ministerio de Educación Nacional.

v) Educación : Vision 2019 - Ministerio de Educación Nacional - Programa Nacional de Bilingüismo.

Parelius, R.J., and Parelius. (1987). From Educational Sociology to the Sociology of Education. http://www.rci.rutgers.edu/ robpar/SOE.html

Richards, J.C., and Rodgers, T.S. (1986). Approaches and Methods in Language Teaching. Cambridge:CUP.

Rohter, L. (2004). Learn English, says Chile, Thinking Upwardly Global in the New York Times. December 9, 2004.

Robinson, P. (1998). State of the Art: SLA research and Second Language Teaching http://jalt-publications.org/tlt/files/97/jul/robinson.html

Spolsky, B. (1989). Conditions for Second Language Learning - Introduction to a General Theory. Oxford: OUP.

Stern, H.H (1983). Fundamental Concepts of Language Teaching. Oxford: OUP.

Taylor, S., ,Rizvi, F., Lingard, B., Henry, M. (Eds.). (1997). Educational Policy and the Politics of Change. London:Routledge.

UNCTAD - United Nations Conference on Trade and Development (2006) Investment Policy Review - Colombia.

UNESCO - statistics in brief http:/www.uis.unesco.org/profiles/EN/EDU/1700.html

UNICEF http://www.reliefweb.int/rw/RWB.NSF/db900SID/AMMF-6UPJJJ? Open Document

Valencia Giraldo, S. (2006). Literacy practices, texts and talk around texts:English language teaching developments in Colombia in Colombian Applied Linguistics Journal, no. 8. Colombia:Universidad Distrital.

Velez-Rendon, G. (2003). English in Colombia:a sociolinguistic profile- in World Englishes, vol. 22, no. 2. 
Vidovich,L. (2001). A Conceptual Framework for Analysis of Education Policy and Practices. http://www.aare.edu.au/01pap/vid01267.htm

World Bank (2005). Expanding Opportunities and Building Competencies for Young People: A new Agenda for Secondary Education Washington DC http://siteresources.worldbank.org/EDUCATION/

Resources/278200-1099079877269/547664-1099079967208/Expanding_Opportunities_Secondary.pdf

Notes

Note 1. I have visited the pilot project school on several occasions and spoken to students, teachers and administrators. Despite the lack of resources and ongoing nature of designing the curriculum, improving the level of English of the teachers and their awareness of EFL methodology, the enthusiasm with which all member of the school have embraced the policy is astounding.

Note 2. "Information about the National Bilingual Programme" National Ministry of Education

Note 3. "Los Mapuche de Chile" http://www.er.uqam.ca/nobel/r27020/id42.htm

Note 4.

http://www.britishcouncil.org/colombia-events-reports-of-past-events-english-language-teaching-bogota-bilingue-launc h.htm

Note 5. http://www.concejobogota.gov.co/contenido.asp? id_sec=200\&id=2887371\&mode=ver_hoja

Note 6. Luis Guillermo Plata, Director of Proexport on p.1/15 of Altablero no. 37

Note 7. Ley General de Educacion 1994, articulo 21(m) and articulo 22 (1)

Note 8. Ley General de Educacion, page 35

Note 9. Personal correspondence with Juan Carlos Grimaldo, Director of the Nacional Bilingual Program

Note 10. Personal discussion with an academic consultant with the Ministry of Education

Note 11. "Information about the National Bilingual Programme" published by the Ministry of Education

\section{Appendix}

A Conceptual Framework for Analyzing Policy

Vidovich (2001:15-18)

\section{Context of Influence}

\section{What struggles are occurring to influence the policy?}

Are global influences and trends evident in this policy domain?

Are there international influences being brought to bear? If so, which are the key nation-states involved?

How are global and international influences operating?

To what extent are global and international level influences mediated within the nation-state?

What are the prevailing idealogical, economic and political conditions?

Who are the policy elite and what interests do they represent?

Which other interest groups are attempting to influence policy?

Which interests are most/least powerful and why?

Over what time period did the context of influence evolve before the policy was constructed?

\section{Context of policy text production}

\section{What struggles are occurring in the production of the policy text?}

When did the construction of the policy text begin, and 'why now'?

Which interest (stakeholder) groups are represented in the production of the policy text and which are excluded?

What processes are used to construct the policy text and why?

What compromises are made between the different interest (stakeholder) groups and how are they achieved?

Whose interests are the policy intended to serve?

What are the dominant discourses of the policy text and what discourses are excluded?

What is the stated intention or purpose of the policy? 
Are there any 'hidden' agendas?

Which values are reflected in the policy?

What are the issues that constitute the focus of the policy, and do they relate to global/international policy agendas?

What are the key concepts of the policy?

What is the format of the policy and why?

What is the language of the policy and why?

Are there inconsistencies and contradictions in the policy text?

Who is the intended audience of the policy text?

How accessible or understandable is the policy text to the audience?

Are the steps for 'implementation' set out as part of the policy text?

Is the 'implementation' funded'?

Is there a specified mechanism to evaluate the policy?

\section{Context of practice/effects}

\section{What struggles are occurring over the policy practices/effects?}

Is this policy being practiced in a wide variety of localized contexts?

How different are the policy practices between, ad within, different localized sites?

Are global/international influences evident in the policy practices at local levels?

Who can access the policy and who does access it?

How open is the policy to interpretation by practitioners?

How well is the policy received?

Who put the policy into practice?

What processes are used to put the policy into practice and why?

To what extent is the policy (actively or passively) resisted?

Is resistance collective or individual?

To what extent is the policy transformed with individual institutions?

How predictable were the policy practices/effects?

Are practitioners at the local level empowered by the policy?

Are practitioners at the local level able to respond rapidly to meet localized needs in the policy domain?

What are the unintended consequences?

What is the impact of the policy on different localized groupings based on class, gender, ethnicity, rurality and disability?

Are there winners and losers? 


\title{
Globalization and Its Impact on the Medium of Instruction
}

\author{
In Higher Education in Malaysia
}

\author{
Mohini Mohamed \\ Department of Science and Mathematics Education, Universiti Teknologi Malaysia \\ Skudai 81310 Johor, Malaysia \\ E-mail: p-mohini@utm.com.my
}

\begin{abstract}
Understanding bilingualism in science and mathematics education and developing a principled instruction is a pressing issue in Malaysian system of education. With the implementation of government policy of teaching science and mathematics in English starting from year 2003, an increasing number of students are affected with this policy. An initial study has been undertaken to examine the view of instructors from two public universities in Malaysia. A total of 175 respondents comprise of professors, associate professors and lecturers from eleven faculties participated in the research. In the context of Malaysia, even though the dilemma was due to governmental initiatives, it is important to raise the consciousness of the bilingual educator and to liberate their view of bilingual education beyond a simple governmental definition or a single societal perspective.
\end{abstract}

Keywords: Bilingualism, Science education, Mathematics education, Higher education

\section{Introduction}

Globalization is impacting on education system in many countries throughout the world. One aspect of this process is the language usage in the teaching of science and mathematics. This is particularly true in the context of Malaysia. The phenomenon where knowledge, value, principle and curricular developed in a local context gaining a global adherence is perceived as being an inevitable outcome. (Clarkson, P.C. 2004)

At the beginning of the 1970's, the main medium of instruction of Malaysian school system was changed from English to Malay, the national language. This was done in some way for political reason and motivated by the call of patriotism and moving away from colonial influence. However from 2003 onwards, the government has launched a reform in education system where all first year primary, secondary and Malaysian matriculation college has to use English in teaching science and mathematics as well as related subjects. The level that started to be affected with this policy were year 1 in primary school, form 1 in lower secondary schools and form 6 for higher secondary and matriculation level. The level that were affected increased gradually and culminated to all level affected by year 2008 including the tertiary level. Public university in Malaysia has mandated that English is to be used as a medium of instruction for all science and mathematics related courses starting from semester 1 for 2005/6 session and all first year courses beginning 2006/7 session. The implementation of this policy brings obvious ramification in the teaching of mathematics in higher education.

\section{English as global issues in science and mathematics education}

Students are required to take English exam as a compulsory requirement for entrance to public university. MUET (Malaysian undergraduate English Test) result for new entry student for the $2007 / 8$ intake at one public university which can be considered as a typical sample for other public university indicated that most students scored below the satisfactory level in English competency. From the population of 2916 new students' intake at a public university, about $72.7 \%$ has a score of band 1, 2 and 3. (Figure 1)

After four years of implementation of a the policy, it is obvious that the incoming students that were admitted to university and other higher institution still have low proficiency in English. This scenario sends alarming signal and brings the Malaysian education system in great turmoil. The greatest dilemma of Malaysian education system has been its inability to understand the ethno linguistic complexity of bilingual education and its impact on student, classroom and society in such a way as to enable teacher and instructor to make informed decision about practice in classroom setting. There is a need in Malaysian education system for information about sociolinguistic and psycholinguistic issues that surround bilingualism in science and mathematics education. It is important to gather theoretical and practical 
information from a variety of societal context in order to empower educators to see possibilities beyond their own constraints and to be able to perform their role appropriately. In the context of Malaysia, even though the dilemma was due to governmental initiatives, it is important to raise the consciousness of the bilingual educators and to liberate their view of bilingual education beyond a simple governmental definition or a single societal perspective (Baker, 1996)

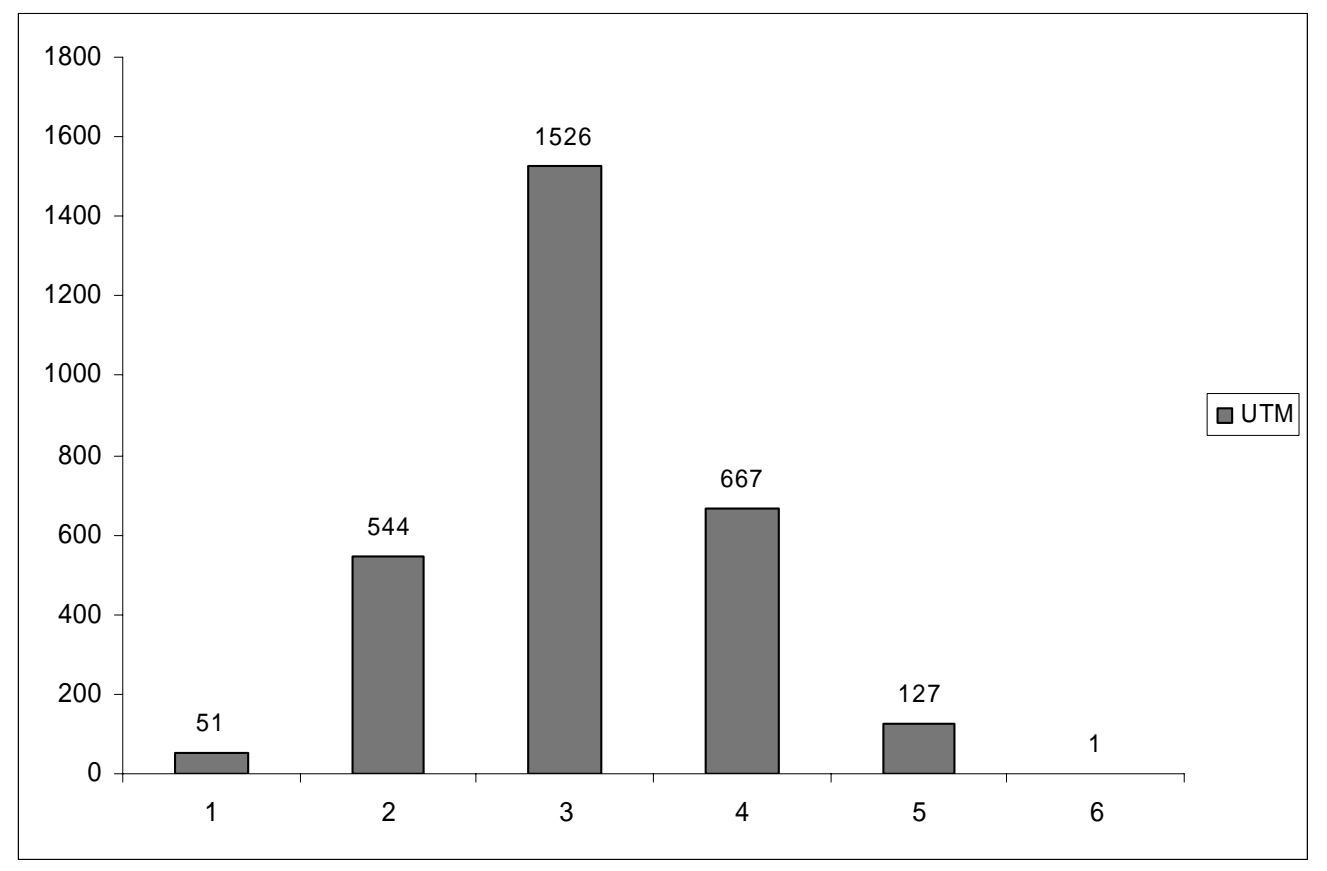

Figure 1. Muet score for 2007/8 student's intake

Courtesy of Centre for Teaching \& Learning, Universiti Teknologi Malaysia (2007)

A common assumption is that mathematics is a universal language and as such mathematical symbols cut across nations, ethnicity and cultures with different languages. However a study by Aziz et al (2000) showed that there is a strong correlation between test score in science and mathematics with English test score. The result indicated that student with high proficiency in English were more likely to achieve high scores in their science and mathematics test. In other word, the findings revealed that students with low proficiency in English are somewhat deprive of achieving high score in science and mathematics. This raise the issues of equity and language gap which is tantamount to creating performance gap in education.

\section{Research methodology}

The data for the research were collected from two public universities in Malaysia. A total of 175 respondents comprise of professors, associate professors and lecturers from eleven faculties had participated in the research. Questionnaires were used as the instrument for data collection and later analyzed using SPSS (Statistical Package for social science) software. The statistics used in the research were frequencies and percentages.

\section{Findings}

The study indicated that some of the reasons behind the use of English in classroom setting for most of the respondent in order of importance were as below:

a. Contributes to the internationalization of the university

b. Is necessary for competition in the job market

c. Is meaningful for Malaysian students, since it provides training in an internationalized context

d. Makes it possible for students from many cultures to learn together

There is an innate wish among the respondents to contribute to the internationalization of their university by conducting their courses in English (Table 1). By doing so, the respondents feel that they can provide platform in enhancing the proficiency of English among their student. The reason for using English can be seen as utilitarian in nature because they hope by acquiring and mastering English among their students can improve their prospect in the job market. The government is exerting effort to make Malaysia as the center of learning in the world map. In line with this aspiration, public universities has received enrollment from international students from various countries especially from the Middle East and Africa. The respondents feel that it is important to conduct their course in English in order to facilitate the students from different countries and cultures to learn together with the local students. 
Table 1. Positive views

\begin{tabular}{|l|l|l|l|}
\hline Items on positive views & M & Disag & Ag \\
\hline 1. Contributes to the internationalization of the university & 2.81 & $\begin{array}{l}10 \\
(6.17)\end{array}$ & $\begin{array}{l}152 \\
(93.83)\end{array}$ \\
\hline $\begin{array}{l}\text { 2. Makes it possible for students from many cultures to learn } \\
\text { together }\end{array}$ & 2.73 & $\begin{array}{l}18 \\
(11.39)\end{array}$ & $\begin{array}{l}140 \\
(88.61)\end{array}$ \\
\hline $\begin{array}{l}\text { Is meaningful for Malaysian students, since it provides training in } \\
\text { an internationalized context }\end{array}$ & 2.73 & $\begin{array}{l}11 \\
(7.43)\end{array}$ & $\begin{array}{l}137 \\
(92.57)\end{array}$ \\
\hline 8. Is unavoidable given the prevalence of the English language & 2.21 & $\begin{array}{l}32 \\
(30.48)\end{array}$ & $\begin{array}{l}73 \\
(69.52)\end{array}$ \\
\hline $\begin{array}{l}\text { 10. Is necessary to compete with the world } \\
\text { 11. Is necessary for competition in the job market }\end{array}$ & 2.69 & $\begin{array}{l}16 \\
(10.60)\end{array}$ & $\begin{array}{l}135 \\
(89.40)\end{array}$ \\
\hline
\end{tabular}

Despite the low English proficiency among Malaysian university students, their instructors strongly feel that Malaysian students are able to compete internationally. However, there are negative arguments as well, such as, Malaysian students are more passive than other international students namely Africans, Bosnian or other Asian students (Table 2 and Table 3). Given their low English proficiency, $81.25 \%$ of the respondent viewed that Malaysian students have insufficient training in stating their opinion in English. Naturally, the student who has a good command of English tend to dominate the class discussion. However, this seem to be an elite group because less than 10 percent of Malaysian population has good command of English and are comfortable in using it as a form of communication (Johari et al., 2006).

Table 2. Positive views for courses taught in English

\begin{tabular}{|l|l|l|l|}
\hline & M & Disag & $\mathrm{Ag}$ \\
\hline 1. It is livelier than a regular course & 1.84 & 30 & 38 \\
& & $(44.12)$ & $(55.88)$ \\
\hline 5. It is exciting since there are many different opinions & 2.07 & $\begin{array}{l}13 \\
(15.48)\end{array}$ & $\begin{array}{l}71 \\
(84.52)\end{array}$ \\
\hline 12. Malaysian students can compete internationally & 2.50 & $\begin{array}{l}6 \\
(4.58)\end{array}$ & $\begin{array}{l}125 \\
(95.42)\end{array}$ \\
\hline
\end{tabular}

Table 3. Negative views for courses taught in English

\begin{tabular}{|c|c|c|c|}
\hline & M & Disag & $\mathrm{Ag}$ \\
\hline $\begin{array}{l}\text { 2. Malaysian students are more passive than other Asian } \\
\text { Students }\end{array}$ & 1.87 & $\begin{array}{l}37 \\
(41.57)\end{array}$ & $\begin{array}{l}52 \\
(58.43)\end{array}$ \\
\hline $\begin{array}{l}\text { 3. Malaysian students are more passive than other non-Asian foreign } \\
\text { students (Africans, Bosnians, etc) }\end{array}$ & 1.84 & $\begin{array}{l}35 \\
(38.46)\end{array}$ & $\begin{array}{l}56 \\
(61.54)\end{array}$ \\
\hline 4. It is difficult since the needs of the students are diverse & 1.64 & $\begin{array}{l}34 \\
(36.96)\end{array}$ & $\begin{array}{l}58 \\
(63.04)\end{array}$ \\
\hline 5. It is exciting since there are many different opinions & 2.07 & $\begin{array}{l}13 \\
(15.48)\end{array}$ & $\begin{array}{l}71 \\
(84.52)\end{array}$ \\
\hline $\begin{array}{l}\text { 6. It is difficult to find teaching material since there are few } \\
\text { English publications that share your viewpoint }\end{array}$ & 1.16 & $\begin{array}{l}122 \\
(91.73)\end{array}$ & $\begin{array}{l}11 \\
(8.27)\end{array}$ \\
\hline 7. The students whose first language is English tend to & 2.16 & 26 & 89 \\
\hline
\end{tabular}




\begin{tabular}{|l|l|l|l|}
\hline dominate the discussions & & $(22.61)$ & $(77.39)$ \\
\hline $\begin{array}{l}\text { 10. Malaysian students have insufficient training in stating their } \\
\text { opinion in English }\end{array}$ & 2.24 & $\begin{array}{l}24 \\
(18.75)\end{array}$ & $\begin{array}{l}104 \\
(81.25)\end{array}$ \\
\hline $\begin{array}{l}\text { 11. Malaysian students have insufficient training in explaining about } \\
\text { their country to non-Malaysians }\end{array}$ & 1.87 & 39 & $\begin{array}{l}58 \\
(59.79)\end{array}$ \\
\hline
\end{tabular}

The study also give evidence that university instructor prefers to write papers in English (Table 4). The main reason is because they perceived that the paper written in English will be read more widely in the world (Table 5). Writing in English for bilingual instructor is of course not without its hurdle. Admittedly, they have difficulties in writing articles in correct grammatical sentences and it became a common challenge for most English learner.

Table 4. Writing and publishing papers

\begin{tabular}{|l|l|l|}
\hline ITEM 15 & Freq & $\%$ \\
\hline 1. I write almost all of my papers in English but I also try to publish in Malay & 117 & 66.86 \\
\hline 2. I write mostly in Malay, but I also try to publish in English & 32 & 18.29 \\
\hline 3. It is not necessary to publish in English in my area & 4 & 2.29 \\
\hline 4. Other (Please explain: & 19 & 10.86 \\
\hline
\end{tabular}

Table 5. Reasons for preference to write in English

\begin{tabular}{|l|l|l|}
\hline ITEM 16 & Freq & $\%$ \\
\hline $\begin{array}{l}\text { 1. The paper will be read more widely in the world that way } \\
\text { in which I can publish }\end{array}$ & 125 & 71.43 \\
\hline $\begin{array}{l}\text { 2. There are not that many academic journals in the national language } \\
\text { 3. People that write in English are more highly considered even within }\end{array}$ & 35 & 31.43 \\
\hline $\begin{array}{l}\text { 4. Other (Please explain: } \\
\text { the }\end{array}$ & 67 & 38.29 \\
\hline
\end{tabular}

\section{Implications}

Unlike the situation that occurs in some western countries, bilingual education in Malaysia is not the needs of minority students but the massive population of student. English is the second language of almost all of the students while their first language maybe Malay, Mandarin or Tamil. How can instructors meet the language development needs of these students while at the same time providing all of them the opportunity to fully develop their science and mathematics knowledge at the requirement level? There is no immediate, absolute or universal answer. All university programs have to be adapted according to the local context.

Students need access to multicultural environment, appropriate use of first language and use effective English method of content instruction as well as opportunity to show their competence in a variety of ways. In an active integrated learning environment, the development of language proficiency, thinking skills and science and mathematics knowledge are all intertwined. In the beginning, the use of instruction time for mathematics might be insufficient because of the emphasis of language development. However one can imagine a range of instructional emphasis as in Figure 1. 


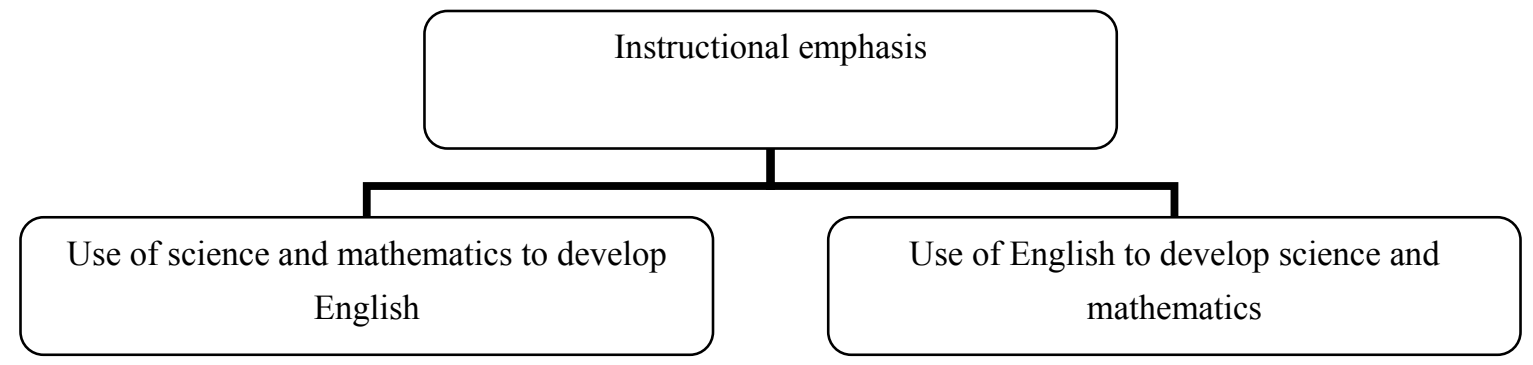

Figure 2. A continuum of instructional emphasis

Situations arise in which end of the continuum maybe appropriate for an instructional emphasis in bilingualism education. And as a continuum, there is not always a clear demarcation between the language focus and the content focus.

The concurrent approaches, the switching back and forth in one lesson between two languages are the most common approach. Concurrent approach is actually a skill that needs to be developed. The rationale for the skilled use of concurrent approach is to make the lesson comprehensible to all students and is accessible in an intellectually challenging ways. However, because of the primacy of language as a vehicle for cognitive and academic development, how it is used in the bilingual classroom can have a significant impact on the question of the learning environment. The following is a summary of recommendations brought forth from this study:

1) Implementation of bilingualism should be grounded in the context of socio cultural, economic and ideological realities.

2) Instead of focusing on deficiencies, instruction should build on the background and interests that student brings to classroom.

3) Bilingualism instruction has to provide a balance and integrated environment in developing thinking skills, science and mathematics knowledge as well as language proficiencies.

4) Concurrent approach or a skilled use of both languages may become a part of teaching process in science and mathematics instruction.

\section{Challenges}

This initial study emphasized that the implementation of bilingualism in science and mathematics raise several dilemmas and issues. The instructors need to cope in situations where they will not have full control of their situation. Intake of students to public university who are low proficiency in English compelled instructors to switch back and forth from their mother tongue to English. Instead of being frown upon, this practice could create opportunities for bilingual learners to flourish. There is a need to shift to other socio cultural perspective in countering the obstacles of bilingualism in science and mathematics learning. A socio cultural perspective shift away from deficiency models of bilingual learner and instead focuses on describing the resources bilingual students use to communicate mathematically (Moschkovich). By refusing to shift to socio cultural perspective, may result in designing instructional policy that neglects the experiences and competencies of student that they bring to science and mathematics classroom. If all we see are students, who don't speak English, mispronounce English words, incapable to discuss in English, instruction will focus on this deficiencies. If, instead, we learn to recognize the science and mathematical ideas this student express in spite of their accents, code-switching, or missing vocabulary, then instruction can build on students' competencies and resources. How to implement socio cultural perspective in order to better understand the processes underlying bilingualism in learning science and mathematics needs further exploration.

\section{Conclusion}

Understanding the complexity of bilingual science and mathematics education and developing a framework for bilingual education in science and mathematics instruction is a pressing practical issue in Malaysia. When the government mandated the policy of using English in teaching science and mathematics, there followed an unquestioned aggressiveness on the part of some administrator of schools and higher education institutions in implementing the rule. An increasing number of students who enter public university will have to face the dilemma of learning science and mathematics and other related courses entirely in English. It is crucial for teachers and educators to make an informed decision and performed an appropriate role in supporting bilingualism in a changing classroom setting.

\section{Acknowledgements}

I would like to appreciate and extend my gratitude to the Malaysian Ministry of Higher Education and Research Management Center of Universiti Teknologi Malaysia for the full support of this research. I am also indebted to 
Professor Rosnani Hashim from International Islamic University of Malaysia for her help in distributing and analyzing the data.

\section{References}

Aziz et al. (2006). Kesan Pembelajaran Matematik dalam Bahasa Inggeris terhadap pencapaian dan minat Pelajar. Buletin persatuan Pendidikan Sains dan Matematik Johor, Jil. 15. bil 1.

Barwell, R. \& Clarkson, P. (2004). "Researching Mathematics Education in Multilingual Contexts: Theory, Methodology and the Teaching of Mathematics." Proceedings of the $28^{\text {th }}$ Conference of the International Group for the Psychology of Mathematics Education, vol. I pp.227-256.

Clarkson, P.C. (2004). Teaching Mathematics in Multilingual Classrooms: The Global Importance of Contexts. In I.P.Cheong, H.S.Dhindsa, I.J.Kyeleve \& O.Chukwu (Eds.), Globalisation Trends in Science, Mathematics and Technical Education, (pp.9-23). Brunei Darussalam: Universiti Brunei Darussalam.

Clarkson, P.C. (2003). Language, Logical Thinking and Communication in School Mathematics: Whose Responsibility. In H.S.Dhindsa, L.S.Bee, P.Achleitner \& M.A.Clements (Eds.), Studies in Science, Mathematics and Technical Education (pp.99-116). Brunei Darussalam: Universiti Brunei Darussalam.

Clarkson, P.C. \& Atweh, B. More. (2003). Perspective on The Impact of Globalisation on Mathematics Education in Higher Education in Australia. In L.Bragg, C.Campbell, G.Herbert \& J.Mousley (Eds.), Mathematics Education Research: Innovation, Networking, Opportunity (.pp.238-245) Geelong, Vic.: Mathematics Education Research Group of Australia.

Ester J. de Jong. (2002). Effective Bilingual Education: From Theory to Academic Achievement in a Two-Way Bilingual Program. Bilingual Research Journal, vol. 26 (1).

Moshkovich, Judith To appear in N.Nassir and Cobb (Eds.). Diversity, Equity, and Access to Mathematical Ideas. Teacher College Press. (In press). 


\title{
The Importance of the Teacher for Developing Interest in Learning English by Chinese Students
}

\author{
Yunbao Yang \\ School of Educational Studies (Bundoora Campus), La Trobe University \\ Post code 3083, Melbourne, Australia \\ Tel: $61419396821 \quad$ E-mail: yangyunbaogeorge@hotmail.com
}

\begin{abstract}
The importance of the English teacher for the development of interest by students in the learning of English is discussed. In the Chinese context, the teacher is regarded traditionally as knowledgeable and the source of learning by students. Commonly, learners have no idea why English language is important to them and their interest in English relies on their teacher. A few perspectives are discussed regarding teachers as motivators of the successful learning of English.
\end{abstract}

Keywords: Interest in learning English, Importance of teacher

\section{Introduction}

Gardner and Lambert $(1959,1972)$ and Gardner $(1985,2001)$ have provided extensive descriptions of the factors in social psychology influencing language learning success in a Canadian context. Factors such as interest in language learning, integrative orientation, parental' influences and the attitudes learners hold toward target cultures were raised. These factors affect the success of learning a language and positive attitudes or emotional feelings enhance learning process. Consequently, learners possessing these characteristics are likely to be more successful learners of language than those who do not have the characteristics.

Theoretically, the factors listed above serve as guidelines for language learning and undoubtedly, they set a background scene for second language learning in Canada where language learners have ready access to native language speakers, either English or French. In other words, the language environment is already provided and learners are expected to integrate with the culture in order to be a part of the main stream society and often interest in the language is expected to be present. However, this may not be the case once the language learning context shifts from a second language learning setting to a foreign language one, such as occurs in China where 'interest' in learning can be one of the problems confronting learners.

According to the social psychological theory of Gardner (1985) and Gardner and Lambert (1972), learners are socially and psychologically influenced such that they are interested in learning a foreign language. A key element of this theory is that learners hold an 'interest' either socially or psychologically. Zhao (2002, p.1) noted that "the New Curriculum for Chinese primary schools emphasizes students' empathy to develop their interest in English and help them build up confidence," suggesting the significant role of 'interest' in the learning of English. It seems this emphasis is the result of 'lack of interest' in the majority of Chinese learners of English and the 'high investment but low efficiency' which has been observed over the past two decades.

The question arises as to how language learners become interested in learning in a context which is far from native community where learners are generally out of contact the native English speakers. It seems that the language teacher is critical because s/he teaches the language and often is the first person, and commonly the only person, to introduce the language to the students and the only person who uses the language whom students can contact. Further questions arise too. For example, are students interested in English once they are taught? Why are they interested in learning it? Are they really interested if they achieve well in the course? Why do the majority Chinese English learners fail the course sooner or later? Numerous questions could be asked, but a key issue is the correlation between the teacher and interest in English on the part of students.

\section{The understanding of 'interest in' English}

Krapp et al. (1992) proposed that there are three definitions of interest. The three definition cover personal interest, situational interest, and interest as a psychological state. (Elliott, 2005, p. 28) noted that "personal interest is seen as a relatively stable and enduring characteristic of an individual. Situational interest is more transitory and is elicited by 
conditions in the environment that focus attention and generated affect." In considering the situation in China, Hau et al. (1996) considered:

Chinese parents strongly emphasize to their children that if one works hard, one will slowly build up one's interest and study skills. The learning of study skills and the cultivation of interest will subsequently lead to an improvement in ability. In contrast, the Western philosophy which stresses individualism and states that interest should come naturally. (p.135)

These authors further noted that Chinese "students are encouraged to learn by drill because it is believed that their interest in study, which initially may be totally lacking, will be cultivated later through their repetitive work" (Hau et al. 1996, p.134-135). It appears that in the Chinese context there is a possible lack of interest in English for one reason or another and learners try to obtain competency with English by conducting drills in which interest is supposed to appear in their learning. Seemingly, Chinese learners do not possess much interest in English, given their learning styles or strategies.

In connection with the latter, very recently, Jiang (2004) surveyed 106 students in year 9 of schooling in Zhejiang Province of the People's Republic of China regarding their motivation. It was found that only $12 \%$ students were interested in learning English.

Pintrich (1996) previously noted that "in school there are many students who have low intrinsic motivation and an important goal for teachers is to raise motivation" (p. 277). To enhance intrinsic motivation, attention must be given to the four areas: challenge, curiosity, control, and fantasy (Lepper \& Hodell, 1989). Consequently, a teacher's role in the development of interest on the part of students appears to be even more important due to the authoritative position of the teacher in the Chinese culture.

\section{The role of the teacher}

Teachers play a key role in the academic achievements of their students and in the Chinese context, learners depend heavily on their teachers, especially for English courses. Meece (1991) claimed that teachers who motivate students to learn often develop intrinsic motivation in students to learn for the sake of knowledge. In the Chinese classroom setting, a teacher of English is the authority of English knowledge and is regarded as the knower of the target culture and students are there to be introduced to learn a totally new foreign language. It is understood that English is not a part of the Chinese culture and naturally, students often find it hard to have an interest in the course. Consequently, they depend on their teacher to develop interest so that they might learn English This is important to them because the test score in English often determines whether a student can stand a place in class or has the possibility to go to a higher level junior secondary school, senior secondary school or even for university education. It is known that English is a major course in the school curriculum in China and developing interest in the course is a significant step for realization of the above aforesaid purposes. However, without a teacher's assistance and guidance, students will find it impossible to proceed. Significantly, Pintrinck and Schunk (1996) claimed that “enthusiastic teachers help foster students' interest and motivation in learning" (p.171).

An important process influencing student motivation involves the expectations that teachers hold for student learning and performance. Researchers on teacher expectations in the past 25 years have addressed such issues as how teachers form expectations, how they communicate them to students, and how these expectations affect outcomes (Braun, 1976; Cooper \& Good, 1983; Cooper \& Tom, 1984; Dusek, 1985; Jussim, 1986, 1991). Schumann (2000) proposed a different view on the issue of "motivation of learners' by querying "how can teachers get students interested in acquiring a second language?' (p.4). This researcher obviously highlighted the importance of a teacher for developing interest in language learning. However, the expectations of a teacher for the academic performance of the student should be based on the establishment of a rapport which facilitates beneticial outcomes.

\section{Teacher-student rapport}

Learning success relies on both teacher and student, not on the materials, so a relationship is important. Schon (1987, p.3) stated that "researchers are now realizing that education does not take place in a laboratory but in a 'soft, slimy swamp." This indicates the complexity of the learning process which involves teacher-student rapport and many other factors. Zhao (2002, p.3) also noted that "a teacher needs to be tolerant in order to create a relaxing psychological atmosphere to share students' worries and concerns." Only under this condition can students approach the teacher for help and assistance to solve their own problems in learning and it is reasonable to assume the language teacher is probably the only option available for them.

In terms of teacher-student relations, a feeling of concern, care, support, and respect for students and positive teacher-student interactions will be associated with positive motivational outcomes (Natriello, 1986; Midgley, Feldaufer, \& Eccles, 1989; also see Calabrese \& Poe, 1990; Eccles, Midgley, et al., 1993). In this connection, Bryke, Lee, and Holland (1993) in their study of Catholic schools observed that a concern for the welfare of others or the creation of a 
caring community can have very positive effects for all students, even those from populations that would be at risk of school failure.

Teacher-student rapport is a highlighted area in the Chinese educational system. This is because "the teacher-student relationship plays an important role in determining the atmosphere of the teaching environment and this combination influences the quality of learning that takes place" (Chambers, 1999, p.35). Thus the teacher-student relationship plays an extremely important part in the success or failure of teaching and learning ( $\mathrm{Li}, 1999)$. The relationship is important for development of interest in and the learning; 'liang shi yiyou' (good teacher and helpful friend) is consistent with establishment of interest in the course on the part of students with the help of their teachers.

Gardner (1985) also considered the importance of the' attitudes of students toward the course and their language teachers. He noted that because the language teacher would be regarded as the focus of the language, it is reasonable to assume that the teacher was the only language user they knew and the only place they possibly use the language would be the classroom. Consequently, the course and the teacher can become closely associated with the language material, and attitudes toward them could thus become highly influential. In contrast, in other subject areas, the material has some link with the individual's own culture; hence, the course and the teacher are not the only focuses (Gardner, 1985, p.7).

Zhang et al. (2003) conducted research in the Number Eight Secondary School in Beijing (a National Key School) by asking students to evaluate their relationships with their teachers. Zhang and her colleagues found that the students' main environment was the school and they tried to adjust themselves to be accepted, to be liked or to be appreciated by their teachers. When the students were in an ideal student-teacher relationship, they would feel capable and healthy in mind; they were confident and had high self-esteem. Consequently, they adopted a positive attitude.

These observations led Yang (2004) to suggest that the students who were in a safe student-teacher relationship, concentrated well and more often with a down-to-earth attitude to learning so as to enhance their learning efficiency. In contrast, a bad teacher-student relationship would always threaten the students and they constantly feared seeing the teacher. Both Zhang et al. (2003) and Yang (2004) agreed that student-teacher rapport played an essential part for the learning success of students. They considered this rapport made teachers approachable and therefore provided students with chances to talk to their teachers and consequently facilitated learning outcomes.

Teacher-student rapport is critical not because it is the development of a personal relationship, but it emphasizes more the role for teachers in understanding students through the teaching process and in return helps students to develop interest in learning. Teacher-student rapport becomes a measure to understand academic performance of students in the Chinese setting. It appears that those who have a close contact with their English teachers often are interested in learning English.

In the development of teacher-student rapport, various learning experiences occur and these positive/negative experiences have strong impacts on students who develop their interest and confidence because they are appreciated by the language teacher rather than feeling frustrated and discouraged due to failure and humiliation as language learning is a 'soft and slippery area.'

\section{Positive and negative learning experiences}

Zhang and Ding (1996) noted that a desirable disposition of a teacher always attracts students; students often transfer their 'respect' of the teacher to 'fond of' the course s/he teaches and finally convert this into motivation in learning. Wang (1996, p.32) also claimed that "a good teacher understands the classroom learning environment and understands better the unexpected result by giving a praise look, a smile, a nod and a word of encouragement." More recently, Yang (2004) considered that the generosity of a teacher in giving positive feedback and creating a positive learning environment promotes student learning. In spite of this, it should be noted that "a teacher who overcorrects the student can lower the expectation for success and destroy the possibility of a reward, thus reducing the students' willingness to pay attention or to persist in language learning (Okada et al., 1996, p.105).

Among different elements of motivation, the experience of the learner is one of the prominent characteristics that affects the interest in learning. Researchers including Rubin and Ryan (1982) and Deci and Ryan (1992) have proved that successful language learners have positive learning experiences while those who fail in learning usually relate to negative experiences. Past success in a particular situation would make a person more likely to engage in achievement behaviours in a similar situation in the future; past failure would generate fear and stifle achievement (Oxford \& Shearin, 1996, p.125). Nakata (2006) considered that learning success and positive learning experience are correlated.

Positive and negative learning experiences are related directly to language learning success because a positive learning experience encourages learners and negative experience proves the defeat in learning. However, positive and negative learning experiences often occur in classroom or classroom-related activities and very often it is a matter of teacher-involvement. In this connection, Rivers (1964, p.92) noted that "foreign language learning classrooms are a fertile ground for frustration, anxiety, embarrassment and humiliation" and Rubin and Thompson (1982, p. 10) considered that "previous experiences with foreign language study may influence attempts" 
The quality of the experience, as well as the achievement itself, are extremely important (Deci \& Ryan, 1992, p.31). With regard to the quality of the experience in learning English as a foreign language, it would be luxurious to expect learners to have quality experience by contacting English native speakers. This is because the setting pre-determines the context where learners are unlikely to have a quality experience. For example, in China it is likely that the majority of learners of English will encounter some negative feedback during the learning process. Quality experience can hardly be guaranteed if an English teacher is neither student-loving nor enthusiastic in teaching.

Negative experience often is associated with physical or language misuse in learning activities, especially in classrooms and in public. For example, Ho (1981, p.89) stated that "physical punishment in school, such as hitting the pupils' hand, is still practised. Ridicule or shaming of the children, such as making them stand out before their classmates, remains a common technique of control." Wong (1992), in a survey of secondary school teachers in Hong Kong, reported that the banning of corporal punishment remained an isolated attempt to improve the pastoral system

More recently, Zhu (2001, p.161) commented that "student's like or dislike of a course is connected with their early learning experiences." Those who experienced failure in learning were likely to be rebuked and their learning incentives withered, leaving no more interest in the course. In contrast, those who liked the course showed strong interest in it. These observations are consistent with the notion that the teacher's personality was closely related to learning success of students. A similar conclusion was reached by Yang (2004) who also considered that it was difficult for students to experience success when the teacher's personality was harsh and cold. This conclusion was reinforced by the observation of Zhou and He (2005) who investigated the learning of English in almost 100 secondary schools in China. They found that 'teacher-student rapport' was one of the most important factors which affected the learning of English in the eyes of students.

The dominant role English plays should not be overlooked in a context where English is treated as a foreign language in China. Students face materials from another cultural community, but more importantly, they are not required to learn the language simply to acquire another language. Instead, they need to learn it as a part of their life, even though the language seems remote and distant from their daily life. This further highlights the importance of the language teacher as a source of motivation for developing the ability of students to learn English.

\section{Conclusion}

In the Chinese context the teacher of English has a unique role and the special position is even more important than teachers of other disciplines. Furthermore, the English teacher is not only a facilitator as in western cultures. Teacher-student rapport and students' learning experience are critical for raising the 'interest in English learning' in students.

\section{References}

Braun, C. (1976). Teacher expectation: Sociopsychological dynamics. Review of Educational Research, 46, 185-213.

Bryk, A., Lee, V. \& Holland, P. (1993). Catholic schools and the common good. Cambridge, MA: Harvard University Press.

Calabrese, R., \& Poe, J. (1990). Alienation: An explanation of high school dropout rates among African-American and Latino students. Educational Research Quarterly, 14, 22-26.

Chambers, G. N. (1999). Motivating language learners. Sydney: Multilingual Matters Ltd.

Chen, C. S., Lee, S. Y. \& Stevenson, H. W. (1996). Academic achievement and motivation of Chinese students. In S. Lau, (Ed.), Growing up the Chinese way: Chinese child and adolescent development (pp: 69-91). Hong Kong: The Chinese University Press.

Cooper, H. M. \& Good, T. L. (1983). Pygmalion grows up: Studies in the expectation communication process. New York: Longman.

Cooper, H. M. \& Tom, D. Y. H. (1984). Teacher expectation research: A review with implications for classroom instruction. Elementary School Journal, 85, 77-89.

Deci, E. L. \& Ryan, R. M. (1992). The initiation and regulation of intrinsically motivated learning and achievement. In A. K. Boggiano \& T. S. Pittman (Eds.), Achievement and motivation: A social-developmental perspective (pp.9-36). Cambridge: Cambridge University.

Dornyei, Z. (2001). Motivational strategies in the language classroom. Cambridge: Cambridge University Press.

Dusek, J. B. (1985). Teacher expectancies. Hillsdale, NJ: Erlbaum.

Eccles, J., Midgley, C., A., Buchnnan, C., Reuman, D., Flaanagan, C. \& Mac Iver, D. (1993). Development during adolescence: The impact of stage-environment fit on young adolescents' in schools and families. American Psychologist, $48,90-101$. 
Elliott, J. G., Hufton, N. R., Willis, W. \& Illushiin, L. (2005). Motivation, engagement and educational performance: International perspectives on the contexts for learning. New York: Palgrave Macmillan.

Gardner, R. C. \& Lambert, W. E. (1959). Motivational variables in second language acquisition. Canadian Journal of Psychology, 13, 266-272.

Gardner, R. C. \& Lambert, W. E. (1972). Attitudes and motivation in second - language learning. Rowley, Massachusetts: Newbury House Publishers.

Gardner, R. C. (1985). Social psychology and language learning: The role of attitudes and motivation. London, Ontario: Edward Arnold.

Gardner, R. C. (2001). Integrative motivation and second language acquisition. In Z. Dornyei \& R. Schmidt (Eds.), Motivation and second language acquisition (pp. 1-20). Hawaii: University of Hawaii.

Hau, K. T. \& Salili, F. (1996). Achievement goals and causal attributions of Chinese students. In Lau, S. (Ed.), Growing up the Chinese way: Chinese child and adolescent development (pp:121-145). Hong Kong: The Chinese University Press.

Ho, D. Y. F. (1981). Traditional pattern of socialization in Chinese society. Acta Psychologica Taiwanica, 23, 81-95.

Jiang, X. N. (2004). Emphasizing on the selection of reading material to improve students reading ability. English Teaching and Research Notes, 4, 31-33.

Jussim, L. (1986). Self-fulfilling prophecies: A theoretical and integrative review. Psychological Review, 93, 429-445.

Jussim, L. (1991). Social perception and social reality: A reflection-construction model. Psychological Review, 98, 54-73.

Krapp, A., Hidi, S. \& Renninger, K. A. (1992). Interest, learning, and development. In K. A. Renninger, S. Hidi \& A. Krapp (Eds.), The role of interest in learning and development (pp.3-25). Hillsdale, NJ: Erlbaum.

Lepper, M. r. \& Hodell, M. (1989). Intrinsic motivation in the classroom. In C. Ames \& R. Ames (Eds.), Research on motivation in education (Vol. 3, pp. 73-105). San Diego: Academic Press.

Meece, J. (1991). The classroom context and students' motivational goals. In M. L. Maehr \& P. R. Pintrich (Eds.), Advances in motivation and achievement (Vol. 7, pp.261-286). Greenwich, CT: JAI Press.

Midgley, C., Feldlauger, H. \& Eccles, J. (1989). Change in teacher efficacy and student self-and task-related beliefs in mathematics during the transition to junior high school. Journal of Educational Psychology, 81, 247-258.

Nakata, Y. (2006). Motivation and experience in foreign language learning. Bern: International Academic Publishers.

Natriello, G. (1986). School dropouts: patterns and policies. New York: Teachers' College Press.

Okada, M., Oxford, R. \& Abo, S. (1996). Not all alike: Motivation and learning strategies among students of Japanese and Spanish in an exploratory study. In R. Oxford (Ed.), Language learning motivation: pathways to the new century (pp.105-120). Hawaii: University of Hawaii

Oxford, R. L. \& Shearin, J. (1996). Language learning motivation in a new key. In R. Oxford (Ed.), Language learning motivation: pathway to the new century (pp.121-144). Honululu: Second Language Teaching and Curriculum Centre: University of Hawaii at Manoa.

Pintrich, P. R. \& Schunk, D. H. (1996). Motivation in Education. NJ: Prentice-Hall, Inc. A Simon \& Schuster Company, Englewood Cliffs.

Rivers, W. M. (1964). The psychologist and the foreign language teacher. Chicago: Chicago Press.

Schumann, J. H. (2000). Getting the student's attention: insight from evolution. Applied Linguistics Forum (official newsletter of the TESOL, applied linguistics interest section), 20, 4-5.

Schunk, D. H. (1989). Self-efficacy and cognitive skill learning volume 3 goals and cognitions. In C. Ames \& R. Ames (Eds.), Research on motivation in education (pp: 13-44). New York: Harcourt Brace Jouvanovich, Publishers.

Wang, T. (1996). Developing interest in English course in primary pupils. English Teaching and Research Notes, 5, 30-32.

Wong, O. H. F. (1992). Perceived effectiveness of rewards and punishment by secondary school students. Unpublished Master's dissertation, Psychology Department, The University of Hong Kong.

Yang, Y. B. (2004). Characteristics of good English learners - urban key senior secondary school students learning English in Yunnan - China. Unpublished MA thesis. Melbourne: La Trobe University.

Zhang, F. L., Shi, X. Y. \& Tan, Y. (2003). Teacher-student relationship affects learning results. (Research report) at the $4^{\text {th }}$ academic conference of Chinese psychology association. Beijing. 
Zhang, Y. G. \& Ding, F. (1996). The essential dispositions of a language teacher. Foreign Language World, 3 , 57-64.

Zhao, X. J. (2002). Current teachers' roles in "English curriculum standard." English Teaching and Research Notes, 11, $1-3$.

Zhou, R. \& He, G. Z. (2005). Investigation on empathy in English teachers of secondary school. Foreign Language Teaching in Schools, 2, 1-5. 


\title{
Simulation of Forming Process as an Educational Tool
}

\section{Using Physical Modeling}

\author{
A. B. Abdullah, M. R. Muda, Z. Samad \\ School of Mechanical Engineering, Universiti Sains Malaysia Engineering Campus \\ 14300 Nibong Tebal, Pulau Pinang, Malaysia \\ E-mail: mebaha@eng.usm.my
}

\begin{abstract}
Metal forming process simulation requires a very high cost including the cost for dies, machine and material and tight process control since the process involve very huge pressure. A physical modeling technique is developed and initiates a new era of educational tool of simulating the process effectively. Several publications and findings have shown a potential of the techniques else where. The objective of the paper is to simulate the closed-die forging. In this work, billet material from plasticine is used and dies are fabricated from perspex. The result indicates that billet volume and geometry of the billet is significant in forming process to measure the filling-ability and forming load required in the process.
\end{abstract}

Keywords: Similarity analysis, Physical modeling, Forming, Educational tool

\section{Introduction}

Forming can be described as a process in which a piece of metal is shaped to the desired form by plastic deformation starting form such as bar, billet, bloom or ingot (Vasquez et al., 1996). Generally there are two types of forming, sheet metal forming or bulk forming and it can be categorized as hot or cold forming. Initially forging operation has various advantages compared to other metal manufacturing including little loss of material, improved strength, geometrical precision of components and high production rates. Currently, forming process design (mainly die) is carries out trial and error based on intuition and experience of the skilled designer who is familiar with the process. In forging process, performance of the die is measure based on quality of the forged parts and reliability of the die itself.

The methods of studying forming processes can be categorized as the analytical, numerical and experimental methods (Vasquez and Altan, 2000). Experimental requires high capital cost in terms of equipments i.e. die and machine and material, therefore to save cost physical modeling is employed. In most cases numerical methods provide more flexibility than physical modeling since they allow for quick changes in the tooling design but the student cannot understand the process effectively since it does not provide definitive response about the process. The similarity law proposed by Powelski (1992) is utilized to initiate the physical modeling technique and extend by several researchers e.g. Navarrete et al. (2001), who derived the dimensional analysis of closed-die forging to study the stress distribution of the die. The use of physical modeling can reduce load and energy required, reduce the size of forming machine, simple experimental procedure, easy observation of the flow pattern and cheap and requires easier methods for material and die preparation. Plasticine is the most widely used model material because of low price, easily found and non-toxic, other material such as lead, tin and wax also being used (Vasquez et al., 1996). For die material, wood, perspex or aluminum is the most often use.

Many researchers have been conducted and among the recent finding are by Pertence and Cetlin, (2000), who simulate the cracking behavior by focusing on ductility of the material. Yuli et al., (2000) used the physical modeling to perform the forging process of grade 2 stator blade. Zhan et al., (2001) extend the study by using plasticine as a billet material and equipped by platform as a damper to produce the same shape. Sofuoglu and Rasty (2000) study the flow behavior of the plasticine by taking into consideration color of the plasticine, lubrication and deformation speed. He found that they had a significant affect. Fereshten-Saniee et al., (2004) study the frictional behavior of bulk metal forming process and in their research thirteen different lubricants and conditions were employed and result shows that physical modeling can effectively model almost all of the friction conditions. Fereshten-Saniee and Hossein (2006) investigate the effect of flash allowance and bar size on forming load and metal flow and indicate that the greater flash allowance, the larger the forming load. They also studied the effect of axisymmetry of part and found out that part with horizontal axis much 
sensitive to forming load compared to vertical. Moon and Tyne (2000) used the physical modeling as a validation tools to investigate the cracking criteria resulting from upper bound technique.

Utilization of physical modeling in simulating the manufacturing process for teaching purpose is still less and one of the example is done by Button (2000) and he found that the physical modeling also can be as an effective educational tool and integrate the numerical simulation to compare with the experimental result. Similarly Kridli and Orady (2003) perform the hydro-forming process and effectively introduced to the student.

The paper intent to demonstrate the die filling performance of forming process and a case study of universal joint is illustrated to simulate the process. Here several design parameters will be studied such as billet weight and shape of the die and the filling-ability and forming load is observed at each parameter and use as a performance indicators. The paper is organized as follows; begins with an introduction, and then theoretical background of the forming process and similarity law is briefly explained. After that the process of CAD/CAM of the dies is present, followed by physical modeling procedure. Next the result is discussed and paper ends with conclusion.

\section{Similarity Law}

\subsection{Theoretical Background}

There are two parameter used in evaluating the forging process i.e. forming load and die filling capability. Based on simplified SLAB method, for closed-die forging process the forming load can be expressed as below (Altan et al., 2005);

$$
P_{c a}=2 \pi r^{2}\left(\frac{m}{\sqrt{3}} \frac{\sigma_{c}}{3} \frac{r}{H}+\frac{\sigma_{e a}}{2}\right)
$$

Where

$H=$ cavity height

$r=$ radius or half width of the cavity

$t=$ thickness of the flash

$w=$ flash width

$\sigma_{f}=$ flow stress in the flash region

$\sigma_{c}=$ flow stress in the cavity

$m=$ frictional shear factor

$\sigma_{e a}=$ stress at the entrance from the cavity to the flash of an axisymmetric cross section

As the process is considered as flashless, so that stress at the entrance of flash, $\sigma_{e a}$ equal to zero and the forming load becomes;

$$
P_{c a}=2 \pi r^{2}\left(\frac{m}{\sqrt{3}} \frac{\sigma_{c}}{3} \frac{r}{H}\right)
$$

And for die filling analysis, the capability is measured based on viscosity of the semi-solid material and friction effect since the forming process involve the metal being pressed to the plasticity stage before it can deform. Kang et al., (1998) study the filling pattern of semi-solid aluminum die shape play important role in filling efficiency. To express the theory, Okano proposed the relationship using the below equation (Okano, 1994);

$$
\left.\eta_{a}=\eta_{L a}\left(1+\frac{\alpha \rho_{m} C^{1 / 3 \dot{\gamma}-4 / 3}}{2\left(\frac{1}{f_{s}}-\frac{1}{0.72-\beta C^{1 / 3 \dot{\gamma}-1 / 3}}\right)}\right)\left(0.72-\beta C^{1 / 3 \dot{\gamma}-1 / 3}\right\rangle f_{s}\right), \alpha=2.03 \times 10^{2}\left(\frac{X}{100}\right)^{1 / 3}, \beta=19.0\left(\frac{X}{100}\right)^{1 / 3}
$$

Where

$\eta_{a}=$ Apparent viscosity of semi-solid material 
$\eta_{L a}=$ Apparent viscosity of molten metal

$C=$ Solidification rate

$\rho_{m}=$ Density of molten metal

$\dot{\gamma}=$ Shear rate

$f_{s}=$ Solid fraction

$X=$ Solute percentage of binary alloy

The friction model for 2D process is proposed by Levanov et al. (1976) can be shown as follows;

$$
\frac{\tau}{k}=m\left(1-\exp \left(-1.25\left(\frac{q}{\sigma_{0}}\right)\right)\right)
$$

Where

$m=$ Friction factor

$q=$ Contact pressure

$\sigma_{0}=$ Equivalent yield stress

\subsection{Similarity Analysis}

Similarity law developed by Powelski (1992) is used to simplify the processes that usually involve many parameters. Initially analysis demands expensive and time-consuming experiment and difficult mathematical calculation. The theory of similarity can be explained by using the following theorem;

Theorem 1: For two similar processes all similarity numbers are equal in pairs

Theorem 2: The similarity numbers are connected in similarity equations, which are dimensionless solutions of the regarded problems and are valid for all similar processes.

Theorem 3: For the similarity of two processes it is necessary and adequate that they are of the same qualitative kind and that their defining similarity numbers are equal in pairs.

From the above equation, forming load is a function of cavity height, $H$, radius or half width of the cavity, $r$, thickness of the flash, $t$, flash width, $w$, flow stress in the cavity, $\sigma_{c}$ and frictional shear factor, $m$. After performing the dimensional analysis, two similarity number have been identified, but the most related and of special interest is $\Pi=\frac{H}{r}$, which related to the effect of the geometry and size of the die to the load required in the process whereas for die filling pattern is a function of apparent viscosity of molten metal $\eta_{L a}$, solidification rate, $C$, density of molten metal, $\rho_{m}$, shear rate, $\dot{\gamma}$, solid fraction, $f_{s}$ solute percentage of binary alloy, $X$ and friction phenomenon. As a result three similarity numbers have been identified but the most relevant is $\Pi=\frac{A_{r}}{A_{a}}$, which shows the same effect to the previous case and for conclusion, from the analysis of both two performance indicators, the most significant factor is the dimension or shape of the part or here consider as weight of the billet material.

\section{Methodology}

The simulation process can be described as follows;

\subsection{CAD/CAM of the Die}

Starts with development of CAD model of the die and here SolidWorks software is used. Followed by die fabrication using $\mathrm{CNC}$ milling machine is as shown in Figure 1 to 3. Physical modeling is conduct after billets are prepared. 


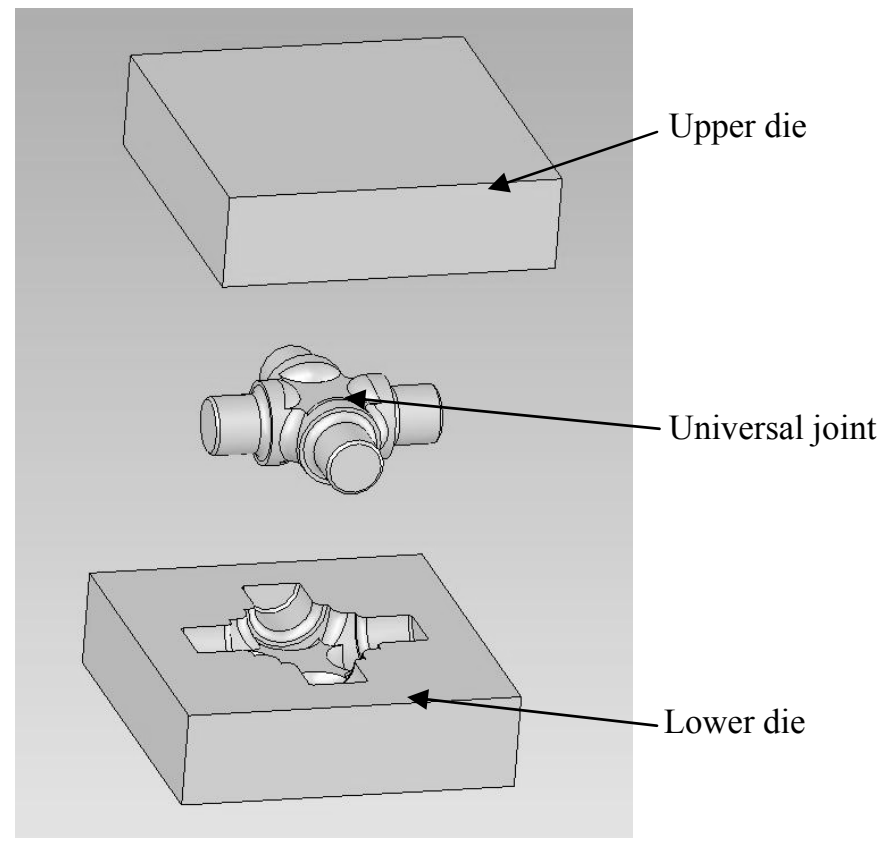

Figure1. CAD model of the upper and lower die

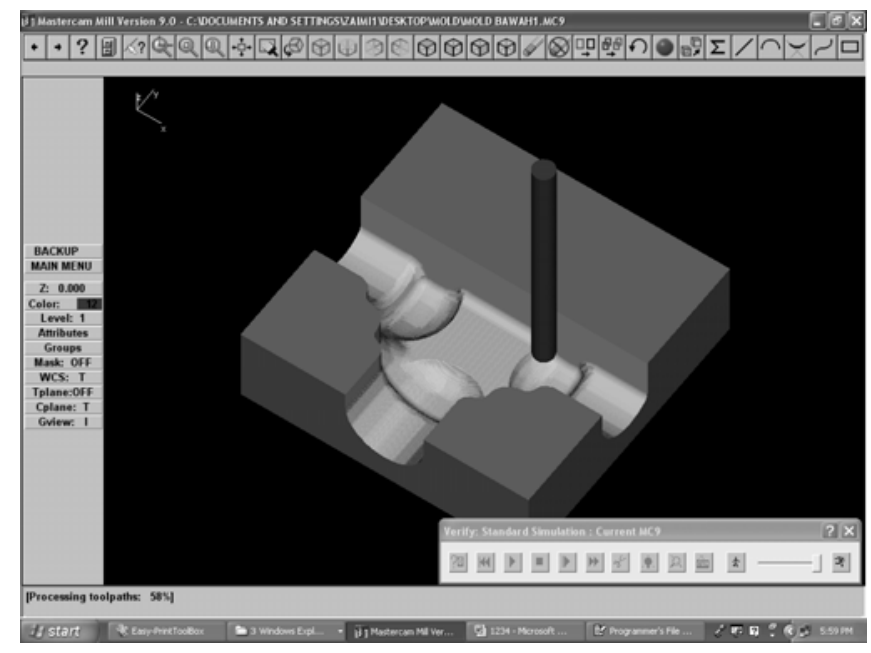

Figure 2. CAM simulation using MasterCAM

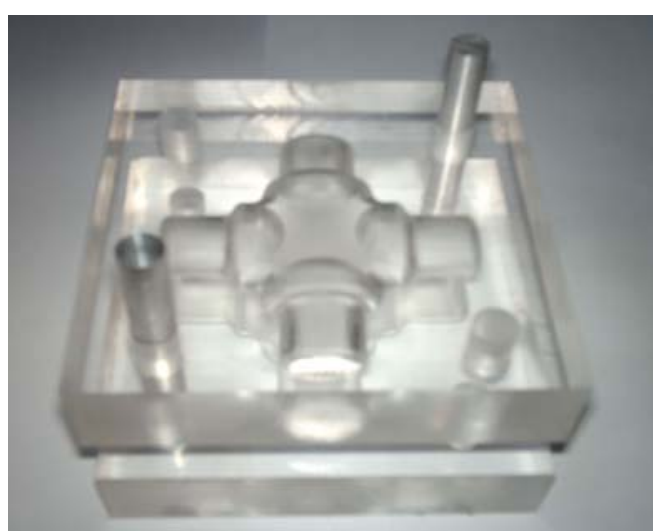

Figure 3. Fabricated lower and upper dies with guide pin 


\subsection{Preparation of the Billet}

In preparing the billet, the reference weight is determine manually by compressing the plasticine into the die and weighted after de-flashing. As a result a billet of 146.20 grams is obtained. To get the exact weight of the billet, a physical modeling is performed and weights of the billets are varied. Figure 4 shows the different size of billet represent different weight of the billet. Here the weight of the billet used rather than volume due to difficulty of getting density of the plasticine.

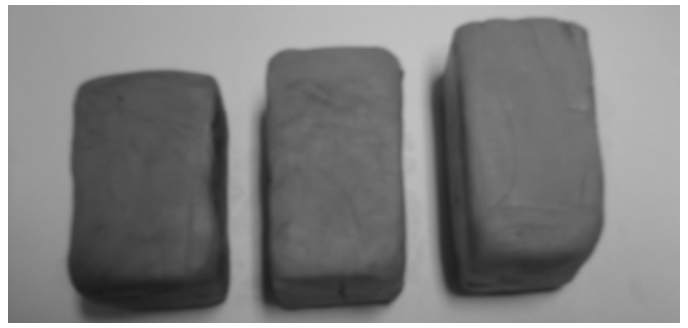

Figure 4. Different size and color of billet

\subsection{Physical Modeling}

The physical modeling flow process is as shown in Figure 5. After the billet is prepared, it is then locate in the middle of lower and upper dies. The compression begins, after the height of the deformation or stroke as shown in Figure 5 is measured. In order to avid material from stuck inside the die, a glycerin is used. Besides that it also acts as lubricant. The weight of the billet is measured before and after forming and final weight of the part is determined after de-flashing.

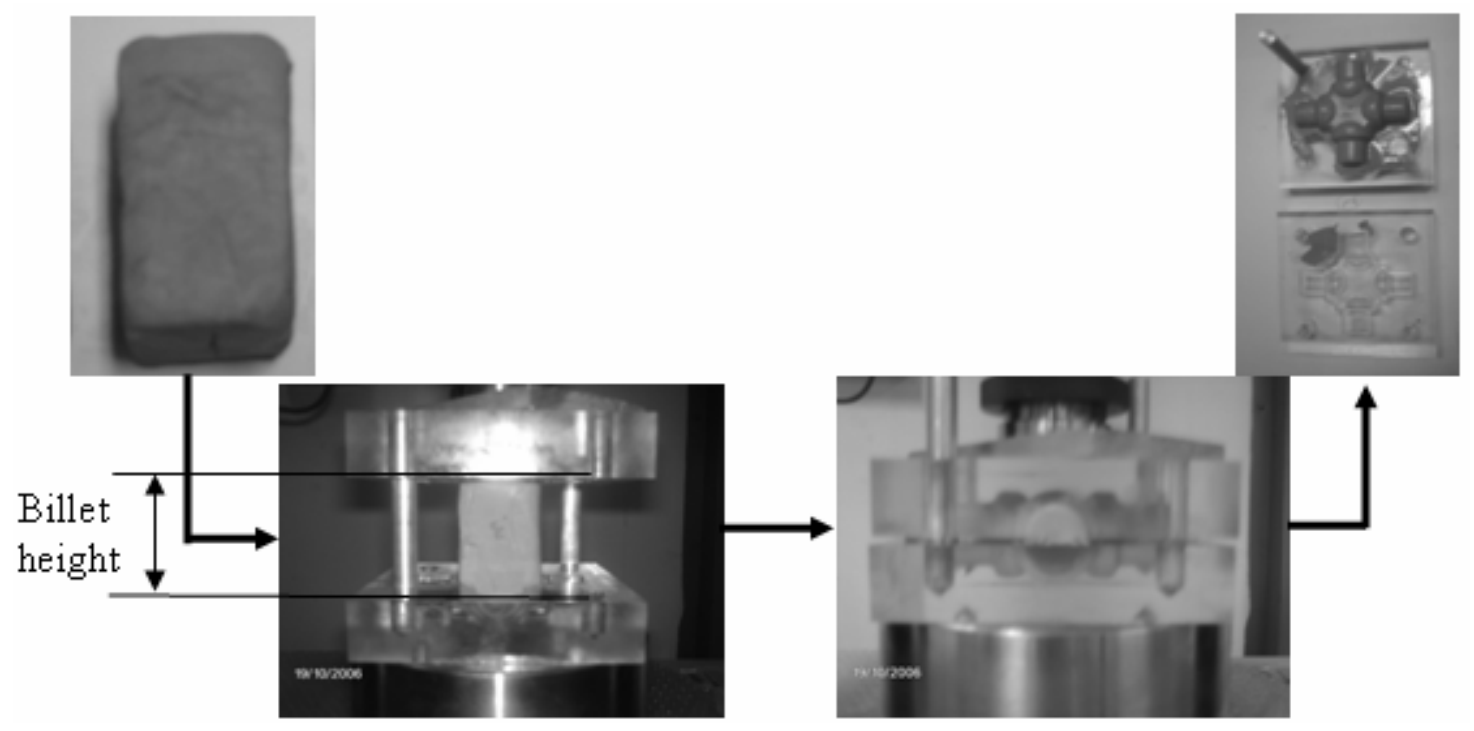

Figure 5. Physical modeling flow process

\section{Density Determination}

Plasticine is a non-homogenous material, so that properties is varies from different manufacturer. Before the forming process is begin, density of the plasticine need to be determined. The value is obtained based on Archimedes Theorem. The result of different water level is determined and before and after experiments, samples are weighted. The density determined will be used to calculate the actual weight of the part, so that it can be compared with result from experimental. For this case four sets of samples is prepared and it can be divided into two, compress and non-compress plasticine:

i) For uncompressed plasticine, there are three types of samples:

Sample \#1 - a sample of same weight and repeated for five times, sample is shown in Figure 6 (a)

Sample \# 2 - five samples in same weight and same shape, samples shown in Figure 6 (b).

Sample \# 3 -five samples almost same weight at varied shape as shown in Figure 6 (c).

ii) For compressed plasticine,

Sample \# 4 - eight samples in varied weight and shape as shown in Figure 6 (d) 


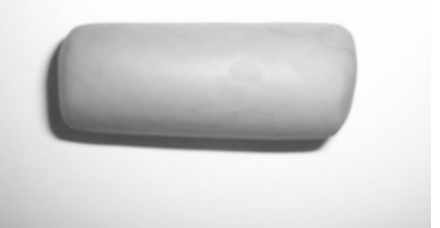

(a) Sample \#1

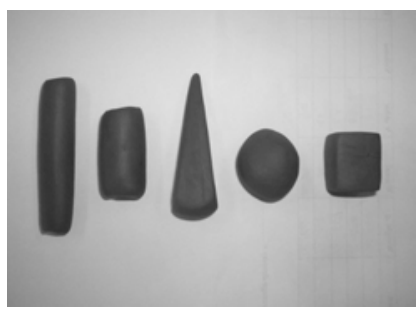

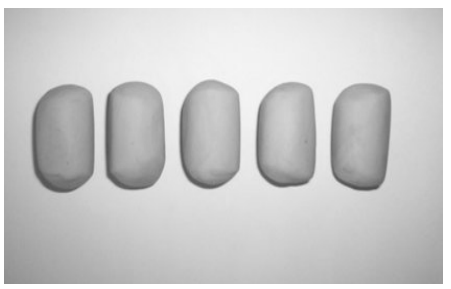

(b) Sample \#2

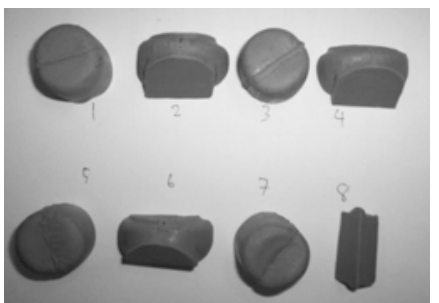

(c) Sample \#3

(d) Sample \#4

Figure 6. Four sets of samples for density determination

From CAD data the volume is of case study i.e. universal joint is $74569.777 \mathrm{~mm}^{3}$. From here the density of each sample is obtained. Since the plasticine used in the physical modeling is compressed during compression process, the density used is $1888.70 \mathrm{~kg} / \mathrm{m}^{3}$.

\section{Result and Discussion}

The experiment is conducted to study the capability of material to fully fill the internal cavity of the die, especially the chamfer and fillet at the end of the part. The result can be divided into three main areas i.e. the effect of billet weight, percentage of un-filled die and forming load. The physical modeling is conducted at varied billet weight. Sample \#2 to \#6 depicts the weight increment by $10 \%$ and Sample \#7 to \#9 represent weight reduction also by $10 \%$ of the reference weight. To get the reference weight, a manual compression test is conduct and the maximum weight of plasticine can be filled in the dies is 146.20 grams. The deformed billet after compression using Universal Testing Machine is as shown in Figure 7. From the experiments, the maximum billet can be fillet in the dies is 153.70 grams (Figure 8) and this amount is assumed as fully filled part and used as reference to calculate filling-ability. From the distribution pattern of the material, shows quite similar pattern and this is proved that un-balance compression is not crucial.

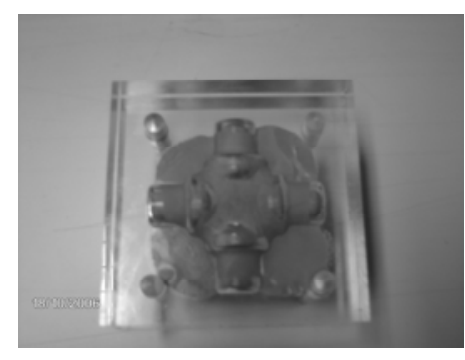

(Sample \#1)

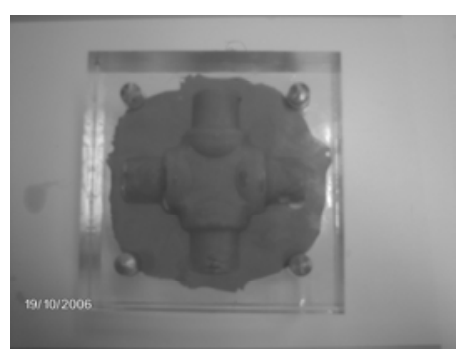

(Sample \#2)

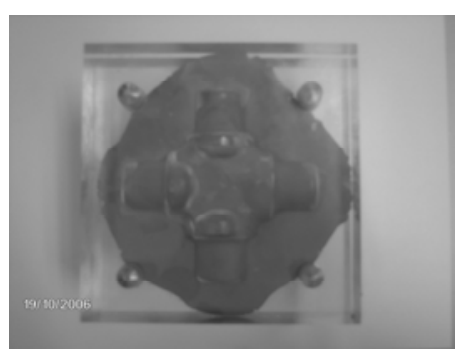

(Sample \#3) 


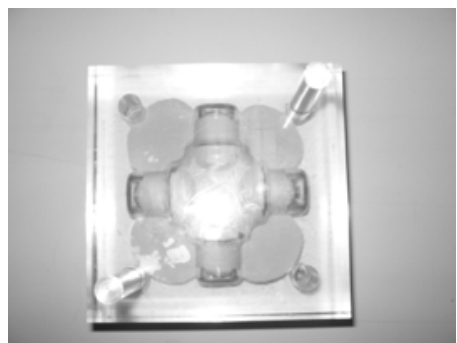

(Sample \#7)

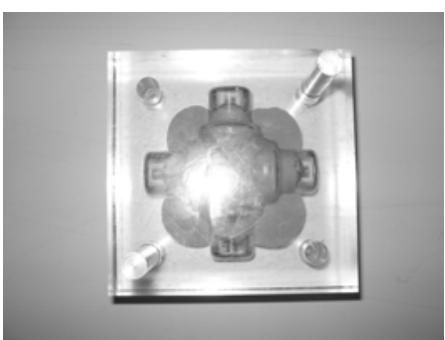

(Sample \#8)

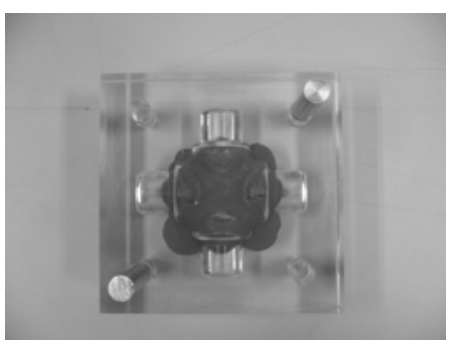

(Sample \#9)

Figure 7. Deformed billet before de-flashing

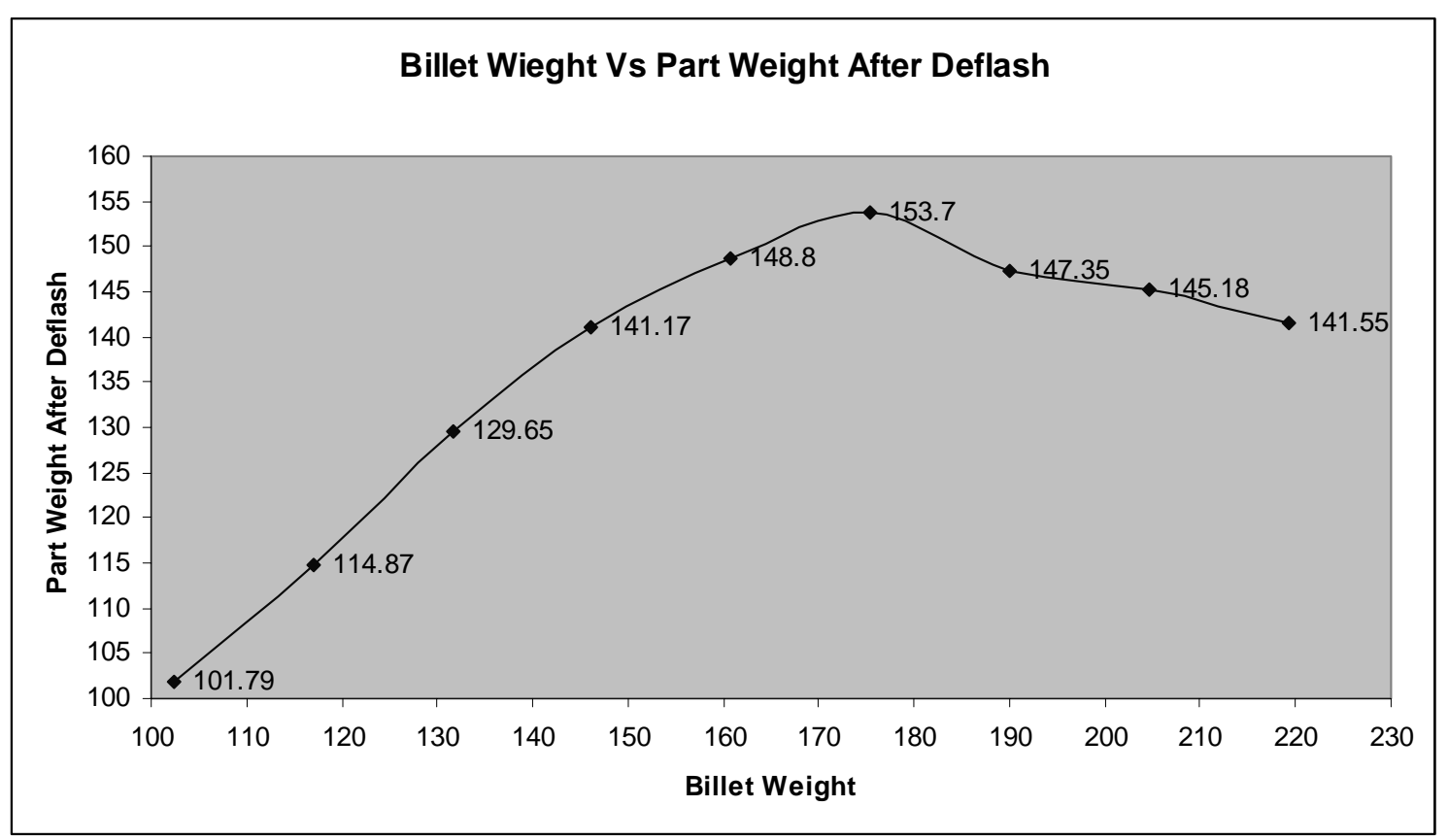

Figure 8. Determination of maximum part weight

\subsection{Die Filling}

From the above result, shown that Sample \#3 shows the highest part weight and here it is assumed that this the maximum weight of part or $100 \%$ filled die. The un-filling weight is determined by comparing the maximum filled part to the measured part from the experiment and the result is summarized in Table 2.

Table 2. Data for un-filling die

\begin{tabular}{|c|c|c|c|}
\hline \# Sample & Part Weight in grams after de-flashing & Un-filling Die in grams & Un-filling Die in \% \\
\hline 1 & 141.07 & -11.92 & 7.79 \\
\hline 2 & 148.66 & -4.33 & 2.83 \\
\hline 3 & 152.99 & 0 & 0 \\
\hline 4 & 147.15 & -5.84 & 3.82 \\
\hline 5 & 145.14 & -7.85 & 5.13 \\
\hline 6 & 141.22 & -11.77 & 7.69 \\
\hline 7 & 129.50 & -23.49 & 15.35 \\
\hline 8 & 114.65 & -38.34 & 25.06 \\
\hline 9 & 101.71 & -51.28 & 33.52 \\
\hline
\end{tabular}

The negative value in the Table 2 means there are sections of the die that material cannot be reached due to complicated shape or too small. For the example, the die filling percentage of Sample \#2 is where only about $3 \%$ unfilled is observed, 
while for Sample \#9 about 34\% unfilled is recoded. Although both of them cannot fulfill the die, but the increase of billet weight give the better die filling.

\subsection{Forming Load}

Figure 9 below shows the summary of the result of the load required for each samples. Compare Sample \#1 with Sample \#6 which has 50 percent more in height than Sample \#1, the maximum load shows a similar value which is about $0.75 \mathrm{kN}$. This mean that relatively when the billet weight increases the higher load is need to complete the forming process. The result also indicates that, the shape or geometry of the billet also affect the load. The effect of billet height and weight is shown in the load-displacement curve (Figure 9). It can be seen that for sample billet with higher in weight, a greater force is needed to form the billet to desired form compare with the sample with lower weight. This could be due to higher contact surface between billet material and die which cause greater friction force and, consequently, larger forming load.

\section{Load Vs Displacement}

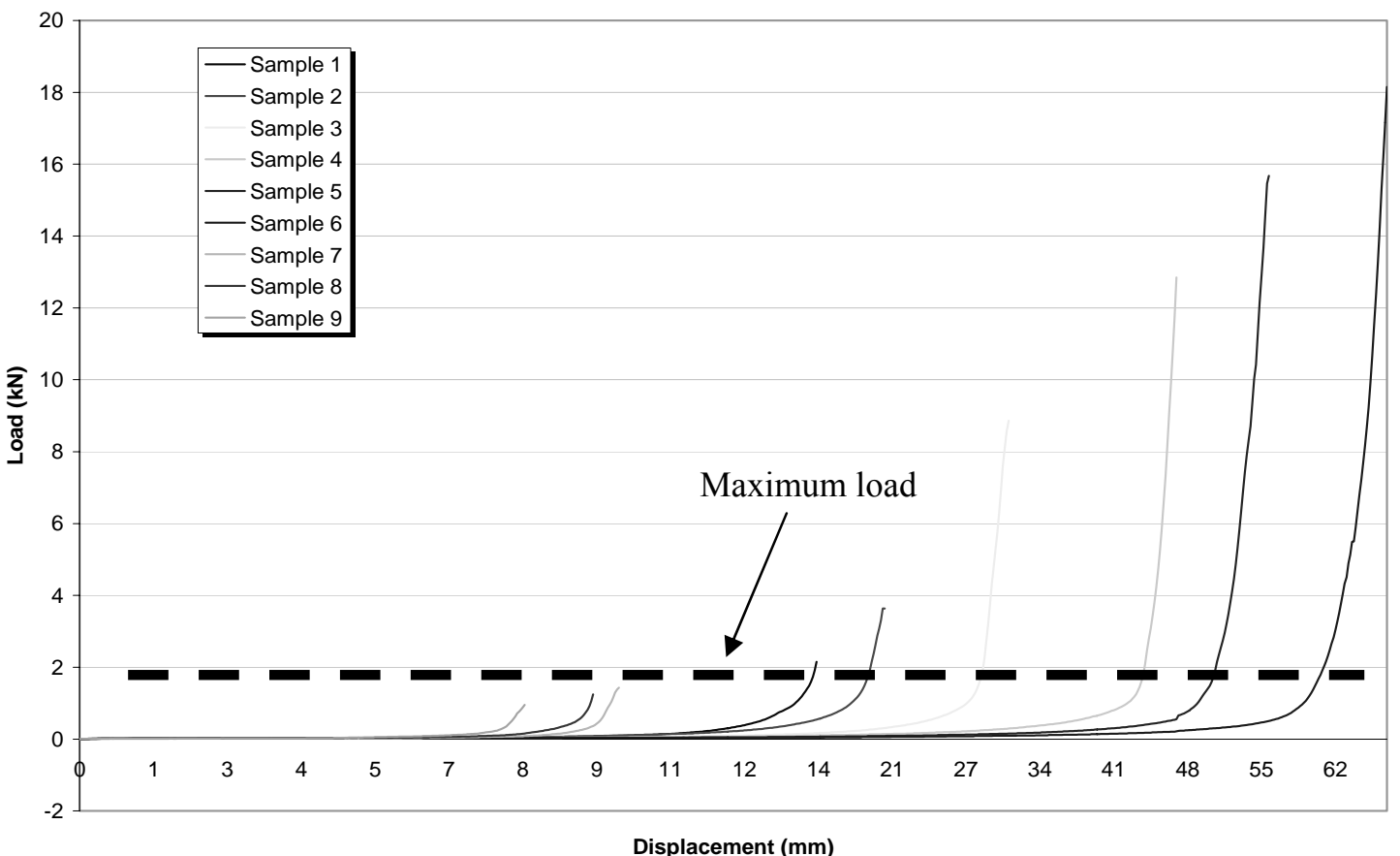

Figure 9. Load-displacement (billet height) curve

\section{Conclusion and Future Works}

The paper presents the exploration of a new approach to enhance the conventional teaching method by utilizing the physical modeling in simulating the forming process. In the simulation, the effect of billet weight to the die filling and forming load of forming process by using physical modeling. By using trial-error method, the exact volume of the part weight is determined and used to use as a reference to obtain the un-filling volume. Here since the density of the plasticine is varied depends on manufacturer and the other factors such as environment and process condition, a simple experimental had been performed to determine the density of the plasticine. The result indicates that the weight of the billet will greatly affect the die filling and forming load. For future research, the die filling performance will be study from the perspective of die geometry in terms of fillet, corner radii and size of part. The utilization of physical modeling prove will helpful in determining the performance of forming process, but due to limitation many factors are not taken into consideration such as stress distribution and effect of lubricant to the process.

\section{Acknowledgements}

The authors would like to thank the School of Mechanical Engineering and Universiti Sains Malaysia for their cooperation and fund provided (A/C 6035175).

\section{References}

Altan, T., G. Ngaile and Shen, G. (2005). Cold and Hot Forging: Fundamentals and Applications, ASM International. 
Button, S. T. (2000). Numerical Simulation and Physical Modeling as Educational Tools to Teach Metal Forming Processes, ICECE 2000 - Int. Conf. on Engineering and Computer Education, São Paulo, S.P.

Fereshteh-Saniee, F., I. Pillinger and P. Hartley. (2004). Friction modelling for the physical simulation of the bulk metal forming processes. Journal of Materials Processing Technology, 153-154, 151-156.

Fereshteh-Saniee, F. and A.H. Hosseini. (2006). The effects of flash allowance and bar size on forming load and metal flow in closed die forging, Journal of Materials Processing Technology, 177(1-3) 261-265.

Kang, C. G., J. S. Choi and D. W. Kang. (2000). A filling analysis of the forging process of semi-solid aluminum materials considering solidification phenomena, Journal of Materials Processing Technology, 73, $289-302$.

G. T. Kridli, and E. A. Orady. (2003). Development of Process Maps for Tube Hydroforming Process, The International Journal of Science and Technology, 14, 23-27.

Levanov, A. N., V. L. Kolmogorov, S. P. Burkin, et al. (1976). Contact friction in Metal forming, Moscow, (in Russian).

Moon, Y. H. and C. J. Van Tyne. (2000). Validation via FEM and plasticine modeling of upper bound criteria of a process-induced side-surface defect in forgings, Journal of Materials Processing Technology, 99(1-3), 185-196.

Navarrete, J, M. E. Noguez, J. Ramirez, G. Salas and T. Robert. (2001). Die Forging Stress Determination: A Dimensional Analysis Approach, Journal of Manufacturing Science and Engineering, 123, 416-419.

Okano, S., (1994), Research Activities in Rheo-technology Limited, in: Third Int. Conf. on Semi-Solid Processing of Alloys and Composites, Chiba 260, Japan, 7-18.

Pertence, A. E. M. and P. R. Cetlin. (2000). Similarity of ductility between model and real materials, Journal of Materials Processing Technology, 103(3), 434-438.

Powelski, O. (1992). Ways and limits of the theory of similarity in application to problems of physics and metal forming, J. Mater. Process. Technology, 34, 19-30.

Sofuoglu, H. and J. Rasty. (2000). Flow behavior of Plasticine used in physical modeling of metal forming processes. Tribology International, 33(8), 523-529.

Vazquez, V. and Altan, T. (2000). New concepts in die design — physical and computer modeling applications. Journal of Materials Processing Technology, 98(2), 212-223.

Vazquez, V., K. Sweeney, D. Wallace, C. Wolff, M. Ober and T. Altan. (1996). Tooling and process design to cold forge a cross groove inner race for a constant velocity joint - physical modeling and FEM process simulation, Journal of Materials Processing Technology, 59(1-2), 144-157.

Yuli, L., D. Kun, Z. Mei, Y. He and Z. Fuwei, Physical modeling of blade forging, Journal of Materials Processing Technology, 99(1-3), 2000, pp. 141-144.

Zhan, M., Y. Liu and H. Yang. (2001). Physical modeling of the forging of a blade with a damper platform using plasticine, Journal of Materials Processing Technology, 117(1-2), 62-65. 


\title{
Problems in Library Construction of Newly-upgraded Local
}

\section{Undergraduate Institutions}

\author{
Chunlan Qiu \\ E-mail:jxust@126.com \\ Library, Jiangxi University of Science and Technology, Ganzhou 341000, China \\ Rongsheng Wen \\ Library, Jiangxi University of Science and Technology, Ganzhou 341000, China
}

\begin{abstract}
Based on an analysis on the features and problems in the libraries of some newly-upgraded local undergraduate institutions, this article finally comes to a series of management countermeasures.

Keywords: Upgraded, Local undergraduate institutions, Library, Construction

\section{Introduction}

Stepping into a new era since late $20^{\text {th }}$ century, Chinese higher education has witnessed many great changes, among which the upgrading of some local academies is a typical one. In spite of their current capacities in collection, staff and building, some problems still exist in the quality and structure of books, service contents and methods, staff allocation and management and so on. With an analysis on the features and problems in the libraries of some newly-upgraded local undergraduate institutions in accordance with our library's reality, this article is to propose some new ideas with the hope to make a humble effort in helping other libraries to serve teaching, research and local economic construction in a better way.
\end{abstract}

\section{Features of Newly-upgraded Local Undergraduate Institution Libraries}

\subsection{Features in Staff}

Newly-upgraded local undergraduate institution libraries generally suffer from insufficient staff as well as wide-ranging qualities. With the expansion of these undergraduate institutions, a multi-functional, multi-level and overall service seems too much for their libraries. In addition, engaged in such over-loaded work, it is impossible for their staff to spare time for professional training or continuing education, hence resulting in the lack of library staff with reasonable age structure, favorable political quality, high professional and management competence, and therefore, influencing their service quality and management level.

\subsection{Features in Service Objects}

In order to improve their qualities and levels, newly-upgraded local undergraduate institutions make great efforts to introduce some experts and scholars with rich teaching and research experience in addition to encouraging their existing staff to concentrate more on teaching and research, hence calling for a collection of books with width and depth. Besides, better service is also required by higher-level student readers.

\subsection{Features in Document Resources}

Due to their formerly small-sized collections, newly-upgraded local undergraduate institution libraries have an unreasonable collection structure due to the short time and heavy load in book purchasing, and therefore, fail to satisfy their readers, especially those science ones. Therefore, it is safe to say that the current document resources of these libraries are unable to satisfy the requirements for professional and systematic services yet.

\section{Major Problems in Newly-upgraded Local Undergraduate Institution Libraries}

\subsection{Lack and Low Quality of Professional Staff}

Man being the major element in library development, professional people seem more important. With the current insufficient professionals mainly allocated in a few university libraries with long history and high level, these newly-upgraded ones are in bad need of such professionals. Actually, many libraries of this kind are hindered in their development just due to the lack of staff, professional staff and those in computer and network. What's more, a majority 
of library staff are characterized by poor academic background, onefold knowledge structure, low professional competence, poor sense of service and initiative, hence failing to fulfill the requirements of knowledge-based economy and prosperous higher education.

\subsection{Unreasonable Collection Structure and Onefold Document Types}

As required by Undergraduate Teaching Assessment conducted by the Ministry of Education and Undergraduate Teaching Random Assessment Programme for Common Higher Education Institutions (for trial implementation), any upgraded undergraduate institution library is expected to have 80 to 100 books for each student in 5 years after its upgrade. According to our surveys, because a half or even two thirds of their books are newly-purchased and mainly about social science, those readers specialized in science cannot be satisfied. In addition, these libraries also suffer from onefold document types, in which printed books and periodicals take the most proportion, while materials in foreign languages and electronic documents are insufficient in different degrees.

\subsection{Laggard Basic Facilities}

Due to so many problems confronting a newly-upgraded undergraduate institution such as the construction of dormitory buildings, teaching buildings, laboratory buildings, its library has to give way to others although its importance has been realized. With the rapidly increasing number of teaching faculty, students as well as books, its insufficient capacity has led to severely incompetent per capita reading space. What's worse, computer software is also lagging behind. Let's take the library of Nanyang Institute of Technology as an example. Wenjin book management system was originally introduced in 1996 and then in 1999 we developed our own automatic book management system, which is flexible to adjust but unsteady, inconsistent with the international standard and poorly adapted to the resource-sharing environment. Accordingly, it calls for upgrade to fulfill readers' satisfaction in acquiring timely and accurate knowledge and information.

\subsection{Unreasonable Staff Allocation and Disordered Work}

A lot of newly-upgraded libraries have exerted every effort to solve the contradiction between the great number of readers and the poor reading capacity. For example, our library is open all day long and deals with book retuning in intensive periods now. Of course, readers' satisfaction will be fulfilled better in this way. However, it causes the contradiction between a severe waste of staff in some departments (a large part of staff stay idle except for the intensive periods of placing books on shelves) and a severe shortage of staff in others (two shifts are required every day in all departments open to readers and therefore there is a bad lack in information service and cataloguing staff). In addition, incomplete systems have also led to unclear responsibilities at different posts.

\section{Management Countermeasures for Newly-upgraded Local Undergraduate Institution Libraries}

\subsection{Establishing Efficient Library Staff}

Talented people, technology and resources are three key elements in library management, among which talented people are the decisive one. First, choosing a really competent head seems particularly important for the whole personnel management. A person who is devoted to library work and has experience in library management and practice is an ideal choice. Second, people with professional and management competence should be chosen for department deans, which are also important for a library's creative work. Finally, measures should be taken to improve the quality of library staff. Since our upgrade in 2004, our library has adopted the following measures to overcome some former problems: (1) some regular training courses have been held by inviting some experts or sending our staff to attend some courses in order to improve our abilities in theory as well as practice; (2) the existing professionals in library management and computer technology have been made full use of to encourage their enthusiasm and creativity; (3) we have also been organized to study and inspect and exchange with other libraries in order to learn their experiences, broaden our sights and increase our knowledge; (4) shifts among different departments and posts have been conducted regularly in order to inform every member of different operation procedures and help them to grasp various skills; (5) position management has been strengthened and the competition system has been set up to push the staff to devote themselves to their work. By conducting the above measures, we have succeeded in improving our whole staff's comprehensive quality as well as establishing efficient staff gradually.

\subsection{Employing Student Assistants to Relieve Staff Shortage}

It has been long-existing practice in western university libraries to employ a great number of students in their daily routine. Currently, a lot of Chinese university libraries are also using students in their basic and mechanical tasks, such as being on duty, putting books on shelves and tidying shelves, processing and examining new books and other non-professional tasks. Obviously, this is a good way to relieve the current staff shortage in these newly-updated university libraries as well as to provide some part-study and part-work opportunities for poor students.

\subsection{Reasonably Collecting Document Resources with Limited Funds}

Most newly-updated undergraduate institution libraries face the greatest difficulty of a severe shortage of document 
resources as well as quite limited funds. Therefore, they are supposed to try their best to use funds efficiently in key parts. According to our reality and other institutions' practice, we think that the following two measures will give some help: (1) we can buy some popular and practical books at a quite low price from some large presses with our cooperation with professional booksellers; (2) about half of our funds can be used to purchase books by inviting bidding in order to get more discount as well as to allocate document resources according to our specialty arrangement. In addition, collection structure should be adjusted from time to time according to specialties and courses, which requires the purchasing staff to learn well about the arrangement of different specialties, readers' demands and publishing of books, to have an overall design for collection structure in the proportion of different books in purchasing and the number of copies, and then to establish scientific collection structure with special characteristics by following professional, systematic and practical principles. As for our library, first, we lay down Rules for Book Purchasing, in which all details about purchasing of document materials give us rules to follow; second, directors from all departments and some backbone teachers in teaching and research have been chosen to form our book purchasing committee to assist the library to purchase books in various specialties. In this way, library purchasing staff's loads will be lessened and the purchased book materials will better satisfy readers in different specialties

\subsection{Conducting Outsourcing of Business and Technical Tasks}

Due to the above mentioned shortage in library staff, especially professionals in library and computer technology, great difficulty has been caused in fulfilling a lot of technique-intensive tasks. Accordingly, we can cooperate with others in the form of outsourcing. Taking our self-developed automatic software into consideration, the following services can be outsourced in order to achieve better effect and efficiency in our library: (1) requiring book suppliers to attach stamps, magnetic stripes, bar codes and establishing individual registration accounts besides to guaranteeing the quality of books as mentioned in our contracts; (2) back issue binding ; (3) inviting computer professionals from other departments to manage and maintain our computerized management system regularly.

\subsection{Facilitating Network Construction and Modernization}

The automatic, net-based and modernized level of its library is one of the important symbols to show an undergraduate institution's teaching quality. Net is the only solution for a library's automatic development, the material base for its information service, an important way to share resources with others as well as the main goal for all libraries. It should be realized that modernization answers the need of our times and advanced technology and facilities are necessities for modernization and service improvement. Therefore, the libraries in those newly-upgraded institutions should plunge themselves into the information network of the whole society to achieve their modernized management as soon as possible.

To be more specific, first of all, these libraries should set up their LANs to realize the automatic and net-based management of their acquisition, cataloguing, collecting, exchanging, and public searching procedures. Second, their LANs can be connected with any other net through campus network to realize the sharing of information and resources. Although our library established our LAN in 1996 and it has become one part of our campus net, our automatic management software is still lagging behind nowadays. Therefore, we are applying for special funds from our university to purchase new automatic book management software in order to serve teaching, research and local economic construction.

\subsection{Expanding Service Range and Improving Service Quality}

Most newly-upgraded undergraduate institution libraries only offer onefold and passive service in book borrowing and returning and offer their consultation service by waiting for readers to come in person or ringing up. With the rapid development of information technology and the constant expansion of institution scale, libraries should make some adjustments in their ways to deliver service in which the current collection and automatic methods should be made full use of to improve their service quality. With the hope to strengthen our service functions, our library takes two new measures. First is our follow-up service: special staff allocated to contact with teachers with projects are supposed to learn about the going-on of projects and demanded materials and then to offer them catalogue information, indexes of specialized materials and the latest research tendencies, hence saving the researchers' time in searching for materials and hence more time in their researches. Second is delivering books to administrative leaders and academic backbone teachers. Third is offering service in book borrowing and returning, answering questions on the net and subject follow-up service to the back bone staff in research and technology in the local well-known enterprises. By conducting these measures, we are definitely able to improve the status of library in an institution or even in the local area. Currently, our library is adding more new contents on our campus net and our library's homepage as a preparation to set up an announcement system of disks enclosed in books and a periodical database.

\subsection{Constructing a Special Collection and Sharing Resources}

Here a special collection means that a library collection has formed certain scale in quantity, kind, variety in some fields or subjects, has high ranks, information values and high document guaranteeing rate. With special collection being the 
core part in collection construction, priorities should be given to this part, in which the goal for the document construction in some key branches and specialties should be set to a quite high rank, with an emphasis on their replacement in variety and quantity and the effort to keep their consistency, integrity and systematicness. Actually, for us newly-upgraded institution libraries, it is particularly important to construct a specialized collection of books. In the case of our university, due to our specialty in science branches, books in architecture, mechanism, electronics and computer take up over $70 \%$ in our library's total collection, which guarantees our specialized document resources. However, due to the difficulty to set up our own document resources system in a short time, sharing document resources seems to be particularly significant, especially those electronic resources kept in some large libraries.

\section{References}

Jia, Guang. (2002). A Research on the Location of the Library of an Upgraded University. Library and Information Service. (5).

Liu, Xiaoqian. (2002). The Ideas on Developing Local University Libraries in the New Period. Journal of Shiyan Technical Institute. (1).

Mo, Zhenxuan. (2004). On the Exploitation of the Library Information Resources after a Technological College Upgraded to a University. Library Construction. (1).

Qiao, Wenming. (2001). Information Resources Construction of University Libraries in Network Environment. Library Tribune. (5).

Wang, Zhen. (2003). Hindering Elements and Countermeasures in Library Development. Researches in Library Science. (1).

Wang, Zhiqiang. (2003). Information Technology and Library Development. Library Tribune. (5). 
A journal archived in Library and Archives Canada

A journal indexed in CANADIANA (The National Bibliography)

A journal indexed in AMICUS

A leading journalin education research

\section{International Education Studies}

\section{Quarterly}

Publisher Canadian Center of Science and Education

Address PO Box 1087, Toronto, Ontario M3A 2Y7

Telephone (416) 585-8198

Fax (416) 585-7247

E-mail IES@ccsenet.org

Website www.ccsenet.org

Printer William Printing Inc.

Price CAD. $\$ 20.00$ 